\title{
Fuzzy rock typing: Enhancing reservoir simulation and modeling by honoring high resolution geological models
}

\author{
Vida Gholami \\ West Virginia University
}

Follow this and additional works at: https://researchrepository.wvu.edu/etd

\section{Recommended Citation}

Gholami, Vida, "Fuzzy rock typing: Enhancing reservoir simulation and modeling by honoring high resolution geological models" (2009). Graduate Theses, Dissertations, and Problem Reports. 4468. https://researchrepository.wvu.edu/etd/4468

This Thesis is protected by copyright and/or related rights. It has been brought to you by the The Research Repository @ WVU with permission from the rights-holder(s). You are free to use this Thesis in any way that is permitted by the copyright and related rights legislation that applies to your use. For other uses you must obtain permission from the rights-holder(s) directly, unless additional rights are indicated by a Creative Commons license in the record and/ or on the work itself. This Thesis has been accepted for inclusion in WVU Graduate Theses, Dissertations, and Problem Reports collection by an authorized administrator of The Research Repository @ WVU. For more information, please contact researchrepository@mail.wvu.edu. 


\title{
FUZZY ROCK TYPING; \\ ENHANCING RESERVOIR SIMULATION AND MODELING BY \\ HONORING HIGH RESOLUTION GEOLOGICAL MODELS
}

\author{
By \\ Vida Gholami \\ Thesis submitted to the \\ College of Engineering and Mineral Resources \\ at West Virginia University \\ in partial fulfillment of the requirements \\ for the degree of \\ Master of Science \\ in \\ Petroleum and Natural Gas Engineering
}

Approved by

Shahab D. Mohaghegh, PhD., Chair

Khashayar Aminian, PhD.

Razi Gaskari, PhD.

Jaime Toro, PhD.

Department of Petroleum and Natural Gas Engineering

Morgantown, West Virginia

2009

Keywords: Fuzzy Rock Typing, Fuzzy Set Theory, Upscaling, Rock Type, Flow Unit Copyright 2009 Vida Gholami 
This work is dedicated to my parents who have raised me to be the person? am today and have been with me every step of the way.

Thank you for all the unconditional love, guidance, and support that you have always given me. You are the main source of my inspiration and the strength of my will. Thank you for everything. I love you! 


\section{Acknowledgments}

First of all, I would like to show my gratitude and appreciation to my research advisor Dr. Shahab Mohaghegh for his advice, guidance, and encouragement during the course of this research. His enthusiasm and humor made these years at West Virginia enjoyable for me and He gave me a complement to increase my confidence and examples of professionalism on how tasks should be completed and presented.

My appreciation goes to Dr. Khashayar Aminian, Dr. Jaime Toro and Dr. Razi Gaskari, who generously accepted to be a member of my thesis committee and all made significant contribution to this work. Their continuous and constructive critiques and suggestions have helped me a lot to improve this work.

Special thanks go to Department Chair Samuel Ameri and my professors in the PNGE Department for their support and for their time to share their knowledge with me. I express my thankfulness to the administrative associate of PNGE department, Beverly Matheny, for her kindness, friendship, and her presence to help the students.

Also, I would like to express my gratitude to Computer Modeling Group, for making the CMG reservoir simulator available to us to perform the reservoir simulations in this work.

I would also like to express my sincere gratefulness to my friends and office-mates, Jalal Jalali, Delal Gunaydin, Yasaman Khazaeni, Camilo Calderon, Yorgi Gomez and Ognjen Gruic for providing a friendly environment and helpful discussions about different issues during past two years. Good luck to each of you in your future endeavors.

My profound gratitude is expended to my parents and siblings. Although they have been miles away from me I have always been supported by their understanding, trust and wholehearted help they have been giving to me. 


\section{Abstract}

Rock typing is an essential part of building geologic model for an asset. Millions of dollars are invested in logs, core measurements, SCAL studies, and geological interpretation that result in definition of different rock types. Rock types overlap and do not have crisp boundaries.

Upon definition of rock types for a series of geological formations geoscientists use approximation of multiple and overlapping rock types to identify a dominant rock type for any grid block in a reservoir simulation model .This defeats the original purpose of performing detail geological, petrophysical studies as far as reservoir flow models are concerned.

The objective of this study is to develop a new and novel methodology based on performing "fuzzy rock typing". Fuzzy rock typing refers to application of fuzzy set theory to the part of reservoir characterization that is concerned with rock type determination. Fuzzy set theory is applied in order to take into account the inherent uncertainties and vagueness associated with rock typing in hydrocarbon bearing reservoirs.

In this work, a numerical simulator has been used as the control environment in order to set up multiple studies that would demonstrate the differences between using conventional (current practices) approach of implementation of geologic models in the reservoir flow simulation studies and the new approach that is the subject of this study. By using the numerical reservoir simulator as the control environment it is intended to study the complexities that exist in upscaling the high resolution geological model using two different approaches.

The high resolution geological model used in its entirety and the flow simulation is performed. The results (production profiles) are compared to first, the upscaled model using conventional (current) practices and then the upscaled model using the proposed technique. The results are analyzed in order to demonstrate the difference between the two techniques and the advantages and disadvantages of each have been identified. 


\section{Table of Contents}

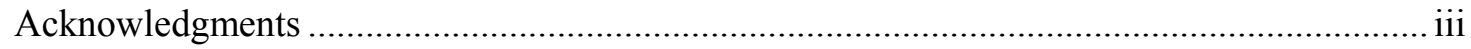

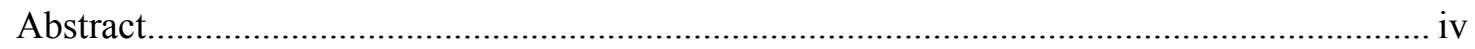

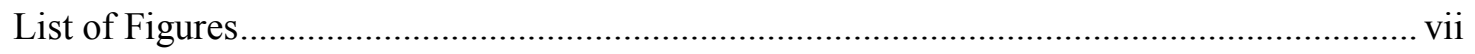

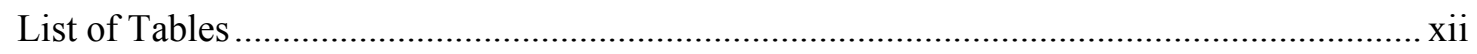

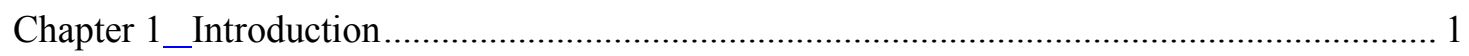

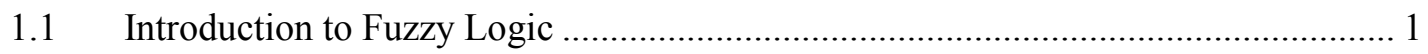

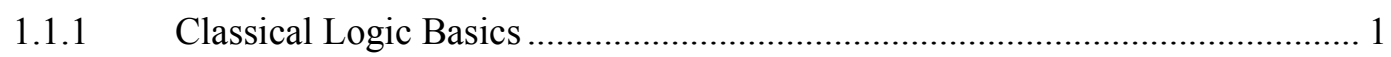

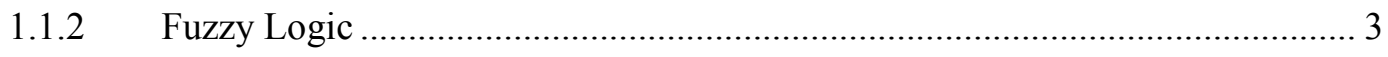

1.2 Introduction to Flow Units and Rock Types........................................................ 11

1.2.1 Permeability-Porosity Relationship ............................................................. 14

1.2.2 Interrelation between Pore Geometry, Capillary Pressure and Rock Types..... 14

1.2.3 Rock Type or Flow Unit Identification Techniques ......................................... 17

1.2.4 Comparison between Flow Units and Rock Types............................................. 31

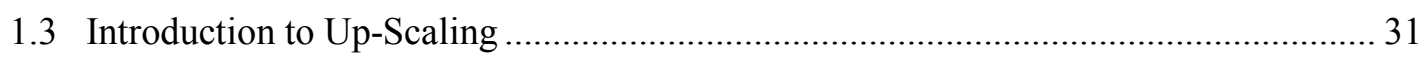

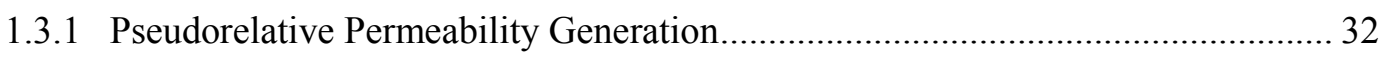

1.3.2 Dynamic Pseudorelative Permeability Methods …................................................. 33

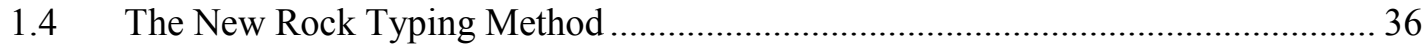

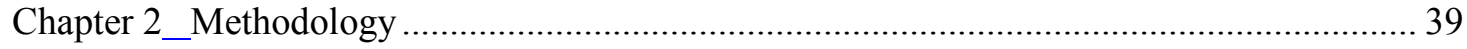

2.1 Relative Permeability, Capillary Pressure, Permeability Upscaling Effect (Scenario 1)

2.2 Relative Permeability, Capillary Pressure, Permeability Upscaling Effect (Scenario 2)

2.3 Relative Permeability, Capillary Pressure, Porosity and Permeability Upscaling Effect

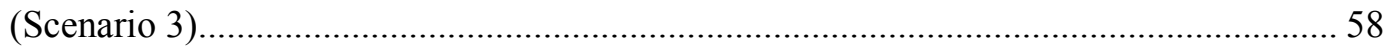

2. 4 Relative Permeability, Capillary Pressure, Porosity and Permeability Upscaling

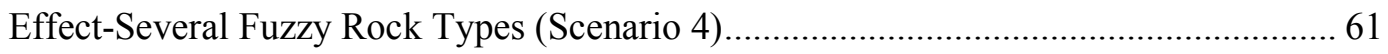

2. 5 Relative Permeability, Capillary Pressure, Upscaling Effect (Scenario 5)............... 65

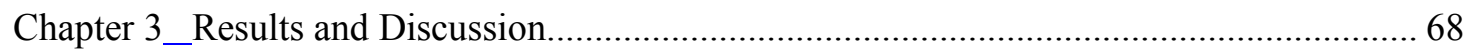

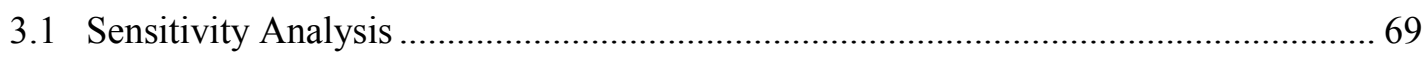

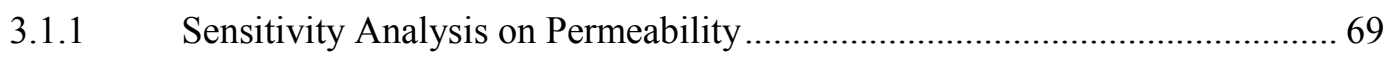


3.1.2 Sensitivity Analysis on Relative Permeability $\left(\mathrm{K}_{\mathrm{row}}, \mathrm{K}_{\mathrm{rw}}, \mathrm{K}_{\mathrm{rg}}, \mathrm{Kr}_{\mathrm{og}}\right) \ldots \ldots \ldots \ldots \ldots \ldots . . . . . . . .11$

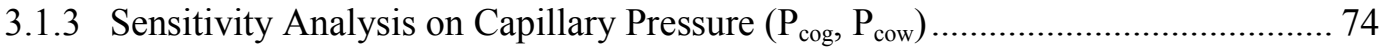

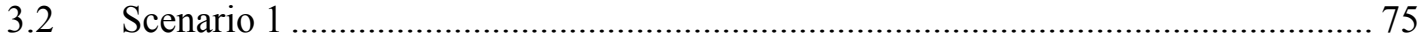

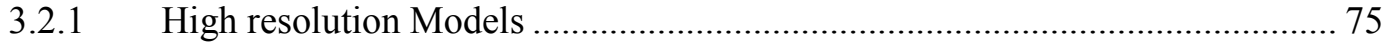

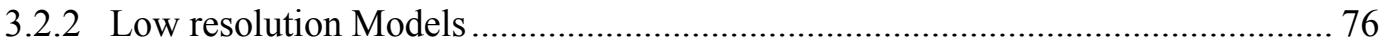

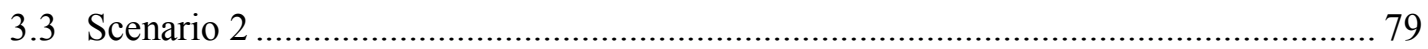

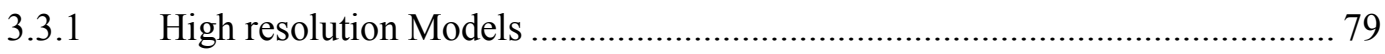

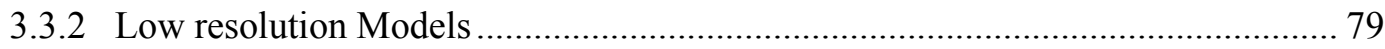

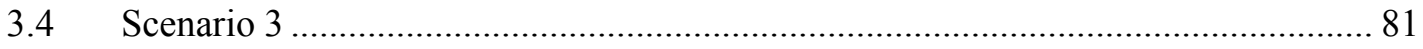

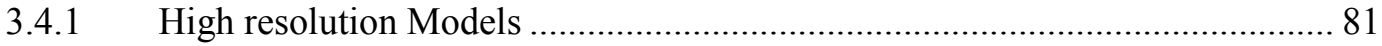

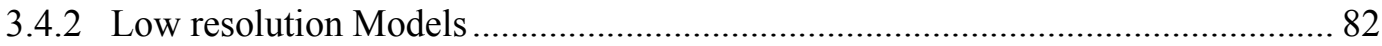

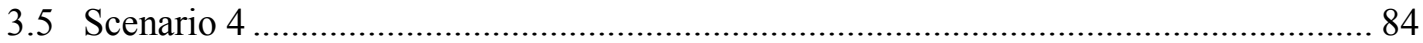

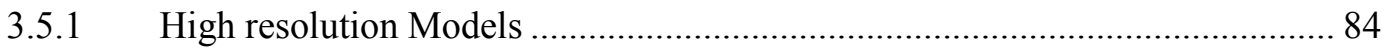

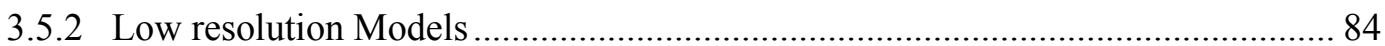

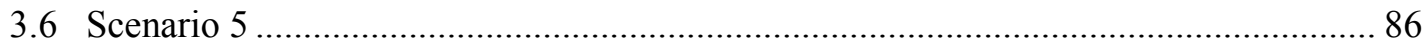

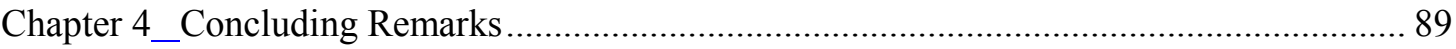

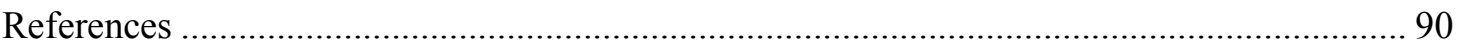

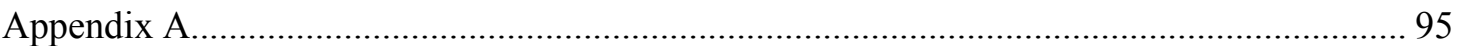

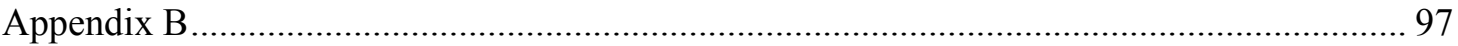

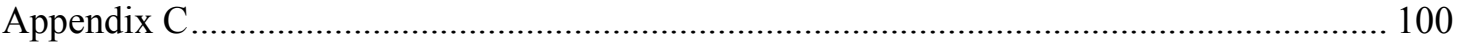

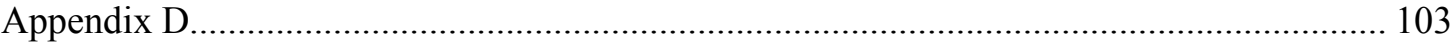

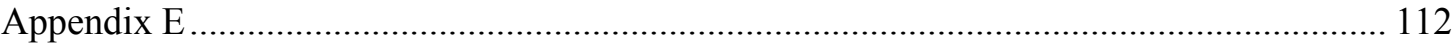




\section{List of Figures}

Figure 1 - 1.(a) Union, (b) intersection, and (c) complement of crisp sets. (2) ........................ 3

Figure 1 - 2. A graphical illustration of $\alpha$-cuts, support, core, and height (1) .......................... 5

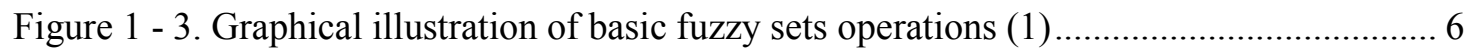

Figure 1 - 4. Graphical illustration of basic fuzzy sets operations intersection, union and

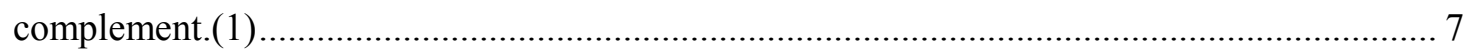

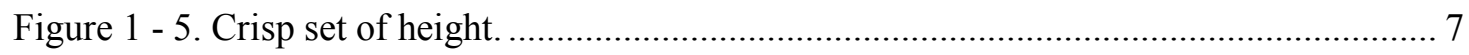

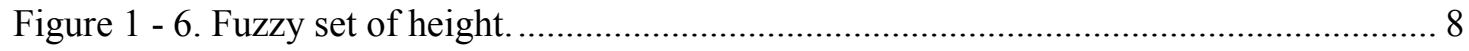

Figure 1 - 7. Common membership functions. a) Triangular, b) Trapezoidal and c) Gaussian (3)

Figure 1 - 8. A schematic of capillary pressure curve for a)completely unsorted grains b)well sorted c)well sorted- coarse skewness d) well sorted-fine skewness e)poorly sorted-slight coarse skewness f)poorly sorted-slight fine skewness. (19) ............................. 17

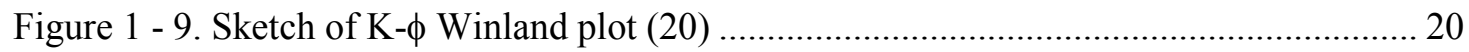

Figure 1 - 10. Sketch of stratigraphic modified Lorenz plot (SLMP) (20)............................. 20

Figure 1 - 11. Sketch of interpreted continuous Stratigraphic Modified Lorenz (20) ............. 21

Figure 1 - 12. A schematic of Stratigraphic Flow Profile (SFP) (20) .................................... 22

Figure 1 - 13. Sketch of Modified Lorenz Plot (MLP) (20) ................................................ 23

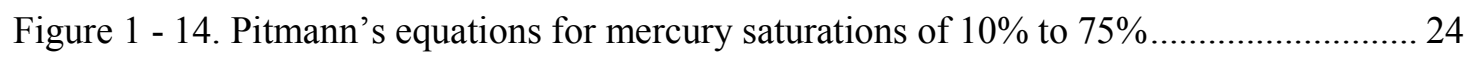

Figure 1 - 15. Thin section and SEM photographs for different rock types (8) ...................... 25

Figure 1 - 16. NMR Transverse relaxation, T2, curves for different rock types. .................... 25

Figure 1 - 17. Determining KT from a plot of J versus $\mathrm{Sw}^{*}$ (4).......................................... 27

Figure 2 - 1.The process followed for comparing the upscaling methods in this work............ 41

Figure 2 - 2.Relative permeability and capillary pressure curves for all the rock types.......... 43

Figure 2 - 3. Winland plot showing the porosity-permeability relationship for all the rock types

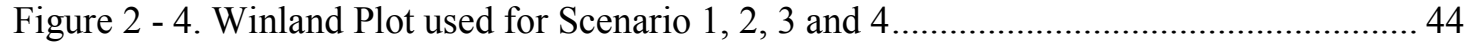

Figure 2 - 5. Assigning single rock type to the whole reservoir .............................................. 45

Figure 2 - 6. Assigning different rock types to the grid blocks ............................................ 46

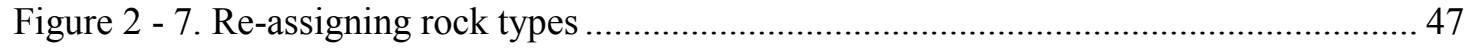

Figure 2 - 8. Rock type distribution in the reservoir................................................................ 49 


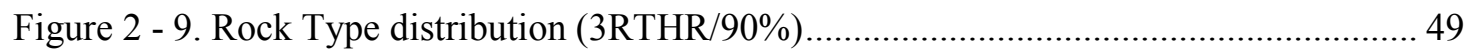

Figure 2 - 10. Rock type distribution in the reservoir (3RTHR/80\%) .................................. 50

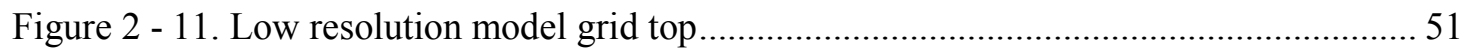

Figure 2 - 12. .Rock type distribution in the reservoir-Conventional upscaled model ............. 51

Figure 2 - 13. Rock type distribution in the reservoir-Fuzzy upscaled model (90\%).............. 53

Figure 2 - 14. Kx distribution in the reservoir-Fuzzy upscaled model (90\%) ......................... 53

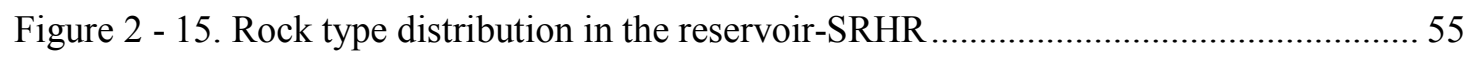

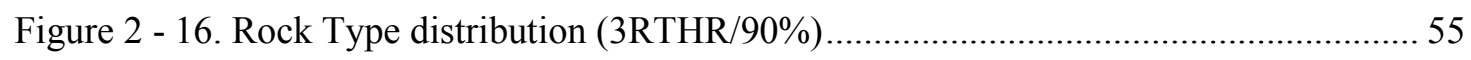

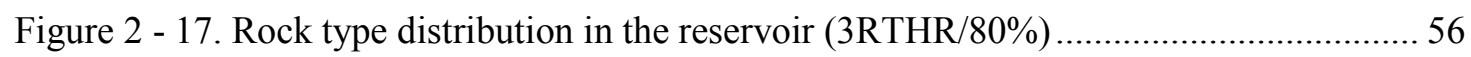

Figure 2 - 18. Rock type distribution in the reservoir-Conventional upscaled model .............. 57

Figure 2 - 19. Rock type distribution in the reservoir-SRHR ................................................. 58

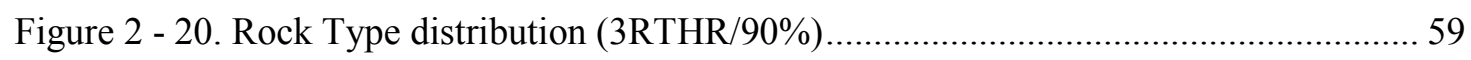

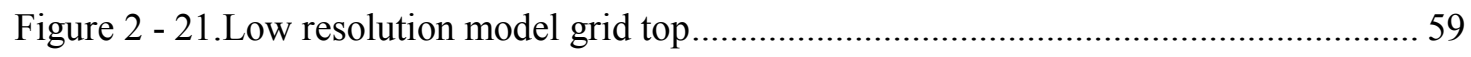

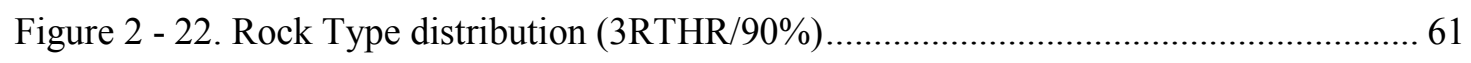

Figure 2 - 23. Low-resolution model grid top

Figure 2 - 24. Rock type distribution -Conventional upscaled model ...................................... 63

Figure 2 - 25. Rock type distribution in the reservoir-Fuzzy upscaled model (90\%).............. 63

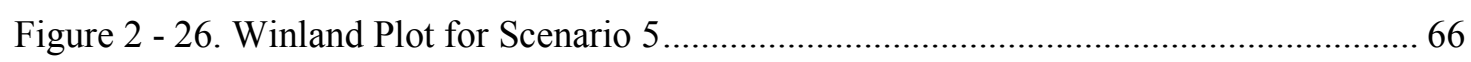

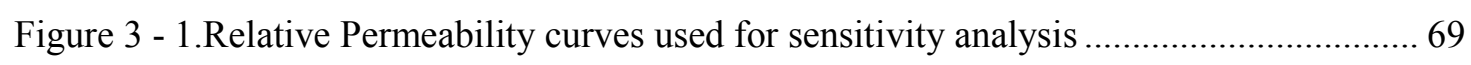

Figure 3 - 2. Sensitivity analysis on permeability-RT1 Properties/Monthly oil production..... 70

Figure 3 - 3. Sensitivity analysis on permeability-RT1 Properties/Cumulative oil production 70

Figure 3 - 4. Sensitivity analysis on permeability-RT2 Properties/Monthly oil production..... 71

Figure 3 - 5. Sensitivity analysis on permeability-RT2 Properties/Cumulative oil production 71

Figure 3 - 6. Sensitivity analysis on Krow- Cumulative oil production ................................... 72

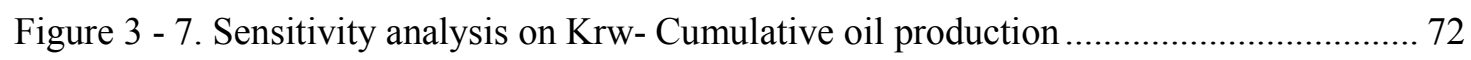

Figure 3 - 8. Sensitivity analysis on Krg- Cumulative oil production .................................... 73

Figure 3 - 9. Sensitivity analysis on Krog- Cumulative oil production ................................... 73

Figure 3 - 10. Sensitivity analysis on Pcog- Cumulative oil production ................................. 74

Figure 3 - 11. Sensitivity analysis on Pcow- Cumulative oil production ................................ 74

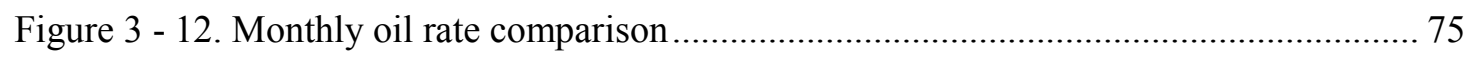

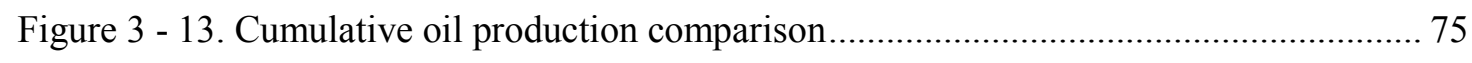

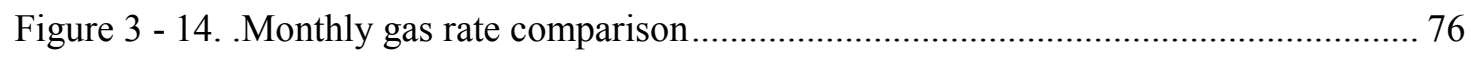

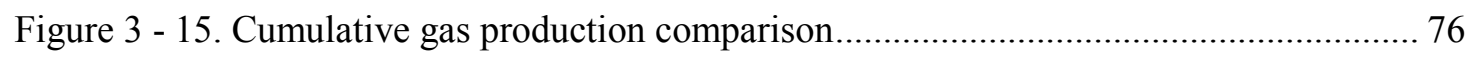

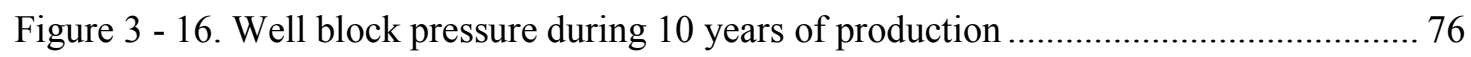


Figure 3 - 17. SRHR and SRLR Models - Oil Production

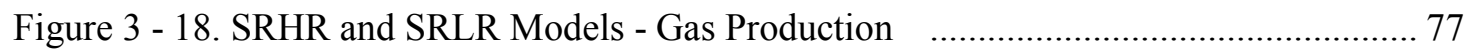

Figure 3 - 19. SRHR and SRLR Models - Water Production

Figure 3 - 20. SRHR and SRLR Models - Well Block Pressure

Figure 3 - 21. 3RHR-90\% and SRLR-90\% - Oil Production

Figure 3 - 22. 3RHR-90\% and SRLR-90\% - Gas Production 78

Figure 3 - 23.Upscaling Error Caused by Two Methods for Scenario1 at Tenth Year of Oil

Production. .78

Figure 3 - 24. Cumulative oil production comparison 79

Figure 3 - 25. SRHR and SRLR Models comparison- Oil Production... 80

Figure 3 - 26. 3RHR-90\% and SRLR-90\% Models comparison- Oil Production. 80

Figure 3 - 27.Upscaling Error Caused by Two Methods for Scenario2 at Tenth Year of Oil

Production. 81

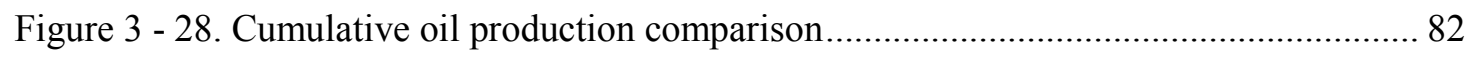

Figure 3 - 29. SRHR and SRLR Models comparison- Oil Production..................................... 82

Figure 3 - 30. 3RHR-90\% and SRLR-90\% Models comparison- Oil Production. 83

Figure 3 - 31.Upscaling Error Caused by Two Methods for Scenario3 at Tenth Year of Oil Production. 83

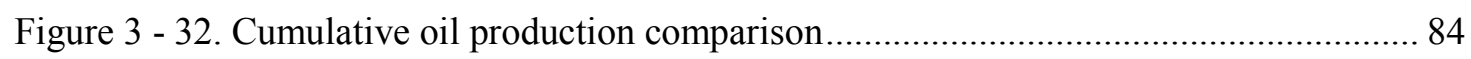

Figure 3 - 33. SRHR and SRLR Models comparison- Oil Production..................................... 85

Figure 3 - 34. 3RHR-90\% and SRLR-90\% Models comparison- Oil Production. 85

Figure 3 - 35.Upscaling Error Caused by Two Methods for Scenario4 at Tenth Year of Oil

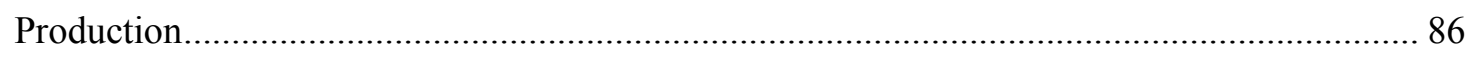

Figure 3 - 36. Cumulative Oil Production for the High Resolution Models in Case 2 2........... 86

Figure 3 - 37. 90\% and 3RLR-90\% Models Comparison- Oil Production............................... 87

Figure 3 - 38. 3RHR-60\% and 3RLR-60\% Models Comparison- Oil Production ................... 87

Figure 3 - 39. Upscaling Error Caused by Two Methods for Case 1 at Tenth Year of Oil

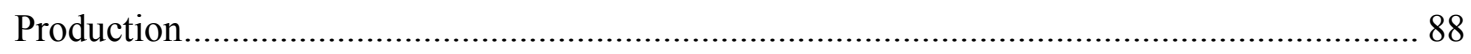

Figure A - 1.Rock type distribution (3RTHR/70\%)

Figure A - 2.Porosity distribution (3RTHR/70\%) 95

Figure A - 3.Kx distribution (3RTHR/70\%)

Figure A - 4.Rock type distribution (3RTHR/60\%) 95

Figure A - 7.Kx distribution -Conventional upscaled model. 96 
Figure B - 1.Kx distribution (3RTHR/90\%)

Figure B - 2.Rock type distribution (3RTHR/70\%)

Figure B - 3.Rock type distribution (3RTHR/60\%)

Figure B - 4.Rock type distribution (3RTHR/50\%)

Figure C - 1.Porosity distribution (3RTHR/90\%)

Figure C - 2. Kx distribution (3RTHR/90\%) 100

Figure C - 3. Rock type distribution (3RTHR/80\%)

Figure C - 4.Rock type distribution (3RTHR/70\%) 100

Figure C - 5.Rock type distribution (3RTHR/60\%) 100

Figure C - 6.Porosity distribution (3RTHR/50\%)

Figure C - 7.Rock type distribution (3RTHR/50\%)

Figure C - 8.Rock type distribution -Conventional upscaled model 101

Figure D - 1.Rock type distribution -SRHR.

Figure D - 2.Porosity distribution (3RTHR/90\%) 103

Figure D - 3.Kx distribution (3RTHR/90\%)

Figure D - 4.Rock type distribution (3RTHR/80\%) 103

Figure D - 5.Rock type distribution (3RTHR/70\%)

Figure D - 6.Rock type distribution (3RTHR/60\%)

Figure D - 7.Rock type distribution (3RTHR/50\%)

Figure D - 8.Porosity distribution -Fuzzy upscaled model (90\%) 104

Figure D - 9.Kx distribution -Fuzzy upscaled (90\%)

Figure D - 10.Porosity distribution -Fuzzy upscaled (80\%) 104

Figure D - 11.Kx distribution -Fuzzy upscaled model (70\%) 107

Figure D - 12.Kx distribution -Fuzzy upscaled model (60\%)

Figure D - 13.Kx distribution -Fuzzy upscaled model (50\%)

Figure E - 1.3RHR-80\% and SRLR-80\% - Oil Production

Figure E - 2. 3RHR-70\% and SRLR-70\% - Oil Production 112

Figure E - 3.3RHR-60\% and SRLR-60\% - Oil Production.

Figure E - 4.3RHR-50\% and SRLR-50\% - Oil Production. 112

Figure E - 5.Monthly oil rate comparison Figure E - 6.Monthly gas rate comparison. 113

Figure E - 7.Cumulative gas production comparison

Figure E - 8.Well block pressure during 10 years of production 113

Figure E - 9. SRHR and SRLR - Gas Production

Figure E - 10.SRHR and SRLR - Water Production 114 
Figure E - 11.SRHR and SRLR Models - Well Block Pressure

Figure E - 12.3RHR-80\% and SRLR-80\% - Oil Production

Figure E - 13.3RHR-70\% and SRLR-70\% - Oil Production...

Figure E - 14.3RHR-60\% and SRLR-60\% - Oil Production. 115

Figure E - 15.3RHR-50\% and SRLR-50\% Models comparison- Oil Production 115

Figure E - 16. Monthly oil rate comparison

Figure E - 17.Monthly gas rate comparison 116

Figure E - 18.Cumulative gas production comparison

Figure E - 19. Well block pressure during 10 years of production 116

Figure E - 20.SRHR and SRLR Models - Water Production

Figure E - 21.SRHR and SRLR Models - Gas Production

Figure E - 22.SRHR and SRLR - Well Block Pressure

Figure E - 23.3RHR-80\% and SRLR-80\% Models - Oil Production

Figure E - 24.3RHR-70\% and SRLR-70\% - Oil Production

Figure E - 25.3RHR-60\% and SRLR-60\% - Oil Production 118

Figure E - 26. 3RHR-50\% and SRLR-50\% Models comparison- Oil Production 118

Figure E - 27.Monthly oil rate comparison

Figure E - 28.Monthly gas rate comparison 119

Figure E - 29.Cumulative gas production comparison

Figure E - 30.Well block pressure during 10 years of production

Figure E - 31. SRHR and SRLR Models - Gas Production.

Figure E - 32. SRHR and SRLR Models - Water Production 120

Figure E - 33. SRHR and SRLR Models - Well Block Pressure

Figure E - 34. 3RHR-80\% and SRLR-80\% - Oil Production 120

Figure E - 35. 3RHR-70\% and SRLR-70\% - Oil Production

Figure E - 36.3RHR-60\% and SRLR-60\% - Oil Production. 121

Figure E - 37. 3RHR-50\% and SRLR-50\% Models comparison- Oil Production 121 


\section{List of Tables}

Table 1 - 1. The value of characteristic functions in crisp sets.............................................. 8

Table 1 - 2. The value of membership functions in fuzzy sets .............................................. 8

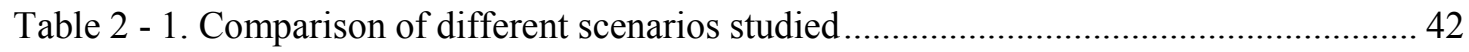

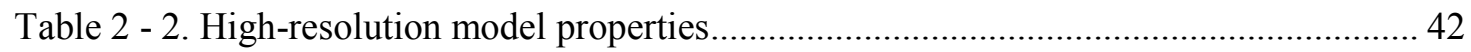

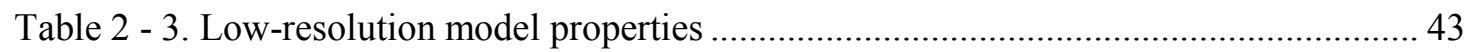

Table 2 - 4. Number of grid blocks for each rock type out of 75 grids. .................................. 48

Table 2 - 5. Porosity and permeability value for each rock type ............................................. 48

Table 2 - 6. Permeability values before and after fuzzy upscaling (90\% of rock type 3$)$......... 52

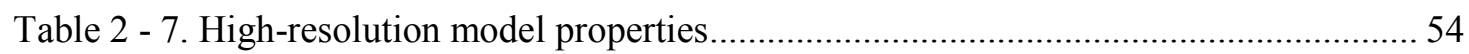

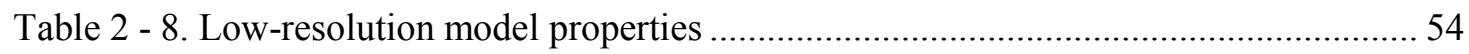

Table 2 - 9. Permeability values before and after fuzzy upscaling (90\% of rock type 3$)$........ 57

Table 2 - 10. Permeability and porosity values before and after fuzzy upscaling $(90 \%$ of rock

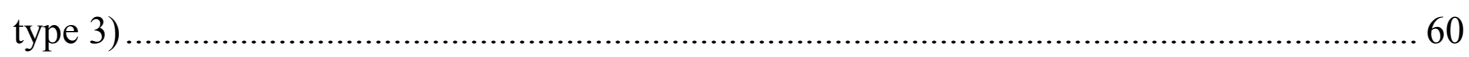

Table 2 - 11 .Permeability values before and after fuzzy upscaling (90\% of rock type 3)...... 64

Table 2 - 12. Porosity values before and after fuzzy upscaling (90\% of rock type 3$)$............. 65

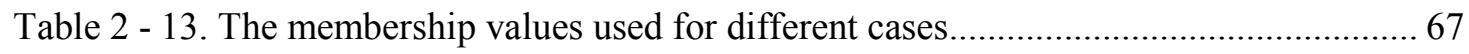

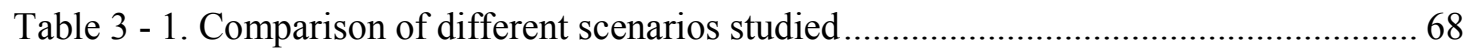

Table A - 1. Permeability values before and after fuzzy upscaling (80\% of rock type 3$)$....... 96

Table A - 2.Permeability values before and after fuzzy upscaling (70\% of rock type 3)........ 96

Table A - 4. Permeability values before and after fuzzy upscaling (50\% of rock type 3 )....... 97

Table B - 1.Permeability values before and after fuzzy upscaling ( $80 \%$ of rock type 3$)$......... 98

Table B - 2.Permeability values before and after fuzzy upscaling (70\% of rock type 3$)$........ 98

Table B - 3.Permeability values before and after fuzzy upscaling (60\% of rock type 3) ........ 99

Table B - 4.Permeability values before and after fuzzy upscaling (50\% of rock type 3)........ 99

Table C - 1.Permeability and porosity values before and after fuzzy upscaling ( $80 \%$ of rock type 3$)$.

Table $\mathrm{C}$ - 2.Permeability and porosity values before and after fuzzy upscaling $(70 \%$ of rock type 3 ).

Table C - 3.Permeability and porosity values before and after fuzzy upscaling (60\% of rock type 3 ). 102

Table C - 4. Permeability values before and after fuzzy upscaling (50\% of rock type 3) ...... 102 
Table D - 1.Porosity values before and after fuzzy upscaling (80\% of rock type 3)............. 104

Table D - 2.Permeability values before and after fuzzy upscaling ( $80 \%$ of rock type 3$)$....... 105

Table D - 3.Permeability values before and after fuzzy upscaling (70\% of rock type 3)...... 106

Table D - 4.Permeability values before and after fuzzy upscaling (70\% of rock type 3$)$....... 107

Table D - 5.Permeability values before and after fuzzy upscaling (60\% of rock type 3$)$....... 108

Table D - 6.Porosity values before and after fuzzy upscaling (60\% of rock type 3)............. 109

Table D - 7.Permeability values before and after fuzzy upscaling (50\% of rock type 3$) \ldots . . .110$

Table D - 8.Porosity values before and after fuzzy upscaling (50\% of rock type 3$)$............. 111 


\section{Chapter 1}

\section{Introduction}

\subsection{Introduction to Fuzzy Logic}

One can view fuzzy sets as a generalization of classical sets, or crisp sets as they are sometimes called. Classical sets and their operations are particularly useful in expressing classical logic and they lead to Boolean logic and its applications in digital systems. Fuzzy sets and fuzzy operations, on the other hand, are useful in expressing the ideas of fuzzy logic leading to applications such as fuzzy controllers.

The following sections start with a short review of classical sets: their notations and operations. This is followed by fuzzy sets and their operations.

\subsubsection{Classical Logic Basics}

To ensure full understanding of the topic that is going to be explained, some definitions are needed.

\section{Definitions}

Sets. The basic definition used in both constant logic (CL) and fuzzy logic domain is that of sets. Per definition, sets are explained as a collection of tangible or intangible objects that have some facets or characteristic in common. These aspects may include shape, color, type or use 
(1). A set may compromise the odd numbers between 1 and 10 or the number of students taking a course. The sets are usually symbolized by capital letters (e.g. $X$ ).

Subsets. They are defined as the sets within the sets and are denoted by capital letters (1). Therefore, $Y \subset X$, Where $\subset$ means set $Y$ is a subset of set $X$.

Elements. Each individual member of a set is called its element, and is signified by lower case letters (e.g. p) (1). Also $\mathrm{p} \in \mathrm{P}$ implies that $\mathrm{p}$ is a member of set $\mathrm{P}$. The set having only one element is called the unit set.

If all the elements should be listed to specify a set, it is written as $\{a, b, c\}$, in which the order of the elements in the bracket is unimportant (1). As an example, $S=\{0,1\}$ represents the set of electric light switch positions. The switch is either "on" or "off".

\section{Special sets.}

(i) Universal set. It contains all the elements in the population. It is represented by 1.

(ii) Null set or empty set. This contains no elements. It is designated by $ø$.

Complimentary set. The compliment of set $X$ is set $X^{\prime}$, where $X+X^{\prime}=1$, which is the universal set. This conclusion can be made that the complement of the universal set is the null set.

Logic Operations. Several CL operations on sets are defined. The intersection "AND" is symbolized by $\cap$. The union "OR" is denoted by $U$.

The preceding definitions of union, intersection, and complement are illustrated in Figure 1 1. Figures such as these are called Venn diagrams or Euler diagrams (2).

Let us assume that $\mathrm{A}, \mathrm{B}$ are subsets of universe $\mathrm{X}$ by $\mathrm{A} \subset X$ and $B \subset X$. When we say "A is a subset of $X$," it means that any elements of the set A belong to set $X$. For example let

$X=\{1,2,3,4,5,6,7,8,9,10\}$

$A=\{1,3,5,7,9\}$

$\mathrm{B}=\{-4,0,4\}$ 
Then $\mathrm{A} \subset X$ but $\mathrm{B} \not \subset \mathrm{X}$ means that set $\mathrm{B}$ is not a subset of set $\mathrm{X}$.

For the previous explained sets, the following properties can be noted.

- Union:

$\mathrm{A} \subset(\mathrm{A} \cup \mathrm{B}), \mathrm{B} \subset(\mathrm{A} \cup \mathrm{B})$

- Intersection:

$(\mathrm{A} \cap \mathrm{B}) \subset \mathrm{A},(\mathrm{A} \cap \mathrm{B}) \subset \mathrm{B}$

- $\quad$ Complement:

A $\cup \bar{A}=\mathrm{X}($ The law of excluded middle)

A $\cap \bar{A}=\varnothing($ The law of excluded middle)

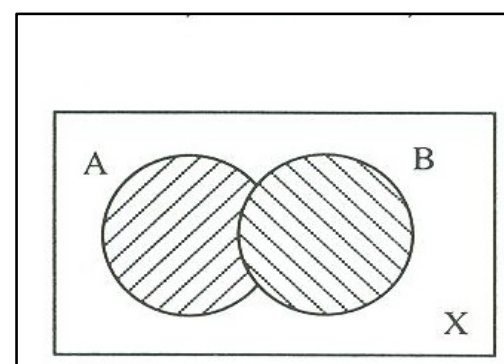

(a)

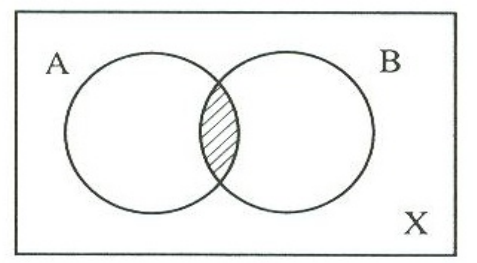

(b)

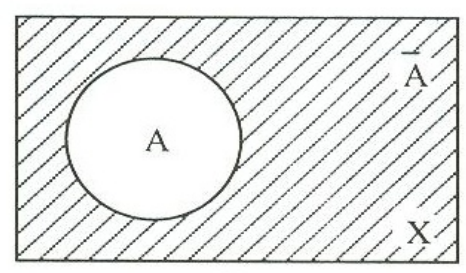

(c)

Figure 1 - 1.(a) Union, (b) intersection, and (c) complement of crisp sets. (2)

In the Venn diagrams in Figure 1 - 1 the surrounding rectangle represents the universe of all sets in the genre.

The OR operation shown above is the inclusive OR. This means set A or B, but not both.

\subsubsection{Fuzzy Logic}

\subsubsection{Fuzzy Sets and Membership Functions}

In crisp logic the boundary of the sets are precise while this is not true for fuzzy logic. In Fuzzy logic, this requirement is relaxed and therefore the set boundaries in this case are vague. 
A fuzzy set is a set where degrees of membership between 1 and 0 are permitted; it allows partial membership. The fuzzy logic Venn diagram does not have a crisp boundary, and boundary zones appear as shading (1).

Having the set $\mathrm{X}$ as the universe and set $\mathrm{A}$ as a fuzzy subset of the universe, the value $\mu_{\mathrm{A}}(\mathrm{x})$ is called the membership value or the grade of membership of $x \in X$. The membership value represents the degree of $\mathrm{x}$ belonging to the fuzzy set $\mathrm{A}$. The value of the characteristic functions for crisp sets is either 0 or 1 , but the membership value of a fuzzy set can be an arbitrary value between 0 and 1.Fuzzy sets can thus better reflect the way intelligent people think. For example, an intelligent person will not classify people into two categories of friends and enemies. These categories are two extremes while there are some people who can be considered in ranges between these categories. It should be noted that there are degrees in every trait can lead to error in decisions (3).

\section{Definition (3)}

Empty fuzzy set. An empty fuzzy set, is a set that membership function for all possible members under consideration in it is zero.

Universal fuzzy Set. A fuzzy set is universal if and only if the value of the membership function is one for all members.

Equal fuzzy sets. Two fuzzy sets $A$ and $B$ are said to be equal iff $\mu_{A}(x)=\mu_{B}(x)$ for all $x \in X$. $\alpha$-cuts. A fuzzy set may be completely distinguished by its $\alpha$-cuts, defined as follows

Strong $\alpha$-cuts: $\quad A_{\alpha}=\left\{x \mid \mu_{A}(x)>\alpha\right\} ; \quad \alpha \in[0,1]$

Weak $\alpha$-cuts: $\quad A_{\alpha}=\left\{x \mid \mu_{A}(x) \geq \alpha\right\} ; \quad \alpha \in[0,1]$

Accordingly, $\alpha$-cuts is a crisp set that consists of all the members of a fuzzy set whose membership functions have values greater than a particular value $\alpha$, or greater than or equal to a specified value; the former condition leads to Strong $\alpha$-cuts and the succeeding one to weak $\alpha$-cuts. All the cuts of a fuzzy set form a family of crisp sets.

Support. The support of a fuzzy set $\mathrm{A}$ is a crisp set supp (A) of all $\mathrm{x} \in \mathrm{X}$ such that $\mu \mathrm{A}(\mathrm{x})>0$. It is a strong $\alpha$-cut for $\alpha=0$. The element $\mathrm{x} \in \mathrm{X}$ at which $\mu \mathrm{A}(\mathrm{x})=0.5$ is called the crossover point. A fuzzy set whose support is a single element in $\mathrm{X}$ with $\mu \mathrm{A}(\mathrm{x})=1$ is referred to as a fuzzy singleton.

Core. The core of a fuzzy set $A$ is a crisp set core (A) of all $x \in X$ such that $\mu \mathrm{A}(\mathrm{x})=1$. The core of a fuzzy set may be an empty set. 
Height. The height, h (A) of a fuzzy set A is the largest value of $\mu(\mathrm{A})$ for which the $\alpha$-cut is not empty. In other words, it is the largest value of the membership function made by an element in the set. A fuzzy set with $\mathrm{h}(\mathrm{A})=1$ is referred to as normal; otherwise it will be referred to as sub-normal.

The concepts of $\alpha$-cuts, support, core, and height are illustrated in Figure 1 - 2.
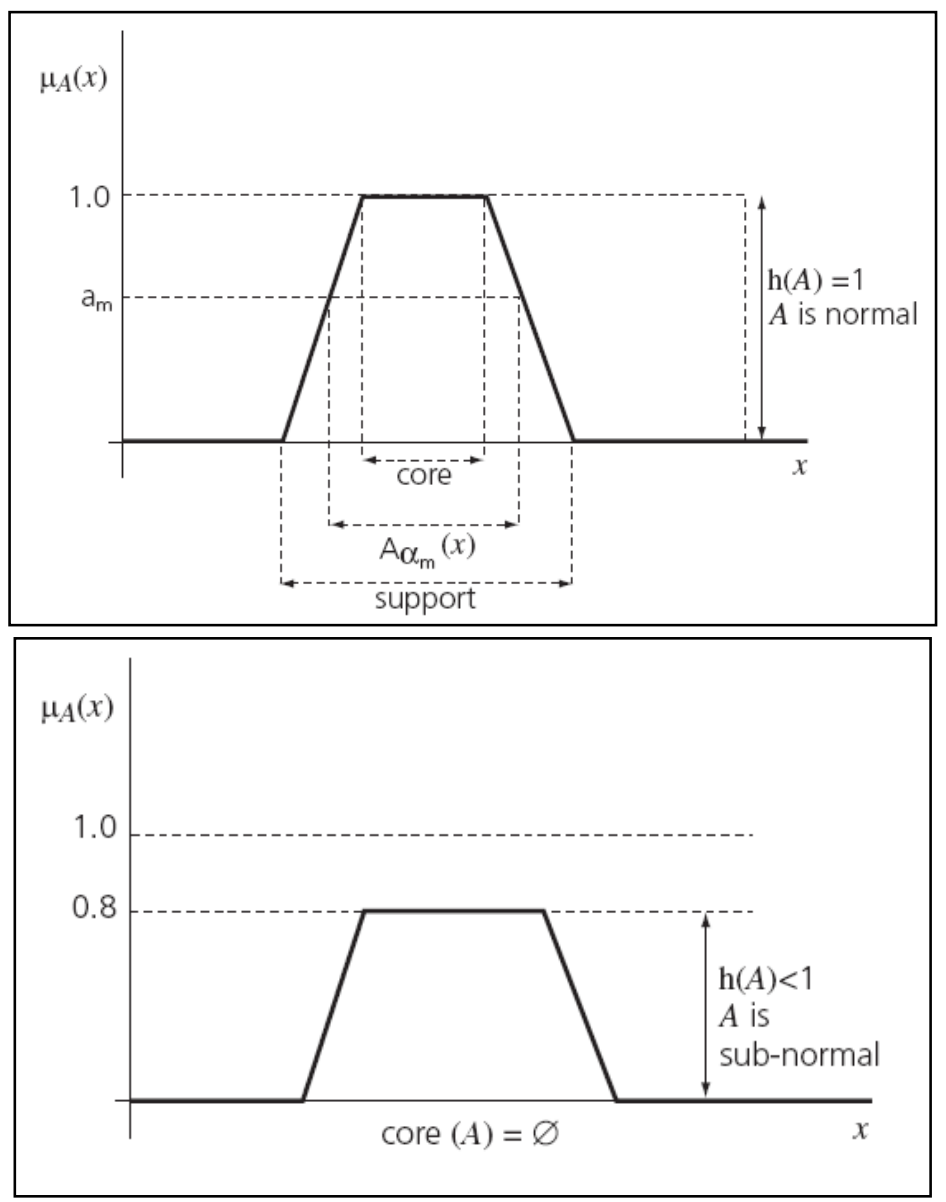

Figure 1 - 2. A graphical illustration of $\alpha$-cuts, support, core, and height (1)

\subsubsection{Logic Operations on Fuzzy Logic}

Complement. The absolute complement of a fuzzy set A is denoted by $\bar{A}$ and its membership function is defined by

$$
\mu_{\bar{A}}=1-\mu_{A}(x) \text { for all } x \in X
$$

Union. The union of two fuzzy sets A and B is a fuzzy set whose membership function is defined by 


$$
\mu_{A \cup B}(x)=\max \left[\mu_{A}(x), \mu_{B}(x)\right]
$$

Intersection. The intersection of two fuzzy sets A and B is a fuzzy set whose membership function is defined by

$$
\mu_{A \cap B}(x)=\min \left[\mu_{A}(x), \mu_{B}(x)\right]
$$

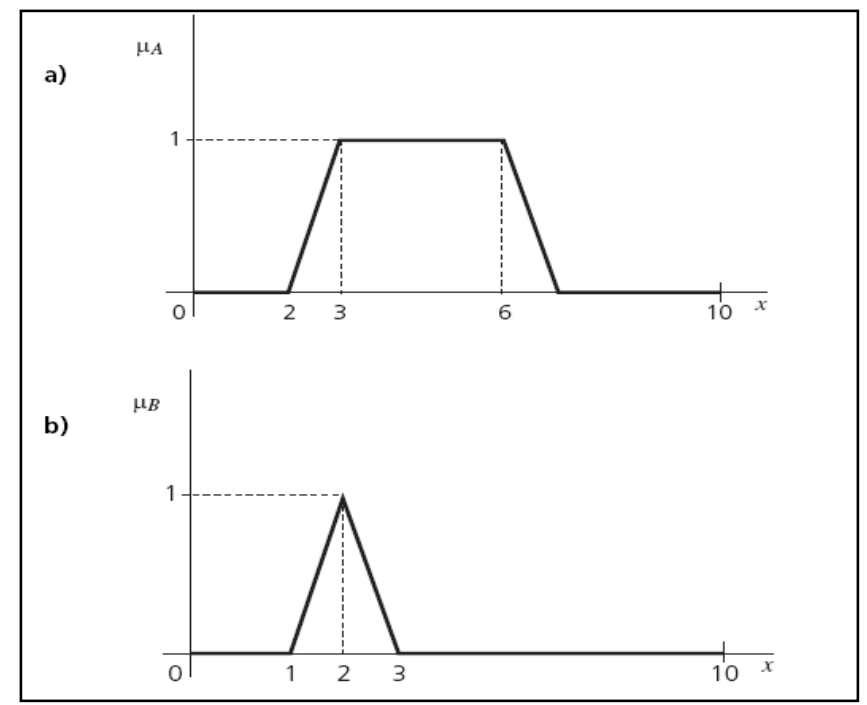

Figure 1 - 3. Graphical illustration of basic fuzzy sets operations (1) 


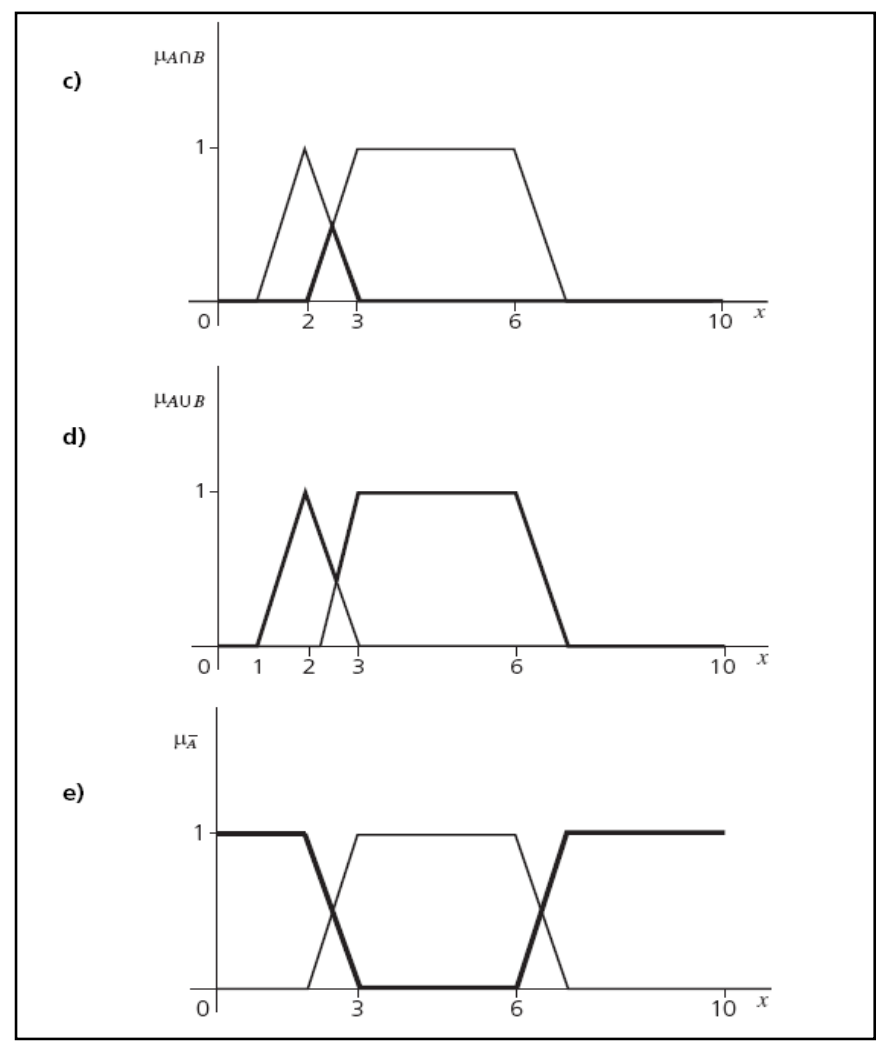

Figure 1 - 4. Graphical illustration of basic fuzzy sets operations intersection, union and complement.(1)

Let us compare the characteristic functions and membership function using an example. Figure 1 - 5 and Figure 1 - 6 show the characteristic and fuzzy functions for person's heights correspondingly for "low", "middle", and high tallness. Now, suppose that there are three persons $\mathrm{A}, \mathrm{B}$, and $\mathrm{C}$ with stature of $179 \mathrm{~cm}, 171 \mathrm{~cm}$, and $168 \mathrm{~cm}$ respectively.

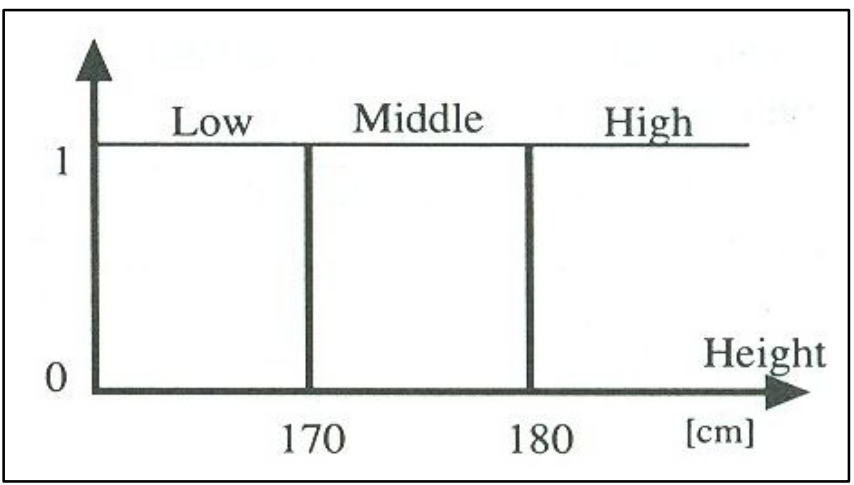

Figure 1 - 5. Crisp set of height. 


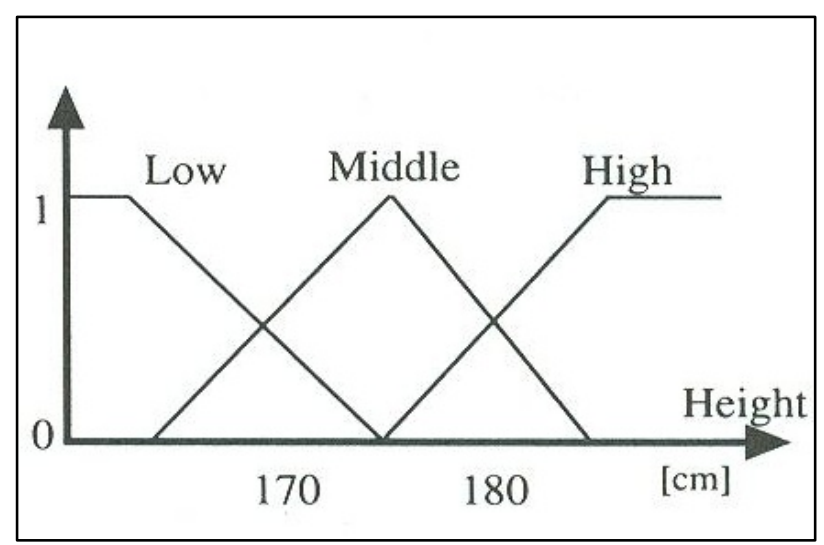

Figure 1 - 6. Fuzzy set of height.

Using the crisp characteristic sets, we can find the characteristic function values as are shown in Table 1 - 1. This table shows that A and B belong to the "Middle" high set, and C belongs to the "low" set. This might seem a little unfair to A and C, because B and C have only $3 \mathrm{~cm}$ difference in height, while $\mathrm{A}$ and $\mathrm{B}$ have $8 \mathrm{~cm}$ difference and still are in the same division.

Table $1-1$. The value of characteristic functions in crisp sets

\begin{tabular}{|c||c|c|c|c||}
\hline & Height & Low & Middle & High \\
\hline \hline $\mathrm{A}$ & $179 \mathrm{~cm}$ & 0 & 1 & 0 \\
\hline $\mathrm{B}$ & $171 \mathrm{~cm}$ & 0 & 1 & 0 \\
\hline $\mathrm{C}$ & $168 \mathrm{~cm}$ & 1 & 0 & 0 \\
\hline
\end{tabular}

On the other hand using the membership functions of Figure 1 - 6 the membership values can be obtained. They are shown in Table $1-2$.

Table $1-2$. The value of membership functions in fuzzy sets

\begin{tabular}{|c||c||c||c|c||}
\hline & Height & Low & Middle & High \\
\hline \hline $\mathrm{A}$ & $179 \mathrm{~cm}$ & 0 & 1 & 0 \\
\hline \hline $\mathrm{B}$ & $171 \mathrm{~cm}$ & 0 & 1 & 0 \\
\hline $\mathrm{C}$ & $168 \mathrm{~cm}$ & 1 & 0 & 0 \\
\hline
\end{tabular}

This table shows that $\mathrm{C}$ belongs to "Low" set with a grade of 0.7 and to the "Middle" set with a grade of 0.3 , whereas it does not belong to "High" set. Their height can be linguistically explained as follows:
A: higher middle,
B: Lower middle, 


\section{C: $\quad$ Relatively low.}

Fuzzy sets should be defined properly, because the meaning of high, middle and low, or fast and slow might be different depending on each case.

The fuzzy sets can be expressed in two ways:

- $\quad$ Discrete expression( when the universe is finite)

In this case, if $\mathrm{X}$ is the universe set then a fuzzy set $\mathrm{A}$ on universe can be represented as follows:

$$
X=\left\{x_{1}, x_{2}, \ldots, x_{n 1}\right\}
$$

$$
\begin{aligned}
A & =\mu_{A}\left(x_{1}\right) / x_{1}+\mu_{A}\left(x_{2}\right) / x_{2}+\ldots+\mu_{A}\left(x_{n}\right) / x_{n} \\
& =\sum_{i=1}^{n} \mu_{A}\left(x_{i}\right) / x_{i}
\end{aligned}
$$

- $\quad$ Continuous expression(when the universe is infinite)

In this case, Fuzzy set A on universe $\mathrm{X}$ is expressed as follows.

$$
A=\int_{x} \mu_{A}\left(x_{i}\right) / x_{i}
$$

The symbol / in above equations is called a separator, which separates the membership value of the element (on the left side) from the member (on the right side). So $/,+\mathrm{a}, \int$ and $\sum$ do not have their mathematical meanings and are only used for fuzzy set definitions.,$+ \int$ and $\sum$ are used for connecting the terms.[1]

\subsubsection{Popular Fuzzy Sets (3)}

\section{Triangular Fuzzy Sets}

The triangular membership function illustrated in Figure 1 - 7 can be expressed as: 


$$
\begin{aligned}
\mu(x) & =a(b-x) /(b-c) ; \quad b \geq x \leq c \\
& =a(d-x) /(d-c) ; \quad c \geq x \leq d \\
& =0
\end{aligned}
$$

\section{Trapezoidal Fuzzy Sets}

The trapezoidal membership function illustrated in Figure 1 - 7 can be expressed as:

$$
\begin{aligned}
\mu(x) & =a(b-x) /(b-c) ; & & b \geq x \leq c \\
& =a ; & & c \geq x \leq d \\
& =a(e-x) /(e-d) ; & & d \geq x \leq e \\
& =0 & &
\end{aligned}
$$

\section{Gaussian Fuzzy Sets}

The Gaussian membership function illustrated in Figure $1-7$ can be expressed as:

$$
\mu(x)=a \exp \left[(-x-b)^{2} /\left(2 \sigma^{2}\right)\right]
$$

Fuzzy sets are the tools, which convert the perceptions of fuzzy logic into algorithms directing to functions. They are used to state accurately what one means by vague terms such as hot, cold, tall, and short. By allowing fractional membership, fuzzy sets can provide computers with algorithms that expand their binary logic and enable them to make human-like decisions. The term fuzzy in this context does not mean imprecise, but exactly the opposite.

It may appear difficult to settle the argument that the objective of fuzzy sets is to enable computing with words with the fact that fuzzy sets are of a mathematical nature. Do humans think in expressions of triangular membership functions, Cartesian multiplications, etc.? Certainly not, but one may think of fuzzy sets and the related mathematics as the media through which the way we think is transferred to a computer, rather than trying to accommodate our thinking to the computer needs. Of course, it would have been more efficient to have a way for direct relocate of thoughts without the transitional stage of mathematics.

The evasion of mathematics occurs in the way to describe a system.

Attempting to transfer our way of thinking into fuzzy set formulation could have an interesting side effect. It gives us an opportunity to consider our own thoughts and actions and reflect on the astuteness of our choices and verdicts. 


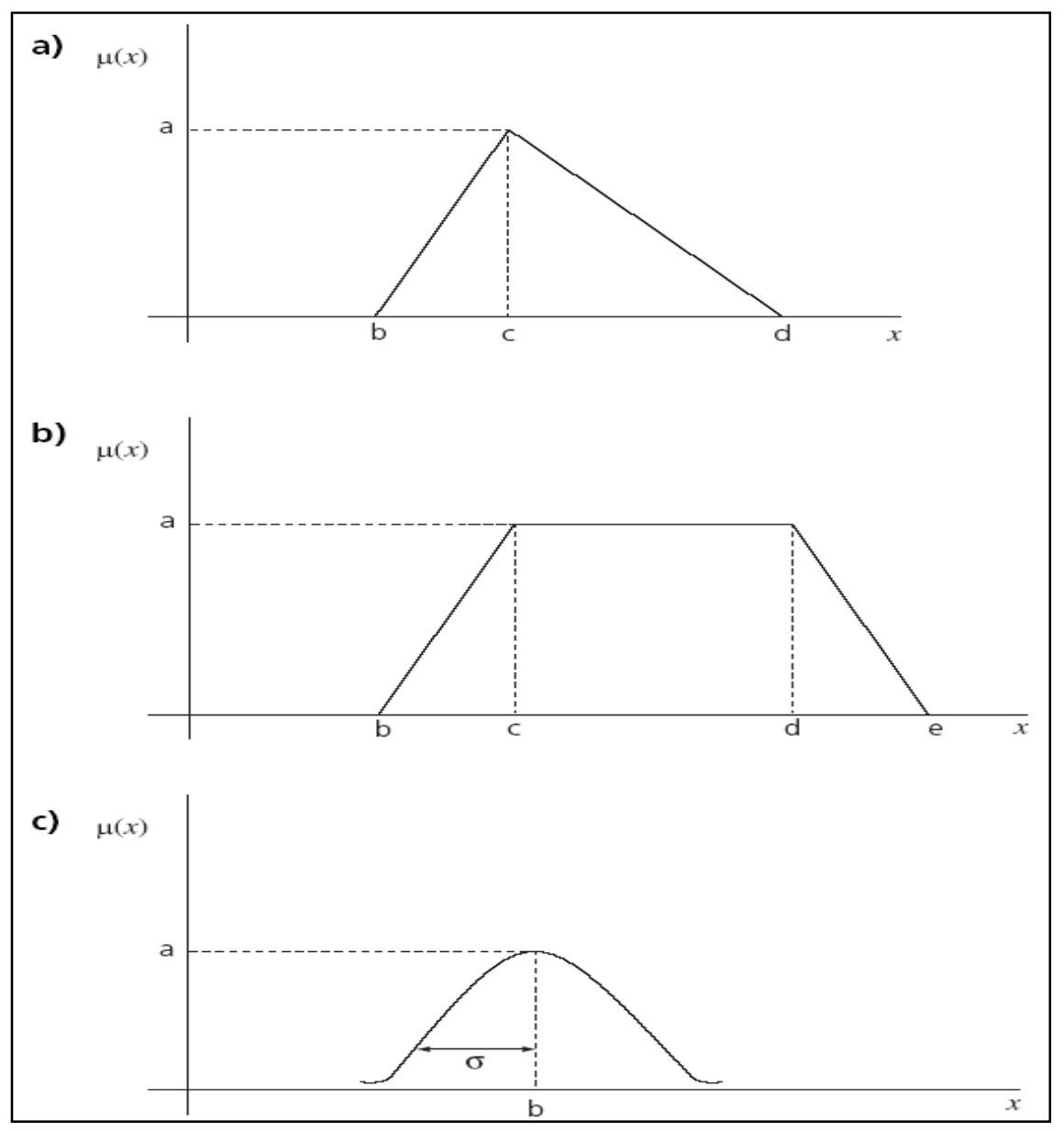

Figure 1 - 7. Common membership functions. a) Triangular, b) Trapezoidal and c) Gaussian (3)

\subsection{Introduction to Flow Units and Rock Types}

A need to define quasi geological/engineering units to shape the description of reservoir zones as storage containers and reservoir conduits for fluid flow have been recognized by petroleum geologists, engineers, and hydrologists.

Flow units are resultant of depositional the depositional environment and digenetic process, and different authors have defined them in different words (4).

Understanding complex variation in pore geometry within different lithofacies rock types is the key to improving reservoir description and exploitation. Core data provide information on various depositional and diagenetic controls on pore geometry. 
Variation in pore geometrical attributes in turn defines the existence of distinct zones (hydraulic units) with similar fluid-flow characteristics.

Hear et al. defined flow unit as a reservoir zone that is laterally and vertically continuous, and has similar permeability, porosity, and bedding characteristic. Gunter et al. defined flow unit as a stratigraphically continuous interval of similar reservoir process that honors the geologic framework and maintains the characteristic of the rock type (5).

According to Tiab flow units have the following characteristics (4):

1. A flow unit is a definite volume of reservoir, composed of one or more reservoir quality lithologies.

2. A flow unit is correlative and mapable at the interval scale.

3. A flow unit zonation is recognizable on wire-line log.

4. A flow unit may be in communication with other flow units.

Taghavi et al. have defined flow units as a lithofacies or group of lithofacies, which have the same petrophysical and flow parameters (6). Petrophysical properties include porosity and permeability. However some other parameters such as capillary pressure and relative permeability are comprise $d$ in the flow parameters category. Defining the flow units in carbonate reservoirs is relatively difficult due to small scale depositional heterogeneities together with post depositional diagenesis and fractures which can substantially alter the flow potential of the depositional unit. They have used both the static and dynamic reservoir data to identify the flow units in a carbonate reservoir in south west of Iran. Ultimately, they have shown that even after considering the porosity-permeability cross plot and capillary pressure data the overlaps of different flow units still exists.

Gunter et al. has another definition for flow units. Based on that, flow unit is defined as is a stratigraphically continuous interval of similar reservoir process speed that honors the geologic framework and maintains characteristics of rock types (7).

As stated by Porras et al. a petrophysical flow unit is an interval of sediment with alike petrophysical properties such as porosity, permeability, water saturation, pore throat radius, storage and flow capacity, that are dissimilar to the intervals immediately above and below. 
Petrophysical flow units are usually clustered to depict containers. Rock types having similar flow capacity are grouped and used in the determination of reservoir flow units (8).

The geologist will also identify various "facies" within the reservoir. This term is used to describe a sedimentary body having distinct physical, chemical and biological attributes (9).Within a given facies the reservoir properties can vary significantly. This variation has lead to a further subdivision known as Flow Units (FU). Flow units are regions in the sedimentary sequence that are judged to control the movement of injected or produced fluids within the reservoir (10).

Bear defined the hydraulic (pore geometrical) unit as the representative elementary volume of the total reservoir rock within which the geological and petrophysical properties of the rock volume are the same (11).

Ebanks defined hydraulic flow units as a mappable portion of the reservoir within which the geological and petrophysical properties that affect the flow of fluid are consistent and predictably different from the properties of other reservoir rock volume (12).

Some other authors believe that a hydraulic unit is defined as the representative volume of the total reservoir rock with geological properties that control fluid flow. It is a reservoir zone that is laterally and vertically continuous and has similar flow and bedding characteristics (13).

The Rock Type concept was introduced by Archie who classified carbonate rocks because of grain type and the amount of visual porosity. Rock types usually were corresponded to flow units in terms of productivity. In fact Rock Types are defined as units of rock deposited under similar conditions which experienced similar diagenetic processes resulting in a unique porosity-permeability relationship, capillary pressure profile and water saturation for a given height above free water in a reservoir (14).

Porosity, permeability, mercury injection capillary pressure, relative permeability, and mineralogical data are usually utilized to portray the reservoir pore system into rock types having similar flow capacity and storage capacity. Characterization of reservoir into rock types in order to determine flow units incorporate geological, petrophysical and production data (8).

Different group of scientists and engineers have defined rock types in different words (15). 
- Geologists' definition of rock type: Rock volumes having similar depositional and diagentic environment identified using core description and core analysis in cored wells. (Lithofacies)

- $\quad$ Petrophysicists' definition of rock type: Rock volumes having similar responses of $\log$ measurement in a whole well profile .(Electrofacies)

- Reservoir Engineers' definition of rock type: Rock volumes having similar pore size distribution, capillary pressure and relative permeability curves at a given wettability.

\subsubsection{Permeability-Porosity Relationship}

The classic scatter plot of permeability versus porosity on semi-log scale has historically been utilized to aid in identifying the relationship between core permeability and core porosity. Amaefule et al. (16) noted that there is apparently no theoretical basis to support this traditional cross plot and that permeability plotted as a function only appears to be $\log$ normally distributed. Often times the scatter of the data negates the value of this technique. Using the core data the empirical permeability is estimated from the log derived porosity equation:

$\log k=a \phi+b$

Equation 1

It has been documented that porosity is generally not dependent upon grain size. As a general rule permeability is very much grain size dependent. Amaefule et al. (16) illustrated this by considering a reservoir having high and low permeability zones. In their example, the porosity was equal for two cores having high and low permeability. As a result, the researchers noted the limitation of the classic approach. However, it was observed that different porositypermeability relationships are supporting detail regarding the presence of multiple flow units.

\subsubsection{Interrelation between Pore Geometry, Capillary Pressure and Rock Types}

Davies (17)further discussed the permeability-porosity relationship. In the case study, the plot of all data exhibited significant scatter. Davies sought to characterize the reservoir in terms of pore geometry. Changes in pore geometry in the reservoir can occur due to changes in lithology, the depositional environment, and chemical changes that have occurred post 
deposition. Such events influence grain size, grain shape, sorting and packing. Using pore geometry as a basis, the researchers identified individual rock types in the reservoir. Because of the subdivision, plots of permeability versus porosity supported the rock type breakdown.

The researchers presented a methodology for reservoir characterization directed at permeability prediction and the resulting improvement in predicting production or injection behavior. Davies et al. investigated and analyzed the "rock type" in two reservoirs. They characterized rock types based on unique pore geometry. The method utilized image analysis via a scanning electron microscope specially equipped for automated image analysis procedures in order to identify various pore geometries.

When integrated with other petrophysical measurements (porosity, permeability, etc.), rock types of non-cored sections were identified from the logs. As a result, the reservoir can be defined in terms of flow units.

Pore geometry analysis coupled with log data allow for significant reservoir characterization. The parameters of pore geometry measurement consider several different aspects of the pore and pore system in order to identify and/or differentiate the rock types.

They classified pore types in terms of several parameters. The scanning electron microscope is essential for this type of analysis:

- Pore Size and Shape - Determined via scanning electron work.

- Pore Throat Size - Determined via scanning electron work and capillary tests.

- Aspect Ratio - Ratio of pore body to throat size.

- Coordination Number - The number of pore throats intersecting each pore.

- Pore Arrangement - Pore distribution is analyzed

The smallest pore throat size that will permit the entry of oil at a given capillary pressure is defined as the minimum effective pore throat size.

The parameters that influence fluid flow are mainly pore throat geometrical features. Pore geometry is in turn controlled by mineralogy and texture (13).

Capillary pressure curves can be interpreted based on their shapes. The shapes of these curves are affected by two factors of sorting and skewness of pore throat sizes. 
Sorting- The range of sedimentary grain sizes that occurs in sediment or sedimentary rock. The term also refers to the process by which sediments of similar size are naturally segregated during transport and deposition according to the velocity and transporting medium. Wellsorted sediments are of similar size (such as desert sand), while poorly sorted sediments have a wide range of grain sizes (as in a glacial till). Well-sorted sandstone tends to have greater porosity than poorly sorted sandstone because of the lack of grains small enough to fill its pores. Conglomerates tend to be poorly sorted rocks, with particles ranging from boulder size to clay size. (18).

In general well-sorted pore arrangement is winnowing of the primary sediments, recrystallization, or dolomitization of rock. In addition, poorly sorting is a primary unwinnowed rock condition.

Skewness- The degree to which a distribution has lost the bilateral symmetry of a normal distribution. Skewness is usually expressed qualitatively rather than quantitatively (18).

The displacement pressure or the height of the column of oil required to offset capillary pressure and dislocate interstitial water of a reservoir rock is a function of the size of throats between interconnected pores and is independent of total porosity.

Some examples of the capillary pressure curve shapes having different sorting and skewness are shown in Figure $1-8$.

Rock grouped together by lithologic, petrophysic and diagentic characteristics have astonishingly similar mercury capillary pressure curves. Permeability and porosity may vary widely but productibility remains conspicuously the same in these rocks (19).

Departure from these capillary pressure curves is dependent of the size of pore throats within each class of rock.

Usually the term "family of curves" is used because the curves in a family are related to each other in shape and have similar departure from the $\mathrm{x}$ and $\mathrm{y}$ axes. Each family of curves is associated to discrete family of rocks. 


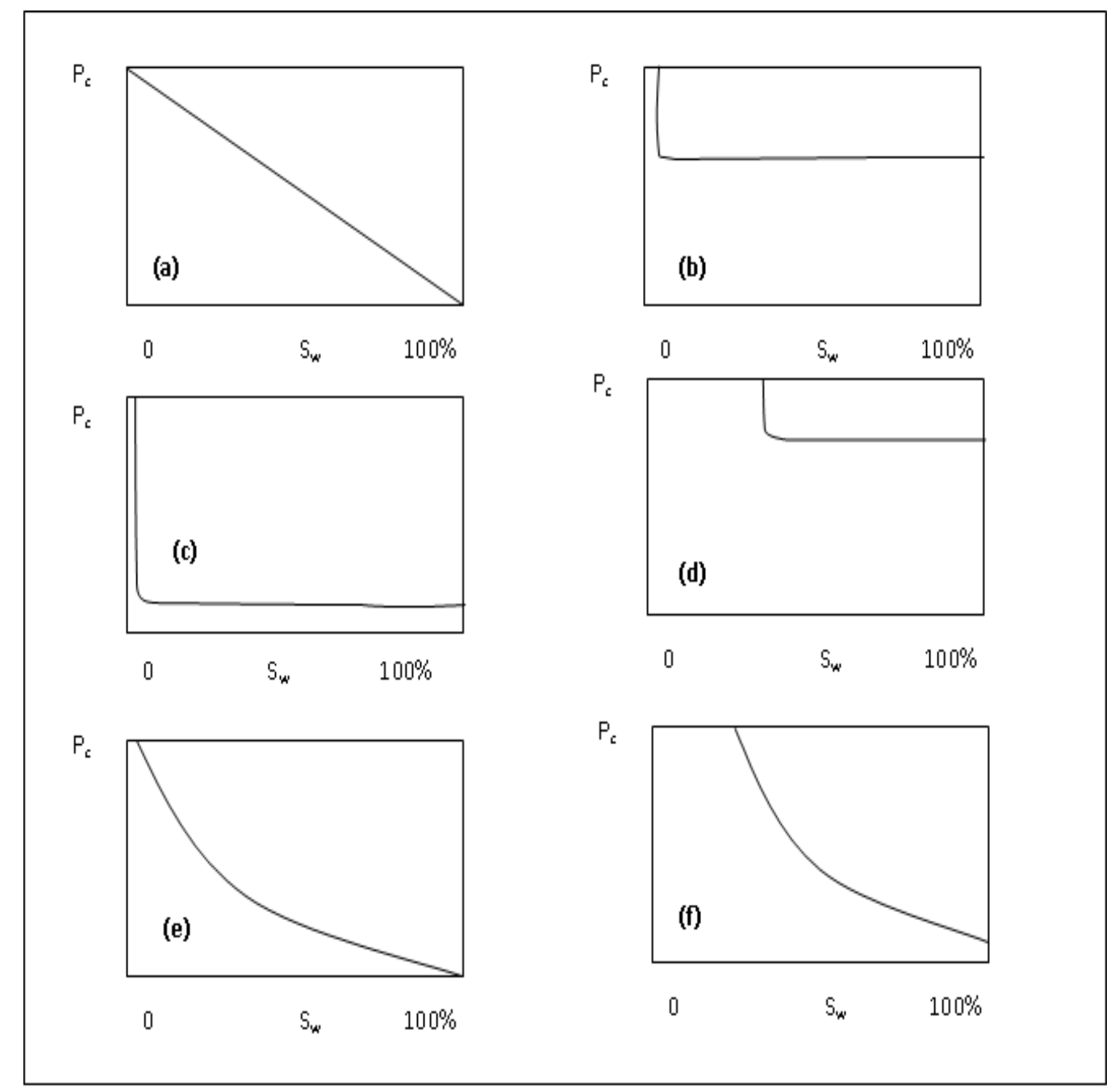

Figure 1 - 8. A schematic of capillary pressure curve for a)completely unsorted grains b)well sorted c)well sorted- coarse skewness d) well sorted-fine skewness e)poorly sorted-slight coarse skewness f)poorly sorted-slight fine skewness. (19)

\subsubsection{Rock Type or Flow Unit Identification Techniques}

Rock type distribution identification is conspicuous, since it is key information to define layering and select the best option for production test interpretation (15).

\section{A) Graphical Method}

1. Gunter et al. pioneered a graphical method for quantifying reservoir flow units based on geological framework, petrophysical rock/pores types, storage capacity, flow capacity, and reservoir process speed (20).

Before explaining their method, it is necessary to define the key terms used in this approach. 
Winland Plot - a semi-log crossplot of permeability (mD) versus porosity (\%), with isopore throat lines (R35Ports) (21), (22).

R35 Ports-correspond to the calculated pore throat radius (microns) at 35\% mercury saturation from a mercury injection capillary pressure test. They can be calculated directly from Winland's equation ( Equation 2) or other equations based on permeability and porosity (23), (24). In this equation, permeability is input in milidarcies and porosity in percent.

$\log R 35=0.732+0.588 \times \log (K)-0.864 \times \log (\phi)$

Equation 2

R35 pore throat radii is a function of entry size and pore throat sorting, and is a good measure of the largest connected pore throats in a rock with intergranular porosity .

K/PHI Ratio on a foot-by-foot basis is a relative measure of reservoir process speed (25) (RPS) and is a simplified form of diffusivity, ignoring viscosity and total compressibility.

Storage capacity - the product of porosity and thickness (20).

Flow capacity - the product of permeability and thickness (20).

Flow Unit Speed (FUS) - percent flow capacity divided by percent storage capacity (20).

Stratigraphic Modified Lorenz Plot (SMLP) - a plot of percent flow capacity versus percent storage capacity ordered in stratigraphic sequence. If the data is continuous (smoothed), it should be constructed using every sample available. It offers a guide as to how many flow units are necessary to honor the geologic framework (20). 
Stratigraphic Flow Profile (SFP) - a plot used to display flow unit interpretation containing a correlation curve (GR or VCL), a generalized core description, porosity, permeability, R35, $\mathrm{K} / \mathrm{PHI}$ ratio, percent storage capacity and percent flow capacity.

Modified Lorenz Plot (MLP) - a plot of flow capacity versus storage capacity that is computed on a flow unit basis and maintains stratigraphic position. This plot is unlike the original Lorenz Plot (26) in that it preserves the stratigraphic information.

According to the method they introduced, the five steps for identifying and characterizing flow units are:

1. Identify rock type and illustrate the Winland porosity-permeability cross plot (Figure 1 -9).

2. Construct the stratigraphic modified Lorenz plot (SMLP) by computing on a foot-foot basis the percent flow capacity (permeability thickness) and percent flow storage (porosity thickness) (Figure 1 - 10).

3. Select flow unit intervals based on inflection points from SMLP. These preliminary flow units must be verified using the SFP geologic framework R35 (calculated pore throat radius (pm) at $35 \%$ mercury saturation) curve and $\mathrm{K} / \phi$ ratio.

4. Prepare final stratigraphic flow profile (SFP) with correlation curve, porositypermeability $\mathrm{K} / \phi$ ratio, $\mathrm{R} 35$, percent storage, and percent capacity.

5. Construct an MLP (modified Lorenz plot) by ordering final flow units in decreasing unit speed (FUS).

Using the SML plot the shaly and sandy formation can be determined. The shaly formations have angles as low as horizontal and the sandy ones have steeper gradient slope on SLM plot (27). 


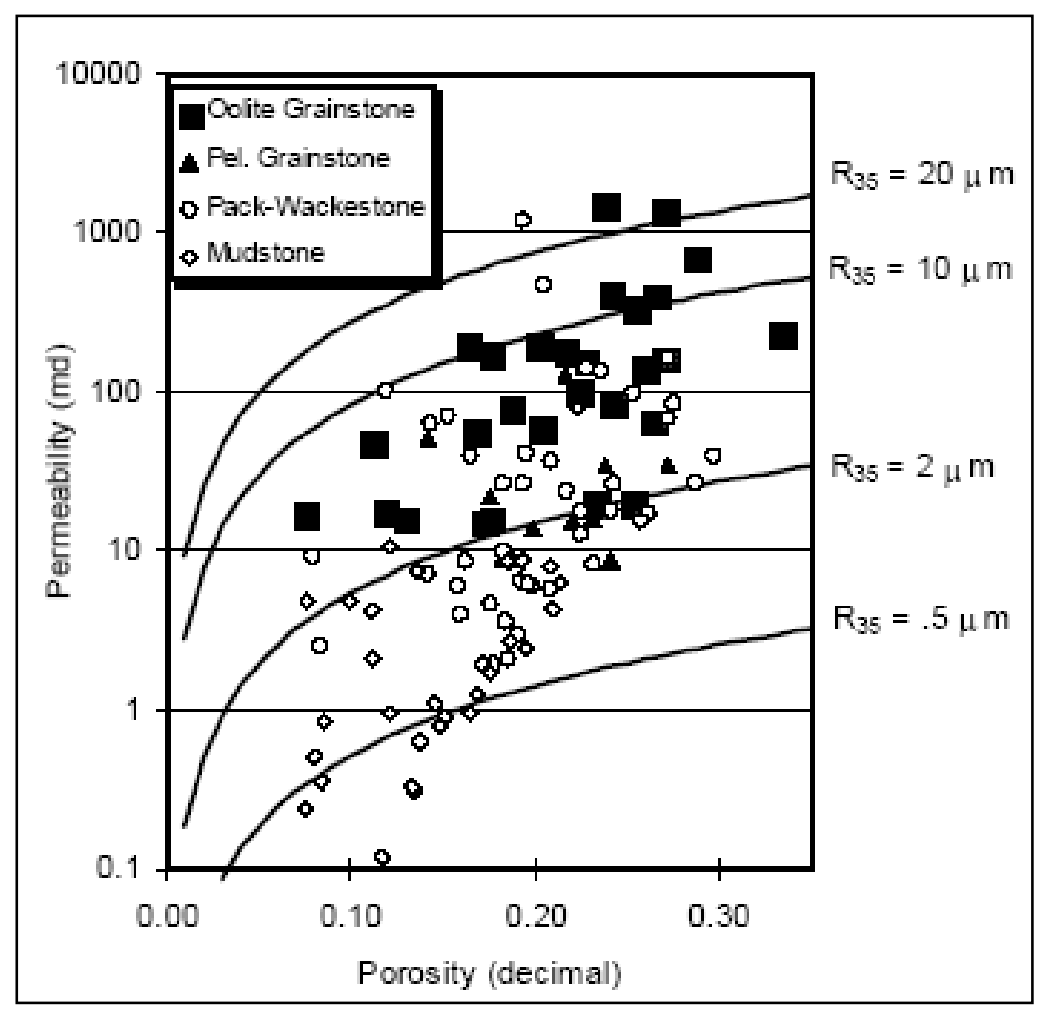

Figure 1 - 9. Sketch of K- $\phi$ Winland plot (20)

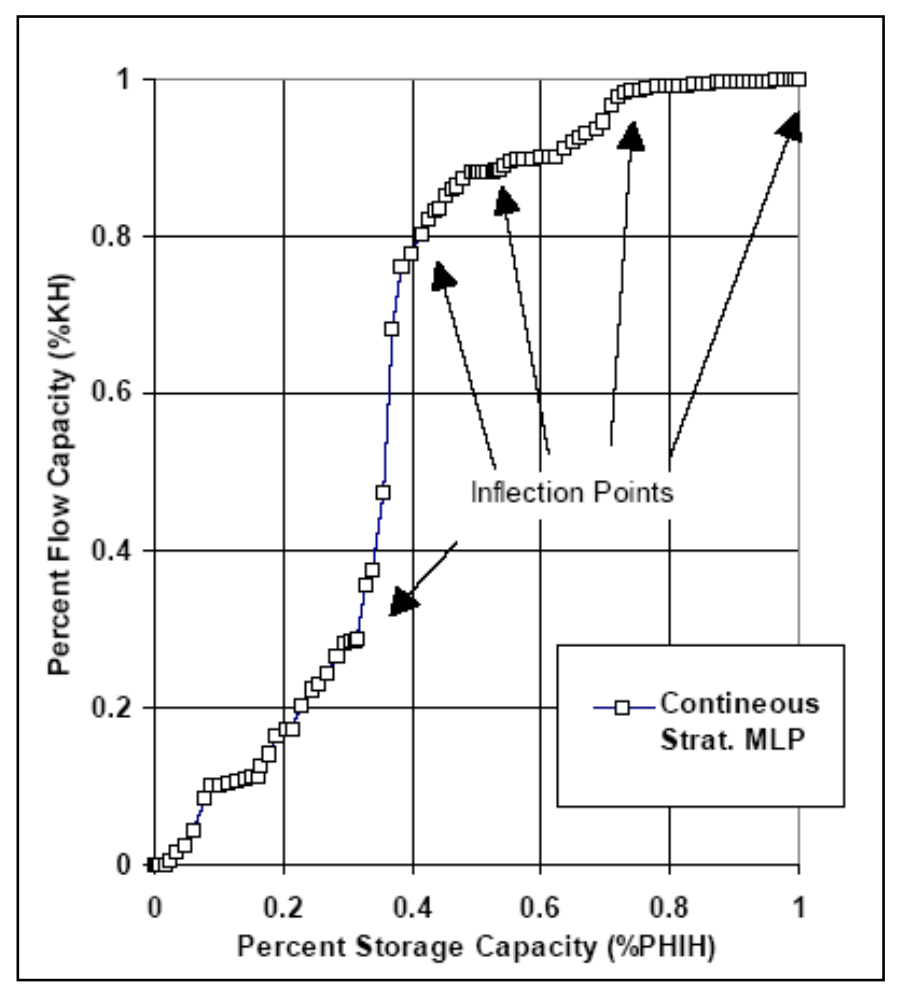

Figure 1 - 10. Sketch of stratigraphic modified Lorenz plot (SLMP) (20) 


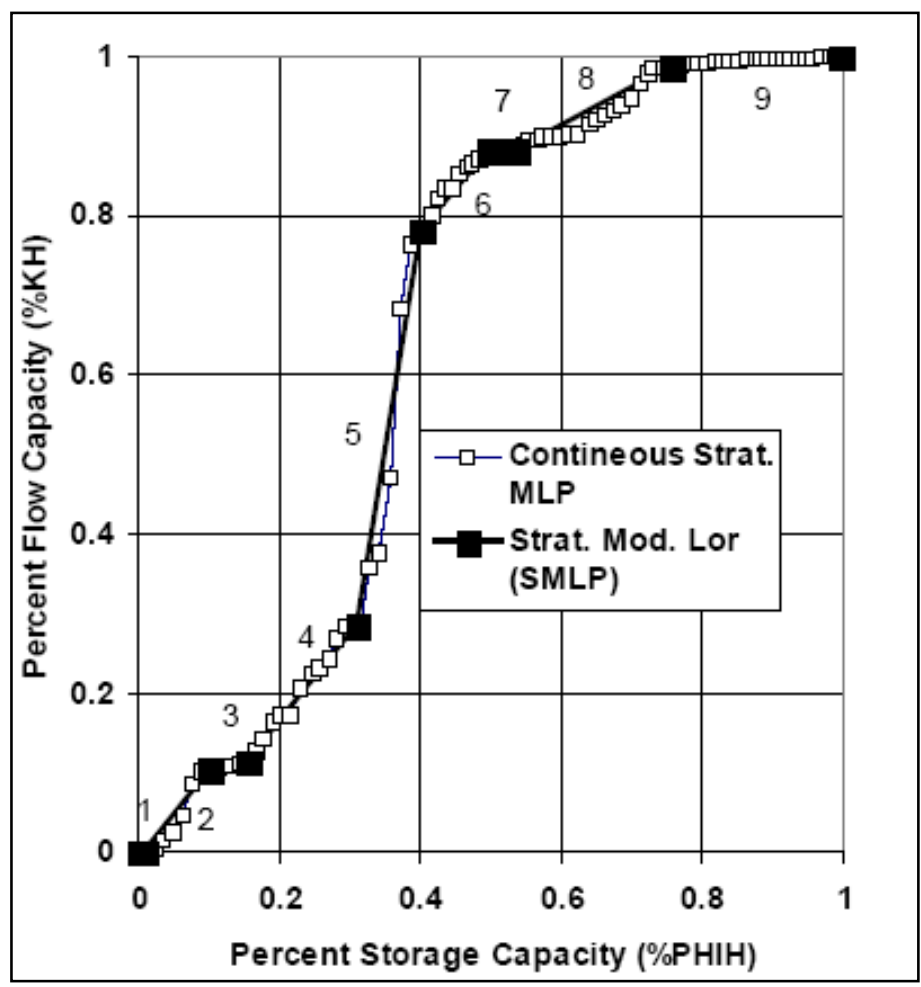

Figure 1 - 11. Sketch of interpreted continuous Stratigraphic Modified Lorenz (20) 


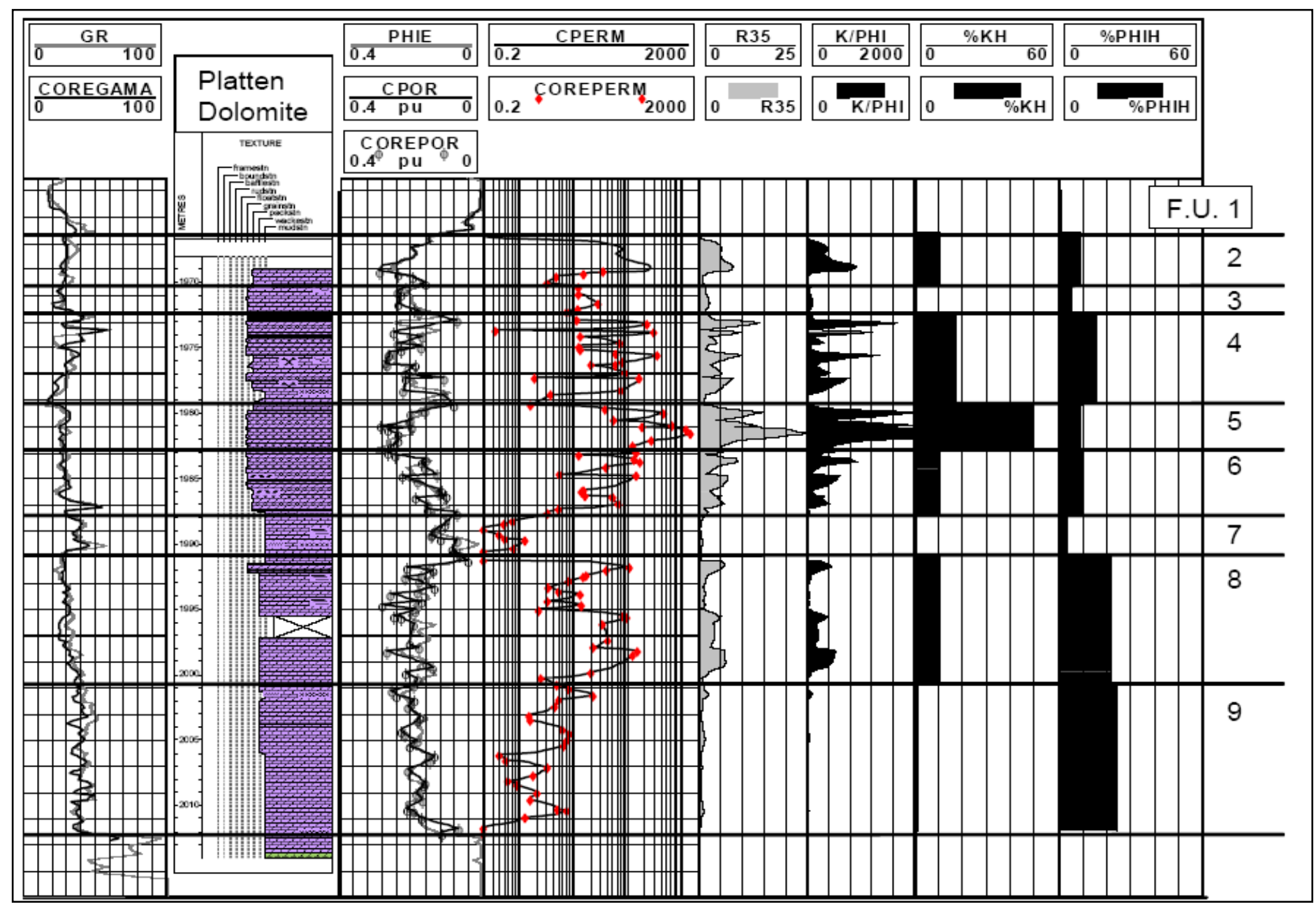

Figure 1 - 12. A schematic of Stratigraphic Flow Profile (SFP) (20) 


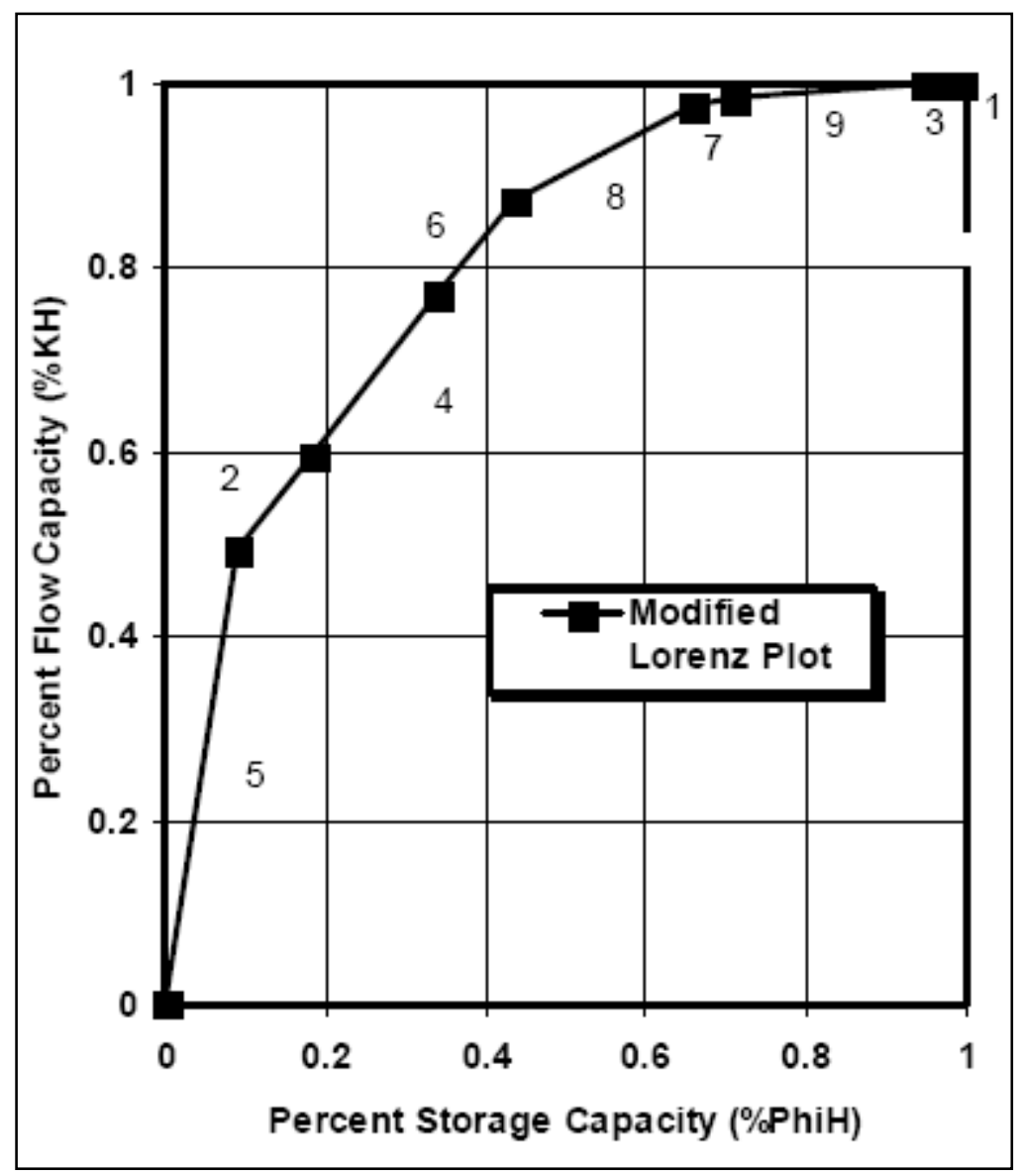

Figure 1 - 13. Sketch of Modified Lorenz Plot (MLP) (20)

Using SMLP, seals, baffles and speed zones can be determined.

Speed zones have high reservoir speed, with steep slope on SMLP. This effect is due to high flow capacity relative to storage capacity. These segments have a high production potential.

Reservoir baffles are segments with flat behavior, which have storage capacity but little flow capacity. These types of formation are typically considered as reservoir baffles when they are laterally extensive.

Seals are defined as segments with neither flow nor storage capacity, if they laterally extend.

1. Most of the graphical methods used in previous studies are very similar in essence and only have a slight difference. One of these methods has been applied in a work done by Porras et al (8) . In 1992, Pitmann, based on Winland's work, developed R35-type equations for pore throats corresponding to mercury saturations from $10 \%$ to $75 \%$.( Figure 1 - 14) 


$$
\begin{aligned}
& \text { LogR10 }=0.459+0.500^{*} \text { LogKair }-0.385^{*} \log \Phi \\
& \text { LogR15 }=0.333+0.509^{*} \text { LogKair }-0.344^{*} \log \Phi \\
& \text { LogR20 }=0.218+0.519^{*} \text { LogKair }-0.303^{*} \log \Phi \\
& \text { LogR25 }=0.204+0.531{ }^{*} \text { LogKair }-0.350 * \log \Phi \\
& \operatorname{LogR30}=0.215+0.547^{*} \operatorname{LogKair}-0.420 * \log \Phi \\
& \text { LogR35 }=0.255+0.565^{*} \text { LogKair }-0.523^{*} \log \Phi \\
& \text { LogR40 }=0.360+0.582^{*} \text { LogKair }-0.680^{*} \log \Phi \\
& \operatorname{LogR45}=0.609+0.608^{*} \operatorname{LogKair}-0.974^{*} \log \Phi \\
& \operatorname{LogR50}=0.778+0.626^{*} \log \text { Kair }-1.205^{*} \log \Phi \\
& \text { LogR55 }=0.948+0.632^{*} \text { LogKair }-1.426^{*} \log \Phi \\
& \operatorname{LogR60}=1.096+0.648^{*} \log \text { Kair }-1.666^{*} \log \Phi \\
& \text { LogR65 }=1.372+0.643^{*} \text { LogKair }-1.979^{*} \log \Phi \\
& \operatorname{LogR70}=1.664+0.627^{*} \text { LogKair }-2.314^{*} \log \Phi \\
& \operatorname{LogR75}=1.880+0.609{ }^{*} \log K a i r-2.626^{*} \log \Phi
\end{aligned}
$$

Figure 1 - 14. Pitmann's equations for mercury saturations of $10 \%$ to $75 \%$

In their work, Porras and Campos have use R45 equation; because the best correlation was obtained between pore throat radii estimated from capillary pressure data versus pore throat radii calculated using Pitmann's R45 equation. The methodology for this method is as follows:

o Calculate R45 pore throat values for data at both ambient and reservoir conditions. Construct the crossplots to obtain the corresponding relationships.

o Plot R45 values against water saturation, in order to determine a possible relationship between both properties.

o Use Spectral Gamma Ray Logs to determine clay types and to detect possible formation changes

o Perform compressibility tests on cores to indicate that confining pressure has a minor effect on porosity

o Classify Reservoir rock based on R45 pore throat radius, which is a dominant control on the permeability and flow characteristics of the reservoirs.

The reservoir rock can be divided into five petrophysical categories (8):

o Megaporous, defined by a pore throat radius $>10$ microns

o Macroporous, defined by a pore throat radius between 2.5 and 10 microns

o Mesoporous, defined by a pore throat radius between 0.5 and 2.5 microns

o Microporous, defined by a pore throat radius between 0.2 and 0.5 microns

$0 \quad$ Nannoporous, defined by a pore throat radius $<0.2$ microns 
Rock types can be semi-quantitatively related to several reservoir response characteristics useful in formation evaluation, such as permeability to porosity ratio, immobile water saturation, initial production rates, and a capillary pressure profile.

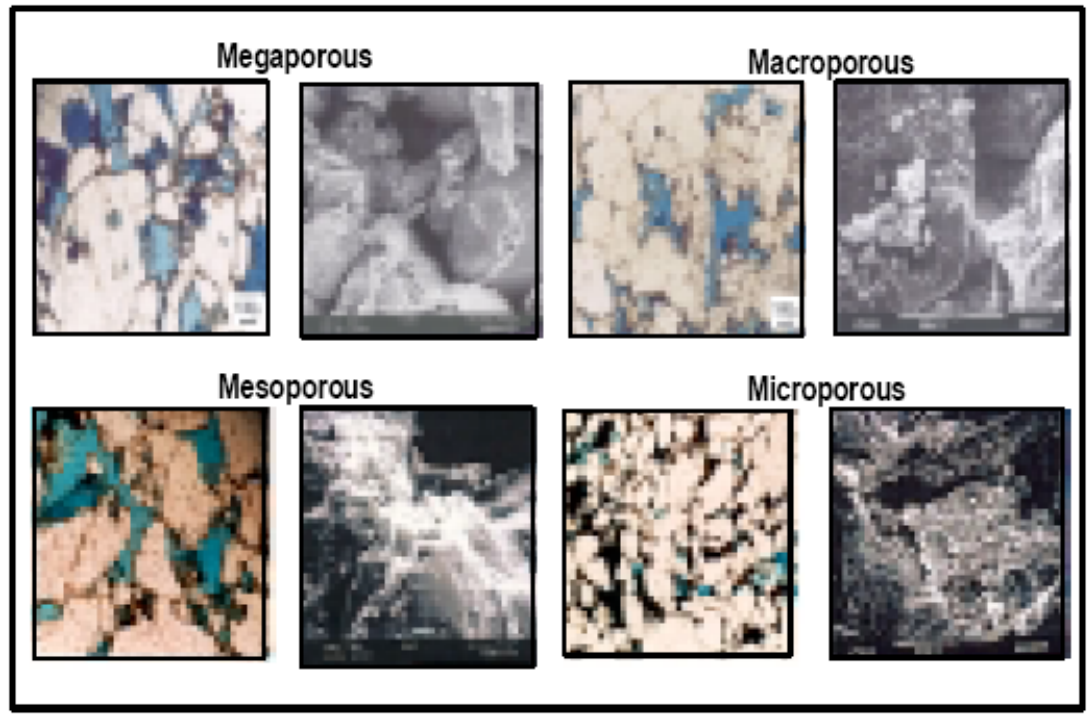

Figure 1 - 15. Thin section and SEM photographs for different rock types (8)

The other criteria used in some works for characterizing the rock types is the transverse relaxation time $\left(\mathrm{T}_{2}\right)$ spectrum constructed from $100 \%$ brine saturated NMR measurements. Each rock type is associated with a specific range of dominant $\mathrm{T}_{2}(28)$.Figure 1 - 16 shows an example of this method.

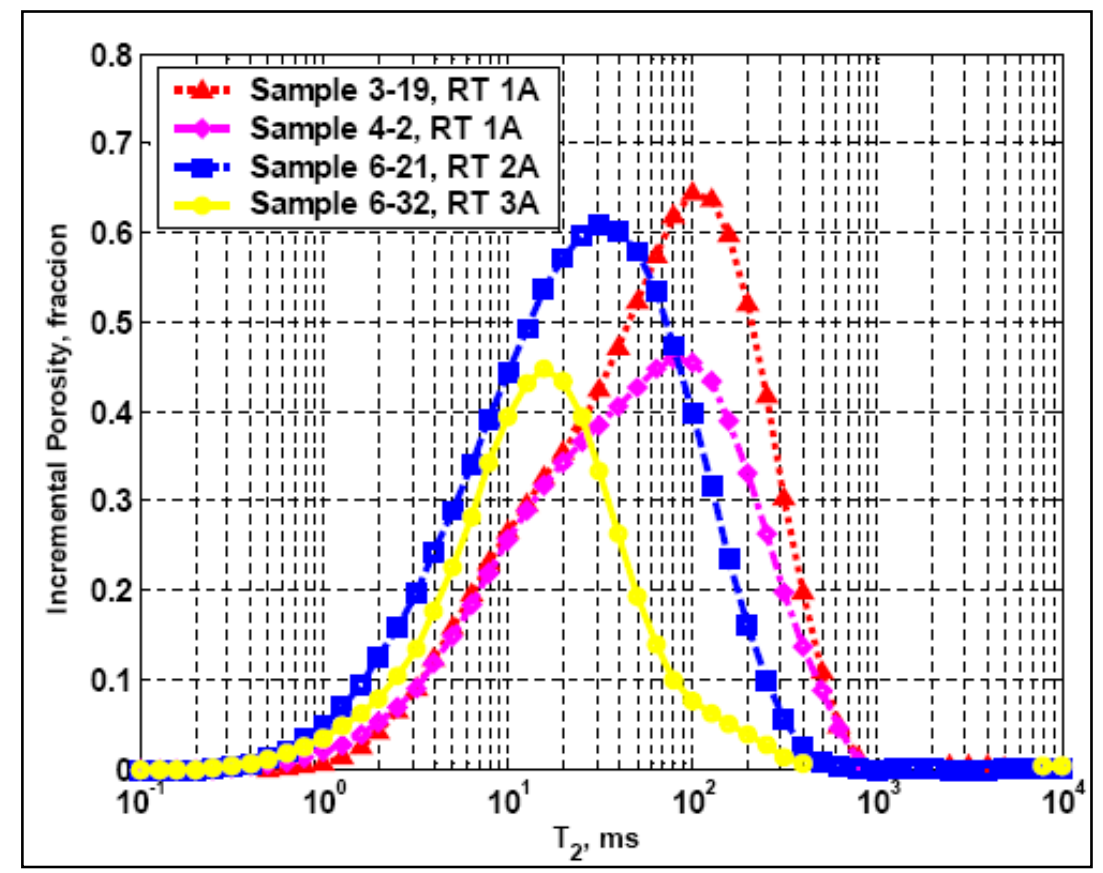

Figure 1 - 16. NMR Transverse relaxation, T2, curves for different rock types. 


\section{B) Mathematical Method}

Tiab has defined the hydraulic flow unit as a continuous body over a specific reservoir volume that practically possesses consistent petrophysical and fluid properties, which uniquely characterize its static and dynamic communication with the wellbore. Tiab (29), Tiab et al. (30), and Amaefule et al. (16) have developed a technique using which a formation having similar hydraulic characteristics, or flow units, based on the microscopic measurements of rock core samples can be identified (29). The technique developed is based on Kozney-Carman equitation that in a general form can be written as (4):

$k=\left(\frac{1}{K_{T} s_{v g r}^{2}}\right)\left(\frac{\phi_{e}^{3}}{\left(1-\phi_{e}\right)^{2}}\right)$

Equation 3

Where:

$\mathrm{k}=$ permeability, $\mu \mathrm{m} 2$,

$\phi \mathrm{e}=$ effective porosity,

$\mathrm{SVgr}=$ specific surface area per unit grain volume,

$\tau=$ tortuosity of the flow path, and

$\mathrm{KT}=\mathrm{Kps} \tau=$ effective zoning factor.

\section{Equation 3}

may be written as:

$$
k=\left(\frac{\phi_{R}}{K_{T} s_{v g r}^{2}}\right)
$$

Where:

$$
\phi_{R}=\left(\frac{\phi_{e}^{3}}{\left(1-\phi_{e}\right)^{2}}\right)
$$

$\mathrm{KT}$ is a parameter which is a function of pore size and shape, grain size and shape, pore and grain distribution, tortuosity, cementation, and type of pore system, e.g. intergranular, intercrystalline, vuggy, or fractured, and is called the pore-level effective zoning factor. This parameter is unique for 
each flow unit but changes between different flow units. For a homogeneous sandstone formation, it can be calculated using the following equation.

$$
K_{T}=\left(\frac{1}{J_{1}^{2}}\right)
$$

The lithology index $J_{1}$ is determined from capillary pressure data. Experimental data show that the plot of the Leverett $\mathrm{J}$-function, $\mathrm{J}\left(\mathrm{S}_{\mathrm{w}}{ }^{*}\right)$, against the normalized water saturation $\mathrm{S}_{\mathrm{w}}{ }^{*}$ on a $\log$ - $\log$ graph yields a straight line according to the following equation:

$\log J\left(S_{w}^{*}\right)=-\lambda \log \left(S_{w}^{*}\right)+\log \left(J_{1}\right)$

Equation 7

Where $\mathrm{J} 1$ is the intercept of the straight line (extrapolated IF necessary) at $\mathrm{Sw}^{*}=1$, as shown in Figure 1 - 17. The normalized water saturation is defined as:

$S_{w}^{*}=\left(S_{w}-S_{w i}\right) /\left(1-S_{w i}\right)$

The pore size distribution index $\mathrm{h}$ is the slope of the line. The lithology index $\mathrm{J}_{1}$ ranges from 0.44 for an unconsolidated spherical grain to 0.20 for a consolidated clean sandstone formation with homogeneous pore size distribution. High values of $\mathrm{J}_{1}$ are usually found in high permeability reservoirs, while low values of $\mathrm{J}_{1}$ correspond to low permeability reservoirs.

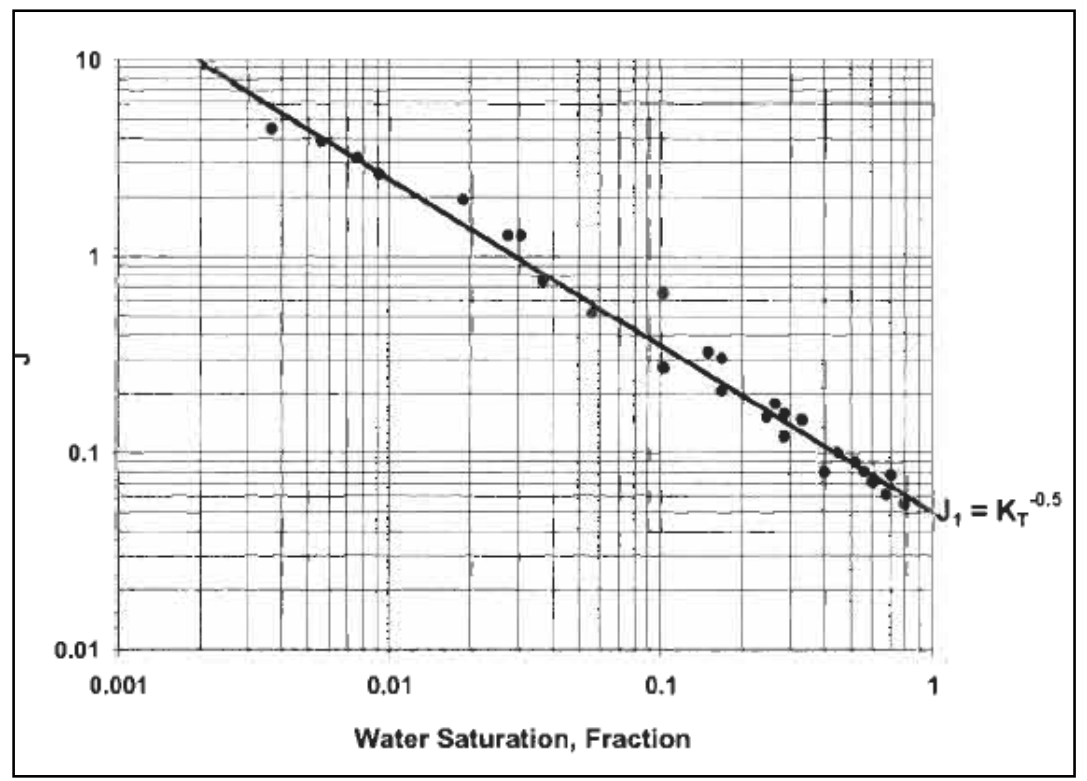

Figure 1 - 17. Determining KT from a plot of J versus $\mathrm{Sw}^{*}$ (4) 


\section{C) Flow Unit Characterization Factor}

\section{a) Reservoir Quality Index (RQI) (4)}

Amaefule et al. introduced the concept of reservoir quality index (RQI), $(K / \phi)^{1 / 2}$ considering the pore-throat, pore and grain distribution, and other macroscopic parameters (16).

The following equation can be derived from

$$
k=\left(\frac{1}{K_{T} s_{v g r}^{2}}\right)\left(\frac{\phi_{e}^{3}}{\left(1-\phi_{e}\right)^{2}}\right)
$$

\section{Equation 3}

$\sqrt{\frac{k}{\phi}}=\left(\frac{1}{s_{v g r} \sqrt{K_{T}}}\right)\left(\frac{\phi_{e}}{\left(1-\phi_{e}\right)}\right)$

On the other hand, specidic surface area $\left(\mathrm{s}_{\mathrm{Vgr}}\right)$ can be calculated from the next equation.

$S_{V g r}=\frac{4.27}{d_{g r}}$

Equation 10

Having the above equations, RQI can be expressed as:

$$
R Q I=0.0314 \sqrt{\frac{k}{\phi_{e}}}
$$

The units for porosity, permeability and RQI are fraction, milidarcies and micrometers respectively.

\section{b) Flow Zone Indicator (FZI) (4)}

Having

Equation 9

$$
\sqrt{\frac{k}{\phi}}=\left(\frac{1}{s_{v g r} \sqrt{K_{T}}}\right)\left(\frac{\phi_{e}}{\left(1-\phi_{e}\right)}\right)
$$

the flow zone indicator can be defined as: 
$F Z I=\frac{1}{s_{V g r} \sqrt{K_{T}}}$

So a relation between RQI and FZI can be expressed:

$R Q I=F Z I\left(\phi_{Z}\right)$

Equation 13

Where $\phi_{\mathrm{z}}$ is the ratio of pore volume to grain volume and can be defined using the following equation.

$\phi_{z}=\frac{\phi_{e}}{1-\phi_{e}}$

Equation

14

Plotting RQI data versus $\phi_{z}$ on a log-log scale yields a straight line with a unit slope. The intercept of this straight line at $\phi_{\mathrm{z}}=1$ is the flow zone indicator. Samples with different FZI values will lie on other parallel lines. Samples that lie on the same straight line have similar pore throat characteristics and, therefore, constitute a flow unit.

Straight lines of slopes equal to unity should be expected primarily in clean sandstone formations. Slopes greater than one indicate a shaly formation.

\section{c) Tiab Flow Unit Characterization Factor $\left(\mathrm{H}_{\mathrm{T}}\right)$}

Geologic units may or may not coincide with hydraulic flow units. It is also possible that a geologic unit will contain several flow units. Equation can be written as

$H_{T}=K_{T} s_{v g r}^{2}=\left(\frac{1}{k}\right)\left(\frac{\phi^{3}}{(1-\phi)^{2}}\right)$

$\mathrm{H}_{\mathrm{T}}$ is called the Tiab flow unit characterization factor, and can be written as

$H_{T}=K_{p s} \phi^{1-m}\left(\frac{K_{g s}}{d_{g r}}\right)^{2}$

$\mathrm{d}_{\mathrm{gr}}$ is the mean grain diameter, $\mathrm{K}_{\mathrm{ps}}$ is $3 \mathrm{D}$ pore shape factor and $\mathrm{K}_{\mathrm{gs}}$ is the grain shape factor. 
$\mathrm{H}_{\mathrm{T}}$ obtained from the above equation reflects microscopic properties of flow units.

$\mathrm{H}_{\mathrm{T}}$ and FZI are related by the following equation:

$$
H_{T}=\frac{1}{F Z I^{2}}
$$

Fadilla Bessa has used RQI and FZI, in his study to determine the flow units. The methodology he has used is to define flow zone indicator for all the wells under study and sorting the FZI increasingly to determine the ideal FZI range of each flow unit (HU) which match properly with both permeability and porosity (13).

\section{D) A Fully Integrated Approach}

Asgari et al. have performed a study in which he has used a new approach for development of rock type characterization (15).

As they have cited, common rock type are based on petrophysical facies classified by log responses, either core description and single-phase data such as porosity and permeability (Static Rock Typing), or SCAL defined rock types at two phases. The second method takes capillary pressure and relative permeability into account.

There is a common mistake that both techniques are thought to be the same but in reality this is not the case.

According to the method they introduced, the steps for identifying and characterizing rock types are:

- Data partitioning and electrofacies determination using multivariative analysis of well-log data with combination of factor analysis (FA) method and cluster analysis (CA).

- Optimal static Rock typing with correspondence analysis.

- Permeability prediction using the porosity permeability correlation and well log data or neural network.

- Dynamic Rock Typing using parameters such as capillary pressure curves, relative permeability curves, wettability, pore network, and structural position within reservoir zonation and static rock type. 
Sometimes the dissimilarity in relative permeability curves of analogous static rock types are observed in different zones, this is attributable to variation of wettability, pore geometry, fluid distribution and its position relative to water contact.

\subsubsection{Comparison between Flow Units and Rock Types}

A review of the studies performed, shows that different authors have usually used the words "rock types", "flow units" and "hydraulic units" interchangeably. Nevertheless, some have pointed out their differences and compared them.

Bessa, for instance believes that rock types can be used to link depositional facies, diagenesis, reservoir properties and wireline log response. While, hydraulic units are related to geological facies distribution but do not necessarily coincide with facies boundary (13).

\subsection{Introduction to Up-Scaling}

For reservoir characterization, it would be idyllic to integrate geological and petrophysical data at a scale at which the data are available. However, computing time, cost and capabilities all restrict our ability to build a data-rich characterization that can be used for reservoir fluid flow simulation. As a result there is, need to cluster data into smaller sets of characteristics that represent the most significant aspects of reservoir. This process is called upscaling.

Upscaling process can be divided in two categories:

- $\quad$ Analytical: such as arithmetic, geometric or harmonic averages, streamlines, etc.

- $\quad$ Numerical: such as single and two phase flow simulations.

One of the steps in the graphical flow unit determination is the SLM plot, which is an easy technique of upscaling using only permeability, porosity, and thickness. However, it should be noted that upscaling and averaging values such as water saturation could provide misleading results particularly in thin-bedded stratigraphic intervals (27).

Geologic models built by geologist are based on honoring the petrophysical and structural data of the reservoir, but usually the production data is not considered during the reservoir characterization process. The geologic data are usually acquired in a fine scale and thereby the models made based on these data are in fine scale as well. The fine scale models are upscaled to a coarse scaled model that will result in approximating geological complexities of the reservoir to a certain extent. Reservoir 
simulation model are built by combining these coarse geological models with rock and fluid properties and other engineering data. These reservoir simulation models will go through a history matching process in order to be calibrated to the field under study and be able to forecast the future behavior of the reservoir in terms of pressure and production rate change under different operating conditions.

Different parameters such as time constraints, ability of the computing resources are the parameters affecting the level of detailed reservoir simulation. This level may change depending on each case that is investigated and the objectives the study. Hence the level of upscaling is justified by these strictures. As a result of this, upscaling of the rock properties, primarily permeability, porosity and relative permeability, to reduce the number of grid blocks and the upscaling of the comprehensive compositional description of the reservoir fluid invariably are key steps in a reservoir simulation study. Any upscaling will result in loss of data and cause error (31).

It is sometimes suggested that scaling up of absolute permeability alone is enough to capture the effects of heterogeneity on two-phase fluid flow simulations. Previous publications $(32 ; 33)$, however, both suggest that this is not true if the correlation length of the heterogeneity not represented on the fluid-flow simulation grid is significant compared with the well spacing. This often happens when long, thin, high-permeability channels; thin, high-permeability layers, or extensive, but thin, shale barriers are present in the reservoir. In these cases, a multiphase upscaling technique is generally required.

The most obvious of these is the use of pseudo relative permeabilities (pseudos), which have been suggested by many authors (34).

\subsubsection{Pseudorelative Permeability Generation}

The role of pseudo relative permeabilities is to determine the flow rate of each phase out of a grid block. They relate the flow rate to the pressure gradient between the grid block and its neighbor, given the average saturation in the grid block (assuming that single-point upstream weighting is used). Both the flow rate and the pressure gradient depend on the details of the saturation distribution within the grid block. Thus, to compute a pseudo relative permeability curve, it is necessary to determine the saturation distribution within the grid block for any given average saturation.

When the flow is dominated by gravity or capillary forces or a combination of the two, the saturation distribution may be determined by assuming capillary/gravity equilibrium. For the case where the 
phases are locally segregated under gravity, "vertical equilibrium” pseudos may be calculated (35; 36). For the capillary-dominated case, pseudos may be calculated by scaling up the permeability of each phase $\left(\mathrm{kk}_{\mathrm{r}}\right)$ and dividing by the scaled-up value of the absolute permeability $(\mathrm{k})$. Each of these quantities can be scaled up by solution of a Laplace equation with periodic lateral boundary conditions (37); however, the dependence of the results on the boundary conditions and the tensorial nature of the scaled-up quantities should be recognized (38).

In some cases, the imposition of local boundary conditions may introduce unacceptable errors; but, if care is taken, it should be possible to obtain reasonably reliable results with this "capillaryequilibrium" method in most cases.

In many reservoirs, however, viscous forces cannot be neglected. In these cases, the saturation distribute on is not uniquely determined by the average saturation but also depends on the production history [i.e., the positions of the wells and their rates (mathematically, on the boundary conditions)]. One way to determine the details of the saturation distribution for a specific production history is by running a simulation with either a fine grid or a dual-scale grid (39). Several methods for calculating pseudo relative permeabilities from the results of such a simulation have been proposed; some of these are discussed here. Pseudo relative permeabilities calculated from the results of a simulation are generically known as dynamic pseudo relative permeabilities.

\subsubsection{Dynamic Pseudorelative Permeability Methods}

In this section, the ability of various dynamic pseudorelative permeability methods to reproduce the results of a given fine grid simulation on a coarse grid are considered. Implicit in this discussion is the assumption that a different set of pseudos will be generated for each coarse grid block and each flow direction, using the results of the given fine-grid simulation. Of course, this is not what would happen in practice, but it is useful for understanding the properties of the various methods (40). The relevant references give details of the various methods discussed (41).

\subsubsection{Kyte and Berry (42) and Similar Methods}

The Kyte and Berry method is very well known and widely used, but is also widely believed to be unreliable, although there is little published evidence for this. A similar method is the "pore-volumeweighted" method, which differs from Kyte and Berry only in the use of a different formula to determine average pressures. 
In both these methods, average pressures for each coarse gridblock and total flow rates of each phase between each pair of adjacent coarse gridblocks are calculated from the fine-grid simulation results. These values are substituted in the coarse-grid Darcy equations to infer the coarse-grid (pseudo) relative permeability values that would be required to reproduce the fine-grid flows.

From the way the pseudos are constructed, it is clear that both these methods should, in principle, allow the fine-grid solution to be reproduced exactly on a coarse grid (43). Thus, these in fact "ideal" methods give the "correct" pseudos for any particular case.

However, in practice, many things can go wrong: it is possible for the net flow of a phase to be in the opposite direction to the average pressure gradient, leading to a negative pseudorelative permeability; there can be a nonzero net flow when the average pressure gradient is zero, leading to an infinite pseudorelative permeability; and the same average saturation may occur more than once in a given coarse gridblock, leading to a multi-valued pseudorelative permeability function (if this occurs, it is difficult for any method). Thus, the pseudos generated by these methods may be unusable.

A further problem with the Kyte and Berry method is that the definition of average pressure differs according to whether one is considering $\mathrm{x}-$, $\mathrm{y}$-, or $\mathrm{z}$-direction flow. Thus, in multidimensional problems, one may have two or three different pseudocapillary pressures (even if there is no capillary pressure in the fine-grid problem). The pore volume- weighted method has only one pseudocapillary pressure, and this is zero when there is no fine-grid capillary pressure. Thus, this method is preferable to the original Kyte and Berry method.

\subsubsection{Stone's Method (44)}

Stone was the first to use total mobility as a way of avoiding the problems associated with estimating the average pressures in the Kyte and Berry method. He suggested computing an average total mobility and a net fractional flow.

The pseudorelative permeabilities can be calculated easily from these two quantities if gravity and capillary pressure are neglected, as they were by Stone, but neglect of gravity imposes a severe limitation on the use of the method. In addition, Stone's formula for average total mobility is inadequate when there are significant variations in total mobility. 
Thus, in cases with significant gravity (or capillary pressure) effects or with significant variations in total mobility, the method can give poor results.

\subsubsection{Quasi-Steady-State Method}

This method in which the permeability $\left(\mathrm{kk}_{\mathrm{r}}\right)$ of each phase is scaled up (by solution of a Laplace equation for example) has appeared in several guises (45). The pseudorelative permeabilities are obtained by dividing the scaled-up value of $\mathrm{kk}_{\mathrm{r}}$ by the scaled-up value of absolute permeability (k); i.e., the method is the same as the capillary-equilibrium method described in the Introduction except that the saturation distribution is taken from the fine-grid simulation rather than being calculated assuming capillary equilibrium.It can be shown that scaling up (averaging) of phase permeability is valid only in the quasisteady-state case. Implicit in the method is the neglect of the time derivative of saturation. In the absence of capillary pressure, this time derivative is infinite at a saturation front and cannot be neglected. The method can thus fail very badly in viscous-dominated cases, which generally involve displacements of a frontal nature. Only when the saturation fronts are smoothed out by capillary forces is the method reliable. An attraction of the method is that the pseudos are generally smooth curves with values between zero and one, so there are no problems with their actual use in the coarse-grid simulation. This, however, does not justify the method's use outside its range of validity.

\subsubsection{Weighted-Relative-Permeability Method}

This is a widely used method, for two reasons. First, it is one of the methods available in PSEUDO, (46) the upscaling program sold with GeoQuest's popular ECLIPSE reservoir simulation software. Second, it generally gives smooth pseudos with values between zero and one. The pseudorelative permeability of a phase is obtained simply as an average of the relative permeability values for that phase in certain blocks in the fine grid. Despite its popularity, the method has little justification because it is consistent with the coarse-grid Darcy equations only under very restrictive conditions and it neglects the coarse-grid gravity term. Thus, there is no guarantee that it will reproduce the fine-grid solution on the coarse grid.

\subsubsection{Other Methods}

Several other dynamic pseudorelative permeability methods have been proposed (47), but in our opinion, these do not offer anything better than the methods we have just discussed (41). 
Obtaining pseudos by history matching (i.e., by adjusting them until the coarse-grid results match the fine-grid results) is difficult to do when many sets of pseudos are used on the coarse grid.

With such pseudos, the fine-grid solution is reproduced at the wells but not necessarily for each block (unless interblock flows and average block pressures are also history matched, which makes the matching even more difficult). The pseudos are thus less likely to be valid if the well rates or positions are changed than are pseudos obtained by one of the constructive methods described previously.

Nonetheless, such a step may have to be performed as a final tuning of pseudos generated by the quasisteady-state or weighted-relative permeability methods.

Authors from Herriot-Watt University (38) have advocated relating the scaling-up step more closely to the geological structures present in the reservoir and the use of tensorial pseudorelative permeabilities. However, the techniques they use for calculating the pseudos are essentially the same as the methods already described.

Finally, in renormalization-based methods (48), the key idea is to perform scaling up in a series of steps rather than in a single step. Thus, a model is scaled up from a fine grid to a slightly coarser grid, then again to an even coarser grid, and so on until the desired coarse grid is reached. At each scalingup step, the methods used to calculate the pseudos needed for the next coarser grid are again the same as those described previously. Note that the repeated scaling up of relative permeabilities compounds the difficulties described later, which may limit the applicability of the renormalization method in this context.

\subsection{The New Rock Typing Method}

Reservoir rocks having similar texture, grain size, sorting etc, can be purely geologically classified into lithofacies classifications. Each lithofacies indicates a certain depositional environment with a distribution trend and dimension. Petrophysical groups are classified by porosity, permeability, capillary pressure and Pore throat size distribution. A Rock Type combines both these classifications by linking petrophysical properties and lithofacies as part of the reservoir rock type definition. According to previous works done, it has been proved that a static rock type can not be used to simulate the fluid flow behavior in the reservoir. 
There is a unique set of properties that define the productivity of hydrocarbon in a reservoir. These properties are discussed under the reservoir characterization concept. There is a link between the geological theory and reservoir engineering/management.

These properties can be put in two categories, as far as reservoir scale is considered. (i) microscale and (ii) macroscale. Microscale properties include pore types, pore connectivity, and capillary and electrical properties, etc., whereas macroscale properties include lateral and vertical connectivity of reservoir layers, flow units, etc. However all these properties are controlled by three geological inputs: (i) depositional texture, (ii) diagenesis and (iii) tectonic features.

The size and shape of the grains, their packing and sorting characteristics, and the nature of any mud matrix are all described using depositional texture. Together these variables define individual lithofacies and the nature and distribution of primary porosity. Diagenesis modifies the depositional texture to either enhance or reduce reservoir potential through dissolution and cementation (including lithification and compaction) respectively.

The current rock type (lithotype) classification is only based on the depositional texture and grain size, sorting, effective pore type and diagenesis.

Based on the old technique criteria, the data needed to define the rock types such as pore throat size distribution can be in general term identified using throat size distribution plot and thin section analysis for each lithotype (49).

There are significant shortcomings in the current method used. Some of them are summarized as follows:

1. Significant degrees of overlap between various rock-types observed on the Porosity/Permeability cross plots.

2. No success proof of the attempts for predicting these lithotypes using conventional logs and a combination of high technology tools.

3. Having no input data from uncored wells for defining Rock Type, and consequent definition of them for the core wells and spatially distributing them.

Varavur et al. have used a new method to define the dynamic rock type in a giant reservoir, that is different with the old scheme, which only honors the geological reservoir properties (49). The 
mercury injection data has been vastly used in their work. The classification generated by clustering of Mercury Injection data has unique Porosity/Permeability correlation for each class.

These classes encompass a number of different rock types defined in the existing scheme. The existing geological model cannot control its spatial distribution. These classes can be predicted using a combination of porosity, permeability, $\mathrm{R}_{50}$ (pore throat radius at $50 \%$ Mercury Saturation) and $\mathrm{R}_{80}$ (pore throat radius at 20\% Mercury Saturation) for wells with Mercury Injection data in addition to Conventional Core Analysis data with an accuracy exceeding 90\%, while the maximum precision in the static rock type method is only $50 \%$.So relative permeability data and mercury injection capillary pressure data have significant effect on the behavior of distinct rock types in the reservoir.

The other issue discussed in this work with affiliation to rock typing, is the upscaling. Building geologic models for an asset require rock typing as an essential part. Information necessitated for defining rock types are obtained from logs, core measurements, SCAL studies, and geological interpretation. Millions of dollars are invested to attain this information. Upon definition of rock types for series of geological formation, geo-scientists are asked to use approximation and identify a dominant rock type for any given grid block in a reservoir simulation model. This defeats the original purpose of performing detail geological, petrophysical and geophysical studies as far as reservoir flow models are concerned.

This approximation of multiple and overlapping rock types into one dominant rock type becomes even more notable when realizing that a typical grid block in a reservoir flow model is almost the size of six football fields., while most of the rock typing studies are performed at the core scale.

Each rock type is associated with a series of relative permeability and capillary pressure curves. Values identified in this study will be used in a fuzzy aggregation method in order to identify the way relative permeability and capillary pressure curves should be used to generate values that are used in the reservoir flow model for a particular grid block.

It is important to note that the methodology and the results presented in this paper marks the start of a larger study that has been initiated to develop a new upscaling technology for reservoir simulation and modeling by integrating reservoir characterization, geology, petrophysics with the state of the art in artificial intelligence and data mining. As such, the results presented here should be considered preliminary and part of a work in progress. 


\section{Chapter 2}

\section{Methodology}

To investigate the effect of fuzzy rock typing on the results of upscaled model, several studies were performed. The approach used for this analysis, has been started by building the high-resolution models having three different rock types.

The necessity for reservoir simulation arises from the need for petroleum engineers to find accurate performance predictions for a hydrocarbon reservoir under different operating conditions. The impact of upscaling the permeability, porosity, relative permeability, and capillary pressure has been probed. A reservoir Simulator (50) is used in different approaches for this study. This process has been explained in detail in these sections. A single well high resolution model has been made. The modeled reservoir includes three different rock types. Specific relative permeability and capillary pressure curves have been assigned to each of the rock types. It is obvious from the Winland plot (Figure 2 - 3) and confirmed by results of some sensitivity analysis that rock type 3 has the most contribution to fluid flow throughout the reservoir.

The objective is to study the impact overlapping rock types on flow of fluid in the reservoir and test a new upscaling technology that would minimize the impact of the upscaling in the outcome of the fluid flow in the reservoir and compare this new technology with the conventional techniques currently being used. To accomplish this task following steps are implemented:

1. Build a high-resolution model with multiple rock types. Run the model and establish a flow rate profile for the well for the high-resolution model. 
2. Upscale the model using conventional upscaling technique (identifying one rock type as the dominant rock type for each upscaled grid bloc). Run the upscaled model and establish a flow rate profile for the well for the low-resolution (conventionally upscaled) model.

3. Upscale the model using the Fuzzy Rock Typing (FRT) upscaling technique (the details to be followed). Run the FRT upscaled model and establish a flow rate profile for the well for the FRT lowresolution model. Compare the three flow rate profiles namely the high-resolution model (representing the geocellular model) with the two upscaled models, the conventional, and the FRT upscaling.

4. Modify the percent of dominant rock type in the high-resolution model and repeat steps 2, and 3. The point is that as the percent of the dominant rock type in the high resolution model decreases (from $90 \%$ to $50 \%$ ), the conventional rock type would still pick the rock type with larger share as the dominant rock type without a distinction on the role it plays in the overall fluid flow and the results of the upscaling will not change. The FRT upscaling method, on the other hand, will take into account the contribution of each rock type to the fluid flow during the upscaling process.

This process is shown in Figure 2 - 1.

In the upscaling step, there are basically two things happening:

i) Homogenization of the medium, and

ii) Coarsening of the computational grid.

The difference in the flow behavior of the coarse and fine models is a reflection of the errors introduced due to both homogenization and coarsening. While homogenization changes the reference permeability field making it smoother, coarsening of the computational grid increases the truncation errors and hence the numerical smearing of the flow results.

In reality there is not a crisp boundary between different rock types in the reservoir on the Winland plot and they might overlap. The properties of each sample on the area that two or more rock types have overlaid are a function of all those rock types. This fact is not honored in the conventional upscaled model and the dominant rock type characteristics are imposed.

The upscaling process is repeated using "Fuzzy Rock Typing". Fuzzy rock typing refers to application of fuzzy set theory in order to take into account the inherent uncertainties and vagueness associated with rock typing in hydrocarbon bearing reservoirs. In this step the membership value of each rock type in the low resolution block will be calculated base on the percent of contribution of that rock type. Higher involvement of specific rock type consequences a membership value closer to one. 


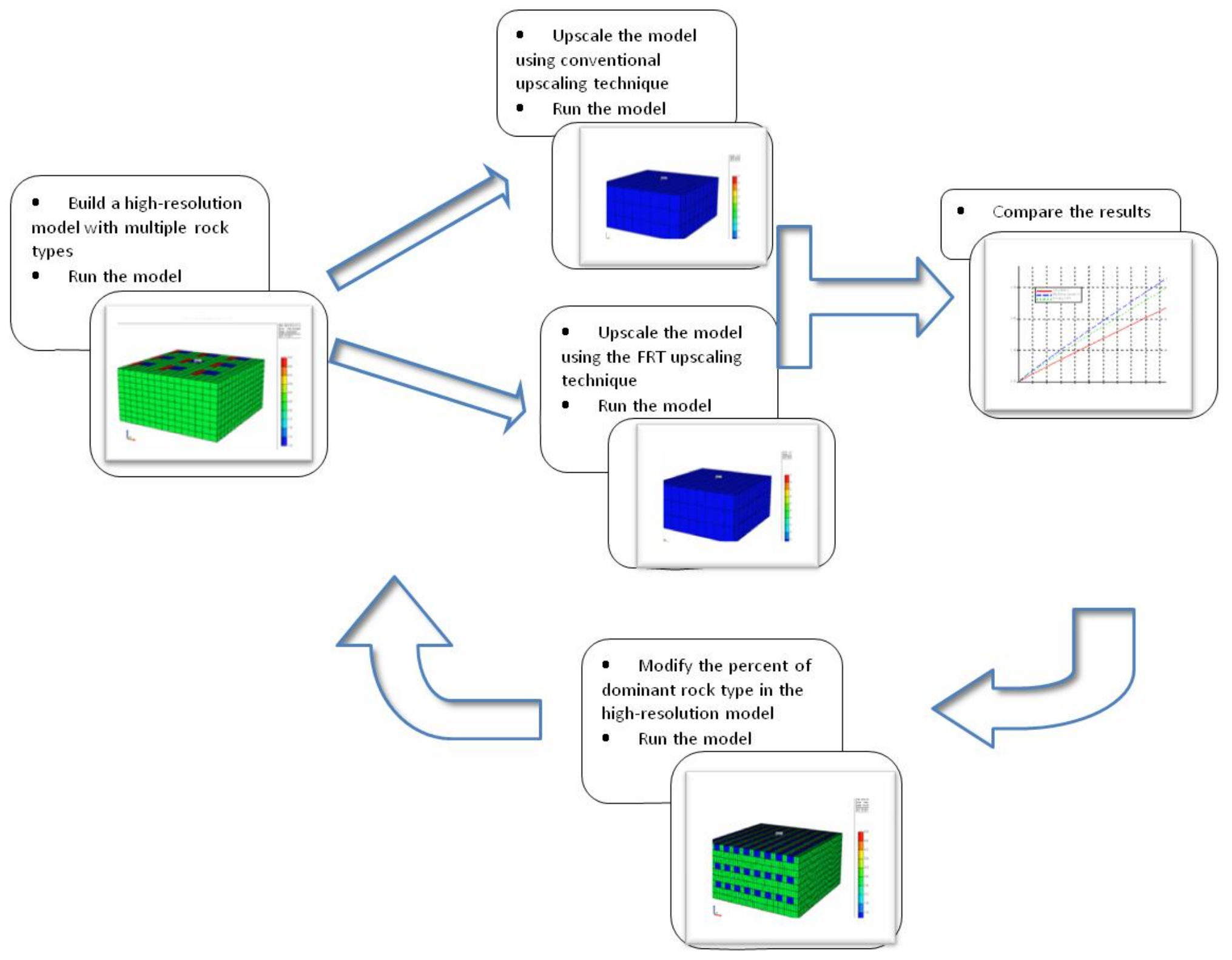

Figure 2 - 1.The workflow of process followed for comparing the upscaling methods in this work 
The scenarios studied in this work have been summarized in the following table.

Table 2 - 1. Comparison of different scenarios studied

\begin{tabular}{|c|c|c|c|c|c|c|c|c|c|c|c|}
\hline \multirow{2}{*}{$\begin{array}{l}\text { Scenari } \\
\quad 0\end{array}$} & \multicolumn{3}{|c|}{$\begin{array}{l}\text { HR } \\
\text { Model }\end{array}$} & \multicolumn{2}{|c|}{$\begin{array}{l}\text { Difference Between } \\
\text { Rock Types }\end{array}$} & \multicolumn{3}{|c|}{ LR Model } & \multirow{2}{*}{$\begin{array}{c}\text { Membershi } \\
\text { p Value } \\
\text { Type }\end{array}$} & \multirow{2}{*}{$\begin{array}{l}\text { Number of } \\
\text { Fuzzy } \\
\text { Rock Types }\end{array}$} & \multirow{2}{*}{$\begin{array}{l}\text { Upscaling } \\
\text { Magnitude }\end{array}$} \\
\hline & $\begin{array}{l}\mathrm{n} \\
\mathrm{x}\end{array}$ & $\begin{array}{l}\mathrm{n} \\
\mathrm{y}\end{array}$ & $\begin{array}{l}\mathrm{n} \\
\mathrm{z}\end{array}$ & $\begin{array}{c}\text { Static } \\
\text { parameters }\end{array}$ & $\begin{array}{c}\text { Dynamic } \\
\text { parameters }\end{array}$ & $\begin{array}{l}\mathrm{n} \\
\mathrm{x}\end{array}$ & $\begin{array}{l}\mathrm{n} \\
\mathrm{y}\end{array}$ & $\begin{array}{l}\mathrm{n} \\
\mathrm{z}\end{array}$ & & & \\
\hline 1 & $\begin{array}{l}1 \\
5\end{array}$ & $\begin{array}{l}1 \\
5\end{array}$ & 9 & $\mathrm{~K}$ & $\mathrm{Kr}-\mathrm{Pc}$ & 3 & 3 & 3 & $\mu \mathrm{V}$ & 1 & 75 \\
\hline 2 & $\begin{array}{l}4 \\
5\end{array}$ & $\begin{array}{l}4 \\
5\end{array}$ & 9 & K & $\mathrm{Kr}-\mathrm{Pc}$ & 9 & 9 & 3 & $\mu_{\mathrm{V}}$ & 1 & 75 \\
\hline 3 & $\begin{array}{l}4 \\
5\end{array}$ & $\begin{array}{l}4 \\
5\end{array}$ & 9 & $\mathrm{~K}-\phi$ & $\mathrm{Kr}-\mathrm{Pc}$ & 9 & 9 & 3 & $\mu_{\mathrm{V}}$ & 1 & 75 \\
\hline 4 & $\begin{array}{l}4 \\
5\end{array}$ & $\begin{array}{l}4 \\
5\end{array}$ & 9 & $\mathrm{~K}-\phi$ & $\mathrm{Kr}-\mathrm{Pc}$ & 9 & 9 & 3 & $\mu_{\mathrm{V}}$ & 5 & 75 \\
\hline 5 & $\begin{array}{l}4 \\
5\end{array}$ & $\begin{array}{l}4 \\
5\end{array}$ & 9 & --- & $\mathrm{Kr}-\mathrm{Pc}$ & 9 & 9 & 3 & $\mu_{\mathrm{V}-} \mu_{\mathrm{K}}$ & 1 & 75 \\
\hline
\end{tabular}

\subsection{Relative Permeability, Capillary Pressure, Permeability Upscaling Effect (Scenario 1)}

In the first scenario, a small model of the reservoir is built. The rock types contributing to the flow in high-resolution case are rock types 1, 3, and 5. The corresponding curves are illustrated in Figure 2 2. In this case, the porosity is considered uniform all over the reservoir. Figure 2 - 3 shows the relationship between the porosity and permeability (Winland plot) for the rock types.

According to this plot, each porosity value corresponds to a permeability value depending on the rock type it belongs. Consequently, the permeability value is not homogeneous in the modeled reservoir.

Table 2 - 2 present the properties of the high resolution model.

Table 2 - 2. High-resolution model properties

\begin{tabular}{||l|l|l||}
\hline \multicolumn{2}{|c||}{ Hroperty } & \multicolumn{1}{c||}{ Value Unit } \\
\hline \hline$\Delta \mathrm{x}$ & 500 & $\mathrm{ft}$ \\
\hline \hline$\Delta \mathrm{y}$ & 500 & $\mathrm{ft}$ \\
\hline \hline$\Delta \mathrm{z}$ & 15 & $\mathrm{ft}$ \\
\hline \hline $\mathrm{nx}$ & 15 & \\
\hline \hline $\mathrm{ny}$ & 15 & \\
\hline \hline $\mathrm{nz}$ & 9 & \\
\hline \hline Reservoir Top & 2000 & $\mathrm{ft}$ \\
\hline Bubble point pressure & 500 & psi \\
\hline \hline Initial reservoir pressure & 4500 & psi \\
\hline \hline Initial oil saturation & 65 & percent \\
\hline \hline Water saturation & 35 & percent \\
\hline
\end{tabular}


Table 2 - 3. Low-resolution model properties

\begin{tabular}{||l|l|l||}
\hline \multicolumn{1}{|c||}{ Low Resolution Model Properties } \\
\hline \hline \multicolumn{1}{|c||}{ Property } & \multicolumn{1}{|c||}{ Value Unit } \\
\hline \hline$\Delta \mathrm{x}$ & 2500 & $\mathrm{ft}$ \\
\hline \hline$\Delta \mathrm{z}$ & 2500 & $\mathrm{ft}$ \\
\hline \hline $\mathrm{nx}$ & 45 & $\mathrm{ft}$ \\
\hline \hline $\mathrm{ny}$ & 3 & \\
\hline \hline $\mathrm{nz}$ & 3 & \\
\hline \hline Reservoir Top & 3 & \\
\hline \hline Bubble point pressure & 2000 & $\mathrm{ft}$ \\
\hline \hline Initial reservoir pressure & 500 & psi \\
\hline \hline Initial oil saturation & 4500 & psi \\
\hline \hline Water saturation & 65 & percent \\
\hline \hline
\end{tabular}
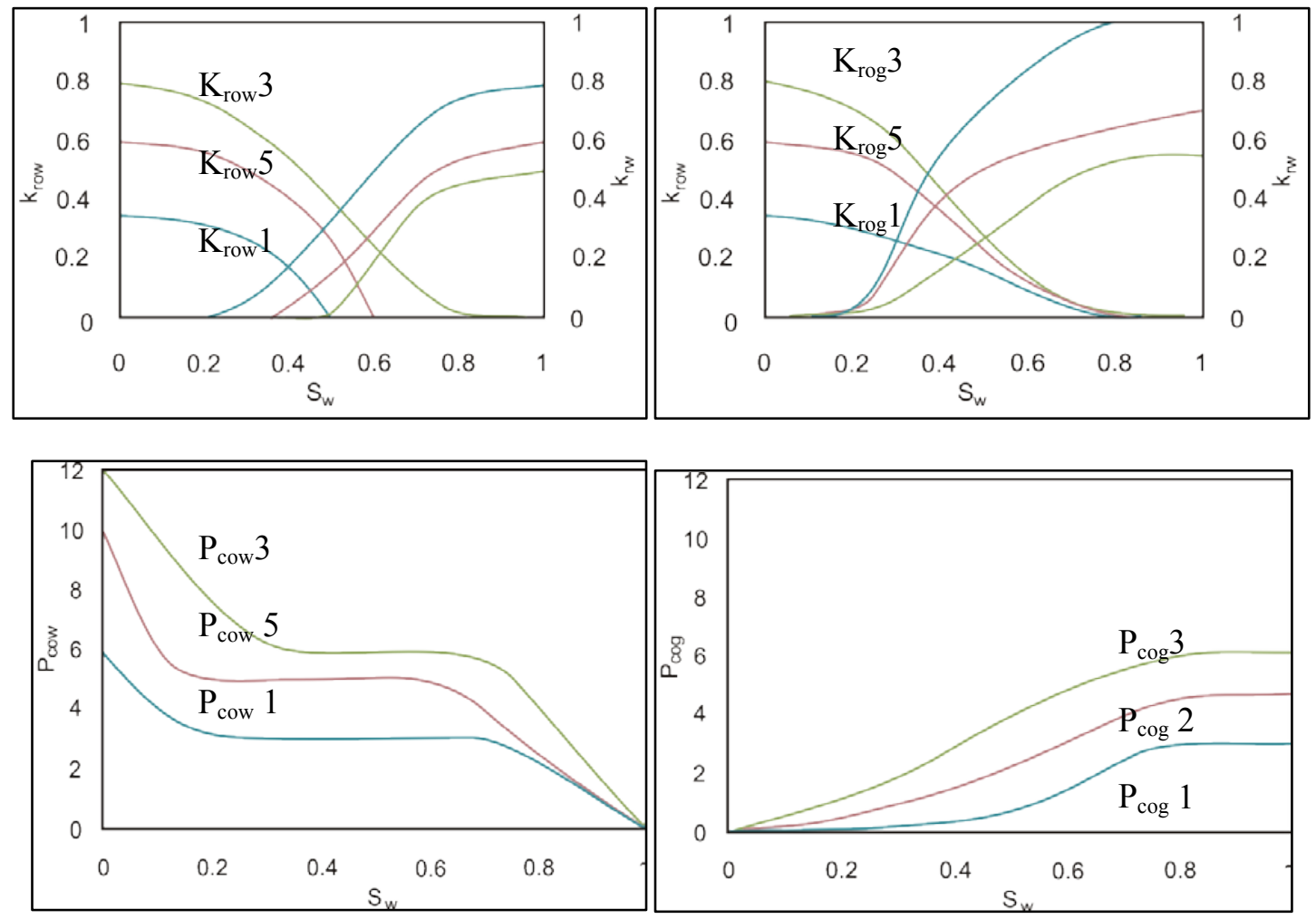

Figure $2-2$. Relative permeability and capillary pressure curves for all the rock types. 


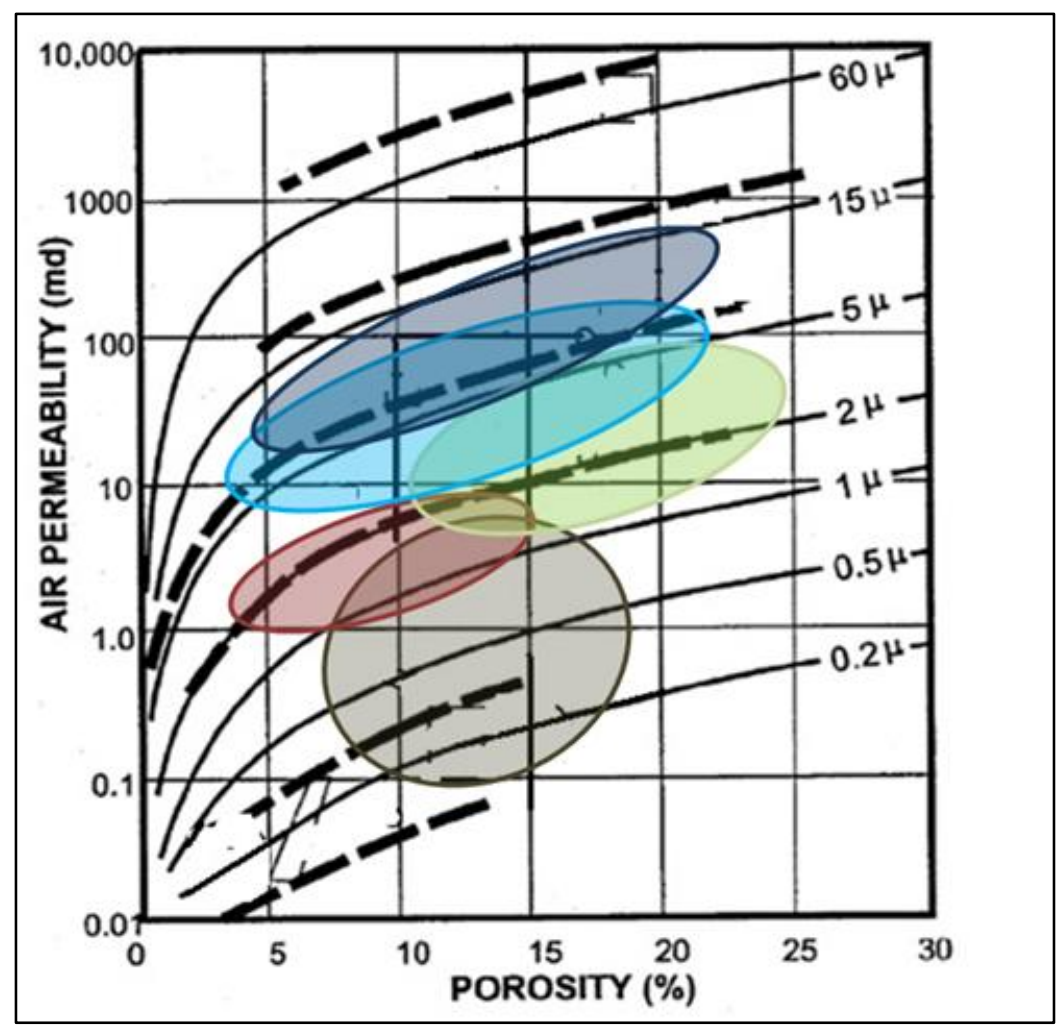

Figure $2-3$. Winland plot showing the porosity-permeability relationship for all the rock types

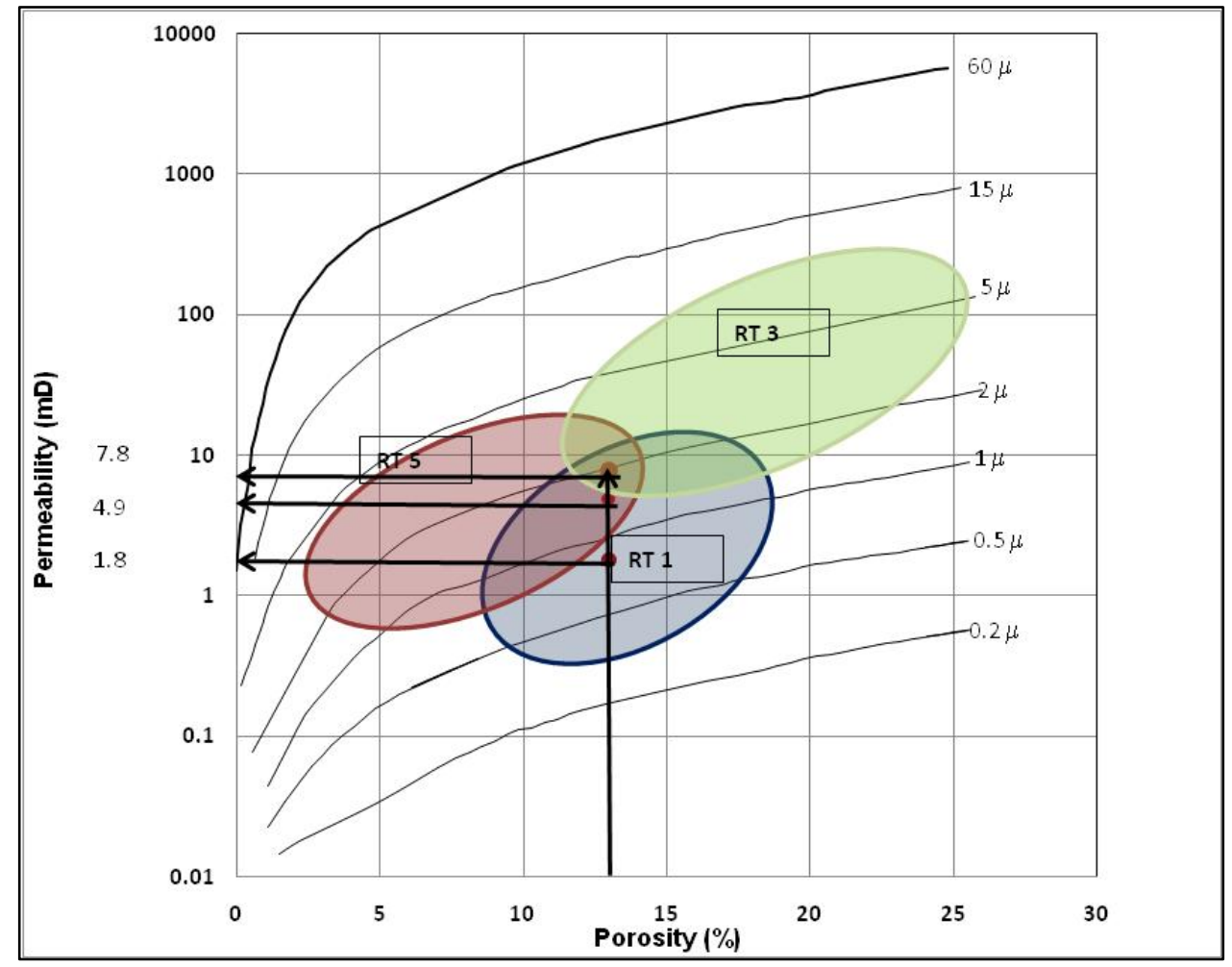

Figure 2 - 4. Winland Plot used for Scenario 1, 2, 3 and 4 
In order to assign a predefined rock type to a specific grid block the following procedure should be followed.

Method 1: Assignment by Layer

- $\quad$ Click the Specify Property box and Scroll over to the Rel Perm Set Num

- $\quad$ Enter which rock type you want to assign for different layer. If 1 is entered for Layer 1 means Rock Type 1 will be used for that particular layer.

- $\quad$ Click OK

- $\quad$ Click OK again to populate the properties inside the grid.

Method 2: Assignment by general Grid block Location

- $\quad$ Click Specify Property and scroll to the Rel Perm Set Num column

- $\quad$ First, the entire Reservoir should be designated as being in Rock Type 3 by Entering 3 in the Whole Grid row. It will create Array for Rel Perm Set Num. (Figure 2 - 6)

\section{- $\quad$ Click OK}

- $\quad$ Click OK again to populate the properties inside the grid.

- $\quad$ Select Rel Perm Set Num under currently displayed Reservoir Property.

- Select the Edit Property icon from the toolbar to edit the displayed reservoir property (RTYPE in this case).

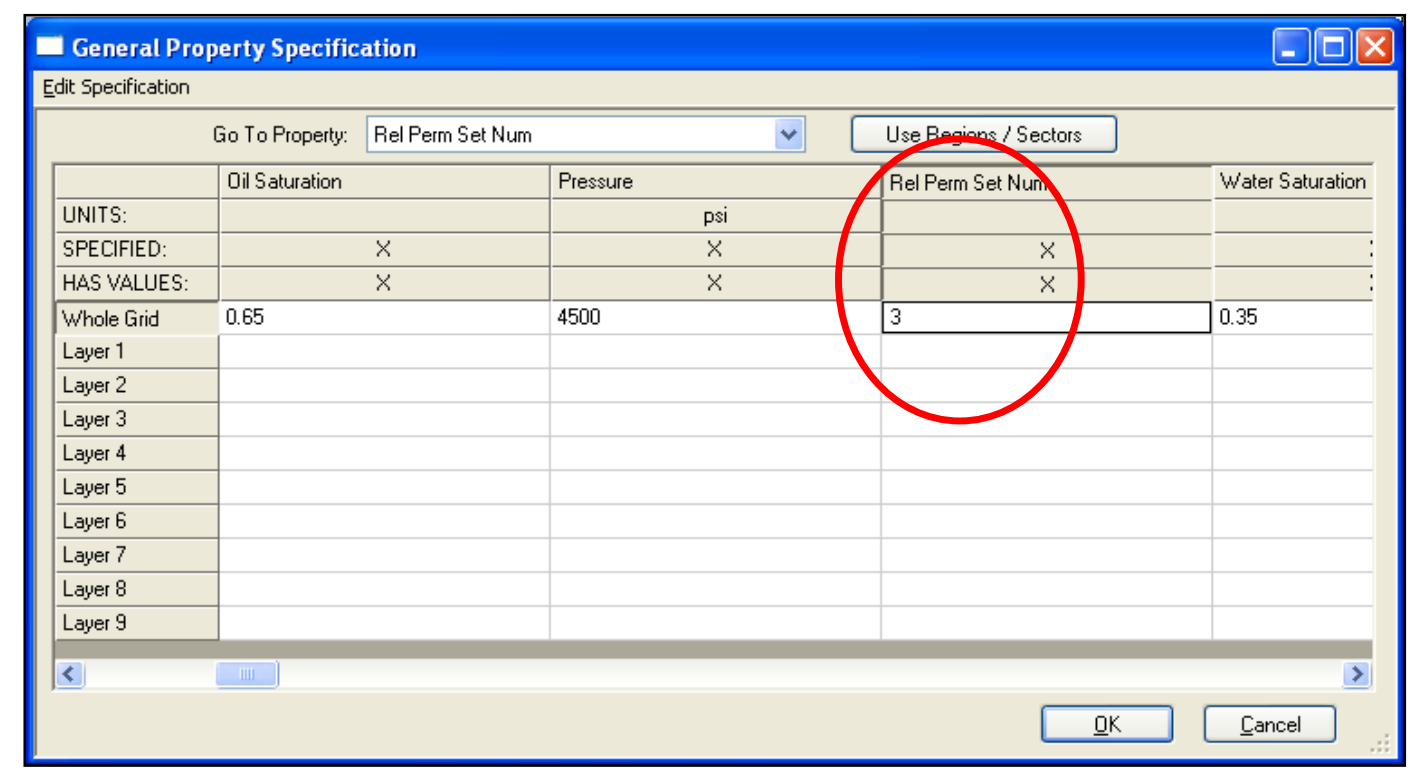

Figure 2 - 5. Assigning single rock type to the whole reservoir 


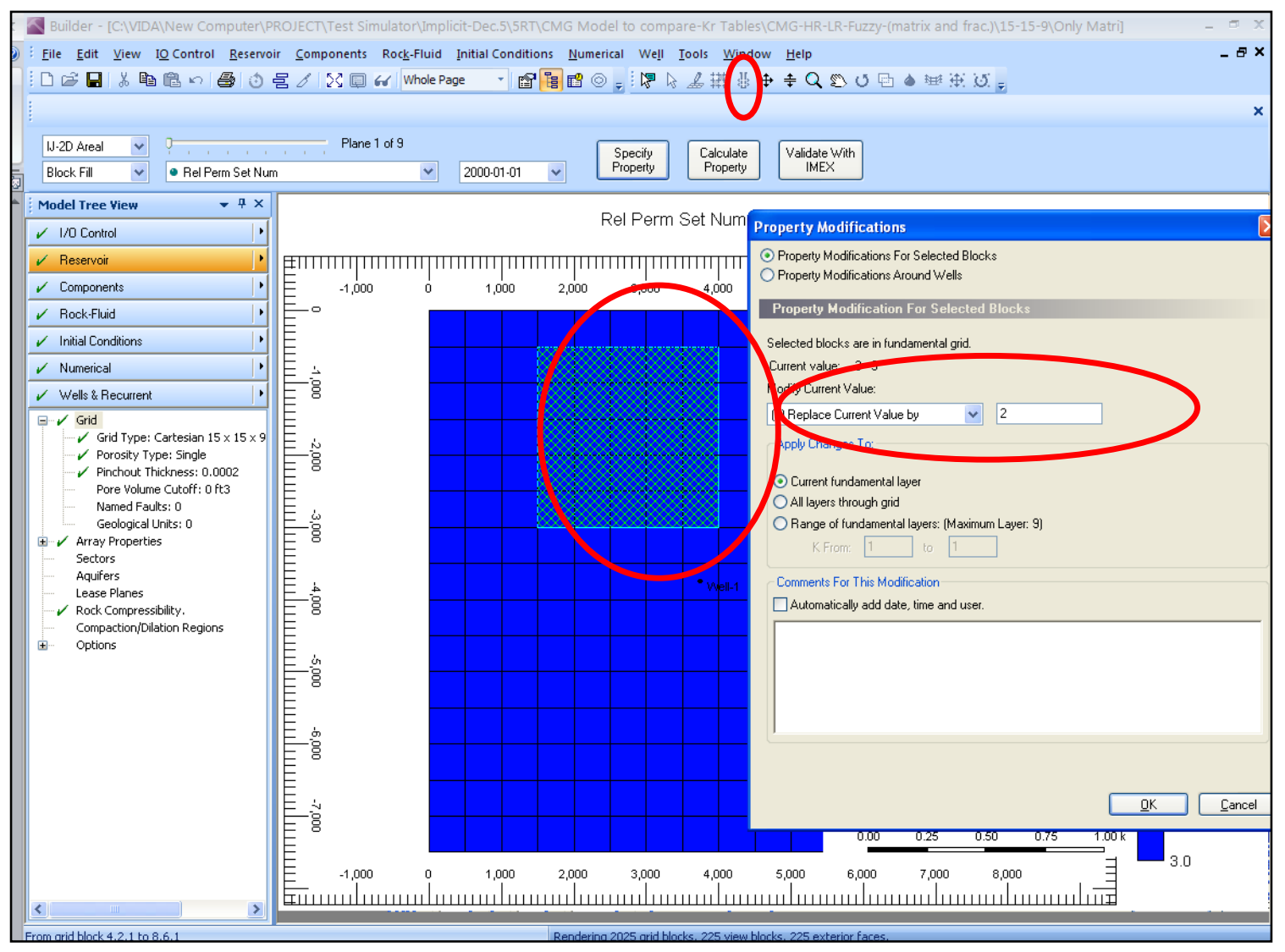

Figure $2-6$. Assigning different rock types to the grid blocks

- Highlight any portion of the reservoir by clicking and holding down the Left Mouse Button while dragging the cursor over the desired section of the grid (For multiple selection hold control key down and press left mouse button simultaneously). For example, highlight the left hand side of the reservoir. Select Property Modifications for Selected Blocks and enter 2 in the Replace Current Value by box. Then select all layers through grid as shown in Figure 2 - 6.

Figure $2-7$ shows how the selected portion of the grids effectively has been re-assigned to Rel. Perm Set Num 2 (RTYPE 2). 


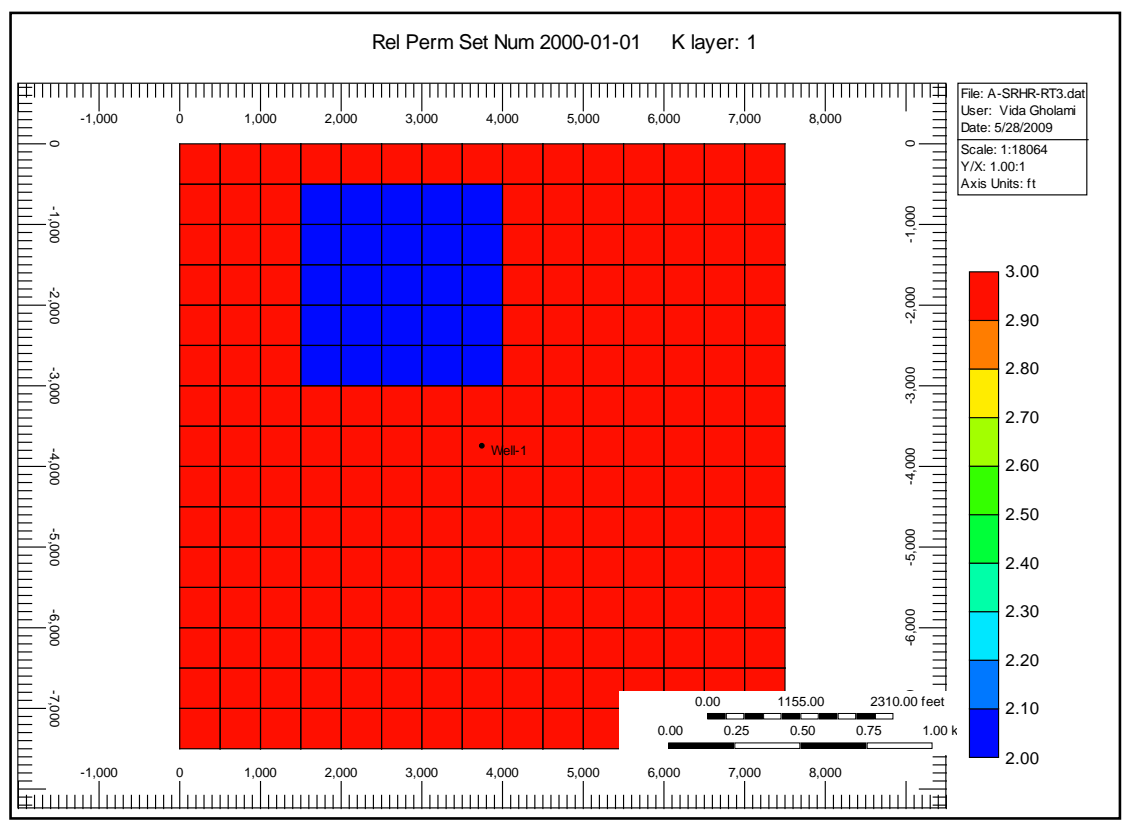

Figure 2 - 7. Re-assigning rock types

Method 3: Assignment by Formula

- $\quad$ Select the Tools tab from the top menu bar, then Select Enter a formula

- $\quad$ Change the name of the Formula from Scheme1 to RelPerm

- $\quad$ Click Add to list of Independent variables, then Select Porosity and Click OK

- $\quad$ Inside the bottom white box Enter the following formula to assign Rel Perm Set Number (i.e.

Rock Types or Regions) by Porosity Range: IF (X0 >=0.15) THEN (1) ELSE (2)

- $\quad$ Click OK twice

- $\quad$ Click Specify Property and scroll to the Rel Perm Set Num column

- $\quad$ Right-Click in the Whole Grid cell, then Select Formula from the displayed list of data source options

- Click the Formula icon and select the formula that just was created using the Array Math option (i.e. the Rel Perm formula).

Based on the sensitivity analysis results, rock type 3 has the most contribution in fluid flow throughout the reservoir. To investigate the effect of rock types' participation in the reservoir, and compare the outcomes of two different upscaling approaches, multiple scenarios have been studied.

In these realizations, rock type 3 is regarded as the dominant rock. The high-resolution model will be upscaled 75 times. This implies that 75 grid blocks will create one low-resolution block in the 
upscaled model. Table 2 - 4 expresses the degree of contribution for all rock type in terms of the number of grids belonging to each in 75 high resolution blocks.

Table 2 - 4. Number of grid blocks for each rock type out of 75 grids.

\begin{tabular}{|c|c|c|c||}
\hline Percentage of RT3 & $\begin{array}{c}\text { Number of RT3 Grid } \\
\text { Blocks }\end{array}$ & $\begin{array}{c}\text { Number of RT5 Grid } \\
\text { Blocks }\end{array}$ & $\begin{array}{c}\text { Number of RT1 } \\
\text { Grid Blocks }\end{array}$ \\
\hline \hline $100 \%$ & 75 & 0 & 0 \\
\hline $90 \%$ & 68 & 3 & 4 \\
\hline $80 \%$ & 60 & 3 & 12 \\
\hline $70 \%$ & 53 & 3 & 19 \\
\hline \hline $60 \%$ & 45 & 3 & 27 \\
\hline \hline $50 \%$ & 38 & 3 & 34 \\
\hline
\end{tabular}

Table $2-5$. Porosity and permeability value for each rock type

\begin{tabular}{|c|c||c|}
\hline \hline Rock Type & Por. Value used & Permeability value used(Kx) \\
\hline \hline 1 & 0.13 & 1.78 \\
\hline \hline 3 & 0.13 & 7.84 \\
\hline \hline 5 & 0.13 & 5 \\
\hline
\end{tabular}

Detailed explanation of this process is followed.

\subsubsection{High resolution Models}

Foremost, the single-rock type- high-resolution model was created. In this model all the grid blocks belong to the dominant rock type (Rock type 3).So the relative permeability and capillary pressure and permeability values of this rock type is assigned to all the blocks. Figure $2-8$ shows the schematic of the reservoir made using CMG-Builder. Since all 2025 grids belong to rock type three, the porosity and permeability distribution will be homogeneous in the reservoir. The model has been run to obtain production and pressure data for 10 years. 


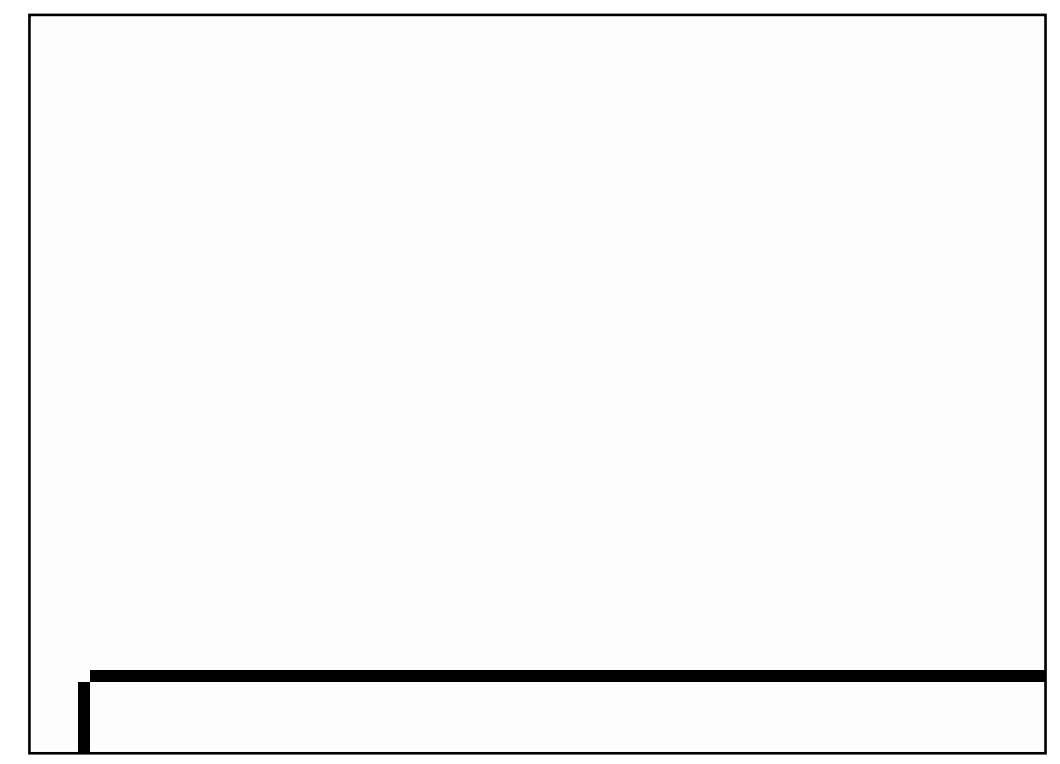

Figure $2-8$. Rock type distribution in the reservoir

According to cases defined in Table 2 - 4, the model has been modified. An example of $90 \%$ and $80 \%$ of dominant rock types are shown in the following figures.

Appendix A includes more graphic representations for other cases studied in this scenario.

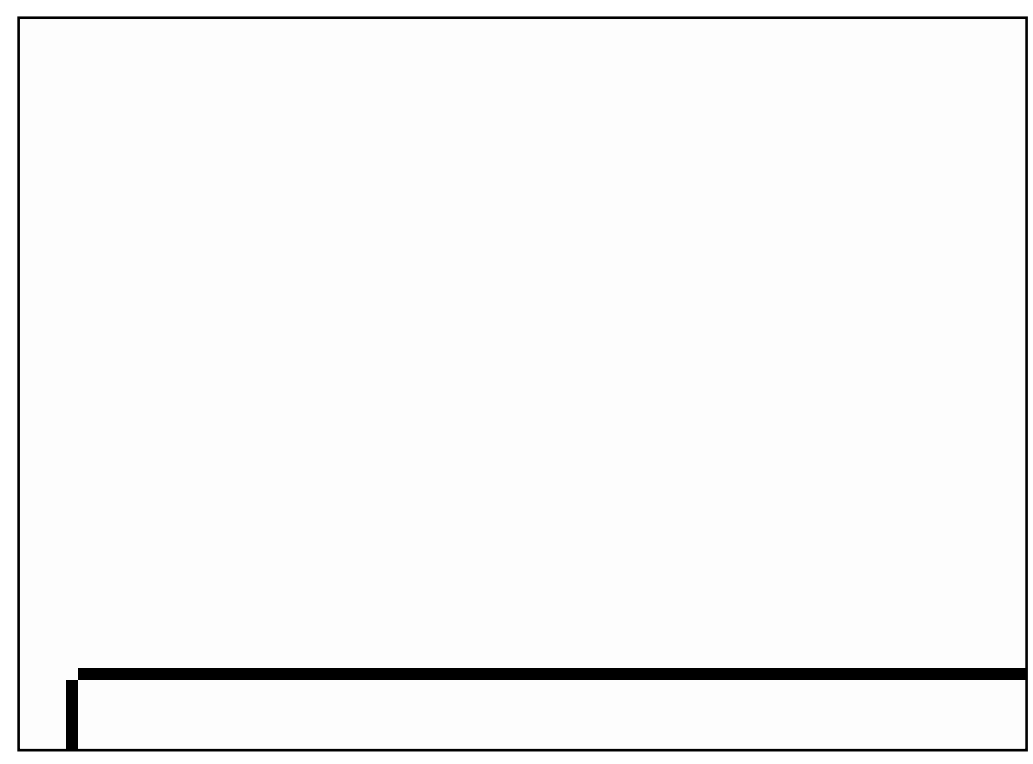

Figure 2 - 9. Rock Type distribution (3RTHR/90\%)

In view of the fact, Winland plot can be utilized to attain the permeability value for each rock type having their porosity. It should be noted that in all cases permeability in $\mathrm{Z}$ direction is considered to be one tenth of the permeability in $\mathrm{x}$ direction. 


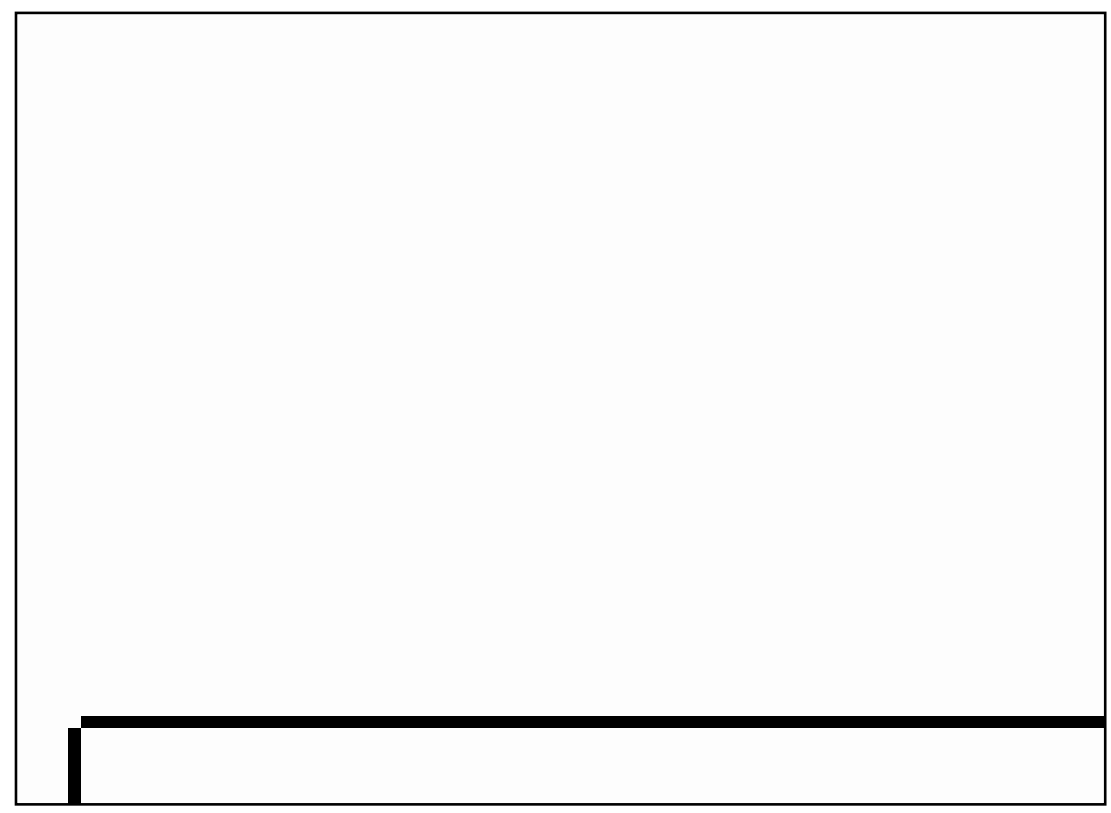

Figure 2 - 10. Rock type distribution in the reservoir (3RTHR/80\%)

\subsubsection{Low resolution Models (Conventionally Upscaled)}

The geological models, referred to as fine grid models, geostatistical models or simply geocellular models, represent geological variation on very fine scales vertically, though their areal resolution is still relatively coarse. For example, a typical geostatistical model might contain layering of thickness $1 \mathrm{ft}$ or less, though cell sizes in the areal direction might be about $50-100 \mathrm{ft}$. Thus, fine grid geological descriptions can be expected to grow further, so the need for reliable upscaling techniques will continue.

In this study a high resolution model was built to symbolize a high resolution replica of the reservoir made based on fine scale geocellular model data. The geocellular models should be upscaled in order to be run in the reservoir simulators.

The upscaling is performed by the order of 75. The low resolution model has three grid blocks in each of $\mathrm{X}$ and $\mathrm{Y}$ direction. Every three layers in $\mathrm{Z}$ direction is upscaled to one layer. Therefore 75 high resolution grids create one low resolution block; consequently the low resolution model has 27 grid blocks while the high resolution one was consisting of 2025 grids.

In conventional upscaling process, the rock type that has the higher number of grids in 75 high resolution block will compel its properties to the whole block. As it was explained in the last sections, rock type 3 is the dominant among all, in all cases. As a result, all 27 blocks will belong to rock type 
3 after carrying out the upscaling. Since it is a fact for all the cases, the upscaled model achieved by this methodology will be indistinguishable for all of them regardless of different rock type distributions.

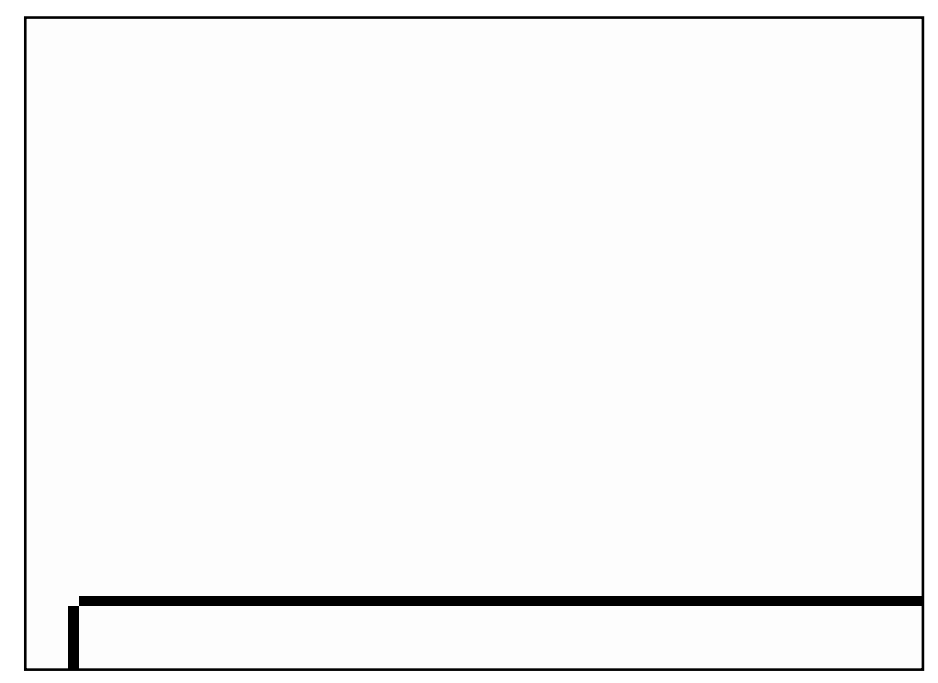

Figure 2 - 11. Low resolution model grid top

According to the new rock type distribution, all the characteristics of rock type three including porosity , permeability $(\mathrm{Kx}, \mathrm{Ky}, \mathrm{Kz})$ and relative permeability and capillary pressure curves are spread out along the reservoir.

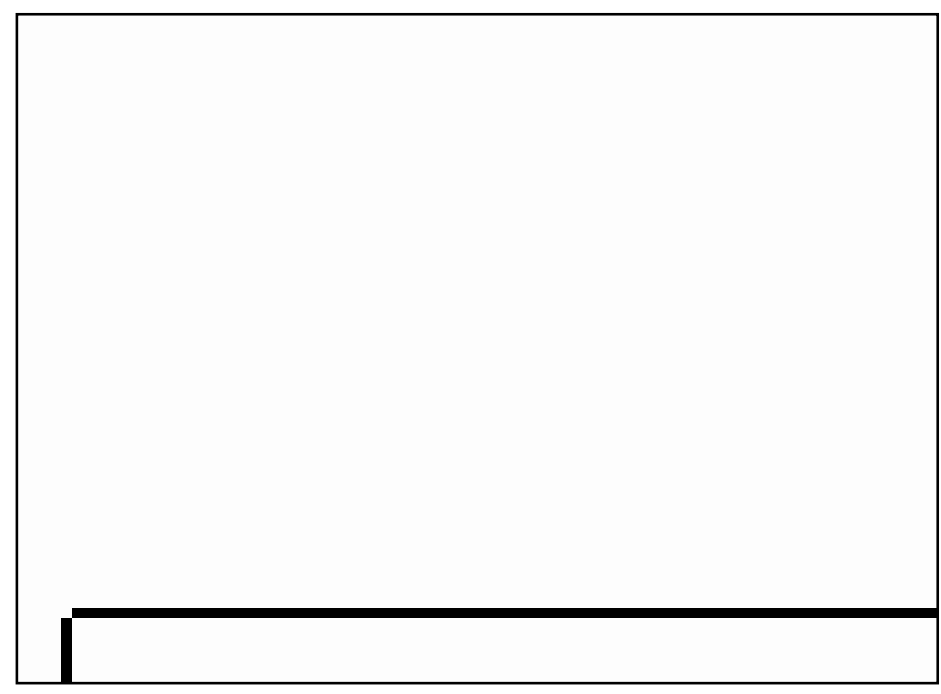

Figure $2-12$. Rock type distribution in the reservoir-Conventional upscaled model 


\subsubsection{Low resolution Models (Fuzzy Upscaled)}

Each rock type is associated with a series of relative permeability and capillary pressure curves. The approximation of multiple and overlapping rock types into a dominant rock type results in defeating the original purpose of performing a detailed geological, petrophysical and geophysical studies as far as reservoir flow models are concerned.

The approach proposed in this research is based on fuzzy set theory. Base on this method, a membership value is defined for each rock type. This value is calculated base on the quantity of the grids belonging to each rock type. For instance if out of 75 grid blocks, 38 of them belong to rock type 3, and rock types 5 and 1 have a share of 3 and 27 apiece, the membership value for rock types 3,5 and 1 will be 60,4 and 36 correspondingly. This membership value has been used to define new rock types after upscaling. These rock types are expected to be more realistic and have closer results to the high-resolution models' outcomes. The porosity, permeability, relative permeability, and capillary pressure data associated to the new rock types have been determined using the membership values. A logical assumption leads us to the fact that each rock type should have an effect in the upscaled block and this effect is rooted in their share of the high-resolution grids. Using the fuzzy set theory, this behavior is trying to be mimicked. In this case, there will not be a unique low resolution model for all the high resolution realizations. The single rock type high resolution model will be upscaled to a single rock type low resolution model identical to the conventionally upscale one. Since the rock type distribution in each 75 grid blocks is identical to the distribution to the other 75 grids, the fuzzy rock type created will be similar for 27 low resolution blocks of a case, but different from another case. Following table shows the fuzzy membership and permeability values before and after upscaling for the case with $90 \%$ of grids fitting in rock type 3 .

Table 2 - 6. Permeability values before and after fuzzy upscaling (90\% of rock type 3)

\begin{tabular}{|c|c|c|c|c|}
\hline Property & $\begin{array}{l}\text { Number of High } \\
\text { Resolution Grids }\end{array}$ & $\begin{array}{c}\text { Fuzzy } \\
\text { Membership } \\
\text { Value } \\
\end{array}$ & $\begin{array}{c}\text { Value before } \\
\text { upscaling }\end{array}$ & $\begin{array}{c}\text { Value after } \\
\text { fuzzy upscaling }\end{array}$ \\
\hline \multirow{3}{*}{$\mathrm{Kx}(\mathrm{mD})$} & "RT 1: 4 & RT 1:0.05 & RT $1: 1.78$ & \multirow{3}{*}{ FRT $1: 7.399$} \\
\hline & RT 3:68 & RT 3: 0.91 & RT 2:7.84 & \\
\hline & RT 5: 3 & RT $5: 0.04$ & RT 3:5 & \\
\hline \multirow{3}{*}{$\mathrm{Ky}(\mathrm{mD})$} & RT 1: 4 & RT 1: 0.05 & RT 1: 1.78 & \multirow{3}{*}{ FRT $1: 7.399$} \\
\hline & RT 3:68 & RT 3: 0.91 & RT 2:7.84 & \\
\hline & RT 5:3 & RT 5:0.04 & RT 3:5 & \\
\hline \multirow{3}{*}{$\mathrm{Kz}(\mathrm{mD})$} & RT 1:4 & RT 1:0.05 & RT 1:0.178 & \multirow{3}{*}{ FRT $1: 0.74$} \\
\hline & RT 3:68 & RT 3: 0.91 & RT 2: 0.784 & \\
\hline & "RT $5: 3$ & RT 5: 0.04 & "RT 3:0.5 & \\
\hline
\end{tabular}




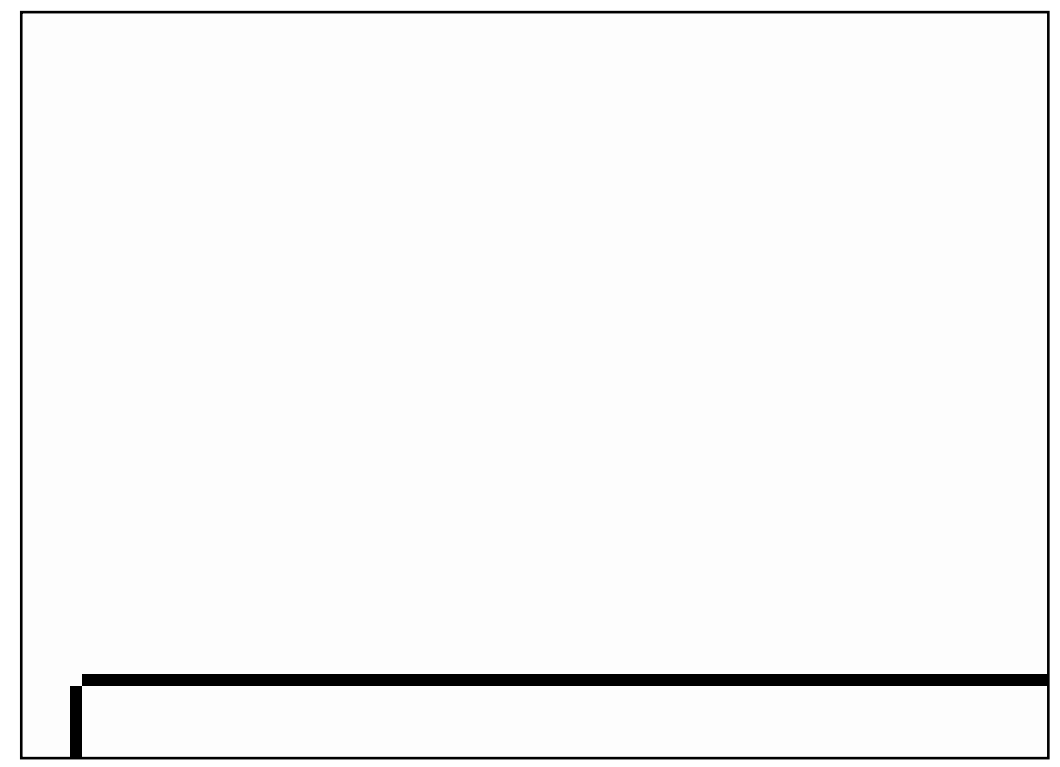

Figure 2 - 13. Rock type distribution in the reservoir-Fuzzy upscaled model (90\%)

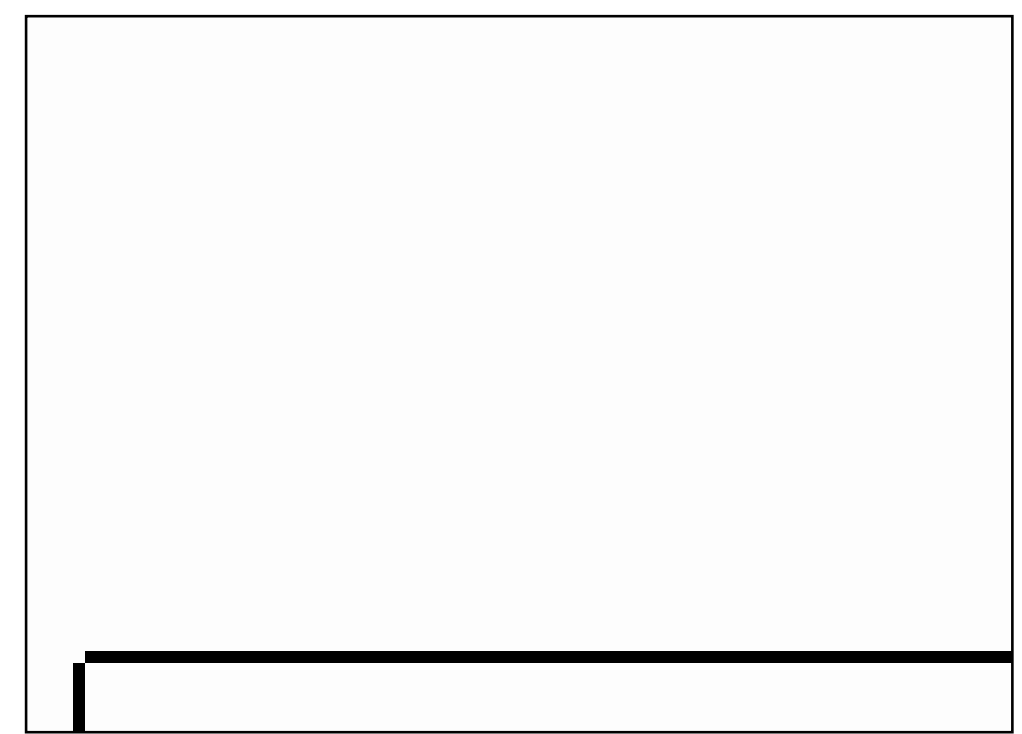

Figure 2 - 14. Kx distribution in the reservoir-Fuzzy upscaled model (90\%)

The tables listing the information related to fuzzy upscaling for other modified models are brought in Appendix A. 


\subsection{Relative Permeability, Capillary Pressure, Permeability Upscaling Effect (Scenario 2)}

The difference of this case with the previously discussed case is in the number of grid blocks used. Table 2 - 7 and

Table 2 - 8 present the properties of the high and low-resolution model correspondingly.

Table 2 - 7. High-resolution model properties

\begin{tabular}{|c|c|c||}
\hline \multicolumn{2}{|c||}{ High Resolution Model Properties } \\
\hline \hline Property & Value & Unit \\
\hline$\Delta \mathrm{x}$ & 500 & $\mathrm{ft}$ \\
\hline$\Delta \mathrm{y}$ & 500 & $\mathrm{ft}$ \\
\hline \hline $\mathrm{zx}$ & 15 & $\mathrm{ft}$ \\
\hline \hline $\mathrm{ny}$ & 45 & \\
\hline $\mathrm{nz}$ & 45 & $\mathrm{ft}$ \\
\hline \hline Reservoir Top & 9 & $\mathrm{psi}$ \\
\hline \hline Bubble point pressure & 2000 & $\mathrm{psi}$ \\
\hline \hline Initial reservoir pressure & 500 & percent \\
\hline \hline Initial oil saturation & 4500 & percent \\
\hline Water saturation & 65 & 35 \\
\hline
\end{tabular}

Table 2 - 8. Low-resolution model properties

\begin{tabular}{|c|c|c||}
\hline \multicolumn{2}{|c||}{ Low Resolution Model Properties } \\
\hline \hline Property & Value & Unit \\
\hline$\Delta \mathrm{x}$ & 2500 & $\mathrm{ft}$ \\
\hline$\Delta \mathrm{y}$ & 2500 & $\mathrm{ft}$ \\
\hline \hline $\mathrm{zx}$ & 45 & $\mathrm{ft}$ \\
\hline $\mathrm{ny}$ & 9 & \\
\hline \hline $\mathrm{nz}$ & 9 & $\mathrm{ft}$ \\
\hline \hline Reservoir Top & 3 & $\mathrm{psi}$ \\
\hline \hline Bubble point pressure & 2000 & $\mathrm{psi}$ \\
\hline \hline Initial reservoir pressure & 500 & percent \\
\hline Initial oil saturation & 4500 & percent \\
\hline Water saturation & 65 & 35 \\
\hline
\end{tabular}

This model is consisting of 18225 grids whereas the prior model had 2025 blocks. This process comprises subsequent steps. 


\subsubsection{High resolution Models}

First, the model having only the dominant rock type has been built. This model then was modified according to the percent of each rock type contributing in the reservoir. Figure 2 - 15 shows the schematic of the reservoir made using CMG-Builder.

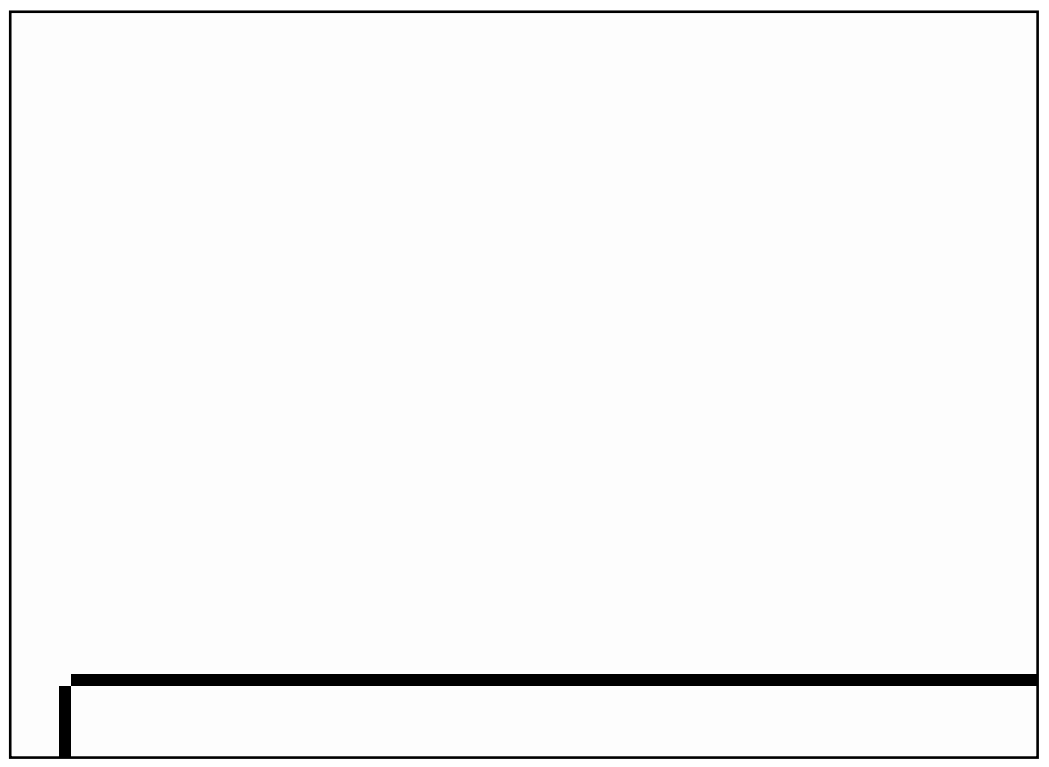

Figure 2 - 15. Rock type distribution in the reservoir-SRHR

Following figures illustrate the rock type arrangement for cases having 90 and 80 percent of rock type 3 as an example. The figures associated to other cases are shown in Appendix B.

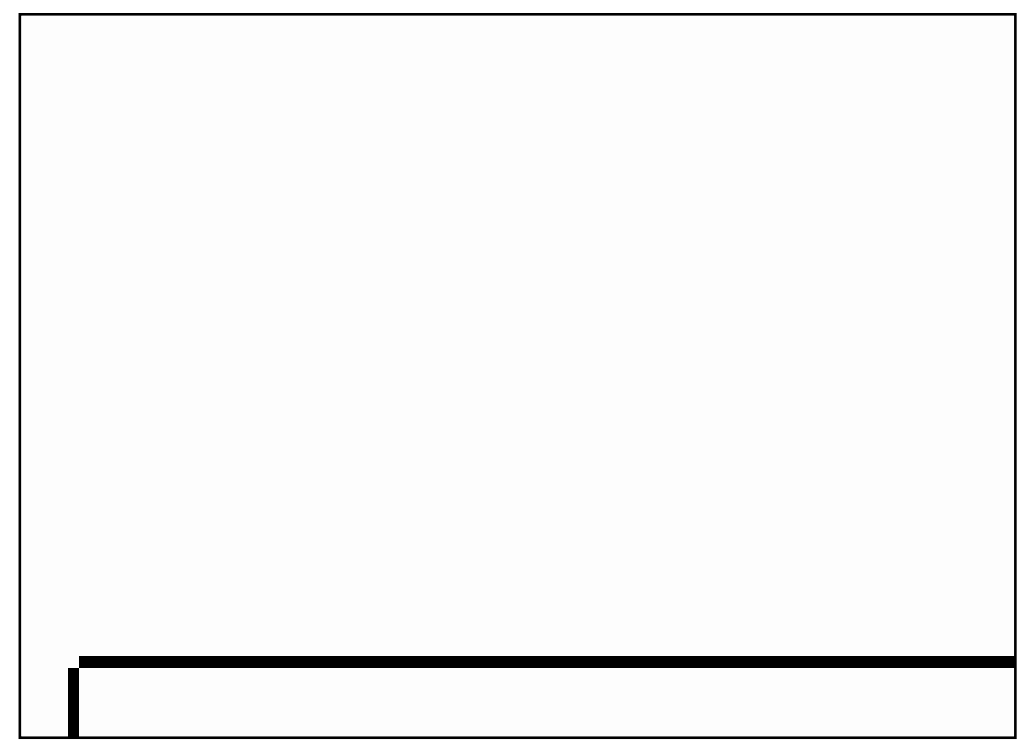

Figure 2 - 16. Rock Type distribution (3RTHR/90\%) 


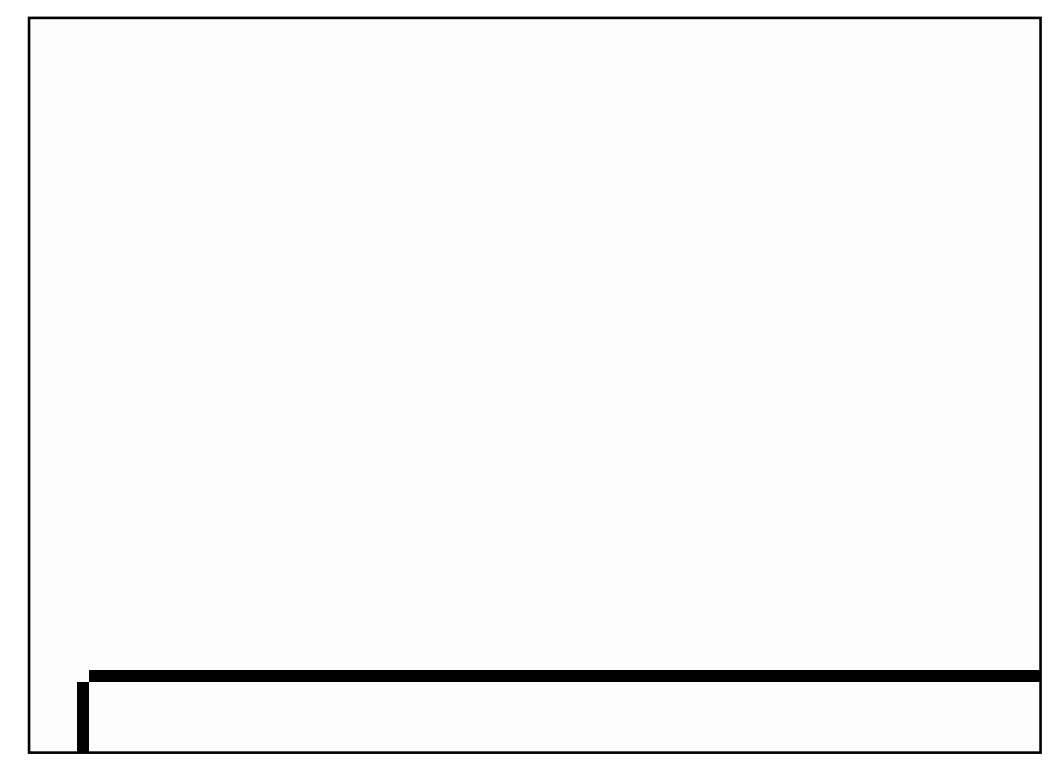

Figure 2 - 17. Rock type distribution in the reservoir (3RTHR/80\%)

\subsubsection{Low resolution Models (Conventionally Upscaled)}

The high-resolution model, which resembles the fine scale geological model, has been upscaled 75 times. The low-resolution model has nine grid blocks in each of $\mathrm{X}$ and $\mathrm{Y}$ direction. Every three layers in $\mathrm{Z}$ direction is upscaled to one layer. Therefore, 75 high-resolution grids create one low-resolution block. The low-resolution model has 243 blocks.

As explained before, in the conventional upscaling technique, only the number of grid blocks plays role. The rock type that encompasses more grids will be considered as a dominant rock type and its properties will be generalized to all grids in that specific upscaled region.

Since rock type three is the dominant rock type in all cases, there will be only one low-resolution model representing all the cases.

A thorough contemplation of this process brings up this question if this upscaled model can stand for all the cases to the same extent.

This inquiry has been investigated and the outcome is shown in the result section. 


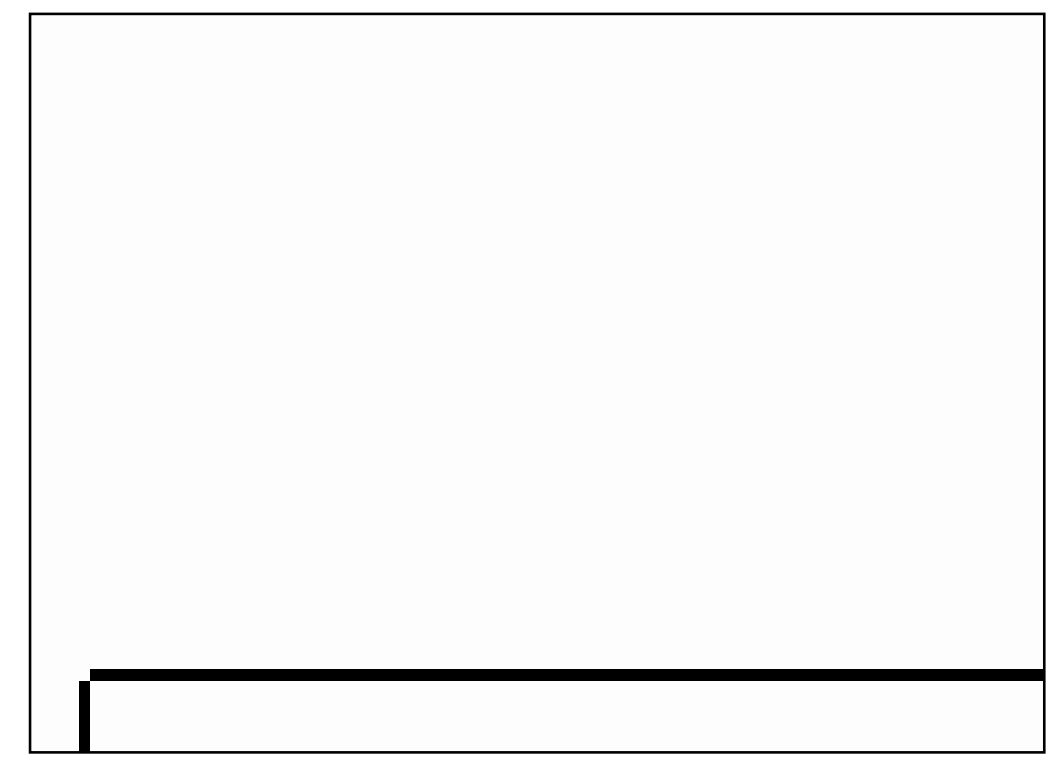

Figure 2 - 18. Rock type distribution in the reservoir-Conventional upscaled model

\subsubsection{Low resolution Models (Fuzzy Upscaled)}

The fuzzy membership value was calculated based on the contribution of each rock type in the high resolution grids. The rock type which encompasses more grids will have a higher membership value. This implies more stunning effect by that rock type on fluid flow in reservoir.

Since the rock type distribution in each 75 grid blocks is identical to the distribution to the other 75 grids, the fuzzy rock type created will be similar for 243 low resolution blocks of a case, but different from another case. Following table shows the fuzzy membership and permeability values before and after upscaling for the case with $90 \%$ of grids fitting in rock type 3.The information related to other cases are listed in tables of Appendix B.

Table 2 - 9. Permeability values before and after fuzzy upscaling ( $90 \%$ of rock type 3 )

\begin{tabular}{|c|c|c|c|c|}
\hline Property & $\begin{array}{l}\text { Number of High } \\
\text { Resolution Grids }\end{array}$ & $\begin{array}{l}\text { Fuzzy Membership } \\
\text { Value }\end{array}$ & $\begin{array}{c}\text { Value before } \\
\text { upscaling }\end{array}$ & $\begin{array}{c}\text { Value after fuzzy } \\
\text { upscaling }\end{array}$ \\
\hline \multirow{3}{*}{$\begin{array}{c}\mathrm{Kx} \\
(\mathrm{mD})\end{array}$} & RT $1: 4$ & RT $1: 0.05$ & RT $1: 1.78$ & \multirow{3}{*}{ FRT $1: 7.399$} \\
\hline & RT 3:68 & RT 3: 0.91 & RT $2: 7.84$ & \\
\hline & RT $5: 3$ & RT 5: 0.04 & RT 3:5 & \\
\hline \multirow{3}{*}{$\begin{array}{l}\mathrm{Ky} \\
(\mathrm{mD})\end{array}$} & RT 1:4 & RT 1:0.05 & RT $1: 1.78$ & \multirow{3}{*}{ FRT $1: 7.399$} \\
\hline & RT 3:68 & RT 3:0.91 & RT 2:7.84 & \\
\hline & RT $5: 3$ & RT 5: 0.04 & RT 3:5 & \\
\hline \multirow{3}{*}{$\begin{array}{c}\mathrm{Kz} \\
(\mathrm{mD})\end{array}$} & RT $1: 4$ & RT 1:0.05 & RT $1: 0.178$ & \multirow{3}{*}{ FRT $1: 0.74$} \\
\hline & RT 3:68 & RT 3:0.91 & RT $2: 0.784$ & \\
\hline & RT $5: 3$ & RT 5: 0.04 & RT $3: 0.5$ & \\
\hline
\end{tabular}




\subsection{Relative Permeability, Capillary Pressure, Porosity and Permeability Upscaling Effect (Scenario 3)}

The same approach for the preceding section has been pursued. The reservoir grid blocks belong to three different rock types. Apart from the relative permeability and capillary pressure curves, the porosity of each rock type is different from the other one as well. The corresponding permeability will be different too according to the Winland cross plot. High-resolution models have been created and run. These models have undergone upscaling processes. Two different methods of upscaling then were compared in order to shed a light on their contrasts and dissimilarities.

\subsubsection{High resolution Models}

Following figure is demonstrating the rock type distribution in the reservoir for the single rock typehigh resolution model. As shown, all the grids belong to rock type three.

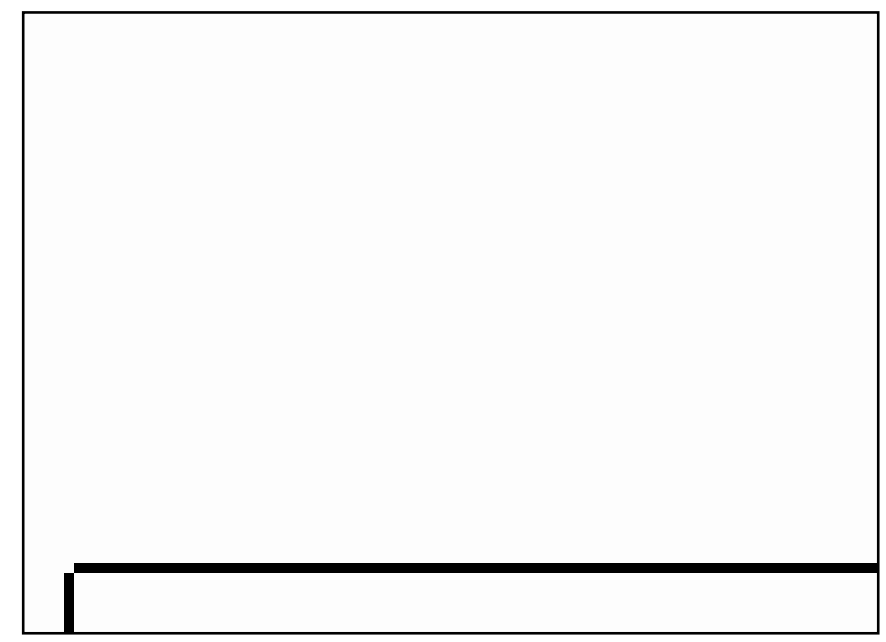

Figure 2 - 19. Rock type distribution in the reservoir-SRHR

As explained before, the high-resolution models are modified to investigate the effect of the percent of different rock types throughout the reservoir.

An example of the model that was altered, so that each 75 grid blocks contain $90 \%$ grids having rock type three characteristics has been shown in the following figure. The graphic representations of other cases are shown in Appendix C. 


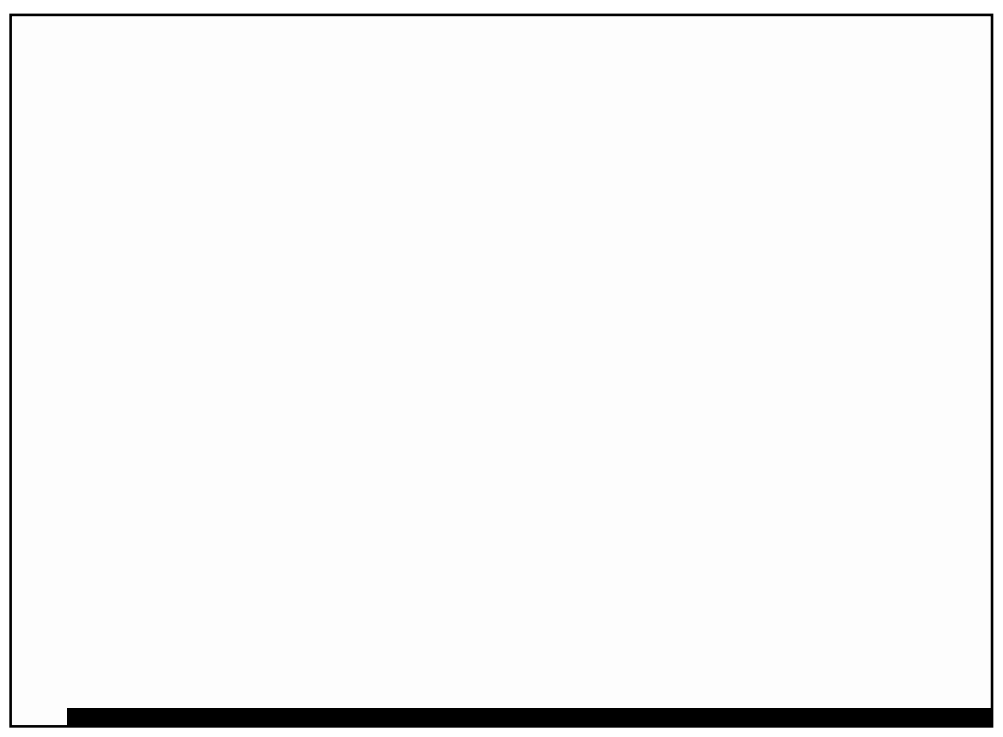

Figure 2 - 20. Rock Type distribution (3RTHR/90\%)

\subsubsection{Low resolution Models (Conventionally Upscaled)}

Given that conventional upscaling was used for upscaling, the properties of the dominant rock type (rock type 3) were dispensed to all the grid blocks.

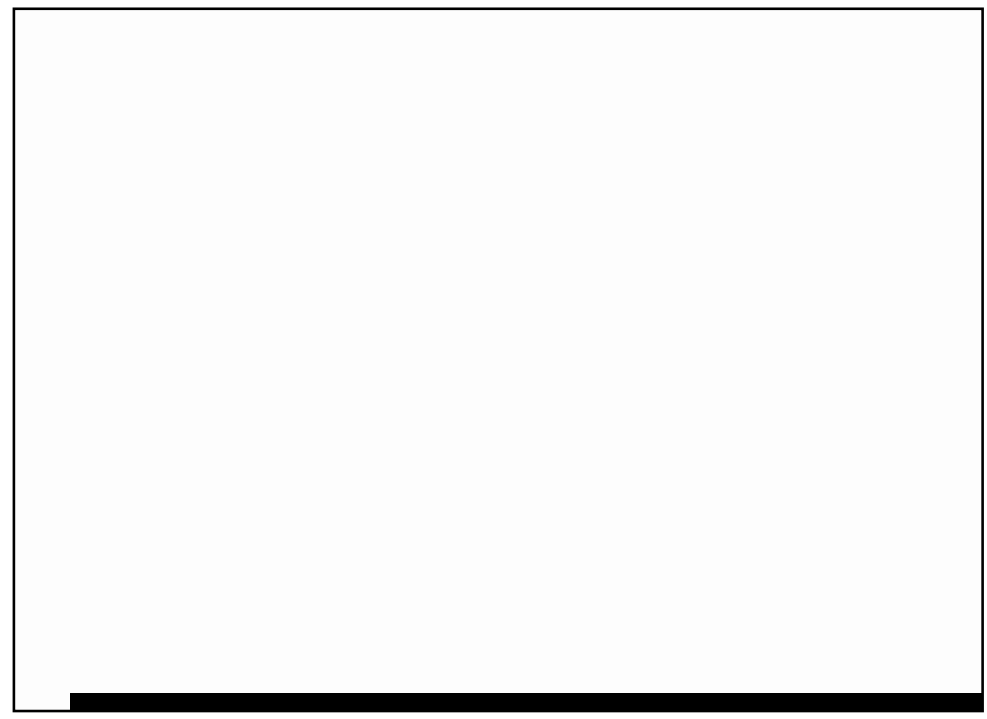

Figure 2 - 21.Low resolution model grid top 


\subsubsection{Low resolution Models (Fuzzy Upscaled)}

The fuzzy membership value for each rock type was calculated based on its participation in reservoir high resolution grid blocks. This value is a function of the number of grid blocks each rock types have been consigned to.

Since the rock type distribution in each 75 grid blocks is identical to the distribution to the other 75 grids, the fuzzy rock type created will be similar for 243 low resolution blocks of a case, but different from another case.

Next table shows the fuzzy membership and permeability values before and after upscaling for the case with $90 \%$ of grids fitting in rock type 3 . The values related to other cases are listed in the tables of Appendix C.

Table 2 - 10. Permeability and porosity values before and after fuzzy upscaling (90\% of rock type 3$)$

\begin{tabular}{|c|c|c|c|c|}
\hline Property & $\begin{array}{l}\text { Number of High } \\
\text { Resolution Grids }\end{array}$ & $\begin{array}{l}\text { Fuzzy Membership } \\
\text { Value }\end{array}$ & $\begin{array}{c}\text { Value before } \\
\text { upscaling }\end{array}$ & $\begin{array}{c}\text { Value after fuzzy } \\
\text { upscaling }\end{array}$ \\
\hline \multirow{3}{*}{$\mathrm{Kx}(\mathrm{mD})$} & RT $1: 4$ & RT $1: 0.05$ & RT 1: 0.519 & \multirow{3}{*}{ FRT $1: 15.18$} \\
\hline & RT 3:68 & RT 3:0.91 & RT 3 : 16.582 & \\
\hline & RT 5:3 & RT 5: 0.04 & RT $5: 2.3$ & \\
\hline \multirow{3}{*}{$\mathrm{Ky}(\mathrm{mD})$} & RT 1:4 & RT 1:0.05 & RT 1: 0.519 & \multirow{3}{*}{ FRT $1: 15.18$} \\
\hline & RT 3:68 & RT 3:0.91 & RT 3 : 16.582 & \\
\hline & RT 5:3 & RT 5:0.04 & RT $5: 2.3$ & \\
\hline \multirow{3}{*}{$\mathrm{Kz}(\mathrm{mD})$} & RT 1:4 & RT 1:0.05 & RT 1: 0.052 & \multirow{3}{*}{ FRT $1: 1.52$} \\
\hline & RT 3:68 & RT 3:0.91 & RT 3: 1.658 & \\
\hline & RT 5:3 & RT $5: 0.04$ & RT $5: 0.23$ & \\
\hline \multirow{3}{*}{$\begin{array}{c}\text { Porosity } \\
(\%)\end{array}$} & RT 1: 4 & RT 1:0.05 & RT 1:5 & \multirow{3}{*}{ FRT $1: 14.33$} \\
\hline & RT 3:68 & RT 3:0.91 & RT 3: 15 & \\
\hline & RT 5:3 & RT 5: 0.04 & RT 5: 10 & \\
\hline
\end{tabular}




\section{4 Relative Permeability, Capillary Pressure, Porosity and Permeability Upscaling Effect-Several Fuzzy Rock Types (Scenario 4)}

The procedure explained in the last sections was followed. A single well model was made. The difference between the current models with the one made in the last section, is different rock type distribution.

The high-resolution model has been made. The grid blocks belong to one of three rock types namely, rock type 1 , rock type 1 and rock type 5.The same as the preceding models, rock type three is the overriding and dominant rock type. The conventional upscaled model has been created. Since, the rock type distribution in each huddle of 75 grid blocks is not the same as the other one; the fuzzy upscaled model will no longer have a single rock type.

\section{4.1 High resolution Models}

Illustrative view of rock type allotment in the reservoir section under the study is displayed in the following figure. This figure is representative of the case having $90 \%$ of the dominant rock type. For more details, please refer to Appendix D.

Figure 2 - 22. Rock Type distribution (3RTHR/90\%) 


\section{4.2 Low resolution Models (Conventionally Upscaled)}

The low-resolution model has been made using two approaches. This section explains the conventionally explained model. This model represents the upscaled model created from the fine scale geological model. This model has 243 blocks that all are affiliated with rock type three, according to the superiority of this rock type in the high-resolution model.

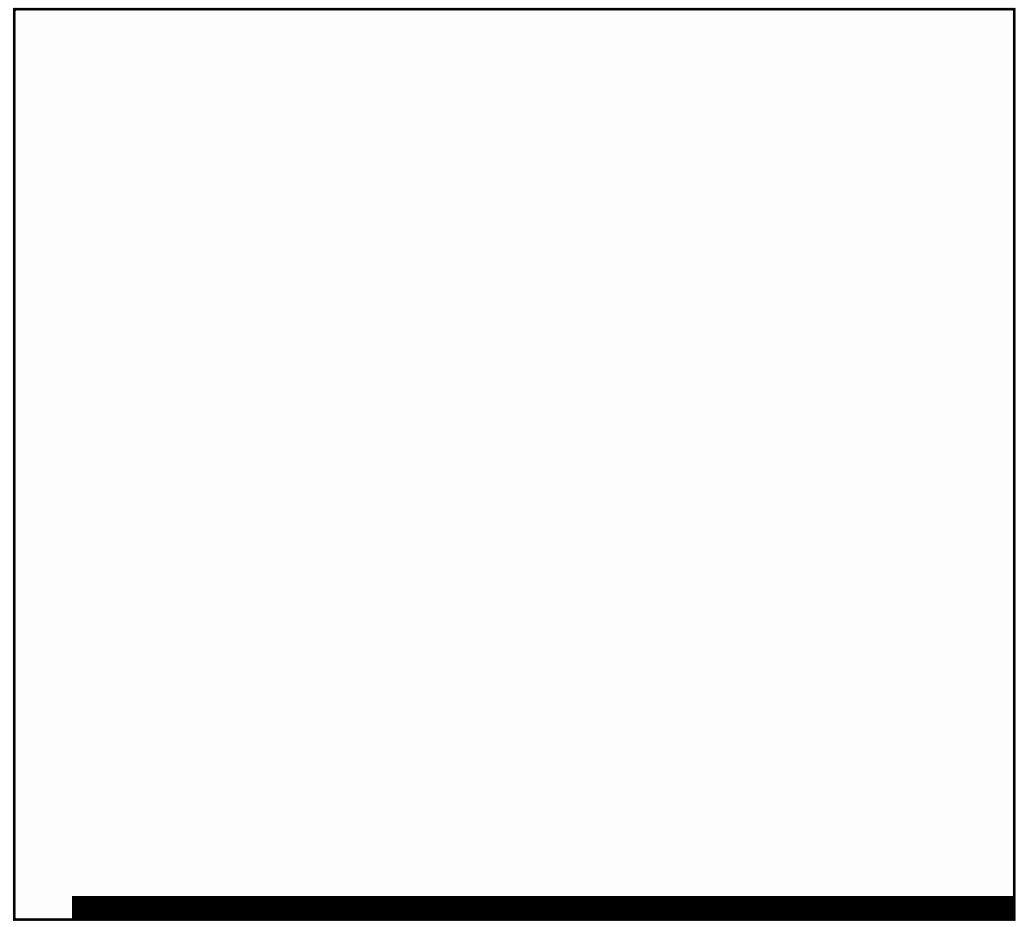

Figure 2 - 23. Low-resolution model grid top 


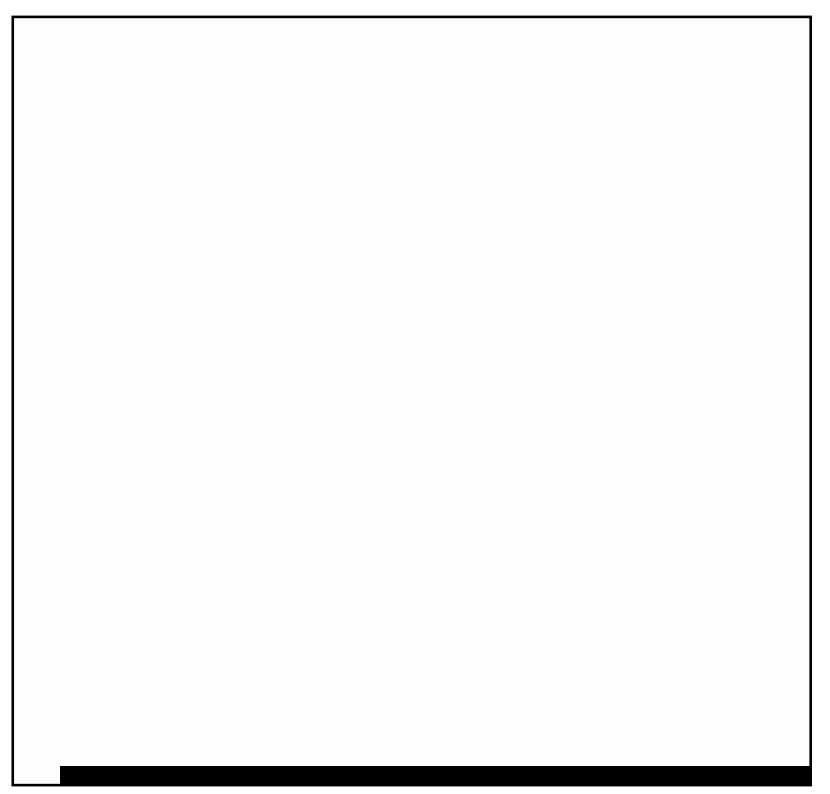

Figure 2 - 24. Rock type distribution -Conventional upscaled model

\section{4.3 Low resolution Models (Fuzzy Upscaled)}

The number of the grid blocks belonging to each rock type is used to calculate the fuzzy membership value.

Since the rock type distribution in each 75 grid blocks is different from the distribution of the other 75 grids, the fuzzy rock type created will be dissimilar for 243 low-resolution blocks of a case. Based on the specific values in this case 5 different fuzzy rock types were creates after upscaling. Following table shows the fuzzy membership and permeability values before and after upscaling for the case with $90 \%$ of grids fitting in rock type 3. More details for the other cases are brought in Appendix D.

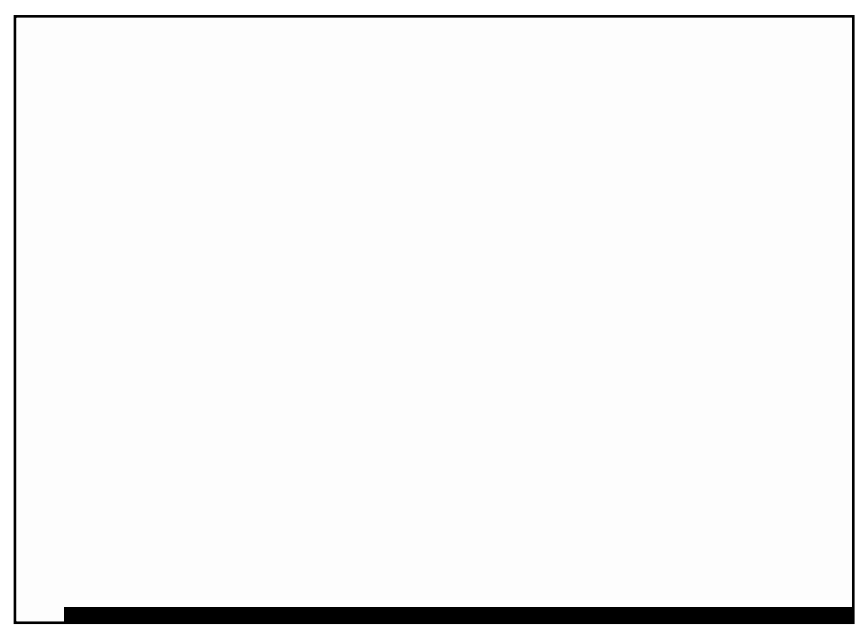

Figure 2 - 25. Rock type distribution in the reservoir-Fuzzy upscaled model (90\%) 
Table 2 - 11 .Permeability values before and after fuzzy upscaling (90\% of rock type 3)

\begin{tabular}{|c|c|c|c|c|}
\hline Property & $\begin{array}{l}\text { Number of High } \\
\text { Resolution Grids }\end{array}$ & $\begin{array}{l}\text { Fuzzy Membership } \\
\text { Value }\end{array}$ & $\begin{array}{l}\text { Value before } \\
\text { upscaling }\end{array}$ & $\begin{array}{l}\text { Value after fuzzy } \\
\text { upscaling }\end{array}$ \\
\hline \multirow{15}{*}{$\mathrm{Kx}(\mathrm{mD})$} & RT1:4 & RT1:0.05 & RT 1:0.519 & \multirow{3}{*}{ FRT1 : 15.18} \\
\hline & RT3: 68 & "RT3 :0.91 & "RT 3 : 16.582 & \\
\hline & RT5 : 3 & "RT5: 0.04 & RT $5: 2.3$ & \\
\hline & RT1:6 & RT1: 0.08 & RT 1:0.519 & \multirow{3}{*}{ FRT2 : 15.15} \\
\hline & RT3: 68 & RT3: 0.91 & RT 3 : 16.582 & \\
\hline & RT5: 1 & RT5 : 0.01 & RT $5: 2.3$ & \\
\hline & RT1:5 & RT1: 0.06 & RT 1: 0.519 & \multirow{3}{*}{ FRT3 : 15.24} \\
\hline & RT3 : 68 & RT3 : 0.91 & RT $3: 16.582$ & \\
\hline & RT5 : 2 & RT5: 0.03 & RT $5: 2.3$ & \\
\hline & RT1: 3 & RT1 : 0.04 & RT 1: 0.519 & \multirow{3}{*}{ FRT4 : 15.22} \\
\hline & RT3:68 & RT3 : 0.91 & RT 3 : 16.582 & \\
\hline & RT5 : 4 & RT5: 0.05 & RT $5: 2.3$ & \\
\hline & RT1:2 & RT1:0.03 & RT $1: 0.519$ & \multirow{3}{*}{ FRT5 : 15.12} \\
\hline & RT3 : 68 & RT3 : 0.91 & RT $3: 16.582$ & \\
\hline & RT5 : 5 & RT5 : 0.06 & RT $5: 2.3$ & \\
\hline \multirow{15}{*}{$\mathrm{Ky}(\mathrm{mD})$} & RT1: 4 & RT1: 0.05 & RT 1:0.519 & \multirow{3}{*}{ FRT1 $: 15.18$} \\
\hline & RT3: 68 & RT3 :0.91 & RT 3 : 16.582 & \\
\hline & RT5:3 & RT5 : 0.04 & RT $5: 2.3$ & \\
\hline & RT1: 6 & RT1: 0.08 & RT 1: 0.519 & \multirow{3}{*}{ FRT2 : 15.15} \\
\hline & RT3: 68 & RT3: 0.91 & "RT 3 : 16.582 & \\
\hline & RT5: 1 & RT5 : 0.01 & RT $5: 2.3$ & \\
\hline & RT1: 5 & RT1:0.06 & RT 1:0.519 & \multirow{3}{*}{ FRT3 : 15.24} \\
\hline & RT3 : 68 & RT3 : 0.91 & RT 3 : 16.582 & \\
\hline & RT5 : 2 & RT5: 0.03 & RT $5: 2.3$ & \\
\hline & RT1:3 & "RT1:0.04 & "RT 1: 0.519 & \multirow{3}{*}{ FRT4 : 15.22} \\
\hline & RT3: 68 & RT3: 0.91 & RT 3 : 16.582 & \\
\hline & RT5: 4 & RT5: 0.05 & RT $5: 2.3$ & \\
\hline & RT1: 2 & RT1:0.03 & "RT 1: 0.519 & \multirow{3}{*}{ FRT5 : 15.12} \\
\hline & RT3: 68 & RT3 : 0.91 & RT 3: 16.582 & \\
\hline & RT5 : 5 & RT5 : 0.06 & RT $5: 2.3$ & \\
\hline \multirow{15}{*}{$\mathrm{Kz}(\mathrm{mD})$} & RT1: 4 & RT1: 0.05 & RT $1: 0.052$ & \multirow{3}{*}{ FRT1 $: 1.518$} \\
\hline & RT3: 68 & RT3 :0.91 & RT 3:1.658 & \\
\hline & RT5:3 & RT5 : 0.04 & RT 5:0.23 & \\
\hline & RT1: 6 & RT1 : 0.08 & RT $1: 0.052$ & \multirow{3}{*}{ FRT2 $: 1.515$} \\
\hline & RT3: 68 & RT3 : 0.91 & RT 3:1.658 & \\
\hline & RT5 : 1 & RT5 : 0.01 & RT $5: 0.23$ & \\
\hline & RT1:5 & RT1:0.06 & RT $1: 0.052$ & \multirow{3}{*}{ FRT3 : 1.524} \\
\hline & RT3 : 68 & RT3 : 0.91 & RT 3: 1.658 & \\
\hline & RT5:2 & "RT5: 0.03 & RT 5:0.23 & \\
\hline & RT1: 3 & RT1:0.04 & RT $1: 0.052$ & \multirow{3}{*}{ FRT4 : 1.522} \\
\hline & RT3:68 & RT3:0.91 & RT 3: 1.658 & \\
\hline & RT5 : 4 & RT5: 0.05 & RT $5: 0.23$ & \\
\hline & RT1:2 & RT1: 0.03 & RT 1:0.052 & \multirow{3}{*}{ FRT5 : 1.512} \\
\hline & RT3: 68 & RT3: 0.91 & RT 3: 1.658 & \\
\hline & RT5: 5 & RT5 : 0.06 & RT 5: 0.23 & \\
\hline
\end{tabular}


Table 2 - 12. Porosity values before and after fuzzy upscaling (90\% of rock type 3 )

\begin{tabular}{|c|c|c|c|c|}
\hline Property & $\begin{array}{c}\text { Number of High Resolution } \\
\text { Grids }\end{array}$ & $\begin{array}{l}\text { Fuzzy Membership } \\
\text { Value }\end{array}$ & $\begin{array}{l}\text { Value before } \\
\text { upscaling }\end{array}$ & $\begin{array}{l}\text { Value after fuzzy } \\
\text { upscaling }\end{array}$ \\
\hline \multirow{15}{*}{ Porosity (\%) } & RT1:4 & RT1:0.05 & RT1: 5 & \multirow{3}{*}{ FRT1 $: 14.33$} \\
\hline & RT3:68 & $\begin{array}{l}\text { RT3 }: 0.91 \\
\end{array}$ & RT3 : 15 & \\
\hline & RT5:3 & RT5 : 0.04 & RT5 : 10 & \\
\hline & RT1: 6 & RT1 : 0.08 & RT1: 5 & \multirow{3}{*}{ FRT2 $: 14.4$} \\
\hline & RT3:68 & RT3: 0.91 & RT3: 15 & \\
\hline & RT5 : 1 & RT5 : 0.01 & RT5 : 10 & \\
\hline & RT1: 5 & RT1 :0.06 & RT1: 5 & \multirow{3}{*}{ FRT3 $: 14.2$} \\
\hline & RT3:68 & RT3 : 0.91 & RT3 : 15 & \\
\hline & RT5:2 & RT5 : 0.03 & RT5 : 10 & \\
\hline & RT1:3 & RT1 :0.04 & RT1:5 & \multirow{3}{*}{ FRT4 :14.27 } \\
\hline & RT3: 68 & RT3: 0.91 & RT3 : 15 & \\
\hline & RT5: 4 & RT5 : 0.05 & RT5 : 10 & \\
\hline & RT1:2 & RT1: 0.03 & RT1:5 & \multirow{3}{*}{ FRT5 :14.47 } \\
\hline & RT3 : 68 & RT3 : 0.91 & RT3 : 15 & \\
\hline & RT5: 5 & RT5 : 0.06 & RT5 : 10 & \\
\hline
\end{tabular}

\section{5 Relative Permeability, Capillary Pressure, Upscaling Effect (Scenario 5)}

The difference of this case with the previously discussed case is in the sample used for the rock types and the approach followed in calculating the fuzzy upscaled values.

\subsubsection{High Resolution Model}

The high-resolution model is created. As indicated in Figure 2 - 26 , all rock types have the same porosity and permeability values of $13 \%$ and $8.14 \mathrm{mD}$ respectively. The sample used is fallen where the rock types have overlapped. These rock types differ in dynamic reservoir properties. Several realizations of rock types distribution have been studied as explained in the preceding case.

\subsubsection{Conventionally Upscaled Model}

As explained in the last sections, the high-resolution model is used as a representation of the fine scale geological model, which should be upscaled in order to be run by the reservoir simulators. The upscaling was performed to the magnitude of 75. Given that conventional upscaling was used for upscaling, the properties of the dominant rock type (rock type 3 ) were dispensed to all the grid blocks. 


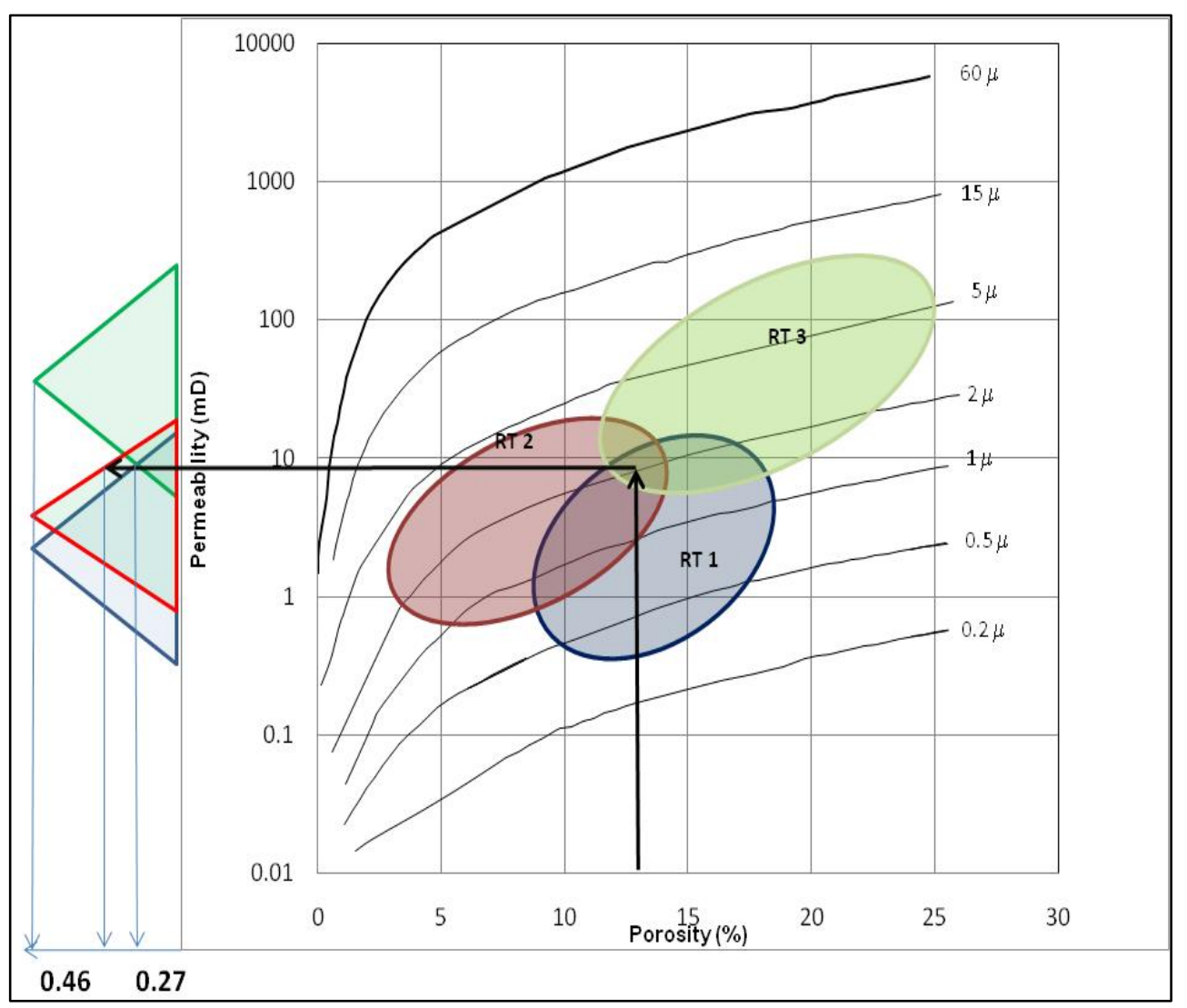

Figure 2 - 26. Winland Plot for Scenario 5

\subsubsection{Fuzzy Upscaled Model}

Apart from calculating the membership values based on the participation of each rock type in making fine scale model grids $\left(\mu_{\mathrm{v}}\right)$, another membership value has been computed using the fuzzy membership functions for permeability $\left(\mu_{\mathrm{k}}\right)$.

The triangular membership function used in this case can be expressed as:

$$
\begin{array}{rlrl}
\mu(\mathrm{x}) & =\mathrm{a}(\mathrm{b}-\mathrm{x}) /(\mathrm{b}-\mathrm{c}) ; & & \mathrm{b} \geq \mathrm{x} \leq \mathrm{c} \\
& =\mathrm{a}(\mathrm{d}-\mathrm{x}) /(\mathrm{d}-\mathrm{c}) ; & \mathrm{c} \geq \mathrm{x} \leq \mathrm{d} \\
& =0 &
\end{array}
$$

The membership value used at the end is the integration of effect of each rock type in making the high-resolution model and its influence in the Winland plot. These values for different cases have been presented in Table 2 - 13. Since the porosity and permeability values are the same for all rock types, only the dynamic reservoir properties (relative permeability and capillary pressure) will be fuzzy upscaled. 
Table 2 - 13. The membership values used for different cases

\begin{tabular}{|c|c|c|c|c|c|}
\hline & RT & $\boldsymbol{\mu}_{\mathrm{K}}$ & $\boldsymbol{\mu}_{\mathrm{V}}$ & New Membership Value & Normalized Membership Value \\
\hline \multirow{3}{*}{$90 \%$ of RT3 } & RT1 & 0.267 & 0.050 & 0.013 & 0.049 \\
\hline & RT2 & 0.456 & 0.040 & 0.018 & 0.066 \\
\hline & RT3 & 0.267 & 0.910 & 0.243 & 0.885 \\
\hline \multirow{3}{*}{$80 \%$ of RT3 } & RT1 & 0.267 & 0.160 & 0.043 & 0.156 \\
\hline & RT2 & 0.456 & 0.040 & 0.018 & 0.066 \\
\hline & RT3 & 0.267 & 0.800 & 0.214 & 0.778 \\
\hline \multirow{3}{*}{$70 \%$ of RT3 } & RT1 & 0.267 & 0.250 & 0.067 & 0.243 \\
\hline & RT2 & 0.267 & 0.710 & 0.190 & 0.690 \\
\hline & RT3 & 0.456 & 0.040 & 0.018 & 0.066 \\
\hline \multirow{3}{*}{$60 \%$ of RT3 } & RT1 & 0.267 & 0.360 & 0.096 & 0.350 \\
\hline & RT2 & 0.267 & 0.600 & 0.160 & 0.583 \\
\hline & RT3 & 0.267 & 0.600 & 0.160 & 0.583 \\
\hline \multirow{3}{*}{$50 \%$ of RT3 } & RT1 & 0.267 & 0.450 & 0.120 & 0.438 \\
\hline & RT2 & 0.267 & 0.510 & 0.136 & 0.496 \\
\hline & RT3 & 0.267 & 0.510 & 0.136 & 0.496 \\
\hline
\end{tabular}




\section{Chapter 3}

\section{Results and Discussion}

As explained before the sensitivity analysis was performed to find out about the effect of different parameters on the flow rate. Different scenarios were performed in this work. For detailed explanation about these scenarios please refer to Chapter 2.

Table 3 - 1. Comparison of different scenarios studied

\begin{tabular}{|c|c|c|c|c|c|c|c|c|c|c|c|}
\hline \multirow{2}{*}{ Scenario } & \multicolumn{3}{|c|}{$\begin{array}{l}\text { HR } \\
\text { Model }\end{array}$} & \multicolumn{2}{|c|}{$\begin{array}{l}\text { Difference Between } \\
\text { Rock Types }\end{array}$} & \multicolumn{3}{|c|}{ LR Model } & \multirow{2}{*}{$\begin{array}{l}\text { Membershi } \\
\text { p Value } \\
\text { Type }\end{array}$} & \multirow{2}{*}{$\begin{array}{l}\text { Number of } \\
\text { Fuzzy } \\
\text { Rock Types }\end{array}$} & \multirow{2}{*}{$\begin{array}{l}\text { Upscaling } \\
\text { Magnitude }\end{array}$} \\
\hline & $\begin{array}{l}\mathrm{n} \\
\mathrm{x}\end{array}$ & $\begin{array}{l}\mathrm{n} \\
\mathrm{y}\end{array}$ & $\begin{array}{l}\mathrm{n} \\
\mathrm{z}\end{array}$ & $\begin{array}{c}\text { Static } \\
\text { parameters }\end{array}$ & $\begin{array}{c}\text { Dynamic } \\
\text { parameters }\end{array}$ & $\begin{array}{l}\mathrm{n} \\
\mathrm{x}\end{array}$ & $\begin{array}{l}\mathrm{n} \\
\mathrm{y}\end{array}$ & $\begin{array}{l}\mathrm{n} \\
\mathrm{z}\end{array}$ & & & \\
\hline 1 & $\begin{array}{l}1 \\
5\end{array}$ & $\begin{array}{l}1 \\
5\end{array}$ & 9 & K & $\mathrm{Kr}-\mathrm{Pc}$ & 3 & 3 & 3 & $\mu \mathrm{V}$ & 1 & 75 \\
\hline 2 & $\begin{array}{l}4 \\
5 \\
\end{array}$ & $\begin{array}{l}4 \\
5 \\
\end{array}$ & 9 & $\mathrm{~K}$ & $\mathrm{Kr}-\mathrm{Pc}$ & 9 & 9 & 3 & $\mu_{\mathrm{V}}$ & 1 & 75 \\
\hline 3 & $\begin{array}{l}4 \\
5\end{array}$ & $\begin{array}{l}4 \\
5\end{array}$ & 9 & $\mathrm{~K}-\phi$ & $\mathrm{Kr}-\mathrm{Pc}$ & 9 & 9 & 3 & $\mu_{\mathrm{V}}$ & 1 & 75 \\
\hline 4 & $\begin{array}{l}4 \\
5\end{array}$ & $\begin{array}{l}4 \\
5\end{array}$ & 9 & $\mathrm{~K}-\phi$ & $\mathrm{Kr}-\mathrm{Pc}$ & 9 & 9 & 3 & $\mu_{\mathrm{V}}$ & 5 & 75 \\
\hline 5 & $\begin{array}{l}4 \\
5\end{array}$ & $\begin{array}{l}4 \\
5\end{array}$ & 9 & --- & $\mathrm{Kr}-\mathrm{Pc}$ & 9 & 9 & 3 & $\mu_{\mathrm{V}-} \mu_{\mathrm{K}}$ & 1 & 75 \\
\hline
\end{tabular}




\subsection{Sensitivity Analysis}

Following figure shows the relative permeability curves used for carrying out the sensitivity analysis.

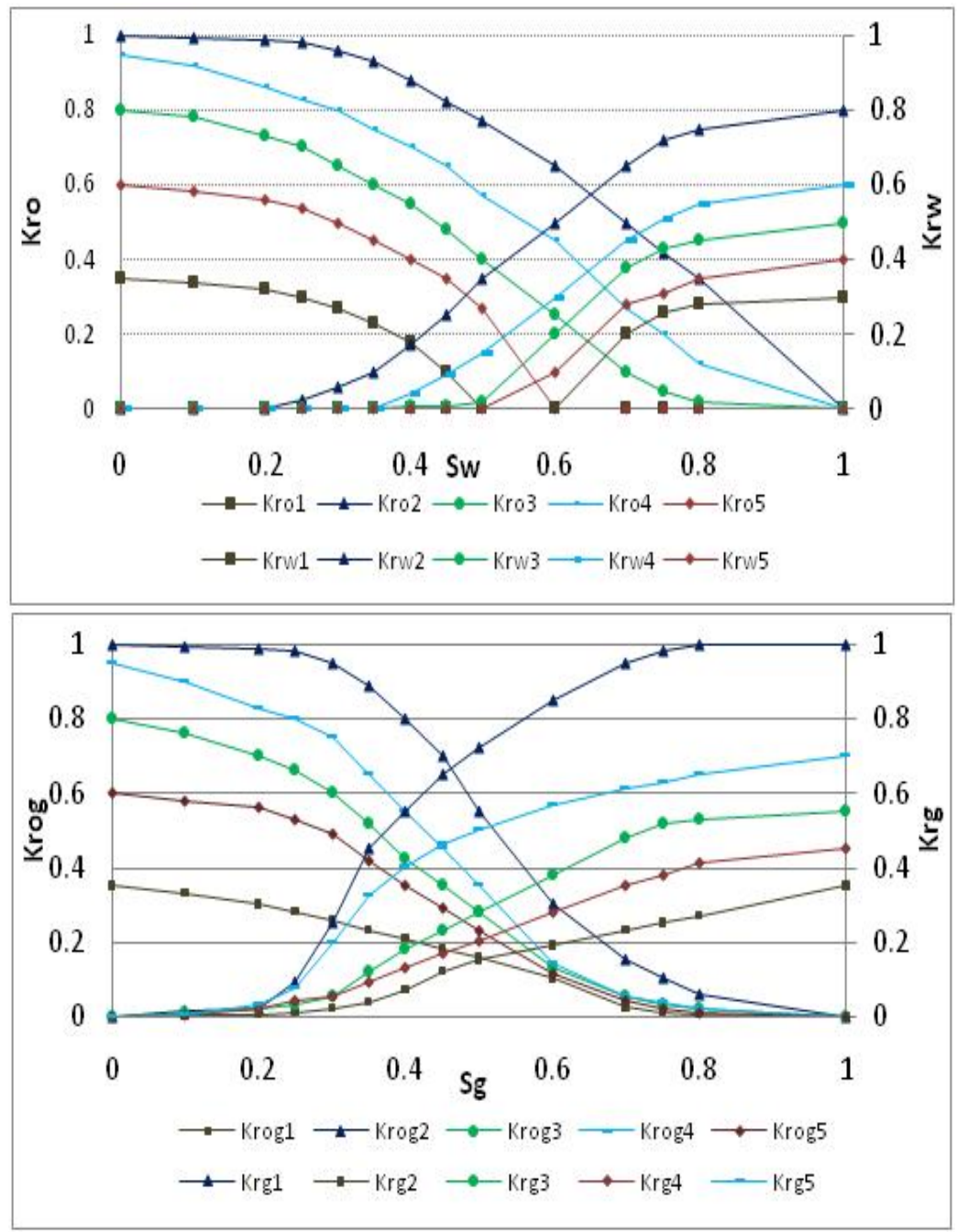

Figure 3 - 1.Relative Permeability curves used for sensitivity analysis

\subsubsection{Sensitivity Analysis on Permeability}

Five models were built all having the same properties as rock type 1 . The only parameter, which is dissimilar in the models, is permeability. The permeability values assigned to the models are, $1.78 \mathrm{mD}, 5 \mathrm{mD}, 7.84 \mathrm{mD}, 46.77 \mathrm{mD}$ and $150 \mathrm{mD}$. 
In the next scenario, the models were modified. Rock type 2 characteristics were consigned to the models. Again, the same permeability values as in the preceding case were used in these five models.

Sensitivity analysis is performed, with the purpose of scrutinizing the influence of permeability on the outcome.

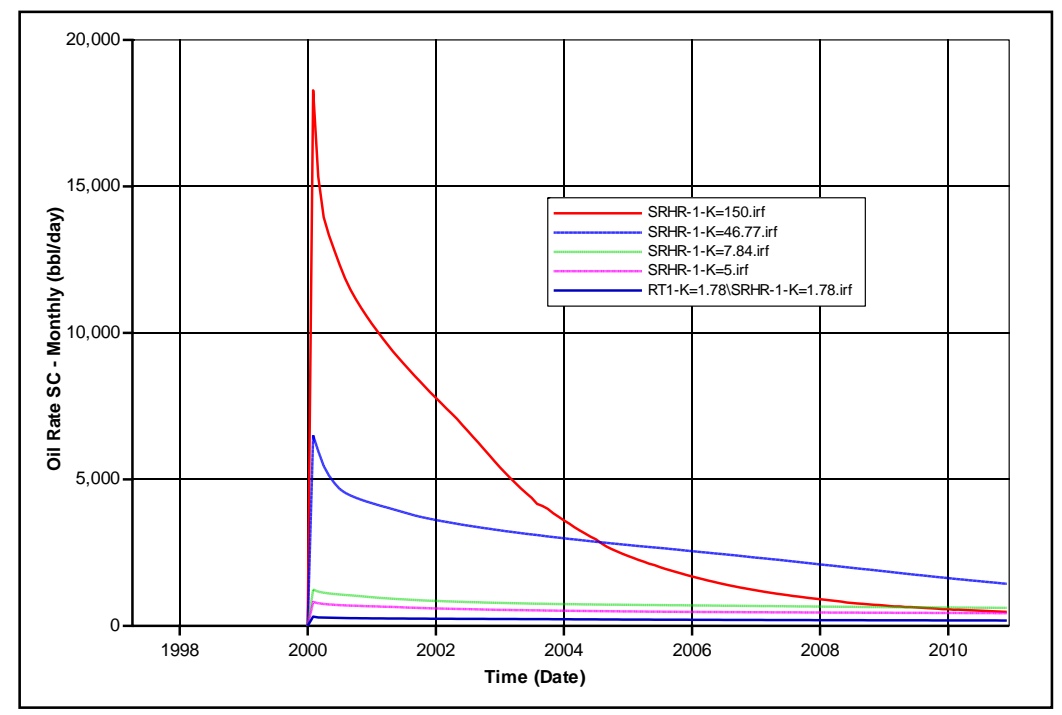

Figure 3 - 2. Sensitivity analysis on permeability-RT1 Properties/Monthly oil production

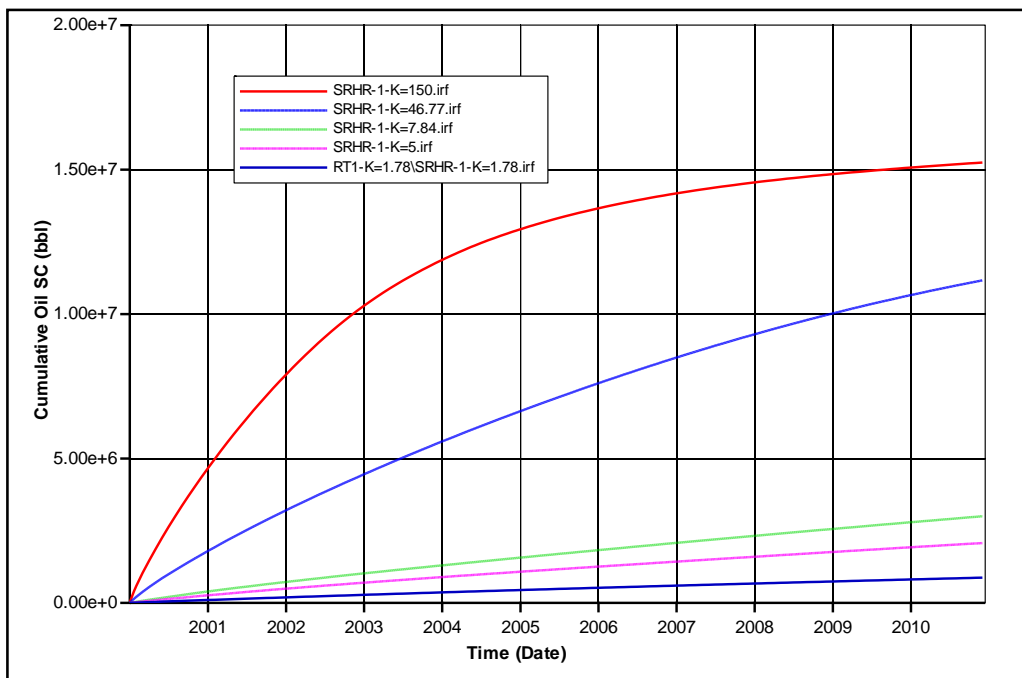

Figure 3 - 3. Sensitivity analysis on permeability-RT1 Properties/Cumulative oil production 


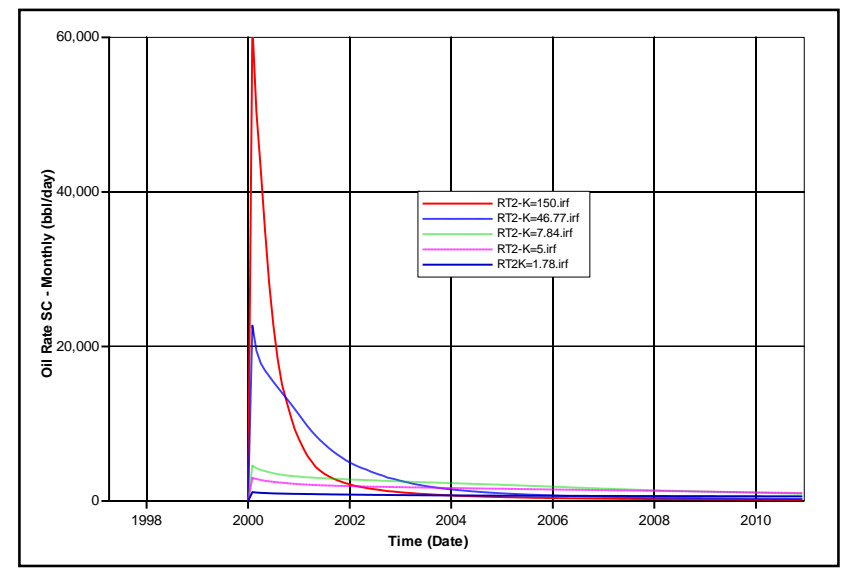

Figure 3 - 4. Sensitivity analysis on permeability-RT2 Properties/Monthly oil production

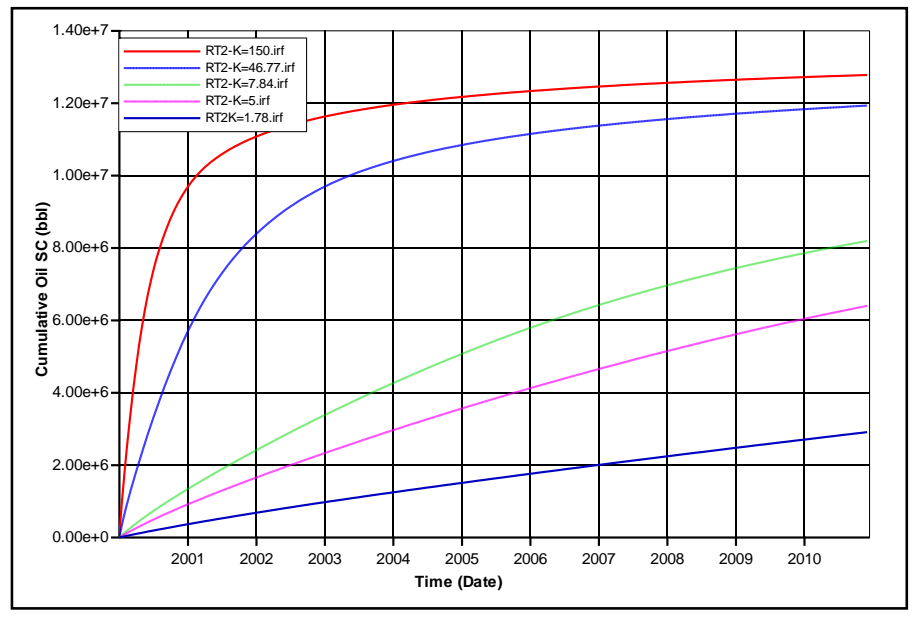

Figure 3 - 5. Sensitivity analysis on permeability-RT2 Properties/Cumulative oil production

Sensitivity analysis is performed, with the purpose of scrutinizing the influence of permeability on the outcome. The results are illustrated in the following figures.As it can be observed in the above graphs, as permeability increases the oil production ascends. This is true in both cases, having two different rock type properties. Although sharp increase in permeability causes significant jump in oil production at beginning, but it can lead to depletion and low production after a while.

\subsubsection{Sensitivity Analysis on Relative Permeability ( $K_{r o w}, K_{r w}, K_{r g}$, $\mathrm{Kr}_{\mathbf{o g}}$ )}

To analyze the effect of relative permeability different cases have been studied.

\subsubsection{Sensitivity Analysis on Krow}

All the properties of rock type 1 were assigned to three models. The only difference between these models is $\mathrm{K}_{\text {row }}$ data. These values are taken from rock type 1,2 and 5.The results are shown in the following figure. 
It can be clearly seen that there is direct relationship between oil-water relative permeability and oil production.

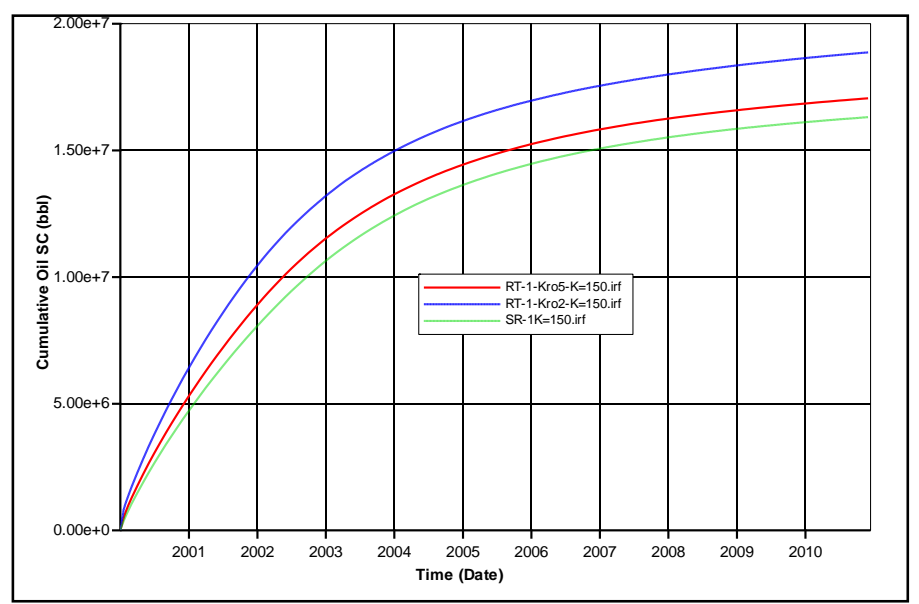

Figure $3-6$. Sensitivity analysis on Krow- Cumulative oil production

\subsubsection{Sensitivity Analysis on $K_{r w}$}

All the properties of rock type 1 were assigned to three models. The only difference between these models is $\mathrm{K}_{\mathrm{rw}}$ data. These values are taken from rock type 1,2 and 5.The results are presented in the next graphs.

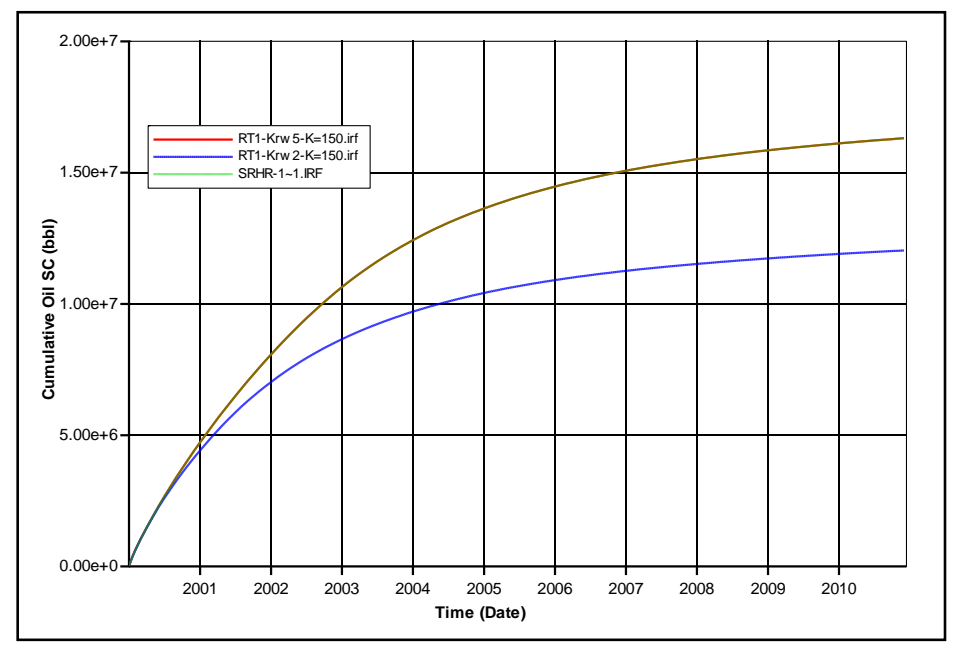

Figure 3 - 7. Sensitivity analysis on Krw- Cumulative oil production

According to this graph increase in water relative permeability is the occasion of decrease in oil production. So they are reversely related to each other.

\subsubsection{Sensitivity Analysis on $K_{r g}$}

The rock type was kept as RT 1 , and only the $\mathrm{K}_{\mathrm{rg}}$ data was changed in 3 cases. (Value of $\mathrm{K}_{\mathrm{rg}}$ from RT 1,2 and 5 were utilized). The consequence of this study is shown below. 


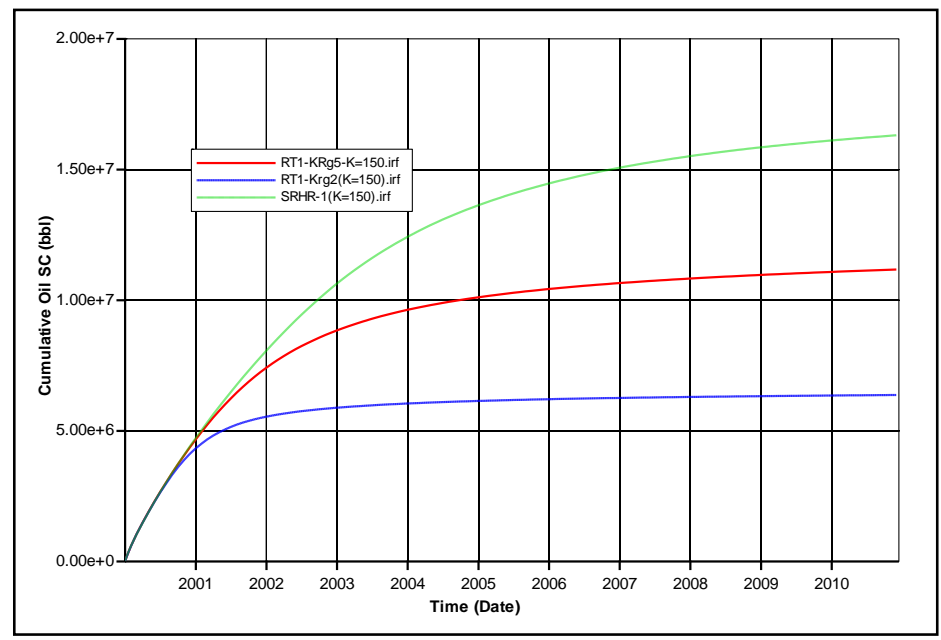

Figure $3-8$. Sensitivity analysis on Krg- Cumulative oil production

According to the above graphic representation, gas relative permeability and oil production are reversely related to each other. Boost in gas relative permeability data causes reduction in oil production.

\subsubsection{Sensitivity Analysis on $K_{\text {rog }}$}

In this case, the same as the last analyses, rock type 1 properties have been assigned to three models. These models are different only in $\mathrm{K}_{\text {rog }}$ values, which are taken from rock types 1,2 , and 5 . Succeeding figure demonstrates the result of sensitivity analysis on oil-gas relative permeability. Base on this result, oil-gas relative permeability is directly related to oil production rate. Hence, an increase in $\mathrm{K}_{\mathrm{rog}}$ caused a raise in oil production.

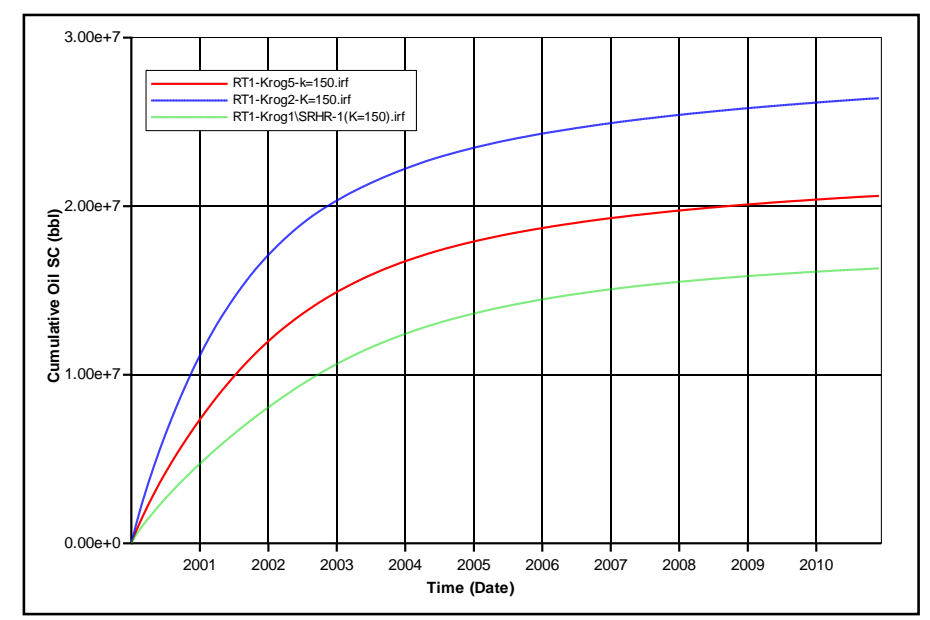

Figure 3 - 9. Sensitivity analysis on Krog- Cumulative oil production 


\subsubsection{Sensitivity Analysis on Capillary Pressure $\left(\mathbf{P}_{\text {cog }}, \mathbf{P}_{\text {cow }}\right)$}

\subsubsection{Sensitivity Analysis on $P_{\text {cog }}$}

Following the procedure for the last cases, three models were built. All the properties are the same in these models but the oil-gas capillary pressure data. Pcog values of rock types 1, 2 and 5 have been used. In accordance with the graph shown below oil-gas capillary pressure and oil production are directly related to each other.

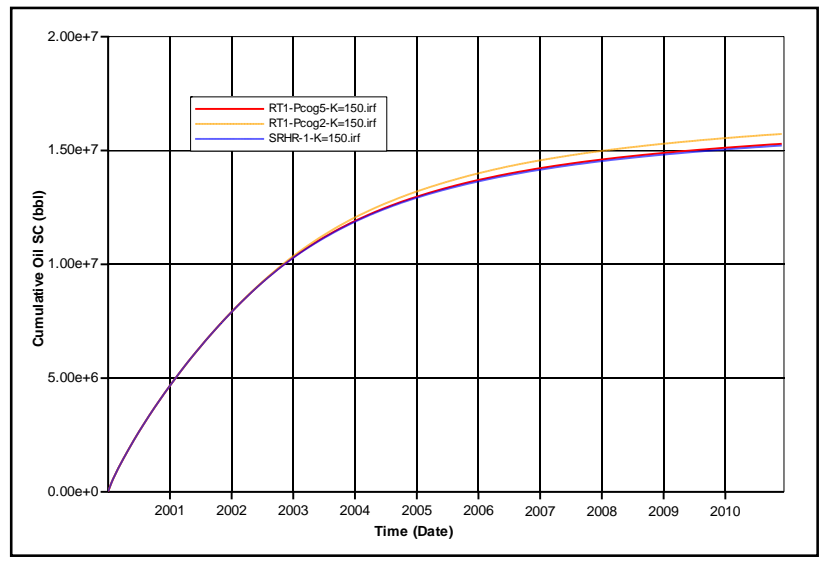

Figure 3 - 10. Sensitivity analysis on Pcog- Cumulative oil production

\subsubsection{Sensitivity Analysis on $\mathbf{P}_{\text {cow }}$}

The sensitivity analysis to investigate about the effect oil-water capillary pressure was performed as well. The same procedure used in previous cases was used here. The result of this analysis is shown in the subsequent figure. In this specific case, the change in oil-water capillary pressure data does not have a significant effect on oil production.

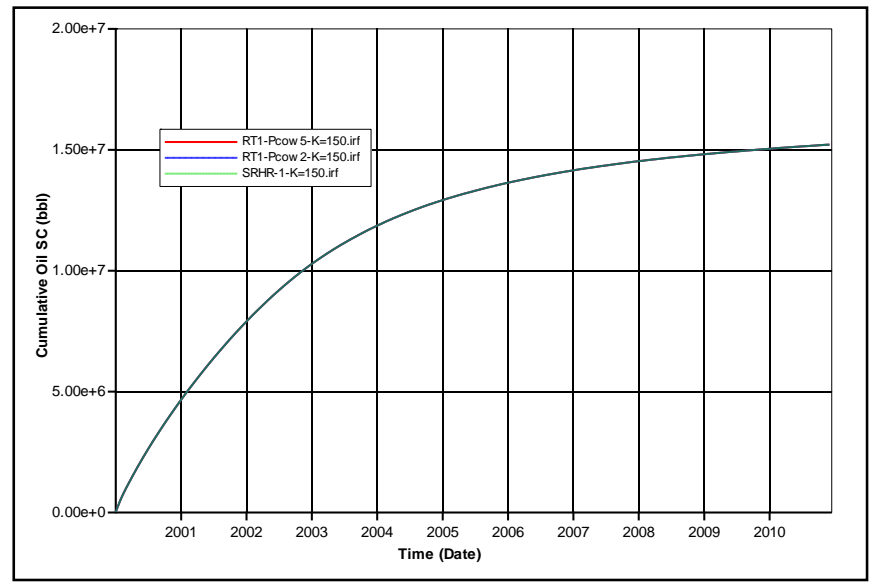

Figure 3 - 11. Sensitivity analysis on Pcow- Cumulative oil production 


\subsection{Scenario 1}

\subsubsection{High resolution Models}

The built high-resolution models were run. The results are shown in the following figures.

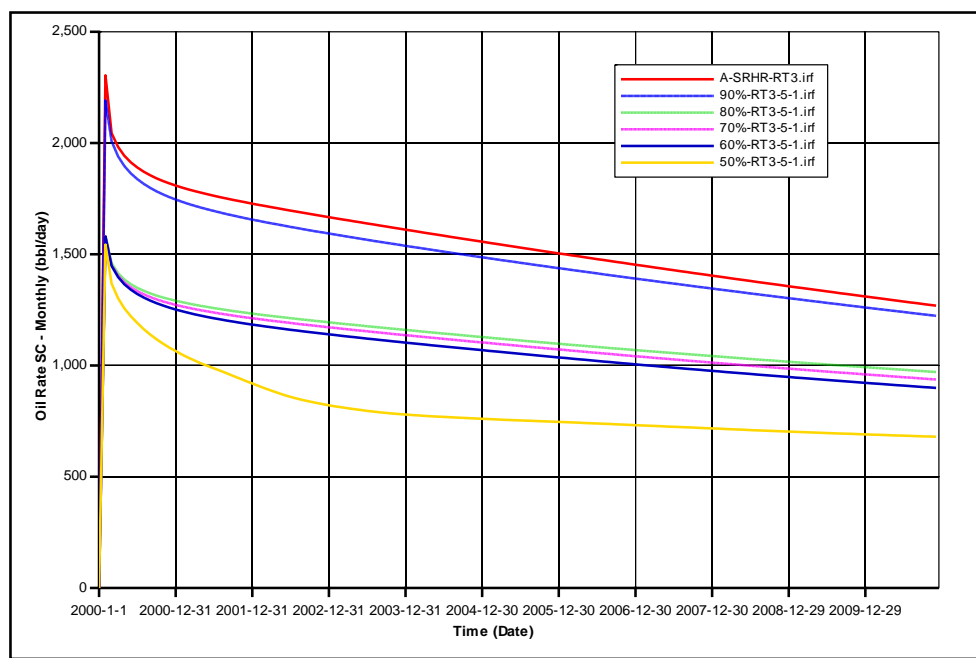

Figure 3 - 12. Monthly oil rate comparison

Figure 3 - 12 compares the monthly oil rate for the cases under study. According to the sensitivity analysis performed, rock type 3 has the most contribution in the flow, rock types 5 and 1 come after in sequence. Hence, the more percentage of rock type 3 is, the higher the oil production will be. This is attested in the above figure.

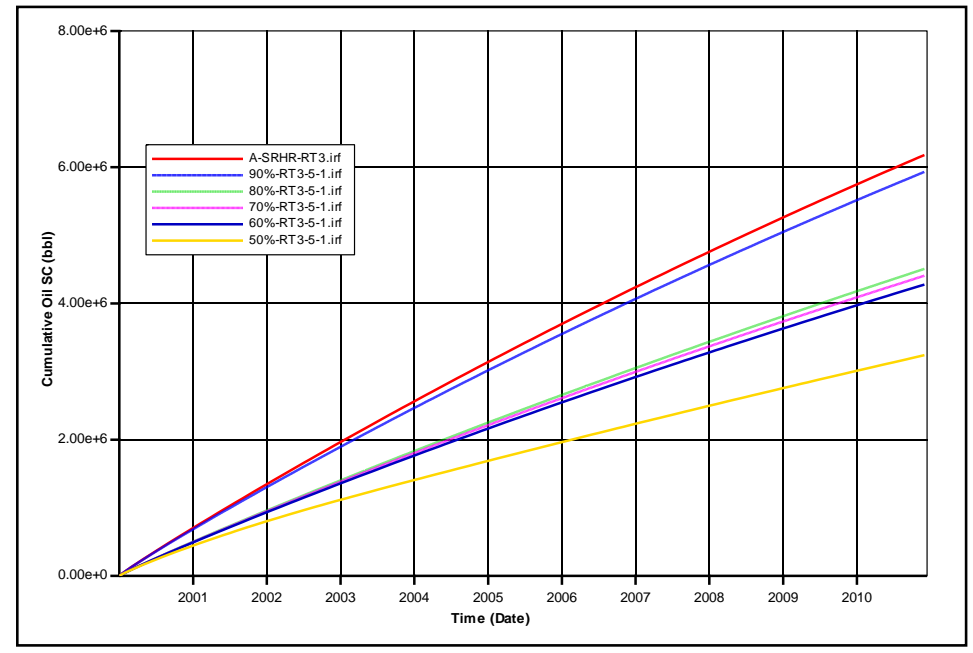

Figure 3 - 13. Cumulative oil production comparison 
The same assessment has been performed for gas production and the results clearly prove that reduction in number of grids belonging to the rock type 3 is the occasion of decrease in amount of produced gas.

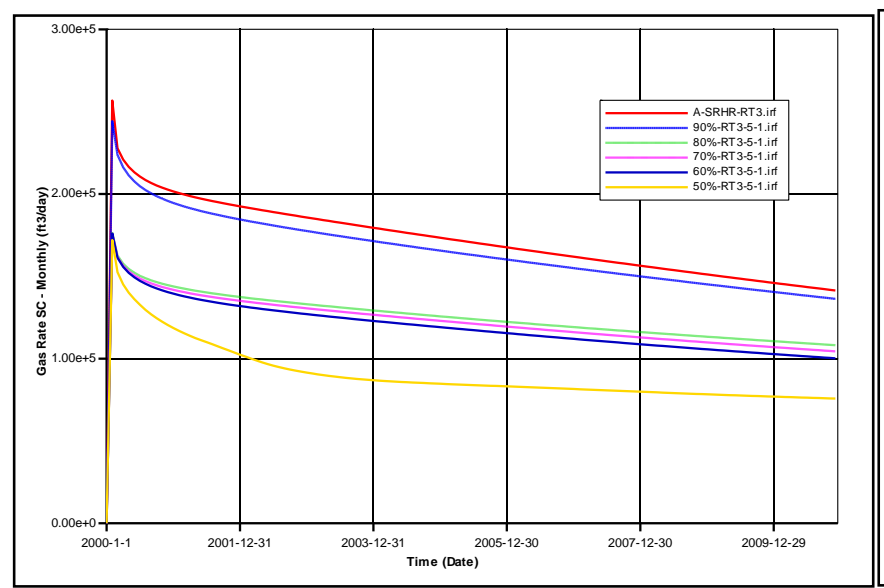

Figure 3 - 14. .Monthly gas rate comparison

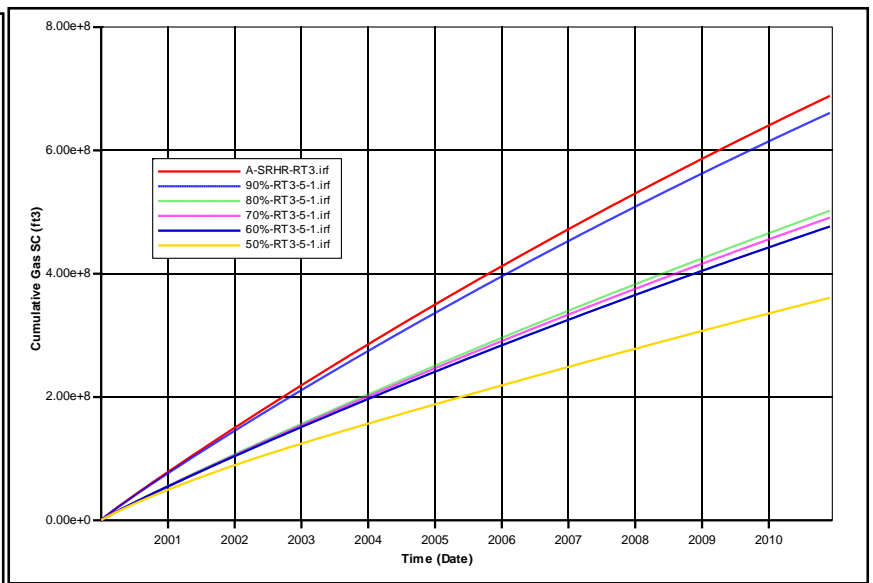

Figure 3 - 15. Cumulative gas production comparison

Following figure shows, reservoir pressure never goes under the bubble point pressure (500 psi) in any of the cases during ten years of production.

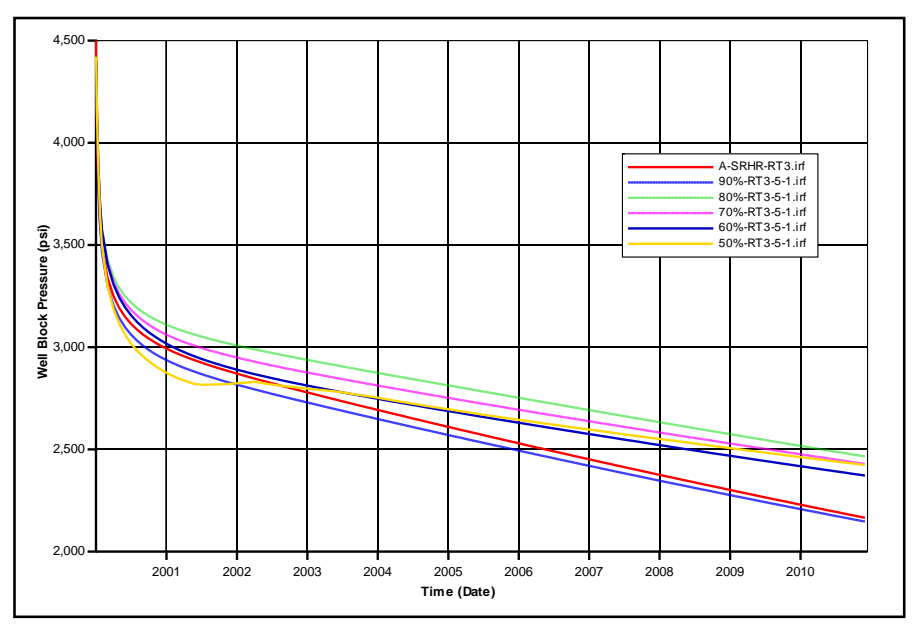

Figure 3 - 16. Well block pressure during 10 years of production

\subsubsection{Low resolution Models}

The models have been upscaled, utilizing two different approaches:

1) Conventional upscaling

2) Fuzzy upscaling 
Oil and gas production and reservoir pressure during ten years have been compared for each method in order to find out the closer results to the high resolution model outcome. The results are shown below.

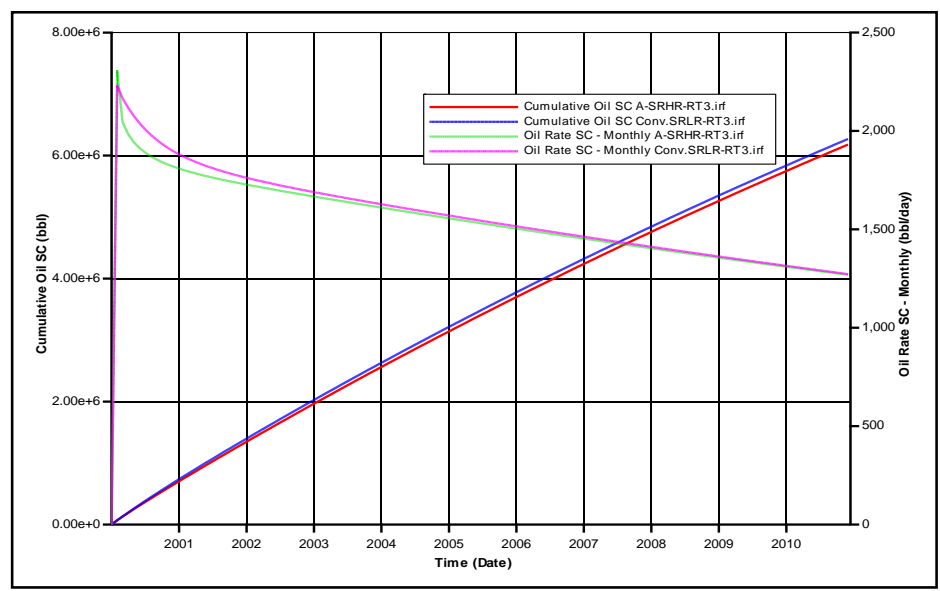

Figure 3 - 17. SRHR and SRLR Models - Oil Production

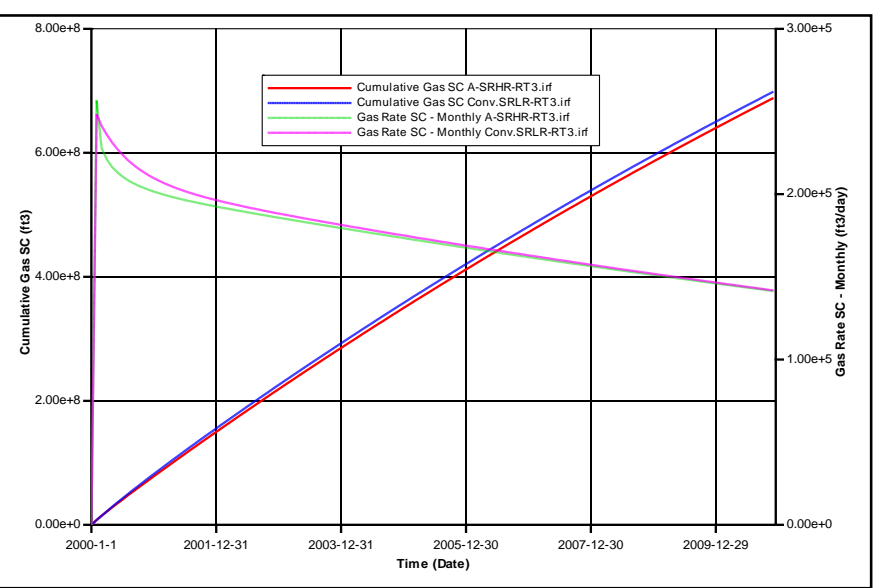

Figure 3 - 18. SRHR and SRLR Models - Gas Production

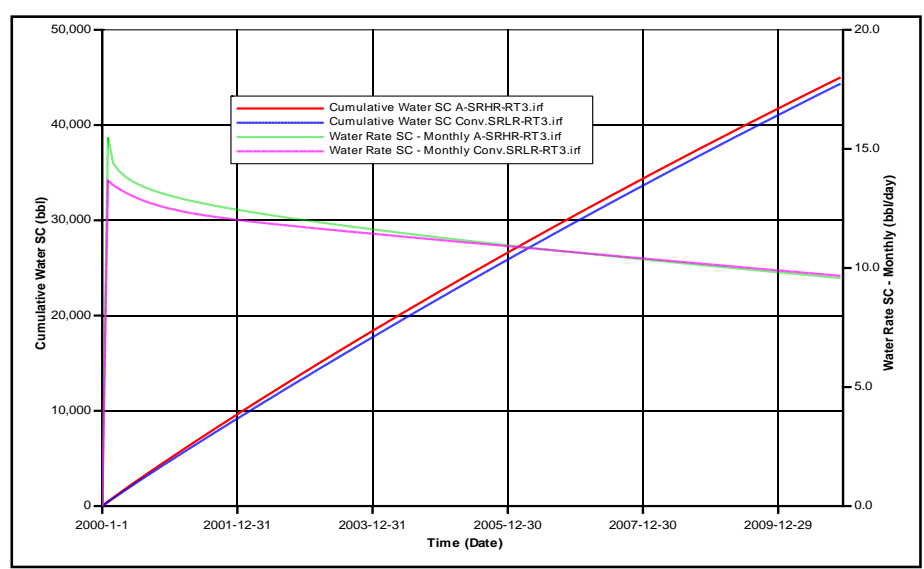

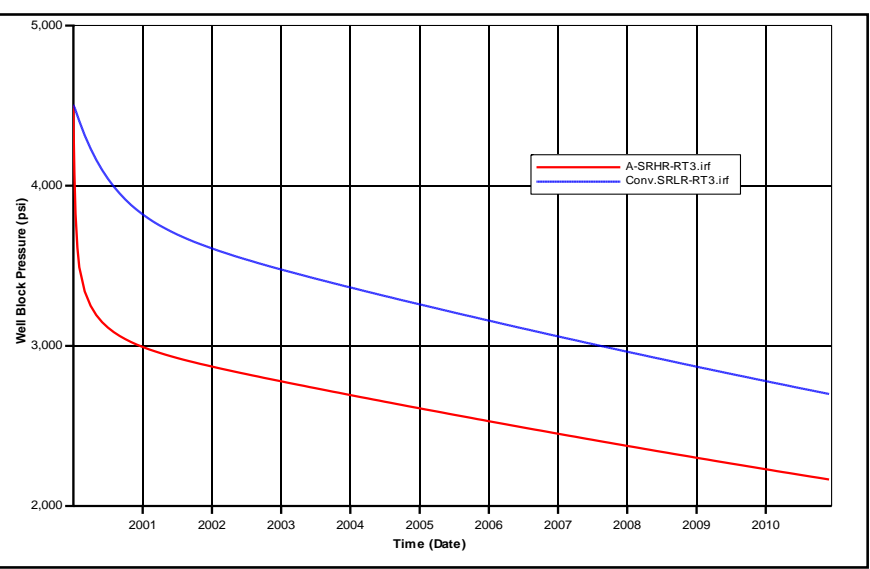

Figure 3 - 19. SRHR and SRLR Models - Water Production Figure 3 - 20. SRHR and SRLR Models - Well Block Pressure

Figure 3 - 17 through Figure 3 - 19, show that resolution change in upscaling process makes a slight different in results even though none of the properties has varied. Following graphs compare the oil and gas production for the high resolution and low-resolution models in the model having $90 \%$ of the dominant rock type. As demonstrated in these plots Fuzzy Upscaled Model result is closer to the high-resolution model compared to the conventional upscaled one. 


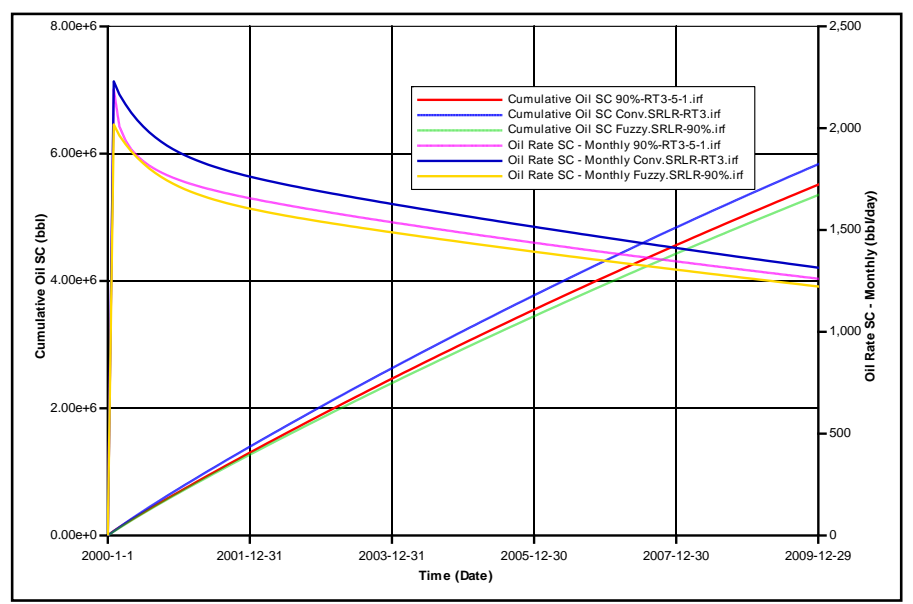

Figure 3 - 21. 3RHR-90\% and SRLR-90\% - Oil Production

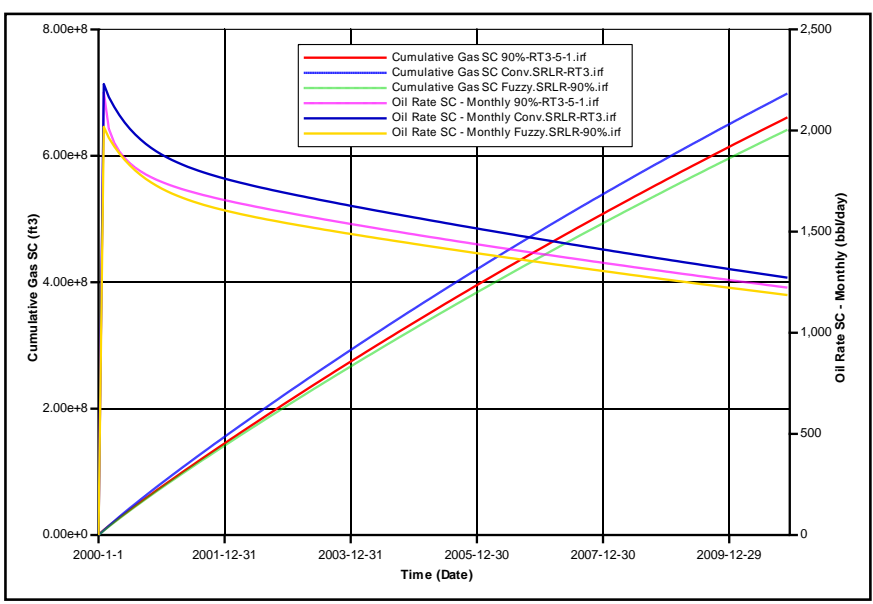

Figure 3 - 22. 3RHR-90\% and SRLR-90\% - Gas Production

The same analysis has been carried out for the models having $80 \%, 70 \%, 60 \%$ and $50 \%$ of the dominant rock type (Rock type 3). The oil production results are shown in Appendix E. These results justify that fuzzy upscaling brings about closer result to the high-resolution model. Thus, the geological and petrophysical data are honored.

The errors caused by upscaling using two explained approaches are compared in Figure 3 - 23.

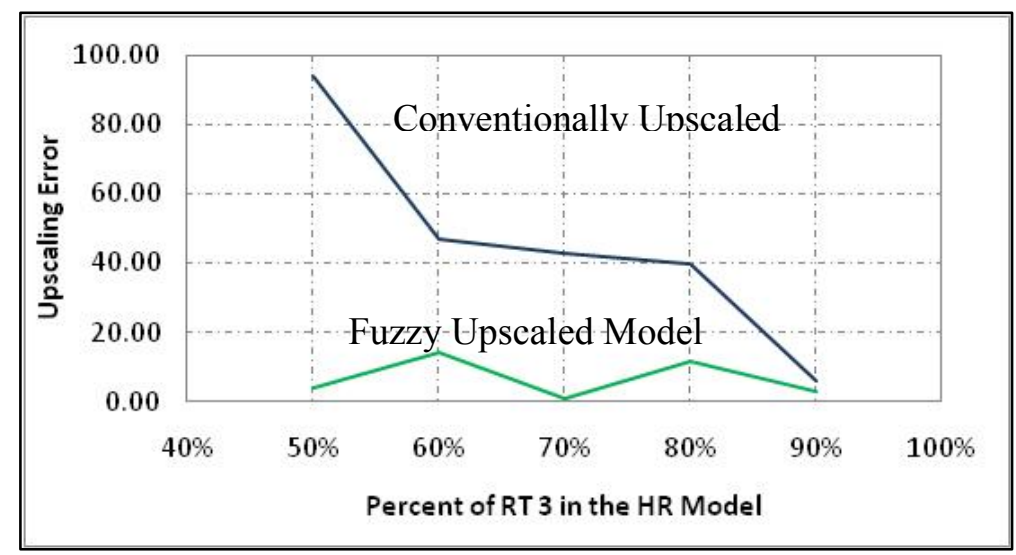

Figure 3 - 23.Upscaling Error Caused by Two Methods for Scenario1 at Tenth Year of Oil Production

It can be observed that the error in conventional upscaled model goes up as the contribution of the dominant rock type in the high-resolution model reduces. This is originated from the fact that the properties of the dominant rock type have been dispensed through all coarsened blocks in the conventional upscaling approach.

The error in fuzzy upscaled model decreases to almost $1 \%$ in the case having $70 \%$ of rock type 3 . This number increases for $60 \%$ and again diminishes after that, which can be explained as a function 
of the rock type allocation in the high-resolution model and direct contact of them with wellbore. Nevertheless, in all cases the percent of error caused by fuzzy upscaled model is astonishingly less than the error generated by conventional upscaling technique.

\subsection{Scenario 2}

\subsubsection{High resolution Models}

The high-resolution models were built having different rock type distribution. Each rock type was associated with different dynamic and static reservoir properties. The models were run. The results are shown in this section.

The cumulative oil production rates are compared in Figure 3 - 24. As it can be observed, decrease in the number of grids associated with rock type 3, causes reduction in oil production. . Referring to the role of each rock type in hydrocarbon production, this behavior can be easily explained.

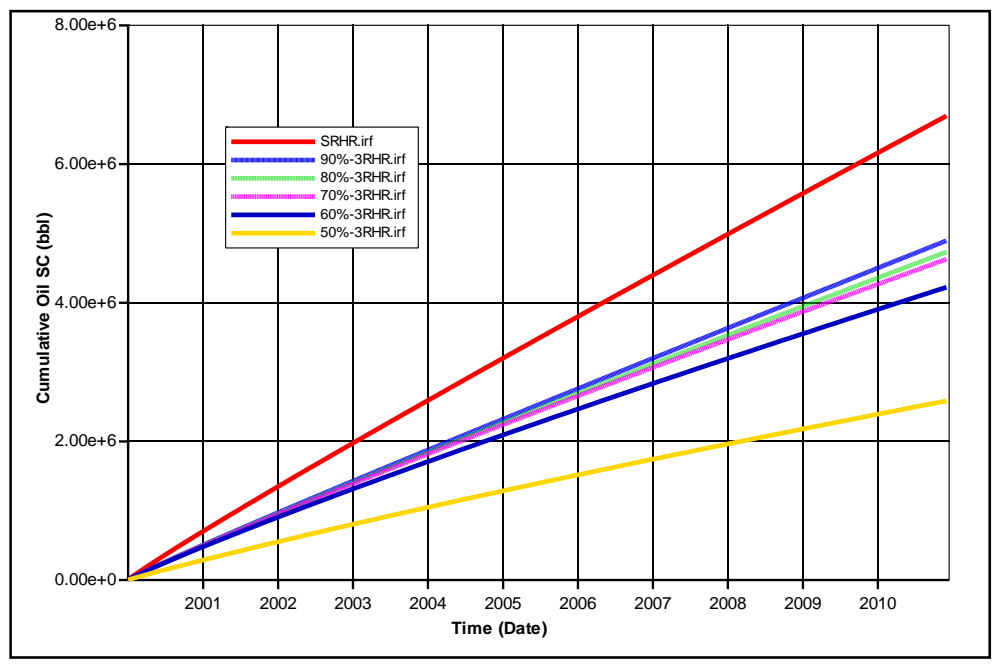

Figure 3 - 24. Cumulative oil production comparison

\subsubsection{Low resolution Models}

Two approaches have been used for upscaling.

1) Conventional upscaling

2) Fuzzy upscaling

The results are compared together in order to find the best methodology to get a closer result to the high-resolution model. 
A percent of the error caused by upscaling is due to resolution change. This statement points out that even though none of the reservoir properties might change, the upscaled result will not be unerringly the same as the high-resolution model. This is justified by comparing the single rock type-high resolution and low-resolution model results in Figure 3 - 25.

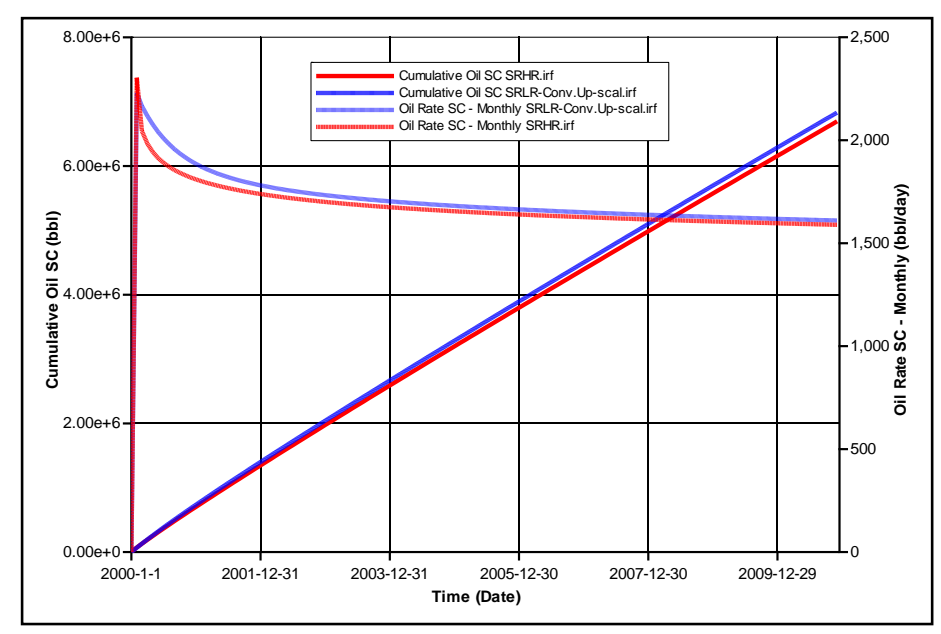

Figure 3 - 25. SRHR and SRLR Models comparison- Oil Production

Following figure demonstrates the effect of upscaling on the result of model having $90 \%$, of the dominant rock type (Rock type 3). The outcomes of the other cases are shown in Appendix E.

Two outstanding principles can be clearly drawn out of these results. Foremost, the fuzzy upscaled model outcomes are largely closer to high-resolution model in comparison to the conventional upscaled one. Furthermore, this difference is more outstanding as the number of grids belonging to the dominant rock type diminishes, and other rock types 'role gets more stunning.

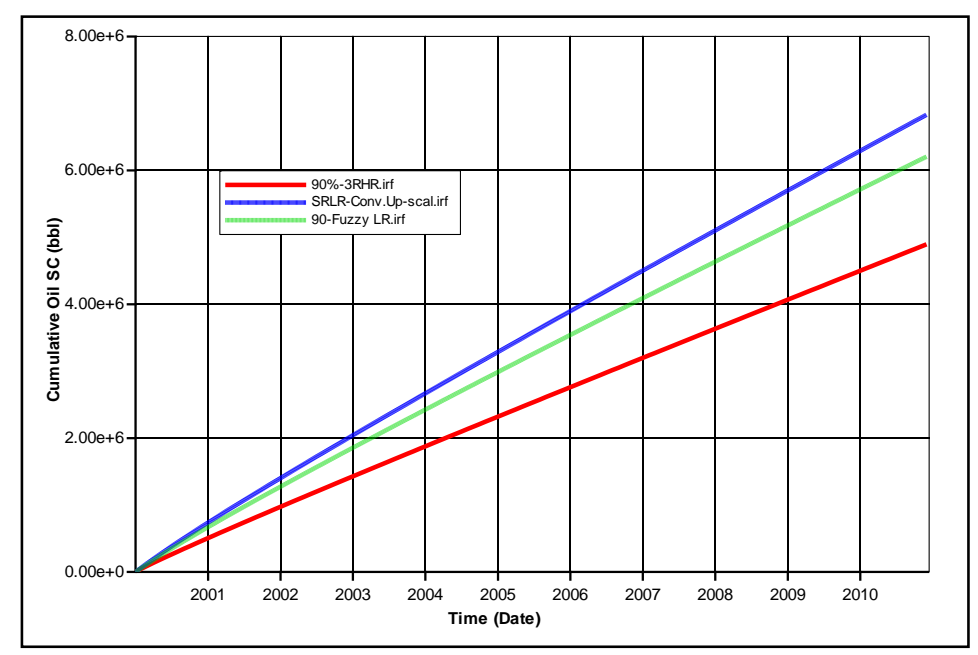

Figure 3 - 26. 3RHR-90\% and SRLR-90\% Models comparison- Oil Production 
The errors caused by upscaling using two explained approaches are compared in Figure 3 - 27.

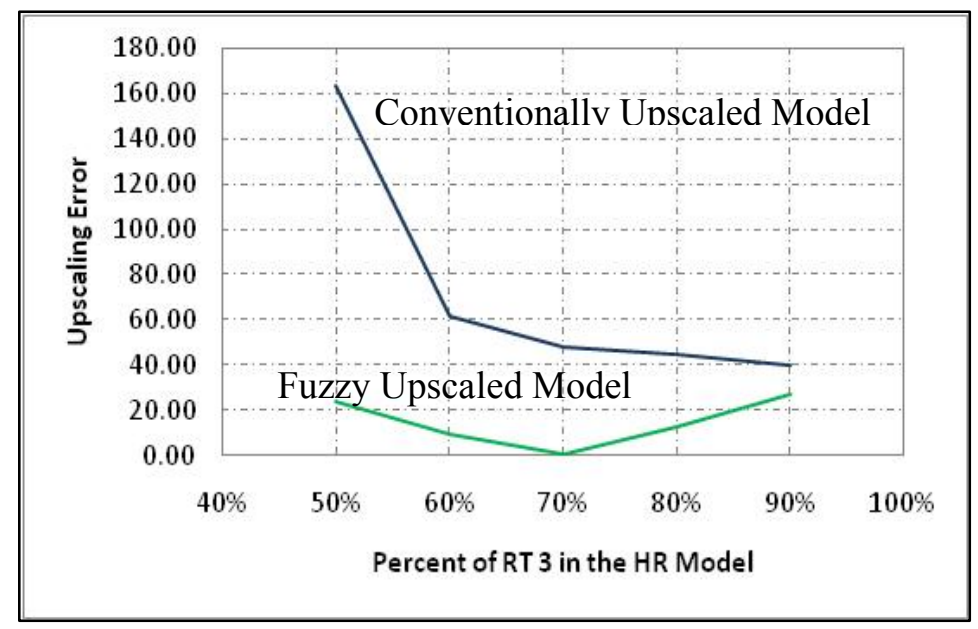

Figure 3 - 27.Upscaling Error Caused by Two Methods for Scenario2 at Tenth Year of Oil Production According to this graph, the error caused by conventional upscaling method goes up because of decrease in the grid blocks belonging to the dominant rock type. This error is always more than the error caused by fuzzy upscaling technique. The geometry and distribution of rock types has an influence on the results obtained by fuzzy rock typing. In this case, for instance, when the number of layers containing rock type one increase, or the number of grid blocks enclosing the wellbore varies, its influence can be seen clearly. This is demonstrated for cases having $60 \%$ and $50 \%$ of the dominant rock type.

\subsection{Scenario 3}

\subsubsection{High resolution Models}

The results of running high-resolution models are shown in the following figure and Appendix E. Rock type three has the highest contribution in oil production in the reservoir; thereby decrease in the number of grids belonging to it results in oil production attenuation. 


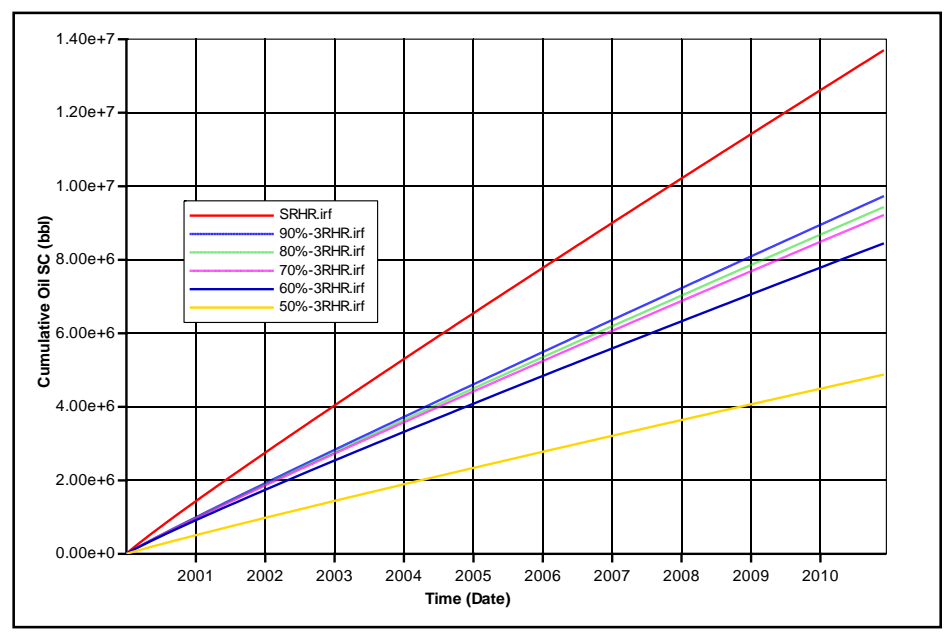

Figure 3 - 28. Cumulative oil production comparison

\subsubsection{Low resolution Models}

The outcomes of two different upscaling approaches have been compared together, to find the closest model to the high-resolution one. Not only change in number of grids related to each rock type varies the result but also the resolution change itself has a slender influence on the final low-resolution model upshot.

Figure 3 - 29 show the aforementioned effect of resolution change.

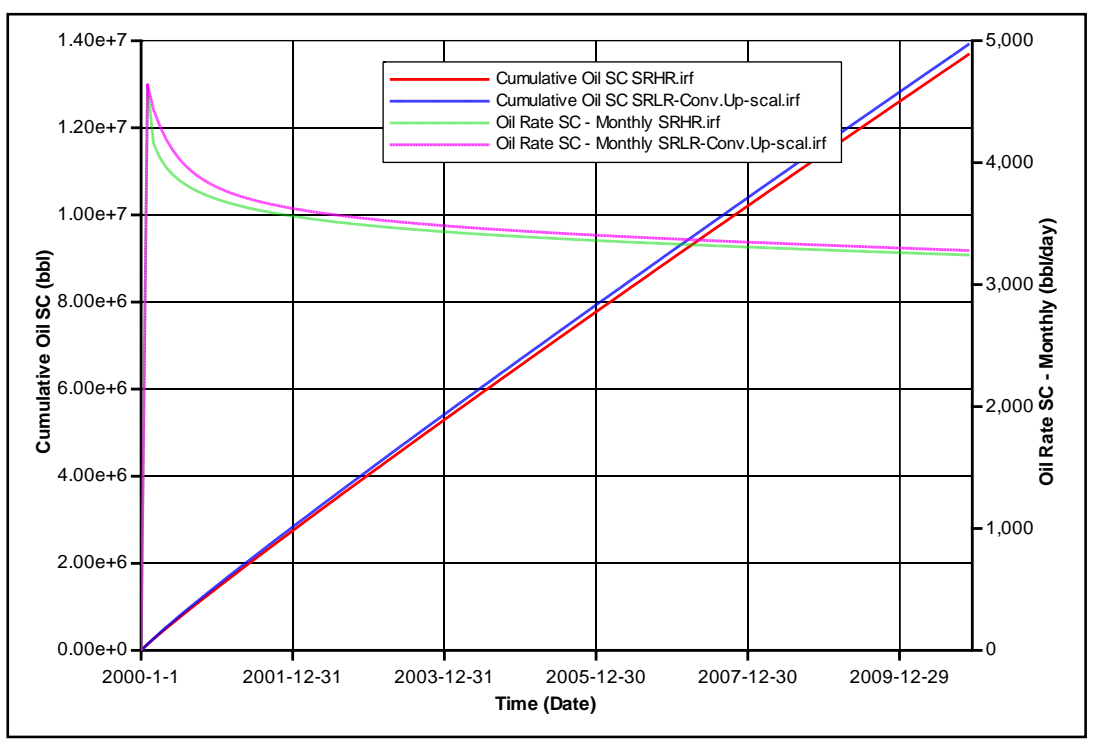

Figure 3 - 29. SRHR and SRLR Models comparison- Oil Production 
Subsequent figure display the effect of upscaling using both approaches, on the results of model having $90 \%$ of the dominant rock type (Rock type 3). For more details about the other cases' results, please refer to Appendix E.

The same observation made in the previous sections can be clearly viewed in these graphic representations. The fuzzy upscaled model results are noticeably closer to the high resolution model particularly when the proportion of involvement of different rock types is not significantly different.

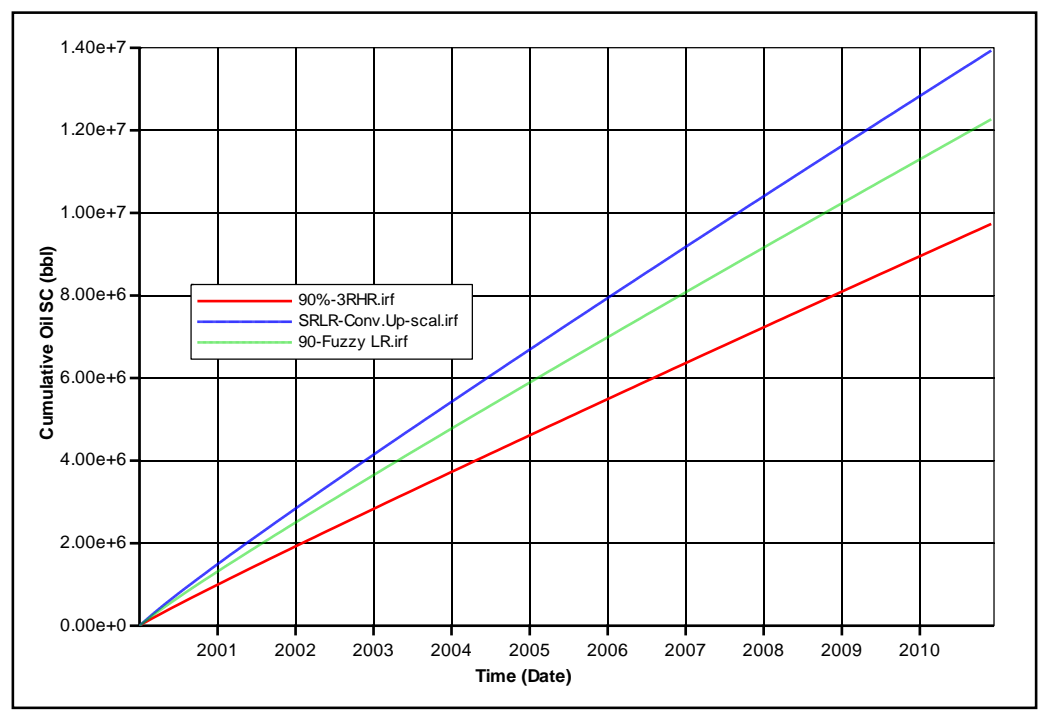

Figure 3 - 30. 3RHR-90\% and SRLR-90\% Models comparison- Oil Production

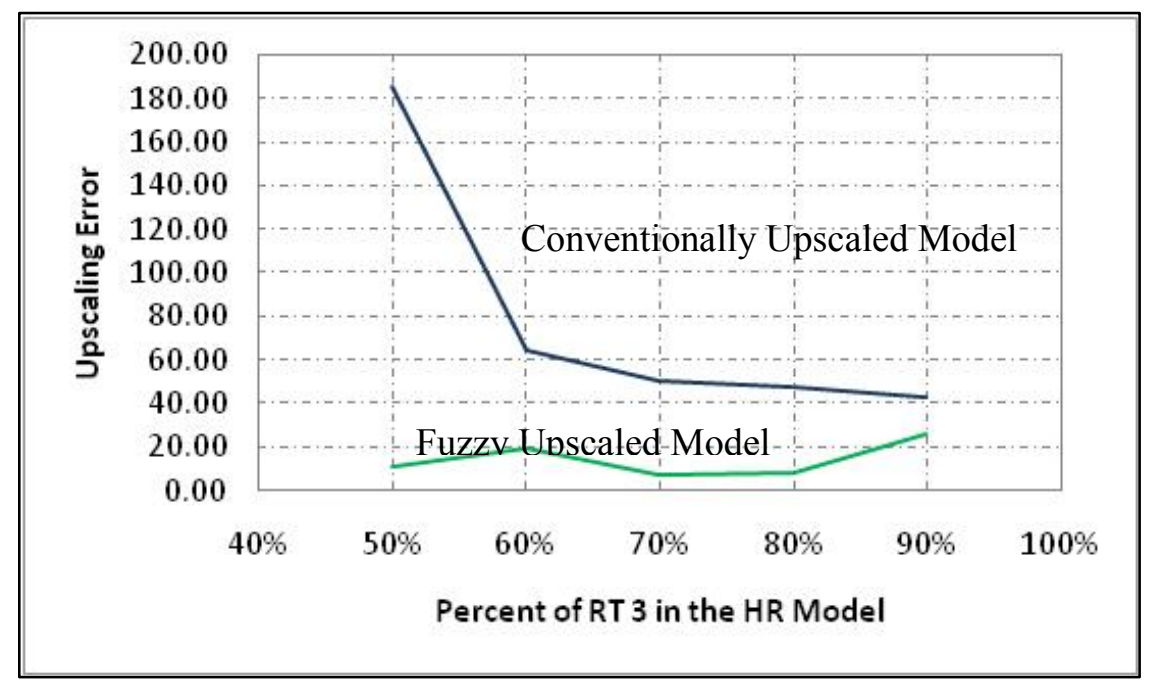

Figure 3 - 31.Upscaling Error Caused by Two Methods for Scenario3 at Tenth Year of Oil Production The preceding figure compared the error caused by coarsening using two different upscaling techniques used in this work. As it is shown, the error in the conventional upscaling has an ascending 
trend as the number of grid blocks belonging to rock type three decreases. The error causes by fuzzy upscaling is significantly less than the previously mentioned method. This error has a jump in $60 \%$ due to the geometry change. Because at this case the number of layers containing rock type one doubles and this has a direct effect on the upscaling results.

\subsection{Scenario 4}

\subsubsection{High resolution Models}

Succeeding figure show the results of running the high resolution models. Decrease in the number of grids affiliated with rock type three, which is the most influent on hydrocarbon flow, is the occasion of oil production reduction.

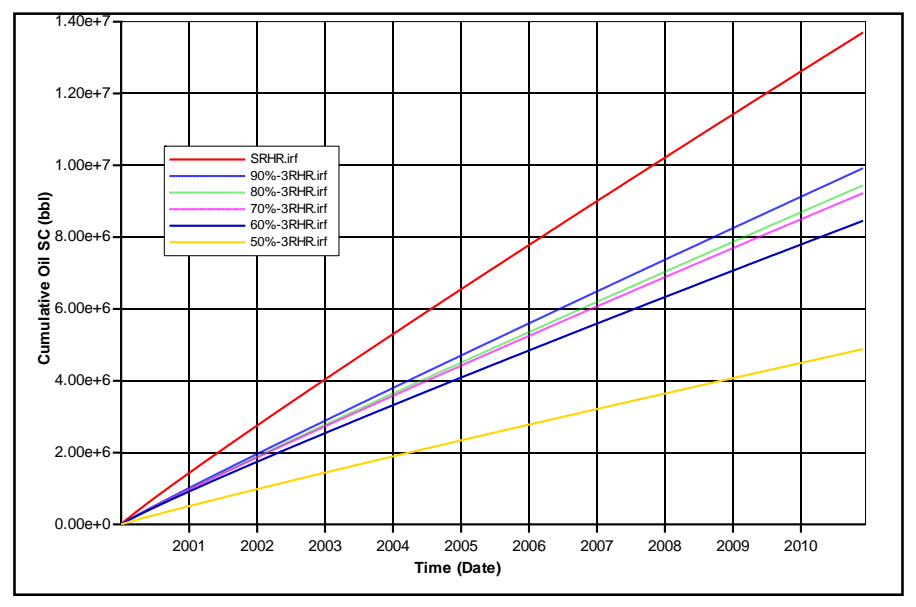

Figure 3 - 32. Cumulative oil production comparison

\subsubsection{Low resolution Models}

The results of the upscaled models are weighed against each other with the intention of finding the best technique to get a closer result to the high-resolution model. Not only change in number of grids associated with each rock type combining to construct the low-resolution block affects the lowresolution outcome, but also the resolution change itself has a slight influence on the final lowresolution model upshot. 


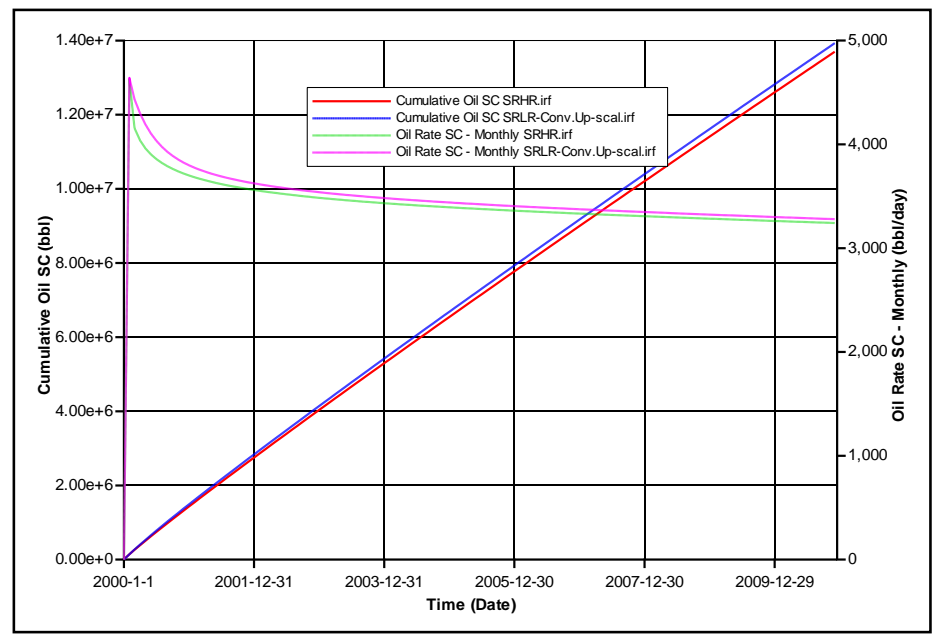

Figure 3 - 33. SRHR and SRLR Models comparison- Oil Production

Subsequent figure display the effect of upscaling using both approaches, on the results of model having 90\%, of the dominant rock type (Rock type 3). More details are shown in Appendix E.

The same surveillance made in the preceding sections can be plainly viewed in the following graphs. The fuzzy upscaled model results are by far closer to the high resolution model specifically when the fraction of different rock types is not to a large extent different.

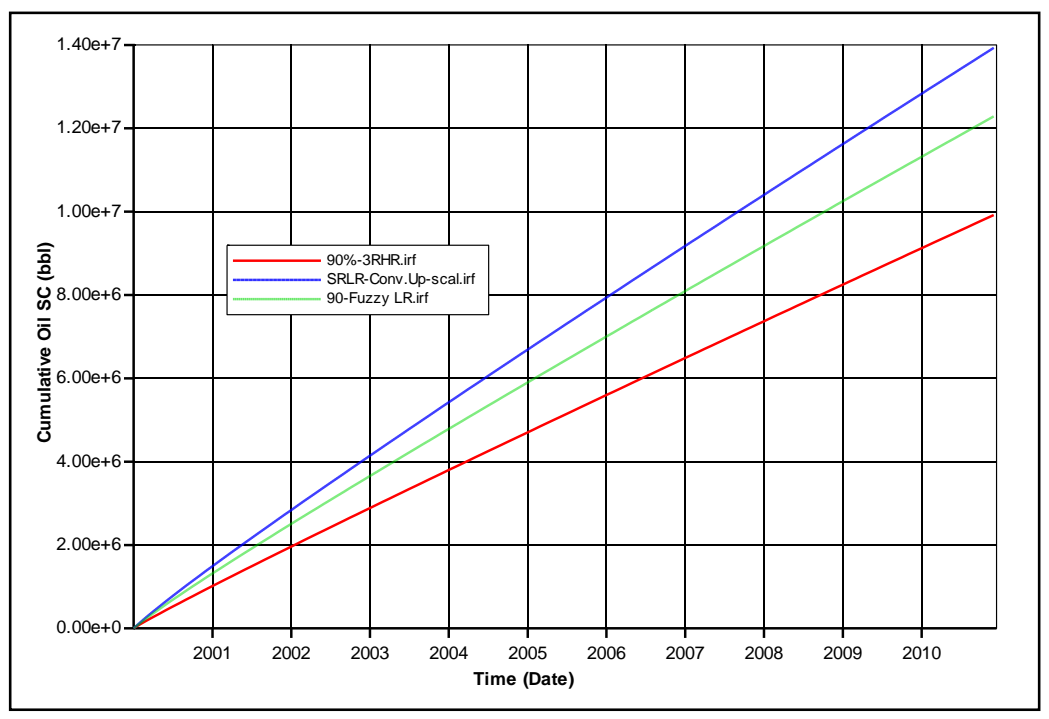

Figure 3 - 34. 3RHR-90\% and SRLR-90\% Models comparison- Oil Production 


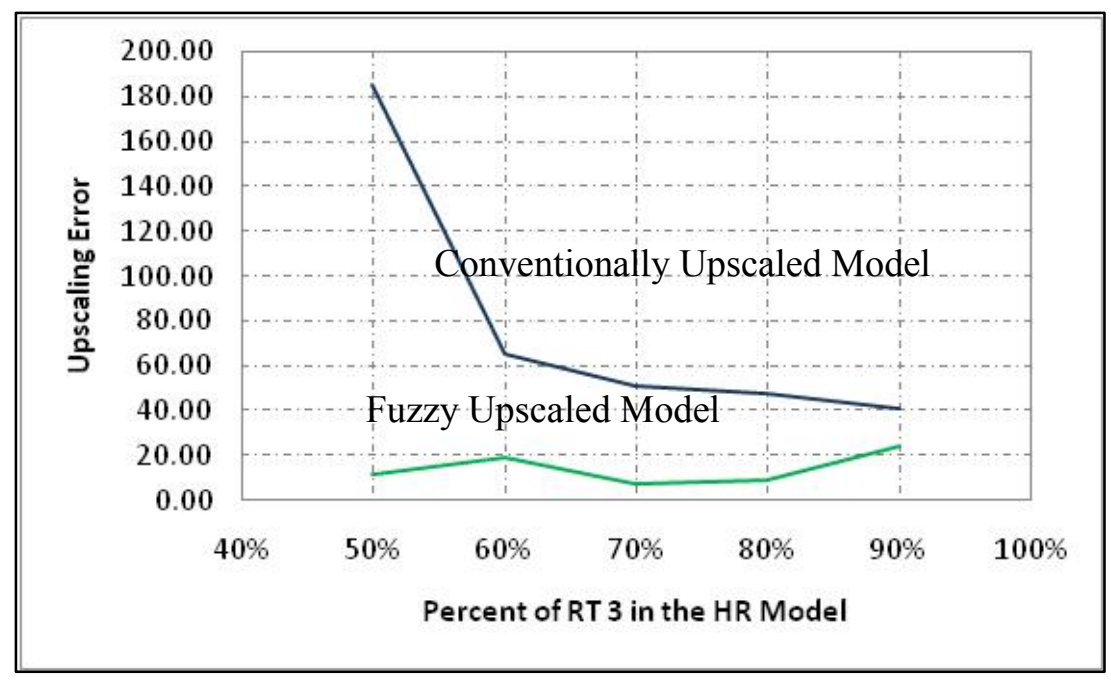

Figure 3 - 35.Upscaling Error Caused by Two Methods for Scenario4 at Tenth Year of Oil Production

The error due to upscaling shown in above figure follows the same trend explained for scenario 3 . It is shown that fuzzy upscaling method still results in closer outcome to the high-resolution models.

\subsection{Scenario 5}

The same analysis explained in the preceding section has been carried out for this case as well. As it can be observed in Figure 3 - 36, decrease in the number of grids associated with rock type 3, causes reduction in oil production. . Referring to the role of each rock type in hydrocarbon production, this behavior can be easily explained.

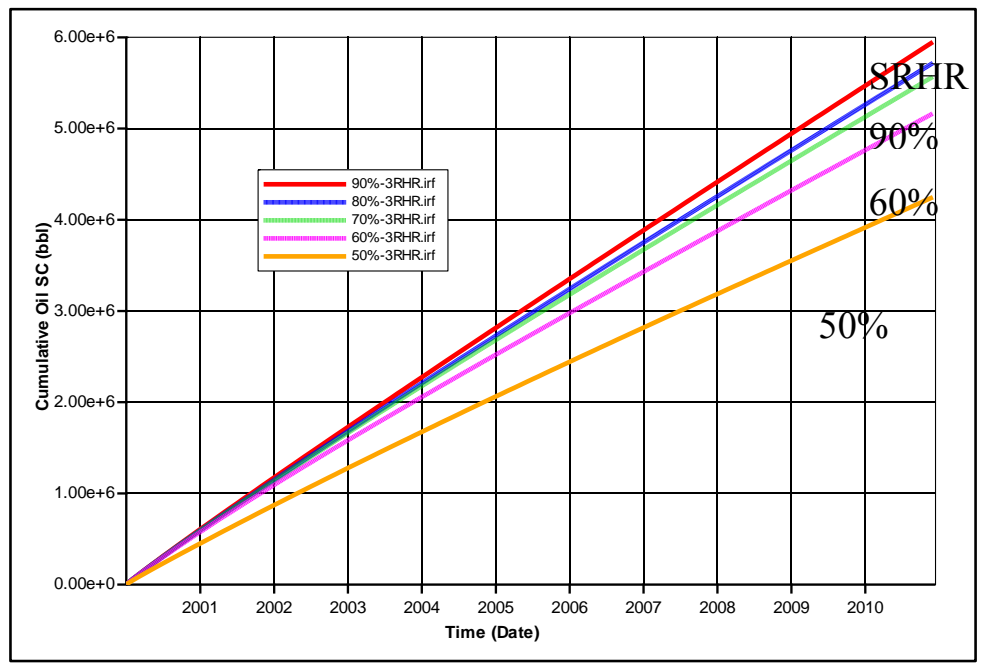

Figure 3 - 36. Cumulative Oil Production for the High Resolution Models in Case 2

The high resolution and upscaled models results have been compared. The results for the cases having 90 and 60 percents of rock type 3 have been demonstrated here as an example. 


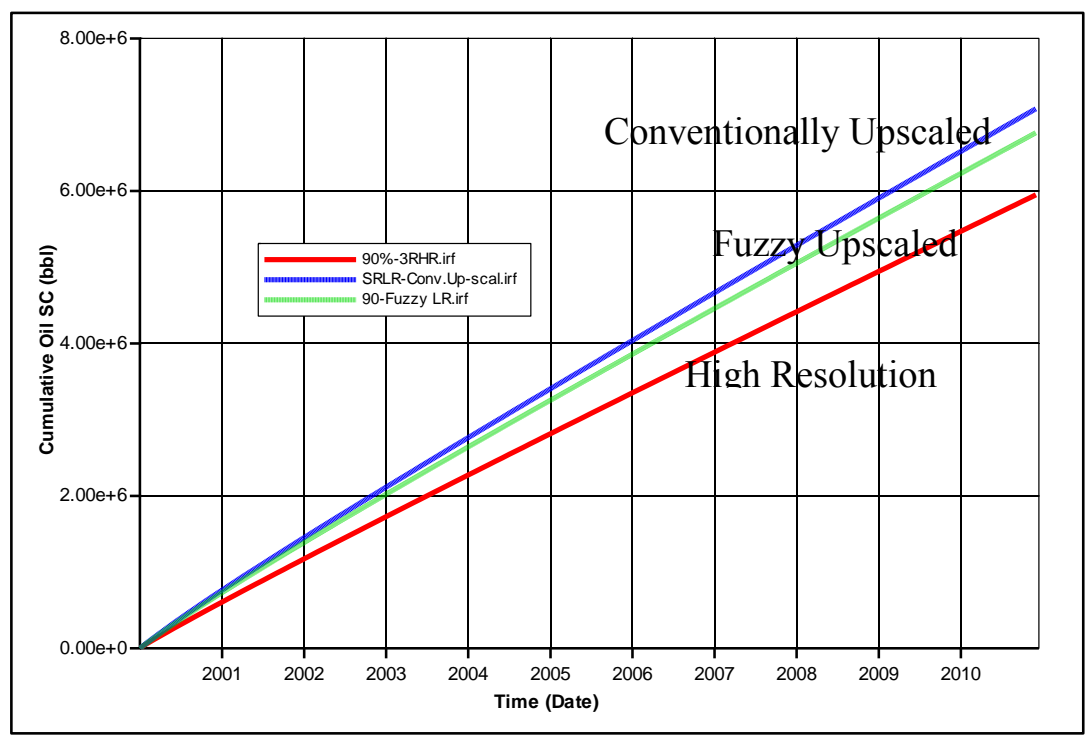

Figure 3 - 37. 90\% and 3RLR-90\% Models Comparison- Oil Production

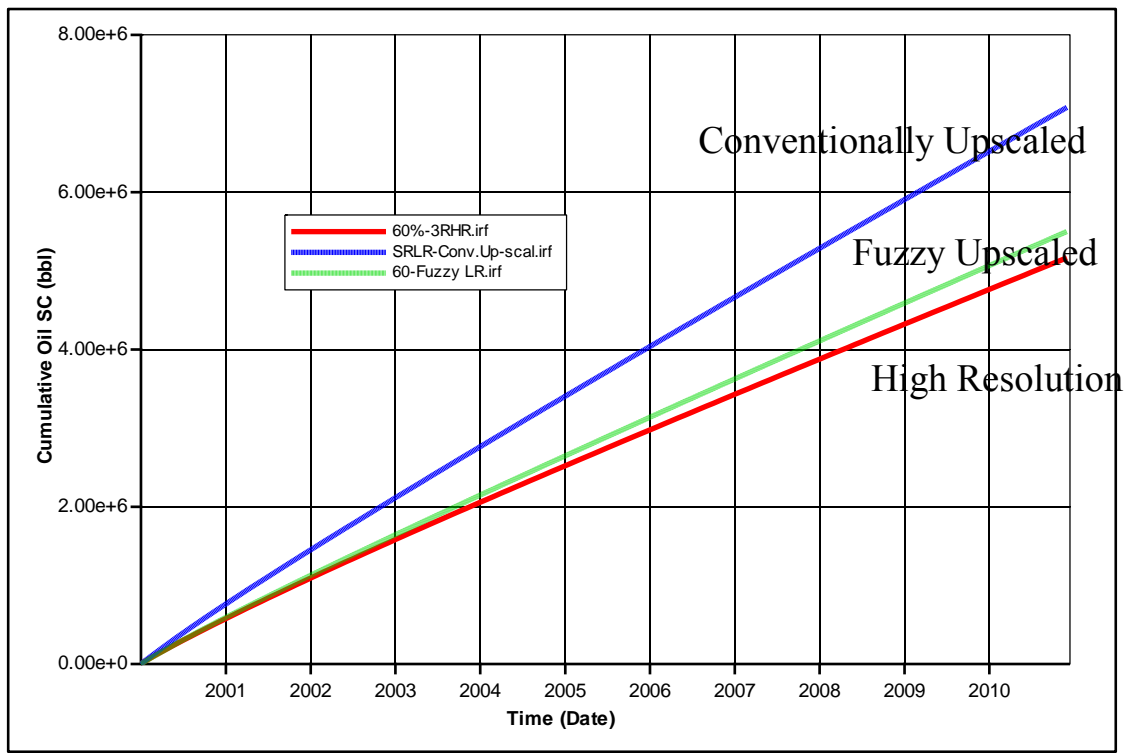

Figure 3 - 38. 3RHR-60\% and 3RLR-60\% Models Comparison- Oil Production

Figure 3 - 39 is the graphical representation of the amount of difference between the high resolution model result and both low resolution models' outcomes, after ten years of oil production. 


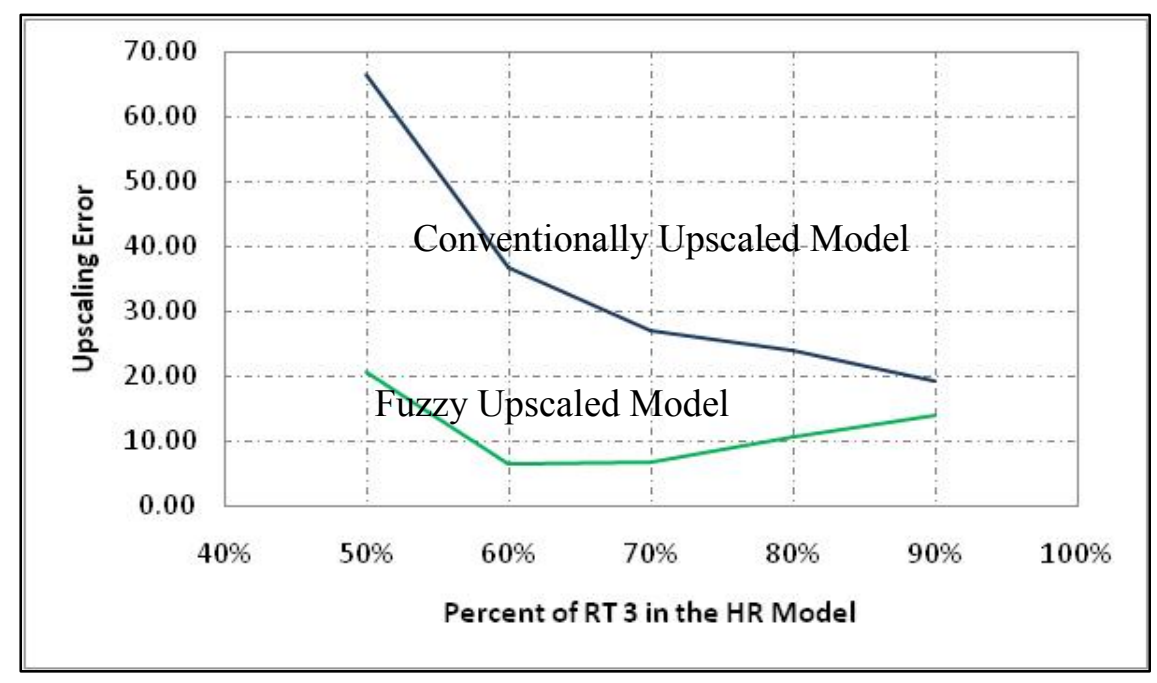

Figure 3 - 39. Upscaling Error Caused by Two Methods for Case 1 at Tenth Year of Oil Production

As it is demonstrated in Figure 3 - 39 the error caused by conventional upscaling is significantly more than fuzzy upscaling. As the percent of rock type three in high-resolution model decreases, the error increase drastically in conventionally upscaled model. However, the error follows a descending trend for fuzzy upscaling models, except for the case having 50\% of rock type three grid blocks in highresolution model. This might be rooted in the geometry of rock type distribution in the reservoir. The blocks that the well is drilled in, and the rock types they belong to play an important role in generating this difference.

In accordance with the results shown in, when overlap of the rock types is higher, the results obtained by fuzzy upscaled models are better in comparison with the conventional upscaling method. 


\section{Chapter 4}

\section{Concluding Remarks}

Different realizations have been generated using commercial reservoir simulator to mimic the behavior of a hypothetic reservoir.

Using multiple studies, the differences between employing conventional approach of implementation of geologic models in the reservoir flow simulation studies and a new approach have been demonstrated. The new methodology used in this study is based on fuzzy set theory.

The intention of this investigation was to establish a new technique for impersonating the reservoir behavior, while the uncertainties have been tried to be taken into account. This method can generate a unique rock type (with relative permeability and capillary pressure properties) for each single upscaled grid block. For example, a model with 100,000 grid blocks ends up with potentially 100,000 rock types each representing the unique characteristics of combination of rock types existing in the high-resolution geological model.

According to the outcomes presented in this work, the fuzzy upscaled model results are by far closer to the high-resolution model than the conventional upscaling technique. The difference between the conventional and fuzzy upscaled models becomes more conspicuous when the percentage of the grids belonging to each rock types gets close and neither one of them is an obvious dominant rock type. In accordance with the analysis performed in this study, as the overlap between different rock types increases, the impact of upscaling using fuzzy rock typing concept becomes more pronounced.

In reference to the results our study demonstrates that using fuzzy set theory as a tool for static and dynamic upscaling reservoir characteristics is indeed an area that has serious potentials and therefore, deserves to be studied, further developed and possibly implemented in large scales. 


\section{References}

1. Harris, J. Fuzzy Logic Applications in Engineering Science. November 28, 2005.

2. Tanakara, K. An introduction to fuzzy logic for practical applications. s.l. : Springer, 1996.

3. Ibrahim, A.M. Fuzzy Logic for Embedded System Applications. s.1. : Elsevier Science, 2003.

4. Djebbar Tiab, Erle C. Donaldson. Petrophysics: Theory and Practice of Measuring reservoir Rock and Fluid Transport Properties. s.l. : Gulf Professional Publishing, 2004.

5. Geological Factors Influencing Reservoir Performance of the Hartzog Draw Field. Hear, C. L., Ebanks, W. J., Tye, R. S. and Ranganatha, V. Wyoming : J. of Petrol. Tech, Aug. 1984. pp. 13351344.

6. A. A. Taghavi, A. Mørk and E. Kazemzadeh. FLOW UNIT CLASSIFICATION FOR GEOLOGICAL MODELLING OF A HETEROGENEOUS CARBONATE RESERVOIR: CRETACEOUS SARVAK FORMATION, DEHLURAN FIELD, SW IRAN. Journal of Petroleum Geology. 21 Mar 2007, Vol. 30, 2, pp. 129-146.

7. Overview of an Integrated Process Model to Develop Petrophysical Based Reservoir Descriptions. Gunter G.W., Pinch J.J., Finneran J.M., Bryant W.T. 1997. SPE Annual Tech. Conf. and Exhibition. SPE Paper 38748.

8. Rock Typing: A Key Approach for Petrophysical Characterization and Definition of Flow Units, Santa Barbara Field, Eastern Venezuela Basin. Porras, J.C.,Campos,O. Buenos Aires, Argentina : s.n., 25-28 March 2001. SPE 69458.

9. Monroe, J. S., Wicander R. Physical Geology - Exploring The Earth. St. Paul, MN : West Publishing Company, 1992.

10. Geological Factors Influencing Reservoir Performance of the Hartzog Draw Field. Hearn, C. L. August 1984, Journal of Petroleum Technology, pp. 1335-1346.

11. J. Dynamics of Fluids in Porous Media. Bear, J. New York : Elsevie, 1972.

12. The Flow Unit Concept-An Integrated Approach to Reservoir Description for Engineering Projects. Ebanks, W. J. 1987. Am. Assoc. Geol. Annual Convention. 
13. Bessa, F. Reservoir Characterization and Reservoir Modeling in the Northwestern Part of hassi Massoud Field Algeria. Hamburg, Germany : s.n., 2004.

14. Archie, G.E. Introduction to Petrophysics of Reservoir Rocks. AAPG Bulletin. Vol. 34, pp. 943961.

15. A fully integrated approach for the development of rock type characterization, in a middle east giant carbonate reservoir. Asgari, A., and Sobhi,G.A. 2006, Journal of Geophysics and Engineering, Vol. 3, pp. 260-270.

16. Enhanced Reservoir Description Using Core and Log Data to Identify Hydraulic (Flow) Units and Predict Permeability in Uncored Intervals/Wells. Amaefule, J. O., Altunbay, M. H., Tiab, D., Kersey, D. G., and Keelan,D. K. 1993. SPE Paper No. 26436.

17. Improved Prediction of Reservoir Behavior Through Integration of Quantitative Geological and Petrophysical Data. Davies, D., Vessell, R., Auman, J. April 1999, Society of Petroleum Engineers Reservoir Evaluation \& Engineering,, pp. 49-160.

18. Schlumberger Oilfield Glossary. [Online] Schlumberger. http://www.glossary.oilfield.slb.com.

19. Dominguez G.C., Samaniego V.F. Carbonate Reservoir Characterization: A GeologicEngineering Analysis,Part I. New York : Elsevier Sciense Publishing Company Inc., 1992.

20. Early Determination of Reservoir Flow Units Using an Integrated Petrophysical Method,SPE 38679. Gunter, G. W., Finneran, J. M., Hartman, D. J. and Miller, J. D. San Antonio, TX : SSPE Annual Technical Conference and Exhibition, 5-8 October 1997.

21. The Analysis of Pore Throat Size and Use of Waxman-Smit to Determine OOIP in Spindle Field Colorado. Kolodzie, S.J. 1980. SPE 55th Annual Fall Tech. Conf. and Exhib. SPE Paper 0382.

22. Martin, A.J., Solomon, S.T., Hartmann, D.J. Characterization of Petrophysical Flow Units in Carbonate Reservoirs. AAPG Bulletin. 1997, Vol. 81, 5, pp. 734-759.

23. Pittman, E.D. Relationship of Porosity and Permeability to Various Parameters Derived from Mercury InjectionCapillary Pressure Curves for Sandstones. AAPG Bulletin. 1992, Vol. 76, 2, pp. 191-198.

24. Katz, A.J., Thompson, A.H. Quantitative Prediction ofPermeability in Pours Rock: Physical Review. Vol. 34, pp. 8179-8181. 
25. Development of Reservoir Descriptions to Aid in Design of EOR Projects. Chopra A.K, Stein M.H., Ader J.C. 1987. SPE California Regional Meeting. Paper 16370.

26. Craig, F.F. The Reservoir Engineering Aspects of Waterflooding. SPE Monograph. 1972, Vol. 3, pp. 63-66.

27. Slatt, R. M. Stratigraphic reservoir characterization for petroleum geologists, geophysicists, and engineers. s.1. : Elsevier, 2006.

28. Salazarluna, J.M. Assessment of permeability from well logs based on core calibration and simulation of mud-filtrate. s.1. : The University of Texas at Austin, May 2004.

29. Tiab, D. Modern Core Analysis,. s.1. : Core Laboratories,, May 1993. Vol. 1.

30. Tiab, D., Marschall, D. M. and Altunbay, M. H. Method for Idenwing and Characterizing Hydraulic Units of Saturated Porous Media: Tri-Kappa Zoning Process. March 9, 1993. U.S. Patent No. 5,193,059.

31. Sablok, R. Upscaling Errors in reservoir Simulation. s.1. : Stanford University, June 2004.

32. A New Method for the Scale Up of Displacement Processes in Heterogeneous Reservoirs. Durlofsky, L.J., Jones, R.C., and Milliken, W.J. Roros, Norway : European Conference on the Mathematics of Oil Recovery, 7-10 June,1994.

33. Muggeridge, A.H. Generation of Effective Relative Permeabilities from Detailed Simulation of Flow in Heterogeneous Porous Media. [ed.] H.B. Carroll, and T.C. Wesson L.W. Lake. Reservoir Characterization II. San Diego, California : Academic Press, 1991, pp. 197-225.

34. Lake, L.W., Kasap, E., and Shook, M. Pseudofunctions-The Key to Practical Use of Reservoir Description. [book auth.] Graham and Trotman. 1990.

35. The Use of Vertical Equilibrium in Two-Dimensional Simulation of Three-Dimensional Reservoir Performance. Coats, K.H., Dempsey, J.R., and Henderson, J.H. March 1971, SPEJ, Vol. 63.

36. Rosenzweig, J.J., Abdelmalck, N.A., and Gochnour, J.R. The Development of Pseudo Functions for Three-Phase Black-Oil Simulators. [ed.] L.W. Lake and H.B. Carroll. Reservoir Characterization. San Diego, California : Academic Press, 1985.

37. Numerical Calculations of Equivalent Gridblock Permeability Tensors for Heterogeneous Porous Media. Durlofsky, L.J. 5, 1991, Water Resources Research , Vol. 25, p. 699. 
38. The Scale-up of Two Phase Flow Using Permeability Tensors. Pickup, G.E. and Sorbie, K.S. Roros, Norway : s.n., 7-10 June,1994. European Conference on the Mathematics of Oil Recovery.

39. Dynamical Upscaling Techniques Applied to Compositional Flows. Thibeau, S., Barker, J.W., and Souillard, Ph. San Antonio,TX: s.n., 12-15 February,1995. SPE Symposium on Reservoir Simulation. SPE 29128.

40. A Critical Review of the Use of Pseudorelative Permeabilities for Upscaling. Baker, J.W.,Thibeau, S.

41. An Analysis of Dynamic Pseudo Relative Permeability Methods. Barker, J.W. and Dupouy, P. Leoben, Austria : s.n., 3-6 September, 1996. European Conference on the Mathematics of Oil Recovery.

42. New Pseudofunctions To Control Numerical Dispersion. Kyte, J.R. and Berry, D.W. August 1975, SPEJ , p. 269.

43. Averaging of Relative Permeability in Heterogeneous Reservoirs. Ekrann, S. and Dale, M. Oxford, U.K. : Oxford U. Press, 1992, The Mathematics of Oil Recovery.

44. Rigorous Black-Oil Pseudofunctions. Stone, H.L. Anaheim, california: SPE Symposium on Reservoir Simulation, 17-20 February, 1991. SPE 21207.

45. Heterogeneity in a Complex Turbiditic Reservoir: Impact on Field Development. Alabert, F.G. and Corre, B. Dallas: SPE Annual Technical Conference and Exhibition, 6-9 October,1991. SPE 22902.

46. PSEUDO Reference Manual. s.1. : Intera Information Technologies Ltd.

47. The Modeling of a Three-Dimensional Reservoir With a Two-Dimensional Reservoir SimulatorThe Use of Dynamic Pseudofunctions. Jacks, H.H., Smith, O.J.E., and Mattax, C.C. June 1973, SPEJ, p. 175.

48. A Renormalization-Based Upscaling Technique for WAG Floods in Heterogeneous Reservoirs. Christie, M.A. et al. San Antonio,TX : SPE Symposium on Reservoir Simulation,, 12-15 February, 1995. SPE 29127.

49. Reservoir Rock Typing in a Giant Carbonate. S. Varavur, H. Shebl, S.M. Salman, T. Shibasaki, and C. Dabbouk. Bahrain : s.n., 12-15 March 2005. SPE 93477. 
50. CMG-IMEX. [Online] Computer Modeling Group LTD. http://www.cmgroup.com.

51. Enhanced Reservoir Description: Using Core and Log Data to Identify Hydraulic (flow units) and Predict Permeability in Uncored Intervals/Wells. Amaefule, J., Altunbay, M., Taib, D., Kersey, D. October 1993. SPE 26436.

52. The Scale-up of Two Phase Flow Using Permeability Tensors. Pickup, G.E. and Sorbie, K.S. 


\section{Appendix A}

\section{Scenario 1-Model Graphic representations and Table of Data}

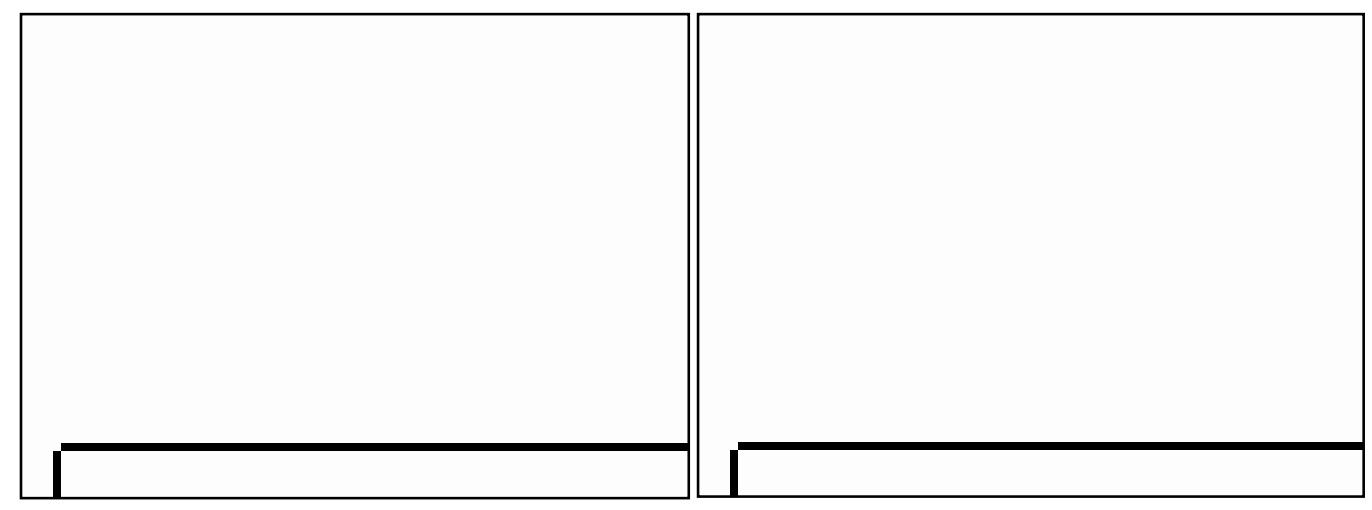

Figure A - 1.Rock type distribution (3RTHR/70\%)

Figure A - 2.Porosity distribution (3RTHR/70\%)

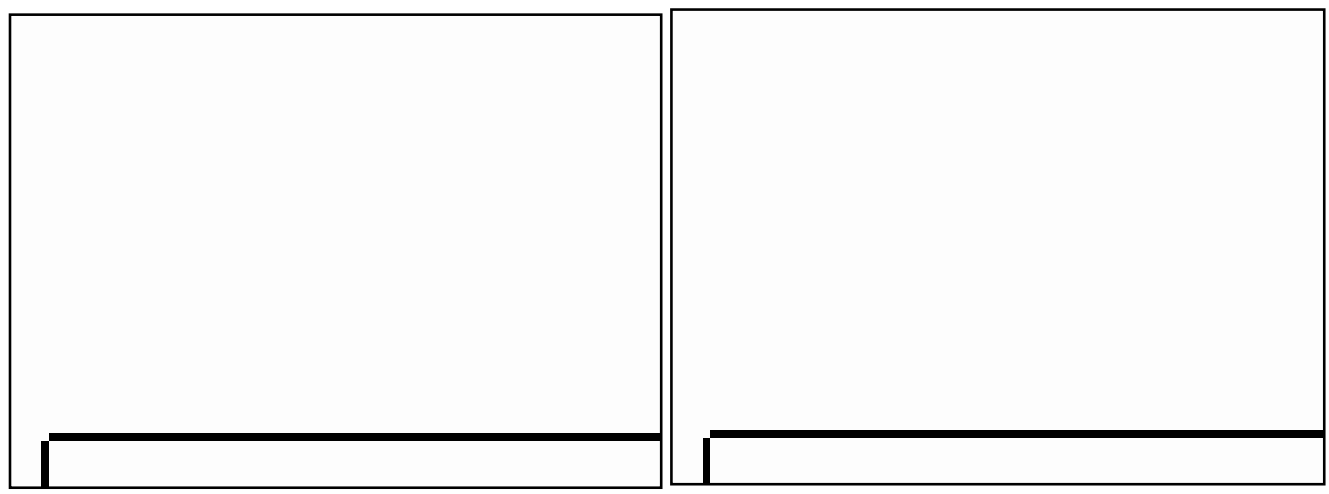

Figure A - 3.Kx distribution (3RTHR/70\%)

Figure A - 4.Rock type distribution (3RTHR/60\%)

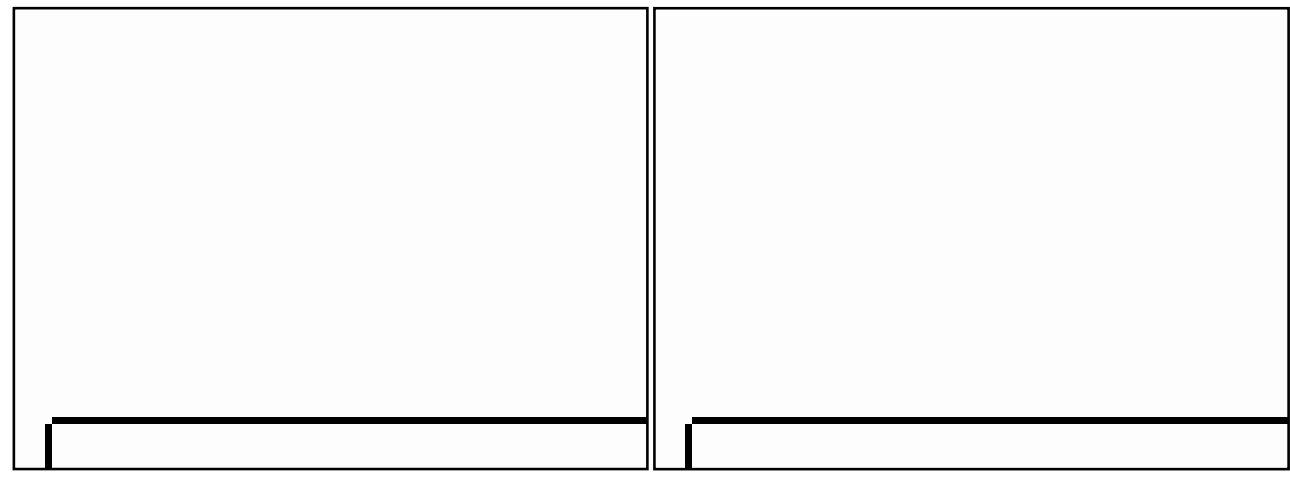

Figure A - 5.Rock type distribution (3RTHR/50\%) Figure A - 6.Porosity distribution -Conventional upscaled model 


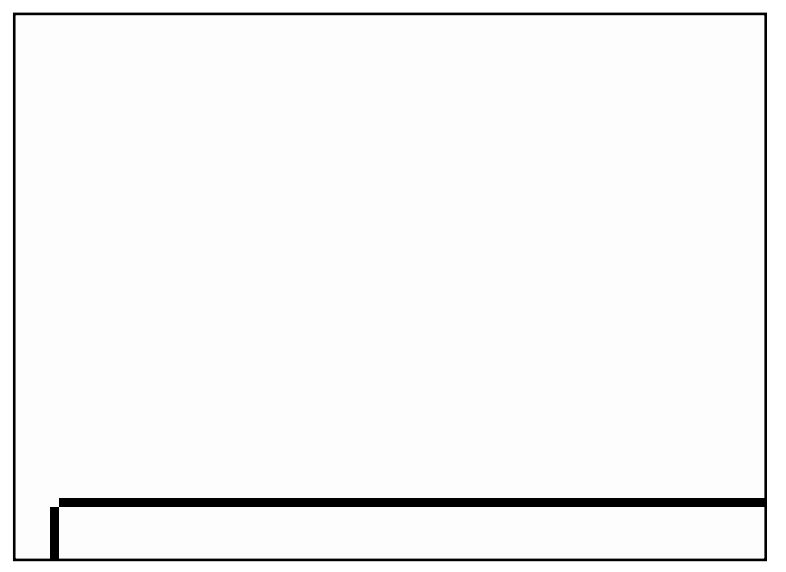

Figure A - 7.Kx distribution -Conventional upscaled model

Table A - 1. Permeability values before and after fuzzy upscaling ( $80 \%$ of rock type 3 )

\begin{tabular}{|c|c|c|c|c|}
\hline Property & $\begin{array}{l}\text { Number of High } \\
\text { Resolution Grids }\end{array}$ & $\begin{array}{l}\text { Fuzzy Membership } \\
\text { Value }\end{array}$ & $\begin{array}{l}\text { Value before } \\
\text { upscaling }\end{array}$ & $\begin{array}{c}\text { Value after fuzzy } \\
\text { upscaling }\end{array}$ \\
\hline \multirow{3}{*}{$\begin{array}{c}\mathrm{Kx} \\
(\mathrm{mD})\end{array}$} & RT $1: 12$ & RT $1: 0.16$ & RT $1: 1.78$ & \multirow{3}{*}{ FRT $1: 6.752$} \\
\hline & RT 3: 60 & RT 3: 0.8 & RT $2: 7.84$ & \\
\hline & RT $5: 3$ & RT $5: 0.04$ & RT 3:5 & \\
\hline \multirow{3}{*}{$\begin{array}{c}\mathrm{Ky} \\
(\mathrm{mD})\end{array}$} & RT 1: 12 & RT 1:0.16 & RT $1: 1.78$ & \multirow{3}{*}{ FRT $1: 6.752$} \\
\hline & RT 3:60 & RT 3: 0.8 & RT 2:7.84 & \\
\hline & RT 5:3 & RT 5:0.04 & RT 3:5 & \\
\hline \multirow{3}{*}{$\begin{array}{c}\mathrm{Kz} \\
(\mathrm{mD})\end{array}$} & RT 1: 12 & RT $1: 0.16$ & RT 1: 0.178 & \multirow{3}{*}{ FRT $1: 0.675$} \\
\hline & RT 3:60 & RT 3: 0.8 & RT $2: 0.784$ & \\
\hline & RT 5:3 & RT $5: 0.04$ & RT 3:0.5 & \\
\hline
\end{tabular}

Table A - 2.Permeability values before and after fuzzy upscaling ( $70 \%$ of rock type 3 )

\begin{tabular}{|c|c|c|c|c|}
\hline Property & $\begin{array}{l}\text { Number of High } \\
\text { Resolution Grids }\end{array}$ & $\begin{array}{l}\text { Fuzzy Membership } \\
\text { Value }\end{array}$ & $\begin{array}{l}\text { Value before } \\
\text { upscaling }\end{array}$ & $\begin{array}{l}\text { Value after fuzzy } \\
\text { upscaling }\end{array}$ \\
\hline \multirow{3}{*}{$\begin{array}{l}\mathrm{Kx} \\
(\mathrm{mD})\end{array}$} & RT 1: 19 & RT $1: 0.25$ & RT $1: 1.78$ & \multirow{3}{*}{ FRT $1: 6.186$} \\
\hline & RT $3: 53$ & RT 3:0.71 & RT $2: 7.84$ & \\
\hline & RT 5: 3 & RT $5: 0.04$ & RT 3:5 & \\
\hline \multirow{3}{*}{$\begin{array}{l}\mathrm{Ky} \\
(\mathrm{mD})\end{array}$} & RT 1: 19 & RT 1:0.25 & RT $1: 1.78$ & \multirow{3}{*}{ FRT $1: 6.186$} \\
\hline & RT 3: 53 & RT 3:0.71 & RT 2:7.84 & \\
\hline & RT $5: 3$ & RT 5: 0.04 & RT 3: 5 & \\
\hline \multirow{3}{*}{$\begin{array}{l}\mathrm{Kz} \\
(\mathrm{mD})\end{array}$} & RT 1: 19 & RT 1: 0.25 & RT $1: 0.178$ & \multirow{3}{*}{ FRT $1: 0.619$} \\
\hline & RT 3: 53 & RT 3:0.71 & RT 2:0.784 & \\
\hline & RT $5: 3$ & RT 5: 0.04 & RT $3: 0.5$ & \\
\hline
\end{tabular}


Table A - 3. Permeability values before and after fuzzy upscaling (50\% of rock type 3 )

\begin{tabular}{|c|c|c|c|c|}
\hline Property & $\begin{array}{l}\text { Number of High } \\
\text { Resolution Grids }\end{array}$ & $\begin{array}{l}\text { Fuzzy Membership } \\
\text { Value }\end{array}$ & $\begin{array}{c}\text { Value before } \\
\text { upscaling }\end{array}$ & $\begin{array}{c}\text { Value after fuzzy } \\
\text { upscaling }\end{array}$ \\
\hline \multirow{3}{*}{$\begin{array}{l}\mathrm{Kx} \\
(\mathrm{mD})\end{array}$} & RT 1:34 & RT $1: 0.45$ & RT $1: 1.78$ & \multirow{3}{*}{ FRT $1: 5.54$} \\
\hline & RT $3: 38$ & RT 3:0.51 & RT $2: 7.84$ & \\
\hline & RT 5:3 & RT 5:0.04 & RT 3:5 & \\
\hline \multirow{3}{*}{$\begin{array}{l}\mathrm{Ky} \\
(\mathrm{mD})\end{array}$} & RT $1: 34$ & RT 1: 0.45 & RT $1: 1.78$ & \multirow{3}{*}{ FRT $1: 5.54$} \\
\hline & RT 3:38 & RT 3:0.51 & RT 2:7.84 & \\
\hline & RT 5:3 & RT $5: 0.04$ & RT 3:5 & \\
\hline \multirow{3}{*}{$\begin{array}{c}\mathrm{Kz} \\
(\mathrm{mD})\end{array}$} & RT 1: 34 & RT 1: 0.45 & RT $1: 0.178$ & \multirow{3}{*}{ FRT $1: 0.554$} \\
\hline & RT 3:38 & RT 3: 0.51 & RT 2:0.784 & \\
\hline & RT $5: 3$ & $\overline{\text { RT 5 : } 0.04}$ & RT 3:0.5 & \\
\hline
\end{tabular}

\section{Appendix B}

\section{Scenario 2-Model Graphic representations and Table of Data}

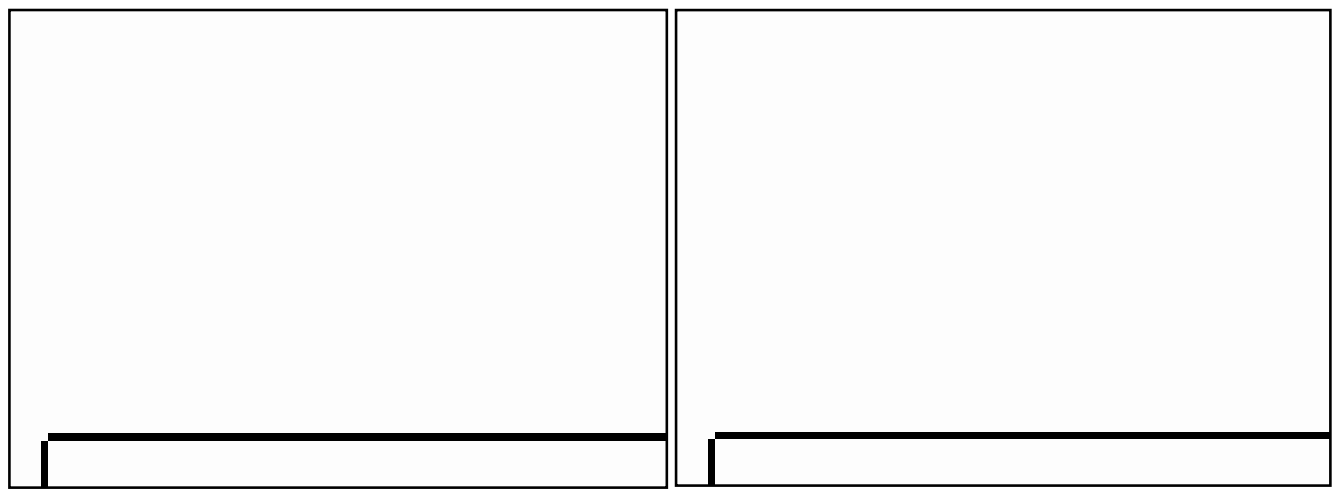

Figure B - 1.Kx distribution (3RTHR/90\%)

Figure B - 2.Rock type distribution (3RTHR/70\%) 


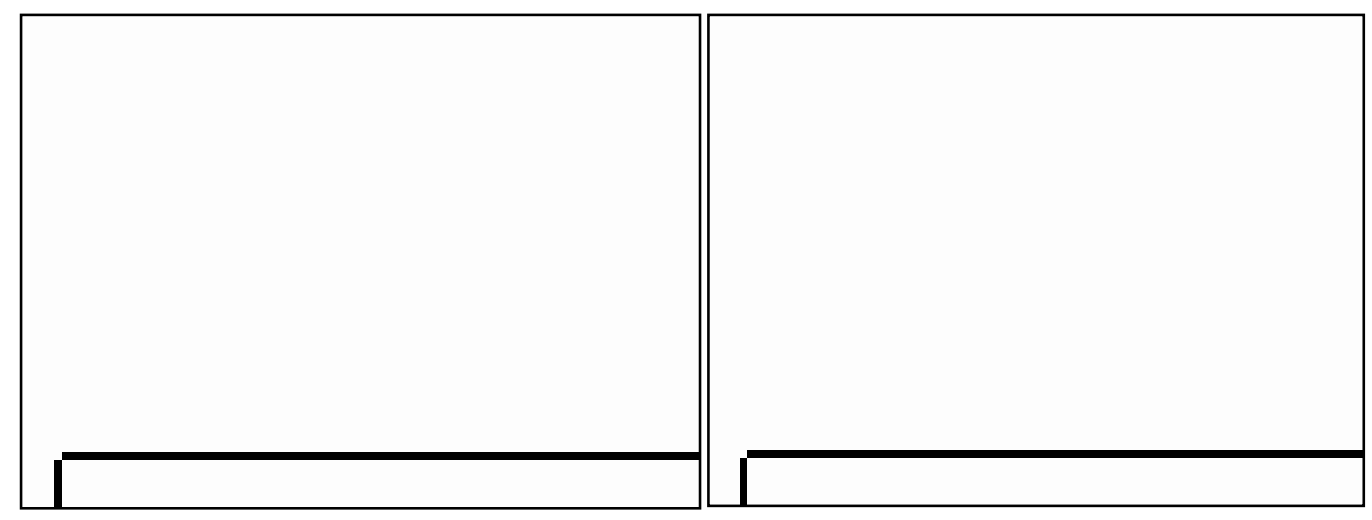

Figure B - 3.Rock type distribution (3RTHR/60\%) Figure B - 4.Rock type distribution (3RTHR/50\%)

Table B - 1.Permeability values before and after fuzzy upscaling ( $80 \%$ of rock type 3$)$

\begin{tabular}{|c|c|c|c|c|}
\hline Property & $\begin{array}{l}\text { Number of High } \\
\text { Resolution Grids }\end{array}$ & $\begin{array}{l}\text { Fuzzy Membership } \\
\text { Value }\end{array}$ & $\begin{array}{l}\text { Value before } \\
\text { upscaling }\end{array}$ & $\begin{array}{c}\text { Value after fuzzy } \\
\text { upscaling }\end{array}$ \\
\hline \multirow{3}{*}{$\begin{array}{c}\mathrm{Kx} \\
(\mathrm{mD})\end{array}$} & RT $1: 12$ & RT $1: 0.16$ & RT $1: 1.78$ & \multirow{3}{*}{ FRT $1: 6.752$} \\
\hline & RT 3:60 & RT 3: 0.8 & RT $2: 7.84$ & \\
\hline & RT 5:3 & RT 5: 0.04 & RT 3:5 & \\
\hline \multirow{3}{*}{$\begin{array}{c}\mathrm{Ky} \\
(\mathrm{mD})\end{array}$} & RT 1: 12 & RT $1: 0.16$ & RT 1: 1.78 & \multirow{3}{*}{ FRT $1: 6.752$} \\
\hline & RT 3:60 & RT 3:0.8 & RT 2:7.84 & \\
\hline & RT 5:3 & RT 5:0.04 & RT 3:5 & \\
\hline \multirow{3}{*}{$\begin{array}{c}\mathrm{Kz} \\
(\mathrm{mD})\end{array}$} & RT 1: 12 & RT $1: 0.16$ & RT 1: 0.178 & \multirow{3}{*}{ FRT $1: 0.675$} \\
\hline & RT 3:60 & RT 3: 0.8 & RT $2: 0.784$ & \\
\hline & RT $5: 3$ & RT $5: 0.04$ & RT $3: 0.5$ & \\
\hline
\end{tabular}

Table B - 2.Permeability values before and after fuzzy upscaling ( $70 \%$ of rock type 3 )

\begin{tabular}{|c|c|c|c|c|}
\hline Property & $\begin{array}{l}\text { Number of High } \\
\text { Resolution Grids }\end{array}$ & $\begin{array}{c}\text { Fuzzy } \\
\text { Membership } \\
\text { Value } \\
\end{array}$ & $\begin{array}{c}\text { Value before } \\
\text { upscaling }\end{array}$ & $\begin{array}{c}\text { Value after } \\
\text { fuzzy upscaling }\end{array}$ \\
\hline \multirow{3}{*}{$\mathrm{Kx}(\mathrm{mD})$} & RT 1: 19 & RT $1: 0.25$ & RT $1: 1.78$ & \multirow{3}{*}{ FRT $1: 6.186$} \\
\hline & RT 3 : 53 & RT 3:0.71 & RT 2:7.84 & \\
\hline & RT $5: 3$ & RT 5: 0.04 & RT 3: 5 & \\
\hline \multirow{3}{*}{ Ky (mD) } & RT $1: 19$ & RT 1:0.25 & RT $1: 1.78$ & \multirow{3}{*}{ FRT $1: 6.186$} \\
\hline & RT $3: 53$ & RT $3: 0.71$ & RT $2: 7.84$ & \\
\hline & RT $5: 3$ & RT 5: 0.04 & RT 3:5 & \\
\hline \multirow{3}{*}{$\mathrm{Kz}(\mathrm{mD})$} & RT 1:19 & RT 1:0.25 & RT 1:0.178 & \multirow{3}{*}{ FRT $1: 0.619$} \\
\hline & RT 3: 53 & RT 3:0.71 & RT $2: 0.784$ & \\
\hline & RT $5: 3$ & RT $5: 0.04$ & RT $3: 0.5$ & \\
\hline
\end{tabular}


Table B - 3.Permeability values before and after fuzzy upscaling (60\% of rock type 3 )

\begin{tabular}{|c|c|c|c|c|}
\hline Property & $\begin{array}{l}\text { Number of High } \\
\text { Resolution Grids }\end{array}$ & $\begin{array}{l}\text { Fuzzy Membership } \\
\text { Value }\end{array}$ & $\begin{array}{l}\text { Value before } \\
\text { upscaling }\end{array}$ & $\begin{array}{l}\text { Value after fuzzy } \\
\text { upscaling }\end{array}$ \\
\hline \multirow{3}{*}{$\begin{array}{l}\mathrm{Kx} \\
(\mathrm{mD})\end{array}$} & RT 1:27 & $\begin{array}{l}\text { RT } 1: 0.36 \\
\end{array}$ & RT 1: 1.78 & \multirow{3}{*}{ FRT $1: 5.54$} \\
\hline & RT $3: 45$ & RT 3: 0.60 & RT $2: 7.84$ & \\
\hline & RT 5:3 & RT 5:0.04 & RT 3:5 & \\
\hline \multirow{3}{*}{$\begin{array}{l}\mathrm{Ky} \\
(\mathrm{mD})\end{array}$} & RT 1:27 & RT 1:0.36 & RT $1: 1.78$ & \multirow{3}{*}{ FRT $1: 5.54$} \\
\hline & RT 3: 45 & RT 3:0.60 & RT 2:7.84 & \\
\hline & RT $5: 3$ & RT 5:0.04 & RT 3:5 & \\
\hline \multirow{3}{*}{$\begin{array}{c}\mathrm{Kz} \\
(\mathrm{mD})\end{array}$} & RT 1: 27 & RT $1: 0.36$ & RT $1: 0.178$ & \multirow{3}{*}{ FRT $1: 0.554$} \\
\hline & RT 3: 45 & RT 3:0.60 & RT 2: 0.784 & \\
\hline & RT $5: 3$ & RT 5: 0.04 & RT $3: 0.5$ & \\
\hline
\end{tabular}

Table B - 4.Permeability values before and after fuzzy upscaling (50\% of rock type 3 )

\begin{tabular}{|c|c|c|c|c|}
\hline Property & $\begin{array}{l}\text { Number of High } \\
\text { Resolution Grids }\end{array}$ & $\begin{array}{l}\text { Fuzzy Membership } \\
\text { Value }\end{array}$ & $\begin{array}{l}\text { Value before } \\
\text { upscaling }\end{array}$ & $\begin{array}{c}\text { Value after fuzzy } \\
\text { upscaling }\end{array}$ \\
\hline \multirow{3}{*}{$\begin{array}{c}\mathrm{Kx} \\
(\mathrm{mD})\end{array}$} & RT 1:34 & RT $1: 0.45$ & RT $1: 1.78$ & \multirow{3}{*}{ FRT $1: 5.54$} \\
\hline & RT 3:38 & RT 3:0.51 & RT 2:7.84 & \\
\hline & RT 5:3 & RT $5: 0.04$ & RT 3:5 & \\
\hline \multirow{3}{*}{$\begin{array}{l}\mathrm{Ky} \\
(\mathrm{mD})\end{array}$} & RT 1:34 & RT 1: 0.45 & RT 1:1.78 & \multirow{3}{*}{ FRT $1: 5.54$} \\
\hline & RT $3: 38$ & RT 3:0.51 & RT 2: 7.84 & \\
\hline & RT $5: 3$ & RT 5:0.04 & RT 3: 5 & \\
\hline \multirow{3}{*}{$\begin{array}{l}\mathrm{Kz} \\
(\mathrm{mD})\end{array}$} & RT 1:34 & RT 1:0.45 & RT $1: 0.178$ & \multirow{3}{*}{ FRT $1: 0.554$} \\
\hline & RT 3:38 & RT 3:0.51 & RT 2:0.784 & \\
\hline & RT 5:3 & RT 5:0.04 & RT 3:0.5 & \\
\hline
\end{tabular}




\section{Appendix C}

\section{Scenario 3-Model Graphic representations and Table of Data}

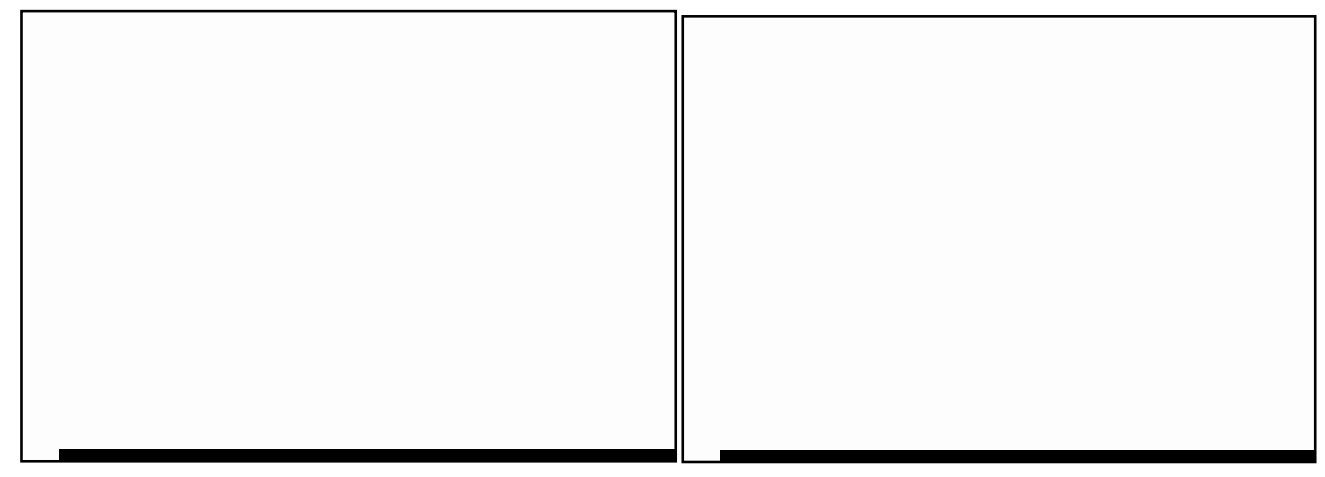

Figure C - 1.Porosity distribution (3RTHR/90\%)

Figure C - 2. Kx distribution (3RTHR/90\%)

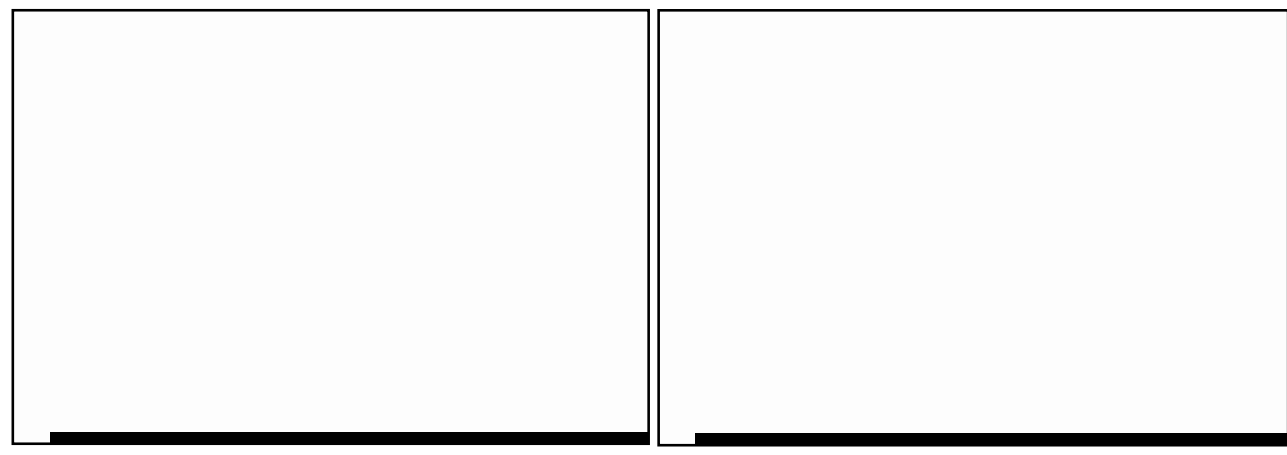

Figure C - 3. Rock type distribution (3RTHR/80\%) Figure C - 4.Rock type distribution(3RTHR/70\%)

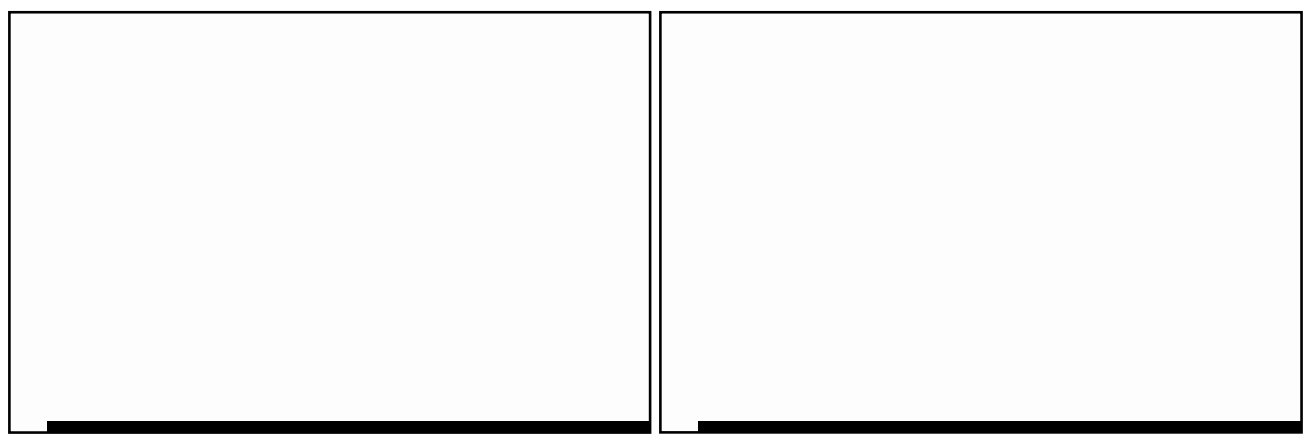

Figure C - 5.Rock type distribution (3RTHR/60\%) Figure C - 6.Porosity distribution (3RTHR/50\%) 


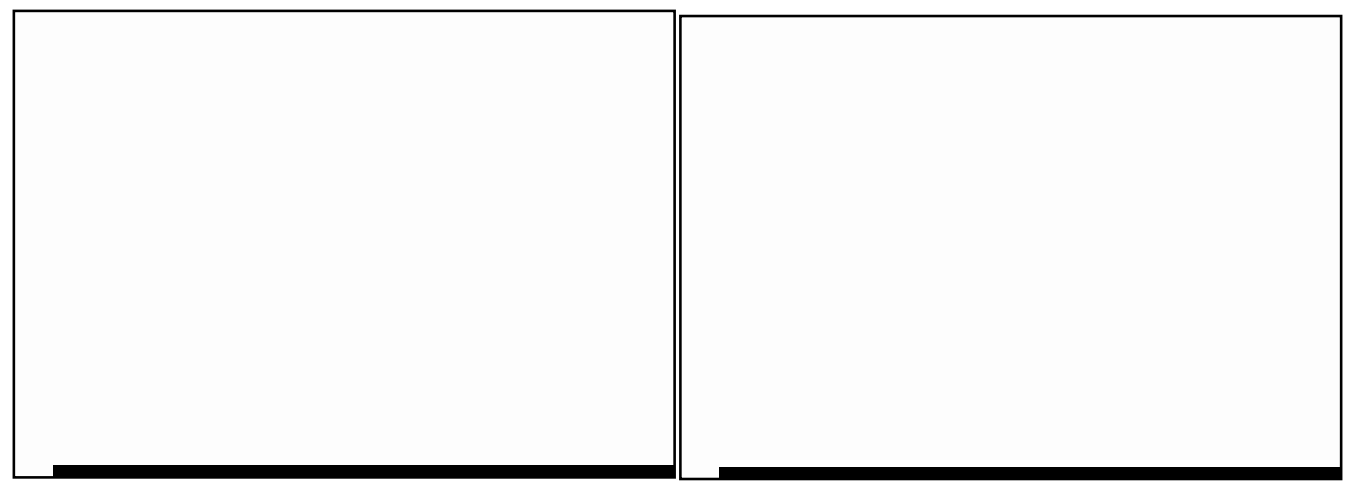

Figure C - 7.Rock type distribution (3RTHR/50\%) Figure C - 8.Rock type distribution - Conventional upscaled model

Table C - 1.Permeability and porosity values before and after fuzzy upscaling ( $80 \%$ of rock type 3 )

\begin{tabular}{|c|c|c|c|c|}
\hline Property & $\begin{array}{l}\text { Number of High } \\
\text { Resolution Grids }\end{array}$ & $\begin{array}{l}\text { Fuzzy Membership } \\
\text { Value } \\
\end{array}$ & $\begin{array}{l}\text { Value before } \\
\text { upscaling }\end{array}$ & $\begin{array}{c}\text { Value after fuzzy } \\
\text { upscaling }\end{array}$ \\
\hline \multirow{3}{*}{$\mathrm{Kx}(\mathrm{mD})$} & RT $1: 12$ & RT $1: 0.16$ & RT 1: 0.519 & \multirow{3}{*}{ FRT $1: 13.47$} \\
\hline & RT 3:60 & RT $3: 0.8$ & RT 3 : 16.582 & \\
\hline & RT 5:3 & RT 5: 0.04 & RT $5: 2.3$ & \\
\hline \multirow{3}{*}{$\mathrm{Ky}(\mathrm{mD})$} & RT 1: 12 & RT 1:0.16 & RT 1:0.519 & \multirow{3}{*}{ FRT $1: 13.47$} \\
\hline & RT 3:60 & RT 3:0.8 & RT 3 : 16.582 & \\
\hline & RT 5:3 & RT $5: 0.04$ & RT $5: 2.3$ & \\
\hline \multirow{3}{*}{$\mathrm{Kz}(\mathrm{mD})$} & RT 1: 12 & RT $1: 0.16$ & RT 1:0.052 & \multirow{3}{*}{ FRT $1: 1.35$} \\
\hline & RT 3:60 & RT 3:0.8 & RT 3 : 1.6582 & \\
\hline & RT $5: 3$ & RT 5:0.04 & RT 5: 0.23 & \\
\hline \multirow{3}{*}{$\begin{array}{l}\text { Porosity } \\
\text { (\%) }\end{array}$} & RT $1: 12$ & RT $1: 0.16$ & RT 1:5 & \multirow{3}{*}{ FRT $1: 13.8$} \\
\hline & RT 3:60 & RT $3: 0.8$ & RT 3: 15 & \\
\hline & RT $5: 3$ & RT 5: 0.04 & RT $5: 10$ & \\
\hline
\end{tabular}

Table C - 2.Permeability and porosity values before and after fuzzy upscaling (70\% of rock type 3$)$

\begin{tabular}{|c|c|c|c|c|}
\hline Property & $\begin{array}{l}\text { Number of High } \\
\text { Resolution Grids }\end{array}$ & $\begin{array}{c}\text { Fuzzy } \\
\text { Membership } \\
\text { Value }\end{array}$ & $\begin{array}{l}\text { Value before } \\
\text { upscaling }\end{array}$ & $\begin{array}{c}\text { Value after } \\
\text { fuzzy upscaling }\end{array}$ \\
\hline \multirow{3}{*}{$\mathrm{Kx}(\mathrm{mD})$} & RT $1: 19$ & RT $1: 0.25$ & RT $1: 0.519$ & \multirow{3}{*}{ FRT $1: 11.97$} \\
\hline & RT 3: 53 & RT 3:0.71 & "RT 3 : 16.582 & \\
\hline & RT 5:3 & RT 5:0.04 & RT $5: 2.3$ & \\
\hline \multirow{3}{*}{ Ky (mD) } & RT 1: 19 & RT 1:0.25 & RT 1: 0.519 & \multirow{3}{*}{ FRT $1: 11.97$} \\
\hline & RT 3: 53 & RT 3: 0.71 & RT 3 : 16.582 & \\
\hline & RT 5:3 & RT 5: 0.04 & RT $5: 2.3$ & \\
\hline \multirow{3}{*}{$\mathrm{Kz}(\mathrm{mD})$} & RT 1: 19 & RT 1: 0.25 & RT $1: 0.052$ & \multirow{3}{*}{ FRT $1: 1.2$} \\
\hline & RT 3: 53 & RT 3: 0.71 & RT 3: 1.6582 & \\
\hline & RT 5:3 & RT 5: 0.04 & RT 5:0.23 & \\
\hline \multirow{3}{*}{ Porosity (\%) } & RT 1:19 & RT 1:0.25 & RT $1: 5$ & \multirow{3}{*}{ FRT $1: 13.33$} \\
\hline & RT $3: 53$ & RT 3:0.71 & RT 3:15 & \\
\hline & RT $5: 3$ & RT 5: 0.04 & RT $5: 10$ & \\
\hline
\end{tabular}


Table C - 3.Permeability and porosity values before and after fuzzy upscaling (60\% of rock type 3$)$

\begin{tabular}{|c|c|c|c|c|}
\hline Property & $\begin{array}{l}\text { Number of High } \\
\text { Resolution Grids }\end{array}$ & $\begin{array}{c}\text { Fuzzy } \\
\text { Membership } \\
\text { Value }\end{array}$ & $\begin{array}{l}\text { Value before } \\
\text { upscaling }\end{array}$ & $\begin{array}{c}\text { Value after } \\
\text { fuzzy upscaling }\end{array}$ \\
\hline \multirow{3}{*}{$\mathrm{Kx}(\mathrm{mD})$} & RT 1:27 & RT 1:0.36 & RT 1: 0.519 & \multirow{3}{*}{ FRT $1: 10.26$} \\
\hline & RT $3: 45$ & RT 3:0.60 & RT 3 : 16.582 & \\
\hline & RT 5:3 & RT 5:0.04 & RT 5:2.3 & \\
\hline \multirow{3}{*}{$\mathrm{Ky}(\mathrm{mD})$} & RT 1:27 & RT 1:0.36 & RT $1: 0.519$ & \multirow{3}{*}{ FRT $1: 10.26$} \\
\hline & RT 3:45 & RT 3:0.60 & RT 3 : 16.582 & \\
\hline & RT $5: 3$ & RT 5:0.04 & RT 5:2.3 & \\
\hline \multirow{3}{*}{$\mathrm{Kz}(\mathrm{mD})$} & RT 1:27 & RT $1: 0.36$ & RT 1:0.052 & \multirow{3}{*}{ FRT $1: 1.03$} \\
\hline & RT $3: 45$ & RT 3:0.60 & RT 3 : 1.6582 & \\
\hline & RT 5:3 & RT 5: 0.04 & RT 5: 0.23 & \\
\hline \multirow{3}{*}{ Porosity (\%) } & RT 1:27 & RT 1:0.36 & RT 1:5 & \multirow{3}{*}{ FRT $1: 12.8$} \\
\hline & RT 3:45 & RT 3:0.60 & RT 3: 15 & \\
\hline & RT 5:3 & RT 5:0.04 & RT 5: 10 & \\
\hline
\end{tabular}

Table C - 4. Permeability values before and after fuzzy upscaling (50\% of rock type 3$)$

\begin{tabular}{|c|c|c|c|c|}
\hline Property & $\begin{array}{l}\text { Number of High } \\
\text { Resolution Grids }\end{array}$ & $\begin{array}{c}\text { Fuzzy } \\
\text { Membership } \\
\text { Value } \\
\end{array}$ & $\begin{array}{l}\text { Value before } \\
\text { upscaling }\end{array}$ & $\begin{array}{c}\text { Value after } \\
\text { fuzzy upscaling }\end{array}$ \\
\hline \multirow{3}{*}{$\mathrm{Kx}(\mathrm{mD})$} & RT 1:34 & RT $1: 0.45$ & RT $1: 0.519$ & \multirow{3}{*}{ FRT $1: 8.76$} \\
\hline & RT 3:38 & RT 3: 0.51 & RT 3 : 16.582 & \\
\hline & RT 5:3 & RT 5: 0.04 & RT 5:2.3 & \\
\hline \multirow{3}{*}{ Ky (mD) } & RT 1:34 & RT 1:0.45 & RT 1: 0.519 & \multirow{3}{*}{ FRT $1: 8.76$} \\
\hline & RT $3: 38$ & RT 3: 0.51 & RT 3 : 16.582 & \\
\hline & RT $5: 3$ & RT 5: 0.04 & RT 5:2.3 & \\
\hline \multirow{3}{*}{$\mathrm{Kz}(\mathrm{mD})$} & RT 1:34 & RT 1: 0.45 & RT 1: 0.052 & \multirow{3}{*}{ FRT $1: 8.76$} \\
\hline & RT 3:38 & RT 3: 0.51 & RT 3: 1.6582 & \\
\hline & RT $5: 3$ & RT 5: 0.04 & RT 5: 0.23 & \\
\hline \multirow{3}{*}{ Porosity (\%) } & RT 1:27 & RT 1:0.36 & RT 1:5 & \multirow{3}{*}{ FRT $1: 10.27$} \\
\hline & RT 3:45 & RT 3: 0.60 & RT 3: 15 & \\
\hline & RT 5:3 & RT 5: 0.04 & RT 5: 10 & \\
\hline
\end{tabular}




\section{Appendix D}

\section{Scenario 4-Model Graphic representations and Table of Data}

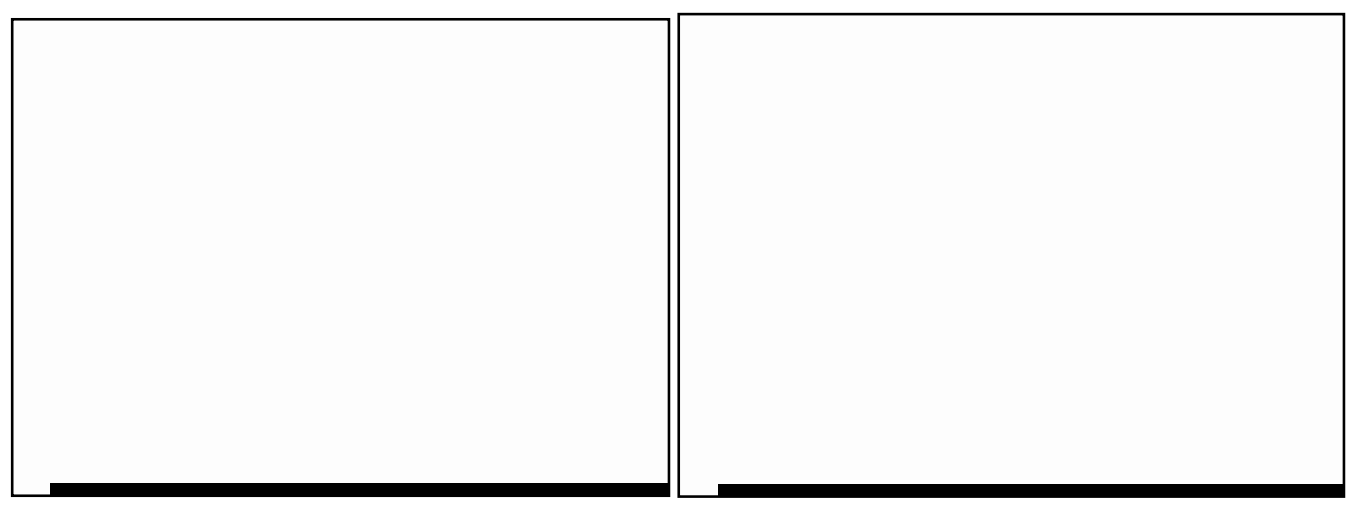

Figure D - 1.Rock type distribution -SRHR.

Figure D - 2.Porosity distribution (3RTHR/90\%)

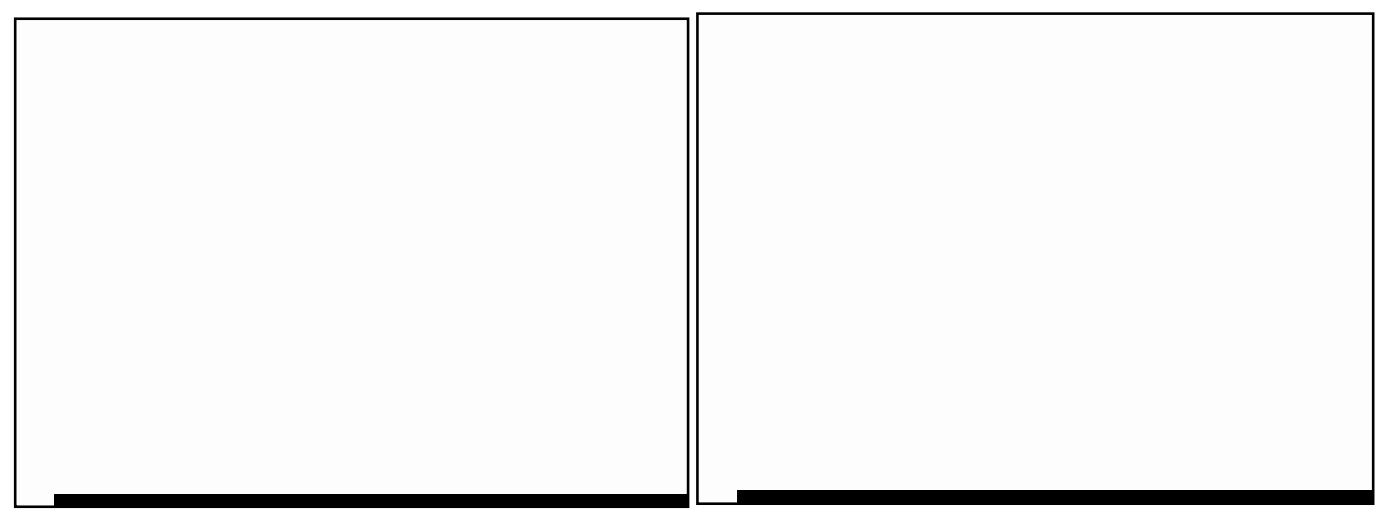

Figure D - 3.Kx distribution (3RTHR/90\%)

Figure D - 4.Rock type distribution (3RTHR/80\%)

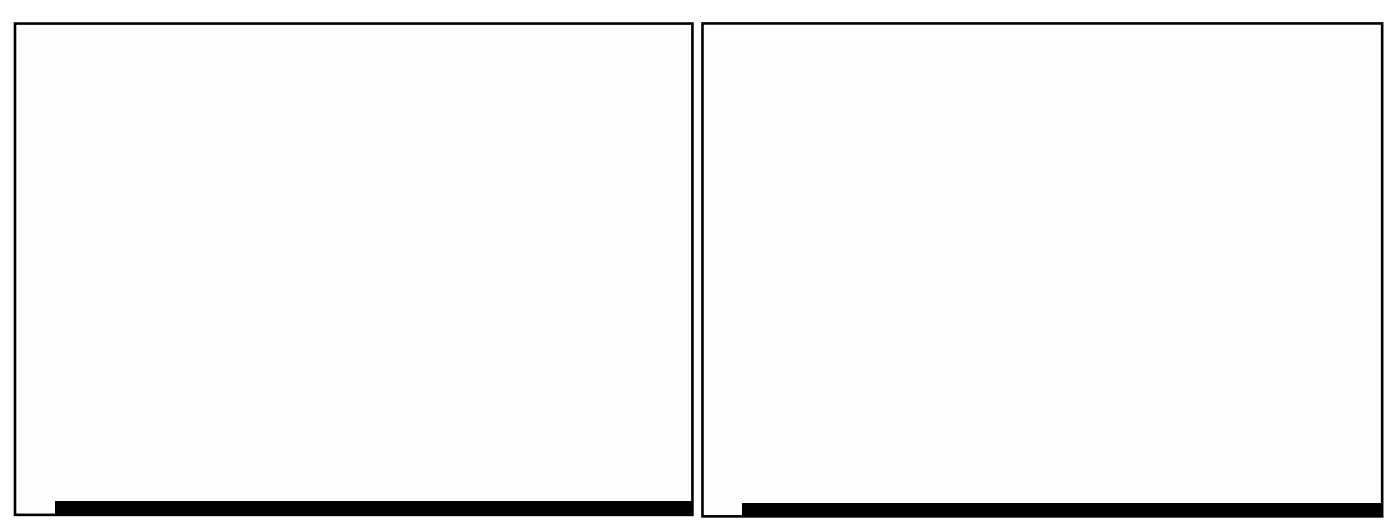

Figure D - 5.Rock type distribution (3RTHR/70\%) Figure D - 6.Rock type distribution (3RTHR/60\%) 


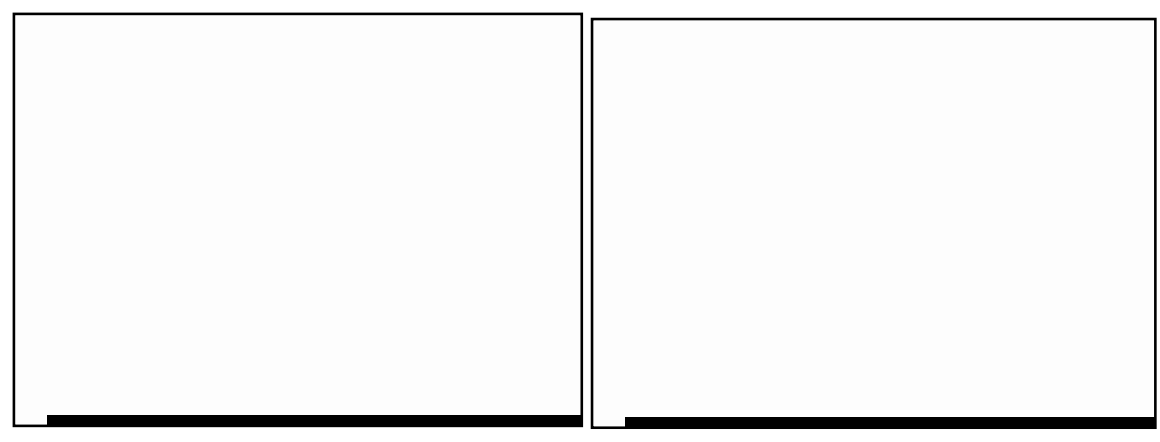

Figure D - 7.Rock type distribution (3RTHR/50\%) Figure D - 8.Porosity distribution -Fuzzy upscaled model $(90 \%)$

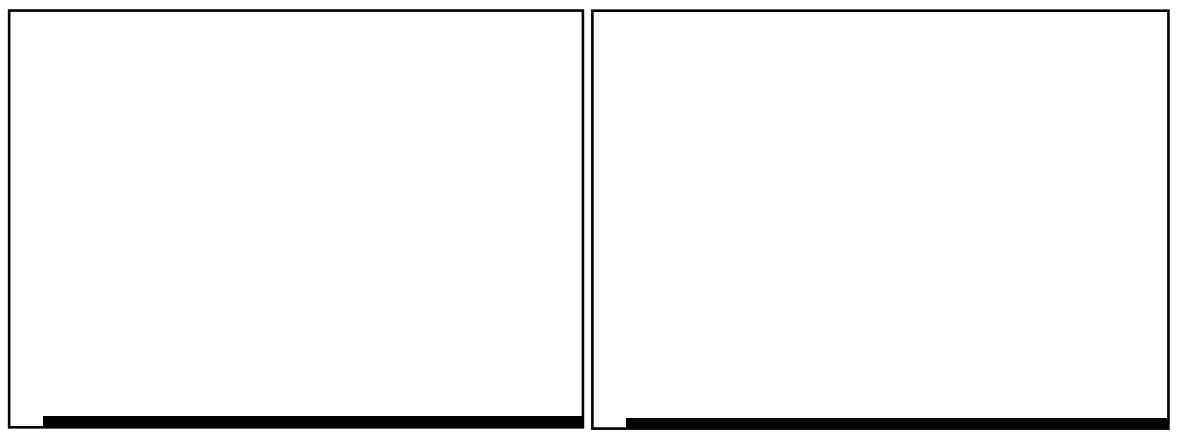

Figure D - 9.Kx distribution -Fuzzy upscaled (90\%) upscaled $(80 \%)$

Figure D - 10.Porosity distribution -Fuzzy

Table D - 1.Porosity values before and after fuzzy upscaling ( $80 \%$ of rock type 3 )

\begin{tabular}{|c|c|c|c|c|}
\hline Property & $\begin{array}{l}\text { Number of High } \\
\text { Resolution } \\
\text { Grids }\end{array}$ & Fuzzy Membership Value & Value before upscaling & $\begin{array}{l}\text { Value after } \\
\text { fuzzy } \\
\text { upscaling }\end{array}$ \\
\hline \multirow{15}{*}{$\begin{array}{c}\text { Porosity } \\
(\%)\end{array}$} & RT1 : 12 & RT1 : 0.16 & RT1: 5 & \multirow{3}{*}{ FRT1 $: 13.8$} \\
\hline & RT3 : 60 & RT3 :0.8 & RT3 $: 15$ & \\
\hline & RT5: 3 & RT5 : 0.04 & RT5 : 10 & \\
\hline & RT1 : 14 & RT1 : 0.19 & RT1: 5 & \multirow{3}{*}{$\begin{array}{l}\text { FRT2: } \\
13.87\end{array}$} \\
\hline & RT3 : 60 & RT3 : 0.8 & RT3 : 15 & \\
\hline & RT5 : 1 & RT5 : 0.01 & RT5 : 10 & \\
\hline & RT1 : 13 & RT1: 0.17 & RT1:5 & \multirow{3}{*}{$\begin{array}{c}\text { FRT3 : } \\
13.67\end{array}$} \\
\hline & RT3: 60 & RT3 $: 0.8$ & RT3 : 15 & \\
\hline & RT5: 2 & RT5: 0.03 & RT5 : 10 & \\
\hline & RT1: 11 & RT1: 0.15 & RT1: 5 & \multirow{3}{*}{$\begin{array}{c}\text { FRT4 : } \\
13.73\end{array}$} \\
\hline & RT3 : 60 & RT3 : 0.8 & RT3 : 15 & \\
\hline & RT5: 4 & RT5 : 0.05 & RT5 : 10 & \\
\hline & RT1 : 10 & RT1 $: 0.14$ & RT1: 5 & \multirow{3}{*}{$\begin{array}{c}\text { FRT5: } \\
13.93\end{array}$} \\
\hline & RT3 : 60 & RT3 : 0.8 & RT3 : 15 & \\
\hline & RT5 : 5 & RT5 : 0.06 & RT5 : 10 & \\
\hline
\end{tabular}


Table D - 2.Permeability values before and after fuzzy upscaling ( $80 \%$ of rock type 3 )

\begin{tabular}{|c|c|c|c|c|}
\hline Property & $\begin{array}{l}\text { Number of High } \\
\text { Resolution Grids }\end{array}$ & $\begin{array}{c}\text { Fuzzy } \\
\text { Membership } \\
\text { Value }\end{array}$ & $\begin{array}{l}\text { Value before } \\
\text { upscaling }\end{array}$ & $\begin{array}{l}\text { Value after fuzzy } \\
\text { upscaling }\end{array}$ \\
\hline \multirow{15}{*}{$\mathrm{Kx}(\mathrm{mD})$} & RT1 : 12 & RT1 : 0.16 & RT $1: 0.519$ & \multirow{3}{*}{ FRT1 : 13.47} \\
\hline & RT3 : 60 & RT3 :0.8 & RT $3: 16.582$ & \\
\hline & RT5 : 3 & RT5 : 0.04 & RT $5: 2.3$ & \\
\hline & RT1: 14 & RT1: 0.19 & RT $1: 0.519$ & \multirow{3}{*}{ FRT2 : 13.44} \\
\hline & RT3: 60 & RT3 : 0.8 & RT $3: 16.582$ & \\
\hline & RT5 : 1 & RT5 : 0.01 & RT $5: 2.3$ & \\
\hline & RT1: 13 & RT1 : 0.17 & RT $1: 0.519$ & \multirow{3}{*}{ FRT3 : 13.53} \\
\hline & RT3 : 60 & RT3 : 0.8 & RT $3: 16.582$ & \\
\hline & RT5 : 2 & RT5 : 0.03 & RT $5: 2.3$ & \\
\hline & RT1 : 11 & RT1 : 0.15 & RT $1: 0.519$ & \multirow{3}{*}{ FRT4 : 13.5} \\
\hline & RT3 : 60 & RT3 : 0.8 & RT $3: 16.582$ & \\
\hline & RT5 : 4 & RT5 : 0.05 & RT $5: 2.3$ & \\
\hline & RT1: 10 & RT1 : 0.14 & RT $1: 0.519$ & \multirow{3}{*}{ FRT5 : 13.4} \\
\hline & RT3: 60 & RT3 : 0.8 & RT $3: 16.582$ & \\
\hline & RT5 : 5 & RT5 : 0.06 & RT $5: 2.3$ & \\
\hline \multirow{15}{*}{$\mathrm{Ky}(\mathrm{mD})$} & RT1 : 12 & RT1 : 0.16 & RT $1: 0.519$ & \multirow{3}{*}{ FRT1 : 13.47} \\
\hline & RT3 : 60 & RT3 :0.8 & RT $3: 16.582$ & \\
\hline & RT5 : 3 & RT5 : 0.04 & RT $5: 2.3$ & \\
\hline & RT1: 14 & RT1 : 0.19 & RT $1: 0.519$ & \multirow{3}{*}{ FRT2 $: 13.44$} \\
\hline & RT3 : 60 & RT3 : 0.8 & RT $3: 16.582$ & \\
\hline & RT5 : 1 & RT5 : 0.01 & RT $5: 2.3$ & \\
\hline & RT1 : 13 & RT1 : 0.17 & RT $1: 0.519$ & \multirow{3}{*}{ FRT3 $: 13.53$} \\
\hline & RT3 : 60 & RT3 : 0.8 & RT $3: 16.582$ & \\
\hline & RT5 : 2 & RT5 : 0.03 & RT $5: 2.3$ & \\
\hline & RT1: 11 & RT1 : 0.15 & RT $1: 0.519$ & \multirow{3}{*}{ FRT4 : 13.5} \\
\hline & RT3: 60 & RT3 : 0.8 & RT $3: 16.582$ & \\
\hline & RT5 : 4 & RT5 : 0.05 & RT $5: 2.3$ & \\
\hline & RT1: 10 & RT1: 0.14 & RT $1: 0.519$ & \multirow{3}{*}{ FRT5 : 13.4} \\
\hline & RT3 : 60 & RT3 : 0.8 & RT $3: 16.582$ & \\
\hline & RT5 : 5 & RT5 : 0.06 & RT $5: 2.3$ & \\
\hline \multirow{15}{*}{$\mathrm{Kz}(\mathrm{mD})$} & RT1: 12 & RT1 : 0.16 & RT $1: 0.052$ & \multirow{3}{*}{ FRT1 $: 1.347$} \\
\hline & RT3 : 60 & RT3 :0.8 & RT $3: 1.6582$ & \\
\hline & RT5 : 3 & RT5 : 0.04 & RT $5: 0.23$ & \\
\hline & RT1: 14 & RT1: 0.19 & RT 1:0.052 & \multirow{3}{*}{ FRT2 $: 1.344$} \\
\hline & RT3 : 60 & RT3 : 0.8 & RT $3: 1.6582$ & \\
\hline & RT5 : 1 & RT5 : 0.01 & RT $5: 0.23$ & \\
\hline & RT1 : 13 & RT1 : 0.17 & RT $1: 0.052$ & \multirow{3}{*}{ FRT3 $: 1.353$} \\
\hline & RT3 : 60 & RT3 : 0.8 & RT $3: 1.6582$ & \\
\hline & RT5 : 2 & RT5 : 0.03 & RT $5: 0.23$ & \\
\hline & RT1: 11 & RT1: 0.15 & RT 1:0.052 & \multirow{3}{*}{ FRT4 : 1.35} \\
\hline & RT3: 60 & RT3 : 0.8 & RT $3: 1.6582$ & \\
\hline & RT5 : 4 & RT5 : 0.05 & RT $5: 0.23$ & \\
\hline & RT1 : 10 & RT1 : 0.14 & RT $1: 0.052$ & \multirow{3}{*}{ FRT5 $: 1.34$} \\
\hline & RT3: 60 & RT3 : 0.8 & RT $3: 1.6582$ & \\
\hline & RT5 : 5 & RT5 : 0.06 & RT $5: 0.23$ & \\
\hline
\end{tabular}


Table D - 3.Permeability values before and after fuzzy upscaling ( $70 \%$ of rock type 3 )

\begin{tabular}{|c|c|c|c|c|}
\hline Property & $\begin{array}{l}\text { Number of High } \\
\text { Resolution Grids }\end{array}$ & $\begin{array}{c}\text { Fuzzy } \\
\text { Membership } \\
\text { Value } \\
\end{array}$ & $\begin{array}{l}\text { Value before } \\
\text { upscaling }\end{array}$ & $\begin{array}{l}\text { Value after fuzzy } \\
\text { upscaling }\end{array}$ \\
\hline \multirow{15}{*}{$\mathrm{Kx}(\mathrm{mD})$} & RT1: 19 & RT1 : 0.25 & RT $1: 0.519$ & \multirow{3}{*}{ FRT1 : 11.97} \\
\hline & RT3 : 53 & RT3 :0.71 & RT $3: 16.582$ & \\
\hline & RT5 : 3 & RT5 : 0.04 & RT $5: 2.3$ & \\
\hline & RT1:21 & RT1: 0.28 & RT $1: 0.519$ & \multirow{3}{*}{ FRT2 : 11.94} \\
\hline & RT3: 53 & RT3 :0.71 & RT 3 : 16.582 & \\
\hline & RT5 : 1 & RT5 : 0.01 & RT $5: 2.3$ & \\
\hline & RT1: 20 & RT1 : 0.27 & RT 1:0.519 & \multirow{3}{*}{ FRT3 : 12.03} \\
\hline & RT3 : 53 & RT3 :0.71 & RT $3: 16.582$ & \\
\hline & RT5 : 2 & RT5 : 0.03 & RT $5: 2.3$ & \\
\hline & RT1 : 18 & RT1: 0.24 & RT $1: 0.519$ & \multirow{3}{*}{ FRT4 : 12} \\
\hline & RT3 : 53 & RT3 :0.71 & RT $3: 16.582$ & \\
\hline & RT5 : 4 & RT5 : 0.05 & RT $5: 2.3$ & \\
\hline & RT1 : 17 & RT1 : 0.23 & RT $1: 0.519$ & \multirow{3}{*}{ FRT5 : 11.9} \\
\hline & RT3 : 53 & RT3 :0.71 & RT $3: 16.582$ & \\
\hline & RT5 : 5 & RT5 : 0.06 & RT $5: 2.3$ & \\
\hline \multirow{15}{*}{$\mathrm{Ky}(\mathrm{mD})$} & RT1: 19 & RT1 : 0.25 & RT $1: 0.519$ & \multirow{3}{*}{ FRT1 : 11.97} \\
\hline & RT3 : 53 & RT3 :0.71 & RT $3: 16.582$ & \\
\hline & RT5 : 3 & RT5 : 0.04 & RT $5: 2.3$ & \\
\hline & RT1: 21 & RT1 : 0.28 & RT $1: 0.519$ & \multirow{3}{*}{ FRT2 : 11.94} \\
\hline & RT3 : 53 & RT3 :0.71 & RT $3: 16.582$ & \\
\hline & RT5 : 1 & RT5 : 0.01 & RT $5: 2.3$ & \\
\hline & RT1: 20 & RT1 : 0.27 & RT $1: 0.519$ & \multirow{3}{*}{ FRT3 : 12.03} \\
\hline & RT3 : 53 & RT3 :0.71 & RT $3: 16.582$ & \\
\hline & RT5 : 2 & RT5 : 0.03 & RT $5: 2.3$ & \\
\hline & RT1 : 18 & RT1 : 0.24 & RT $1: 0.519$ & \multirow{3}{*}{ FRT4 : 12} \\
\hline & RT3: 53 & RT3 :0.71 & RT $3: 16.582$ & \\
\hline & RT5 : 4 & RT5 : 0.05 & RT $5: 2.3$ & \\
\hline & RT1: 17 & RT1: 0.23 & RT $1: 0.519$ & \multirow{3}{*}{ FRT5 : 11.9} \\
\hline & RT3: 53 & RT3 :0.71 & RT $3: 16.582$ & \\
\hline & RT5 : 5 & RT5 : 0.06 & RT $5: 2.3$ & \\
\hline \multirow{15}{*}{$\mathrm{Kz}(\mathrm{mD})$} & RT1 : 19 & RT1 : 0.25 & RT $1: 0.052$ & \multirow{3}{*}{ FRT1 : 1.197} \\
\hline & RT3 : 53 & RT3 :0.71 & RT $3: 1.6582$ & \\
\hline & RT5 : 3 & RT5 : 0.04 & RT $5: 0.23$ & \\
\hline & RT1:21 & RT1 : 0.28 & RT $1: 0.052$ & \multirow{3}{*}{ FRT2 : 1.194} \\
\hline & RT3: 53 & RT3 :0.71 & RT $3: 1.6582$ & \\
\hline & RT5 : 1 & RT5 : 0.01 & RT $5: 0.23$ & \\
\hline & RT1:20 & RT1 : 0.27 & RT $1: 0.052$ & \multirow{3}{*}{ FRT3 $: 1.2$} \\
\hline & RT3 : 53 & RT3 :0.71 & RT $3: 1.6582$ & \\
\hline & RT5 : 2 & RT5 : 0.03 & RT $5: 0.23$ & \\
\hline & RT1: 18 & RT1 : 0.24 & RT $1: 0.052$ & \multirow{3}{*}{ FRT4 $: 1.2$} \\
\hline & RT3 : 53 & RT3 :0.71 & RT $3: 1.6582$ & \\
\hline & RT5 : 4 & RT5 : 0.05 & RT $5: 0.23$ & \\
\hline & RT1 : 17 & RT1 : 0.23 & RT $1: 0.052$ & \multirow{3}{*}{ FRT5 : 1.19} \\
\hline & RT3: 53 & RT3 :0.71 & RT $3: 1.6582$ & \\
\hline & RT5 : 5 & RT5 : 0.06 & RT $5: 0.23$ & \\
\hline
\end{tabular}


Table D - 4.Permeability values before and after fuzzy upscaling ( $70 \%$ of rock type 3 )

\begin{tabular}{|c|c|c|c|c|}
\hline Property & $\begin{array}{c}\text { Number of High Resolution } \\
\text { Grids }\end{array}$ & $\begin{array}{c}\text { Fuzzy } \\
\text { Membership } \\
\text { Value }\end{array}$ & $\begin{array}{c}\text { Value } \\
\text { before } \\
\text { upscaling }\end{array}$ & $\begin{array}{l}\text { Value after } \\
\text { fuzzy } \\
\text { upscaling }\end{array}$ \\
\hline \multirow{15}{*}{ Porosity (\%) } & RT1: 19 & RT1: 0.25 & RT1:5 & \multirow{3}{*}{ FRT1 $: 13.33$} \\
\hline & RT3 : 53 & RT3 :0.71 & RT3 : 15 & \\
\hline & RT5: 3 & "RT5 : 0.04 & RT5 : 10 & \\
\hline & RT1:21 & RT1 : 0.28 & RT1: 5 & \multirow{3}{*}{ FRT2 : 13.4} \\
\hline & RT3 : 53 & RT3 :0.71 & RT3 : 15 & \\
\hline & RT5 : 1 & RT5 : 0.01 & RT5 : 10 & \\
\hline & RT1: 20 & RT1: 0.27 & RT1:5 & \multirow{3}{*}{ FRT3 $: 13.2$} \\
\hline & RT3 : 53 & RT3 :0.71 & RT3 : 15 & \\
\hline & RT5 : 2 & RT5: 0.03 & RT5 : 10 & \\
\hline & RT1 : 18 & RT1 : 0.24 & RT1: 5 & \multirow{3}{*}{ FRT4 : 13.27} \\
\hline & RT3: 53 & RT3 :0.71 & RT3 : 15 & \\
\hline & RT5 : 4 & RT5 : 0.05 & RT5 : 10 & \\
\hline & RT1: 17 & RT1: 0.23 & RT1: 5 & \multirow{3}{*}{ FRT5 : 13.47} \\
\hline & RT3 : 53 & RT3 :0.71 & RT3 : 15 & \\
\hline & RT5 : 5 & RT5 : 0.06 & RT5 : 10 & \\
\hline
\end{tabular}

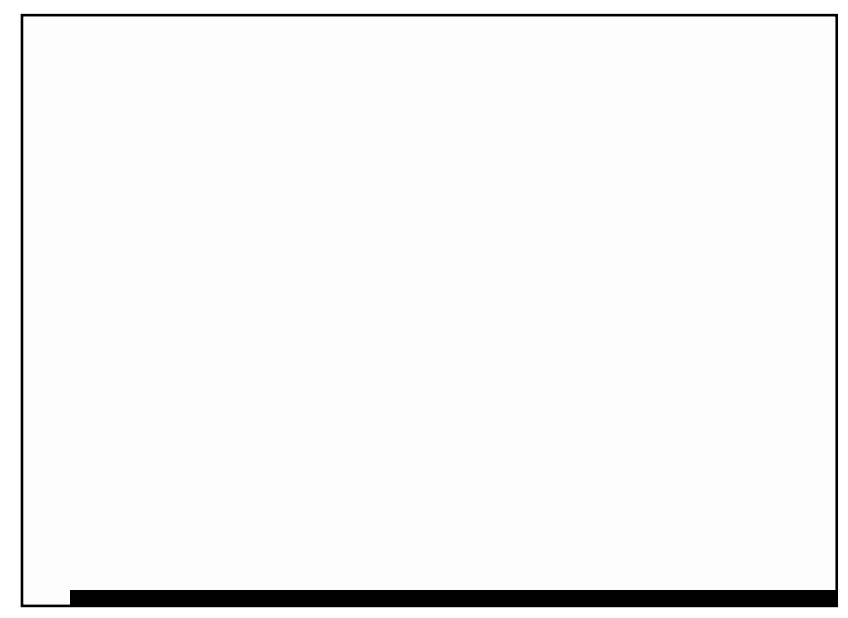

Figure D - 11.Kx distribution -Fuzzy upscaled model (70\%) 
Table D - 5.Permeability values before and after fuzzy upscaling (60\% of rock type 3 )

\begin{tabular}{|c|c|c|c|c|}
\hline Property & $\begin{array}{l}\text { Number of High } \\
\text { Resolution Grids }\end{array}$ & $\begin{array}{c}\text { Fuzzy } \\
\text { Membership } \\
\text { Value } \\
\end{array}$ & $\begin{array}{l}\text { Value before } \\
\text { upscaling }\end{array}$ & $\begin{array}{l}\text { Value after fuzzy } \\
\text { upscaling }\end{array}$ \\
\hline \multirow{15}{*}{$\mathrm{Kx}(\mathrm{mD})$} & RT1:27 & RT1: 0.36 & RT $1: 0.519$ & \multirow{3}{*}{ FRT1 : 10.26} \\
\hline & RT3 : 45 & RT3 :0.6 & RT $3: 16.58$ & \\
\hline & RT5 : 3 & RT5 : 0.04 & RT $5: 2.3$ & \\
\hline & RT1:29 & RT1: 0.39 & RT $1: 0.519$ & \multirow{3}{*}{ FRT2 : 10.22} \\
\hline & RT3 : 45 & RT3 :0.6 & RT $3: 16.582$ & \\
\hline & RT5 : 1 & RT5 : 0.01 & RT $5: 2.3$ & \\
\hline & RT1 : 28 & RT1 $: 0.37$ & RT $1: 0.519$ & \multirow{3}{*}{ FRT3 : 10.32} \\
\hline & RT3 : 45 & RT3 :0.6 & RT $3: 16.582$ & \\
\hline & RT5 : 2 & RT5 : 0.03 & RT $5: 2.3$ & \\
\hline & RT1:26 & RT1: 0.35 & RT 1:0.519 & \multirow{3}{*}{ FRT4 : 10.29} \\
\hline & RT3 : 45 & RT3 :0.6 & RT $3: 16.582$ & \\
\hline & RT5 : 4 & RT5 : 0.05 & RT $5: 2.3$ & \\
\hline & RT1 : 25 & RT1 : 0.33 & RT $1: 0.519$ & \multirow{3}{*}{ FRT5 : 10.19} \\
\hline & RT3 : 45 & RT3 :0.6 & RT $3: 16.582$ & \\
\hline & RT5 : 5 & RT5 : 0.06 & RT $5: 2.3$ & \\
\hline \multirow{15}{*}{$\mathrm{Ky}(\mathrm{mD})$} & RT1 : 27 & RT1: 0.36 & RT $1: 0.519$ & \multirow{3}{*}{ FRT1 : 10.26} \\
\hline & RT3 : 45 & RT3 :0.6 & RT $3: 16.582$ & \\
\hline & RT5 : 3 & RT5 : 0.04 & RT $5: 2.3$ & \\
\hline & RT1 : 29 & RT1 : 0.39 & RT $1: 0.519$ & \multirow{3}{*}{ FRT2 : 10.22} \\
\hline & RT3 : 45 & RT3 :0.6 & RT $3: 16.582$ & \\
\hline & RT5 : 1 & RT5 : 0.01 & RT $5: 2.3$ & \\
\hline & RT1 : 28 & RT1: 0.37 & RT $1: 0.519$ & \multirow{3}{*}{ FRT3 : 10.32} \\
\hline & RT3 $: 45$ & RT3 :0.6 & RT $3: 16.582$ & \\
\hline & RT5 : 2 & RT5 : 0.03 & RT $5: 2.3$ & \\
\hline & RT1 : 26 & RT1 : 0.35 & RT $1: 0.519$ & \multirow{3}{*}{ FRT4 : 10.29} \\
\hline & RT3 : 45 & RT3 :0.6 & RT $3: 16.582$ & \\
\hline & RT5: 4 & RT5 : 0.05 & RT $5: 2.3$ & \\
\hline & RT1 : 25 & RT1: 0.33 & RT $1: 0.519$ & \multirow{3}{*}{ FRT5 : 10.19} \\
\hline & RT3 : 45 & RT3 :0.6 & RT $3: 16.582$ & \\
\hline & RT5 : 5 & RT5 : 0.06 & RT $5: 2.3$ & \\
\hline \multirow{15}{*}{$\mathrm{Kz}(\mathrm{mD})$} & RT1 : 27 & RT1: 0.36 & RT $1: 0.052$ & \multirow{3}{*}{ FRT1 : 1.026} \\
\hline & RT3 : 45 & RT3 :0.6 & RT $3: 1.658$ & \\
\hline & RT5: 3 & RT5 : 0.04 & RT $5: 0.23$ & \\
\hline & RT1: 29 & RT1: 0.39 & RT $1: 0.052$ & \multirow{3}{*}{ FRT2 : 1.02} \\
\hline & RT3 : 45 & RT3 :0.6 & RT $3: 1.658$ & \\
\hline & RT5 : 1 & RT5 : 0.01 & RT $5: 0.23$ & \\
\hline & RT1: 28 & RT1: 0.37 & RT $1: 0.052$ & \multirow{3}{*}{ FRT3 : 1.032} \\
\hline & RT3 : 45 & RT3 :0.6 & RT 3:1.658 & \\
\hline & RT5 : 2 & RT5 : 0.03 & RT $5: 0.23$ & \\
\hline & RT1 : 26 & RT1 $: 0.35$ & RT $1: 0.052$ & \multirow{3}{*}{ FRT4 : 1.029} \\
\hline & RT3 : 45 & RT3 :0.6 & RT 3: 1.658 & \\
\hline & RT5 : 4 & RT5 : 0.05 & RT $5: 0.23$ & \\
\hline & RT1: 25 & RT1: 0.33 & RT $1: 0.052$ & \multirow{3}{*}{ FRT5 : 1.019} \\
\hline & RT3 : 45 & RT3 :0.6 & RT $3: 1.658$ & \\
\hline & RT5: 5 & RT5 : 0.06 & RT $5: 0.23$ & \\
\hline
\end{tabular}


Table D - 6.Porosity values before and after fuzzy upscaling (60\% of rock type 3 )

\begin{tabular}{|c|c|c|c|c|}
\hline Property & Number of High Resolution Grids & $\begin{array}{c}\text { Fuzzy } \\
\text { Membership } \\
\text { Value }\end{array}$ & $\begin{array}{c}\text { Value } \\
\text { before } \\
\text { upscaling }\end{array}$ & $\begin{array}{l}\text { Value after } \\
\text { fuzzy } \\
\text { upscaling }\end{array}$ \\
\hline \multirow{15}{*}{ Porosity (\%) } & RT1:27 & RT1 : 0.36 & RT1: 5 & \multirow{3}{*}{ FRT1 : 12.8} \\
\hline & RT3 : 45 & RT3 :0.6 & RT3 : 15 & \\
\hline & RT5 : 3 & RT5 : 0.04 & RT5 : 10 & \\
\hline & RT1:29 & RT1: 0.39 & RT1: 5 & \multirow{3}{*}{ FRT2 $: 12.87$} \\
\hline & RT3 : 45 & RT3 :0.6 & RT3 : 15 & \\
\hline & RT5 : 1 & RT5: 0.01 & RT5 : 10 & \\
\hline & RT1 : 28 & RT1 : 0.37 & RT1 : 5 & \multirow{3}{*}{ FRT3 $: 12.67$} \\
\hline & RT3 : 45 & RT3 :0.6 & RT3 : 15 & \\
\hline & RT5 : 2 & RT5 : 0.03 & RT5 : 10 & \\
\hline & RT1 : 26 & RT1 $: 0.35$ & RT1 : 5 & \multirow{3}{*}{ FRT4 : 12.73} \\
\hline & RT3 : 45 & RT3 :0.6 & RT3 : 15 & \\
\hline & RT5 : 4 & RT5 : 0.05 & RT5 : 10 & \\
\hline & RT1 : 25 & RT1 : 0.33 & RT1 : 5 & \multirow{3}{*}{ FRT5 : 12.93} \\
\hline & RT3 : 45 & RT3 :0.6 & RT3 : 15 & \\
\hline & RT5 : 5 & RT5 : 0.06 & RT5 : 10 & \\
\hline
\end{tabular}

Figure D - 12.Kx distribution -Fuzzy upscaled model (60\%) 
Table D - 7.Permeability values before and after fuzzy upscaling (50\% of rock type 3 )

\begin{tabular}{|c|c|c|c|c|}
\hline Property & $\begin{array}{l}\text { Number of High } \\
\text { Resolution Grids }\end{array}$ & $\begin{array}{c}\text { Fuzzy } \\
\text { Membership } \\
\text { Value }\end{array}$ & $\begin{array}{l}\text { Value before } \\
\text { upscaling }\end{array}$ & $\begin{array}{c}\text { Value after fuzzy } \\
\text { upscaling }\end{array}$ \\
\hline \multirow{15}{*}{$\mathrm{Kx}(\mathrm{mD})$} & RT1:34 & RT1 : 0.45 & RT 1:0.519 & \multirow{3}{*}{ FRT1 $: 8.76$} \\
\hline & RT3 : 38 & RT3 :0.51 & RT 3: 16.58 & \\
\hline & RT5 : 3 & RT5 : 0.04 & RT $5: 2.3$ & \\
\hline & RT1: 36 & RT1 : 0.48 & RT $1: 0.519$ & \multirow{3}{*}{ FRT2 $: 8.72$} \\
\hline & RT3 : 38 & RT3 :0.51 & RT $3: 16.582$ & \\
\hline & RT5 : 1 & RT5 : 0.01 & RT $5: 2.3$ & \\
\hline & RT1 : 35 & RT1 : 0.47 & RT $1: 0.519$ & \multirow{3}{*}{ FRT3 $: 8.82$} \\
\hline & RT3 : 38 & RT3 :0.51 & RT $3: 16.582$ & \\
\hline & RT5 : 2 & RT5 : 0.03 & RT $5: 2.3$ & \\
\hline & RT1 : 33 & RT1 : 0.44 & RT $1: 0.519$ & \multirow{3}{*}{ FRT4 : 8.79} \\
\hline & RT3 : 38 & RT3 :0.51 & RT $3: 16.582$ & \\
\hline & RT5 : 4 & RT5 : 0.05 & RT $5: 2.3$ & \\
\hline & RT1 : 32 & RT1 : 0.43 & RT $1: 0.519$ & \multirow{3}{*}{ FRT5 : 8.69} \\
\hline & RT3: 38 & RT3 :0.51 & RT $3: 16.582$ & \\
\hline & RT5 : 5 & RT5 : 0.06 & RT $5: 2.3$ & \\
\hline \multirow{15}{*}{$\mathrm{Ky}(\mathrm{mD})$} & RT1: 34 & RT1 : 0.45 & RT $1: 0.519$ & \multirow{3}{*}{ FRT1 $: 8.76$} \\
\hline & RT3 : 38 & RT3 :0.51 & RT $3: 16.582$ & \\
\hline & RT5 : 3 & RT5 : 0.04 & RT $5: 2.3$ & \\
\hline & RT1: 36 & RT1 : 0.48 & RT $1: 0.519$ & \multirow{3}{*}{ FRT2 $: 8.72$} \\
\hline & RT3: 38 & RT3 :0.51 & RT $3: 16.582$ & \\
\hline & RT5 : 1 & RT5 : 0.01 & RT $5: 2.3$ & \\
\hline & RT1 : 35 & RT1 : 0.47 & RT $1: 0.519$ & \multirow{3}{*}{ FRT3 $: 8.82$} \\
\hline & RT3 : 38 & RT3 :0.51 & RT $3: 16.582$ & \\
\hline & RT5 : 2 & RT5 : 0.03 & RT $5: 2.3$ & \\
\hline & RT1 : 33 & RT1 : 0.44 & RT $1: 0.519$ & \multirow{3}{*}{ FRT4 : 8.79} \\
\hline & RT3: 38 & RT3 :0.51 & RT $3: 16.582$ & \\
\hline & RT5 : 4 & RT5 : 0.05 & RT $5: 2.3$ & \\
\hline & RT1: 32 & RT1 : 0.43 & RT $1: 0.519$ & \multirow{3}{*}{ FRT5 : 8.69} \\
\hline & RT3: 38 & RT3 :0.51 & RT $3: 16.582$ & \\
\hline & RT5 : 5 & RT5 : 0.06 & RT $5: 2.3$ & \\
\hline \multirow{15}{*}{$\mathrm{Kz}(\mathrm{mD})$} & RT1:34 & RT1: 0.45 & RT $1: 0.052$ & \multirow{3}{*}{ FRT1 $: 0.876$} \\
\hline & RT3: 38 & RT3 :0.51 & RT 3:1.658 & \\
\hline & RT5 : 3 & RT5 : 0.04 & RT $5: 0.23$ & \\
\hline & RT1: 36 & RT1 : 0.48 & RT $1: 0.052$ & \multirow{3}{*}{ FRT2 $: 0.872$} \\
\hline & RT3: 38 & RT3 :0.51 & RT 3:1.658 & \\
\hline & RT5 : 1 & RT5 : 0.01 & RT $5: 0.23$ & \\
\hline & RT1 : 35 & RT1 : 0.47 & RT $1: 0.052$ & \multirow{3}{*}{ FRT3 : 0.882} \\
\hline & RT3 : 38 & RT3 :0.51 & RT $3: 1.658$ & \\
\hline & RT5 : 2 & RT5 : 0.03 & RT $5: 0.23$ & \\
\hline & RT1: 33 & RT1 : 0.44 & RT $1: 0.052$ & \multirow{3}{*}{ FRT4 : 0.79} \\
\hline & RT3: 38 & RT3 :0.51 & RT 3:1.658 & \\
\hline & RT5 : 4 & RT5 : 0.05 & RT $5: 0.23$ & \\
\hline & RT1 : 32 & RT1 : 0.43 & RT $1: 0.052$ & \multirow{3}{*}{ FRT5 : 0.869} \\
\hline & RT3 : 38 & RT3 :0.51 & RT $3: 1.658$ & \\
\hline & RT5 : 5 & RT5: 0.06 & RT $5: 0.23$ & \\
\hline
\end{tabular}


Table D - 8.Porosity values before and after fuzzy upscaling (50\% of rock type 3)

\begin{tabular}{|c|c|c|c|c|}
\hline Property & $\begin{array}{c}\text { Number of High Resolution } \\
\text { Grids }\end{array}$ & $\begin{array}{c}\text { Fuzzy } \\
\text { Membership } \\
\text { Value }\end{array}$ & $\begin{array}{c}\text { Value } \\
\text { before } \\
\text { upscaling }\end{array}$ & $\begin{array}{l}\text { Value after } \\
\text { fuzzy } \\
\text { upscaling }\end{array}$ \\
\hline \multirow{15}{*}{ Porosity (\%) } & RT1: 34 & RT1 : 0.45 & RT1: 5 & \multirow{3}{*}{ FRT1 $: 10.27$} \\
\hline & RT3 : 38 & RT3 :0.51 & RT3 $: 15$ & \\
\hline & RT5 : 3 & RT5 : 0.04 & RT5 : 10 & \\
\hline & RT1: 36 & RT1 $: 0.48$ & RT1: 5 & \multirow{3}{*}{ FRT2 $: 10.2$} \\
\hline & RT3 : 38 & RT3 :0.51 & RT3 $: 15$ & \\
\hline & RT5 : 1 & RT5 : 0.01 & RT5 : 10 & \\
\hline & RT1 : 35 & RT1 $: 0.47$ & RT1: 5 & \multirow{3}{*}{ FRT3 $: 10.4$} \\
\hline & RT3 : 38 & RT3 :0.51 & RT3 : 15 & \\
\hline & RT5 : 2 & RT5 : 0.03 & RT5 : 10 & \\
\hline & RT1 : 33 & RT1 $: 0.44$ & RT1: 5 & \multirow{3}{*}{ FRT4 : 10.3} \\
\hline & RT3 $: 38$ & RT3 :0.51 & RT3 $: 15$ & \\
\hline & RT5: 4 & RT5 : 0.05 & RT5 : 10 & \\
\hline & RT1 : 32 & RT1 $: 0.43$ & RT1: 5 & \multirow{3}{*}{ FRT5 $: 10.33$} \\
\hline & RT3 : 38 & RT3 :0.51 & RT3 $: 15$ & \\
\hline & RT5 : 5 & RT5 : 0.06 & RT5 : 10 & \\
\hline
\end{tabular}

Figure D - 13.Kx distribution -Fuzzy upscaled model (50\%) 


\section{Appendix E}

\section{Results \\ Scenario 1}
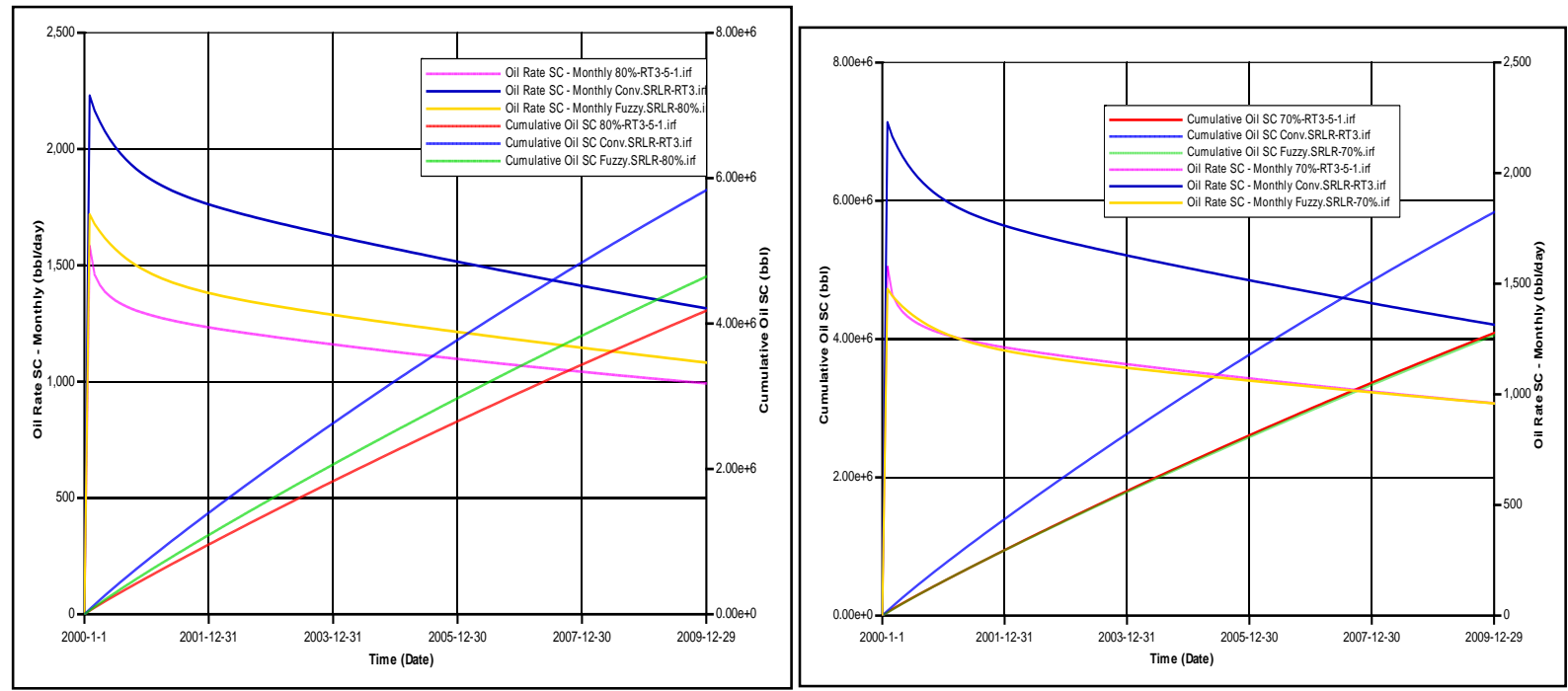

Figure E - 1.3RHR-80\% and SRLR-80\% - Oil Production Figure E - 2. 3RHR-70\% and SRLR-70\% - Oil Production
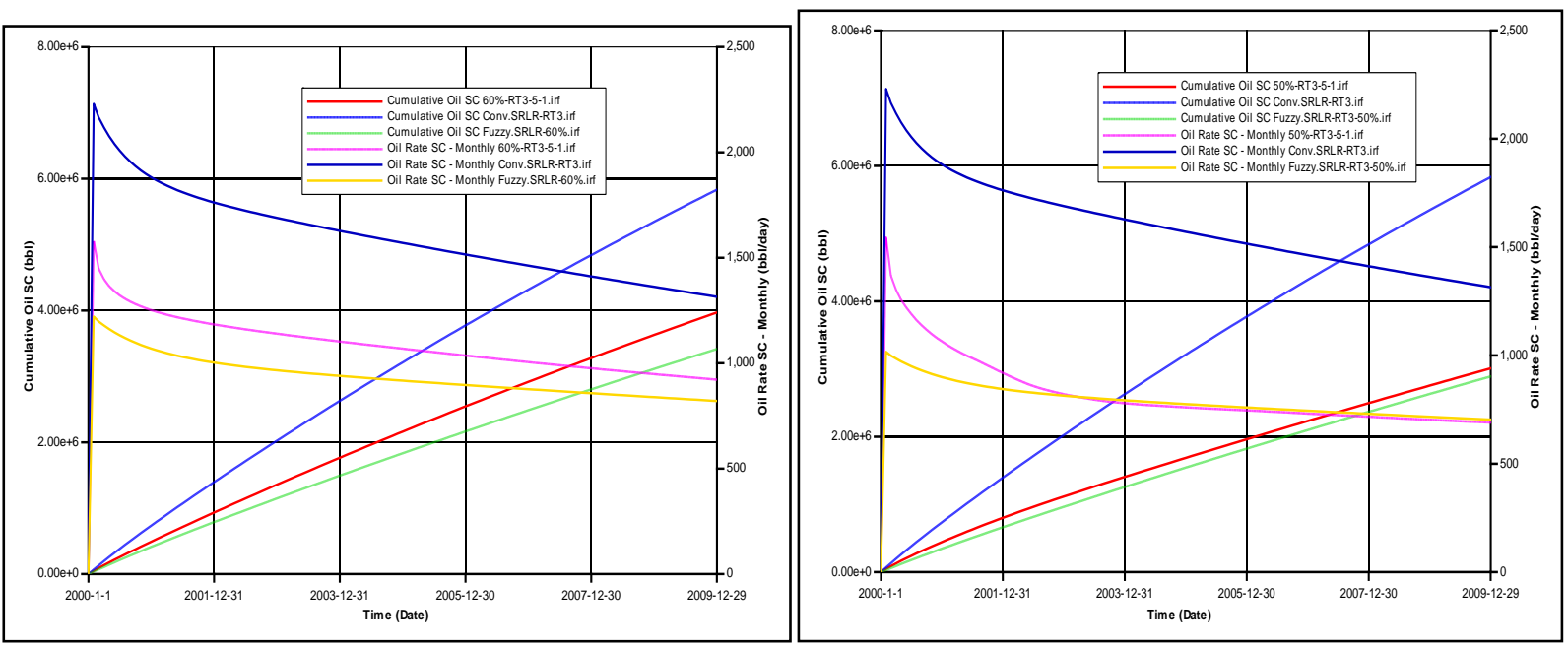

Figure E - 3.3RHR-60\% and SRLR-60\% - Oil Production Figure E - 4.3RHR-50\% and SRLR-50\% - Oil Production 


\section{Scenario 2}

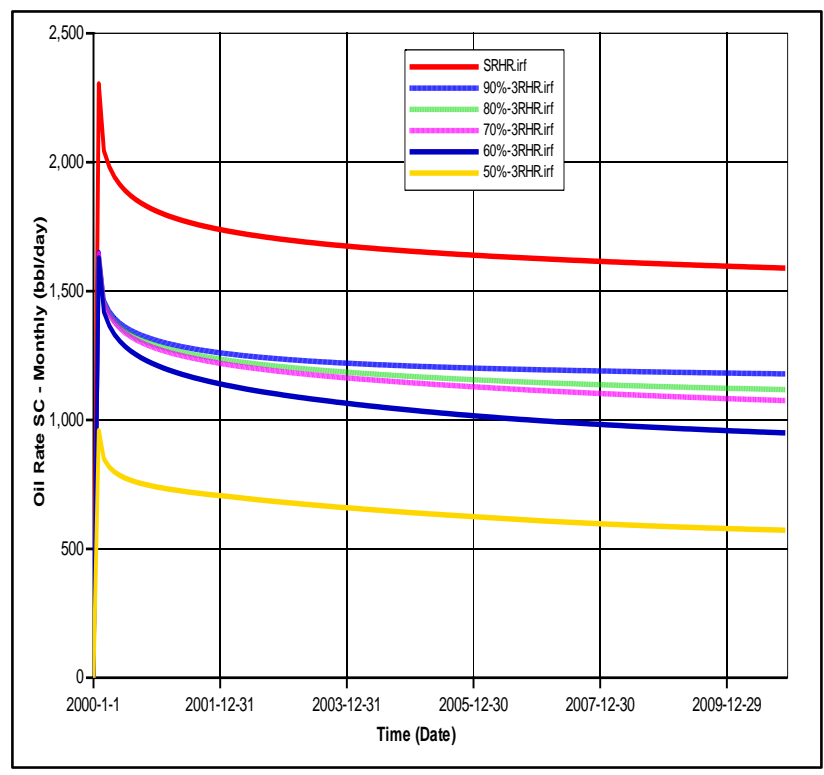

Figure E - 5.Monthly oil rate comparison

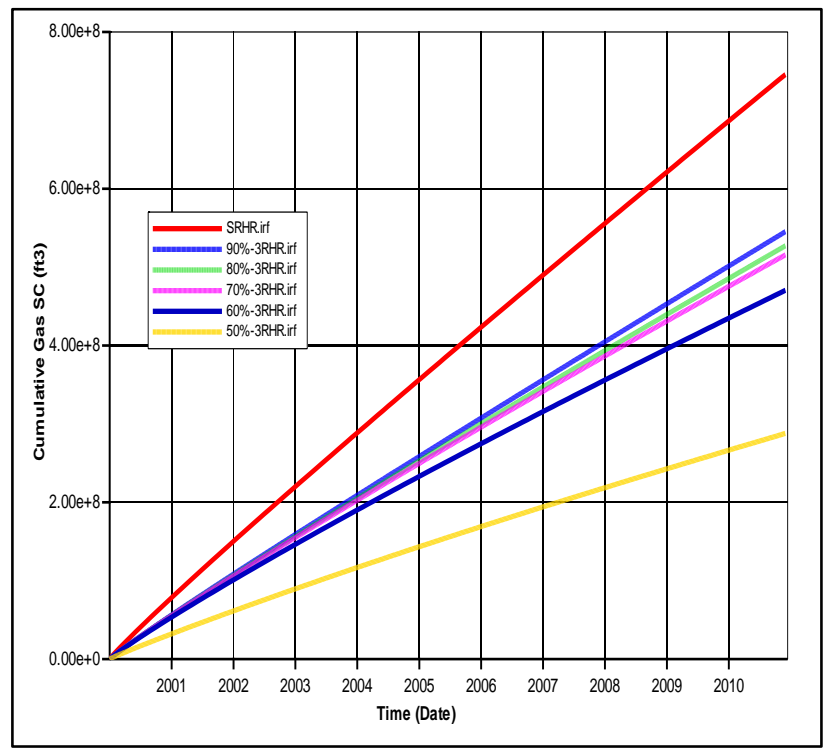

Figure E - 7.Cumulative gas production comparison

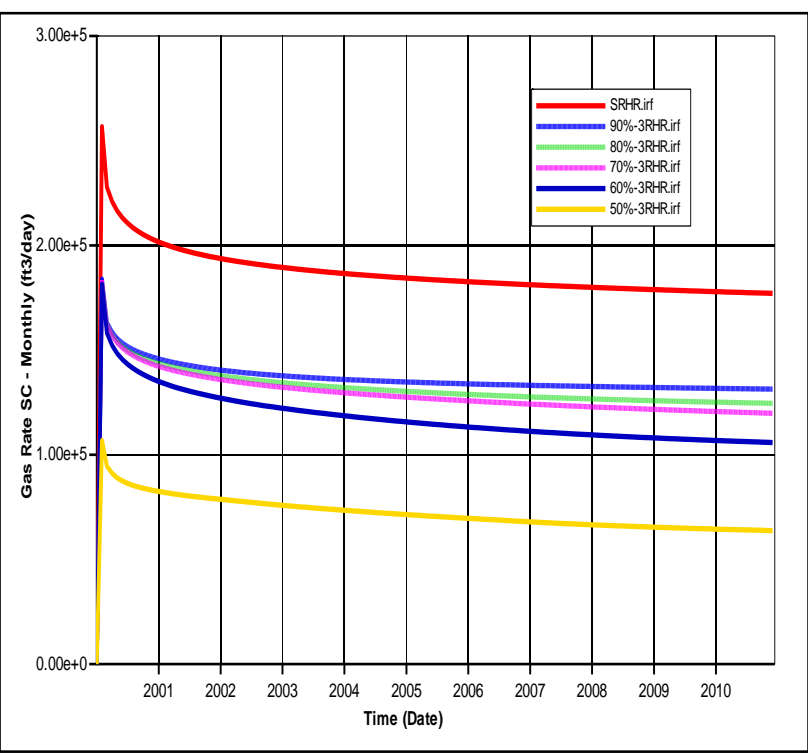

Figure E - 6.Monthly gas rate comparison

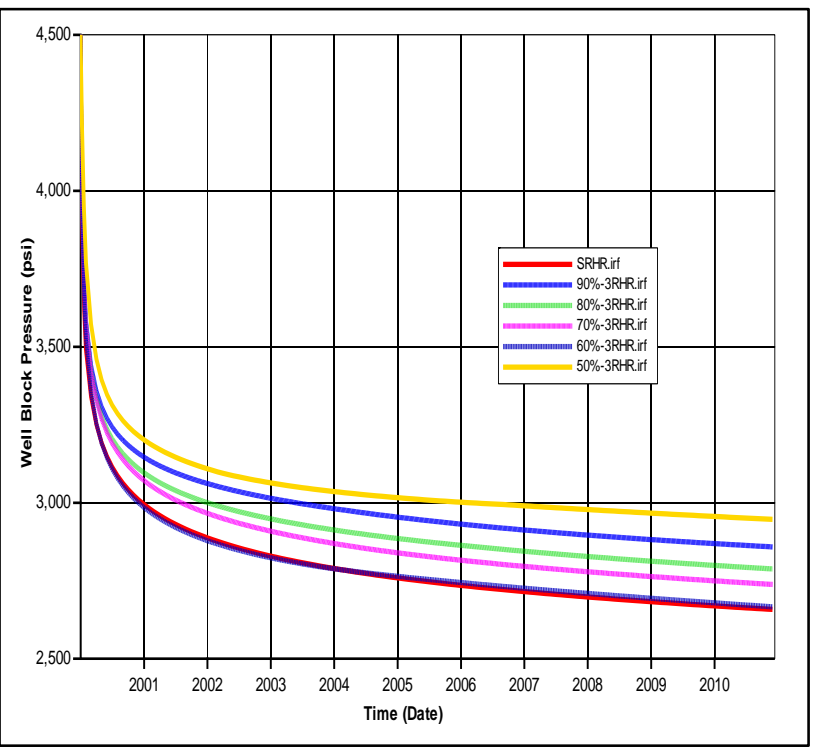

Figure E - 8.Well block pressure during 10 years

of production 


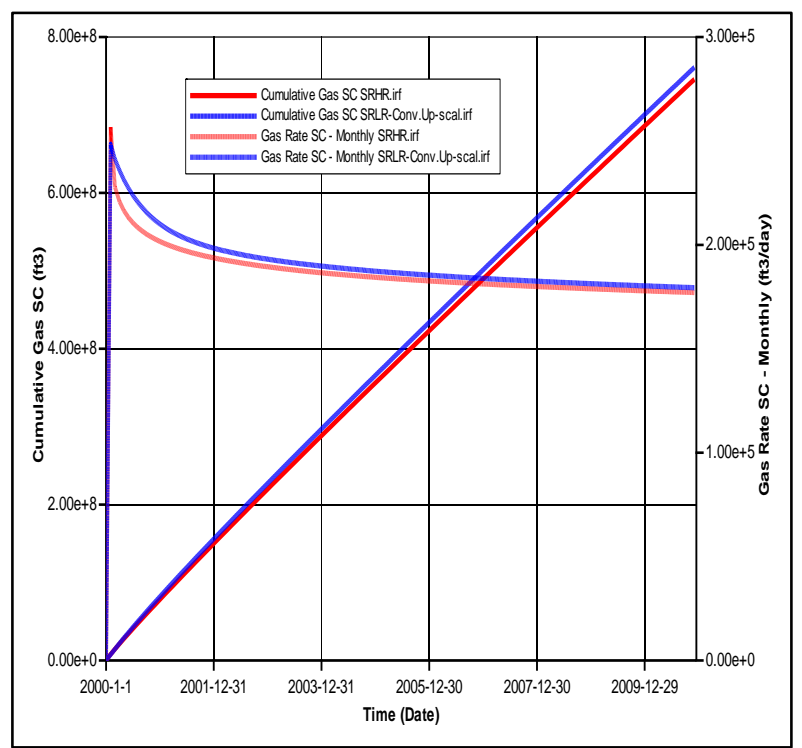

Figure E - 9. SRHR and SRLR - Gas Production

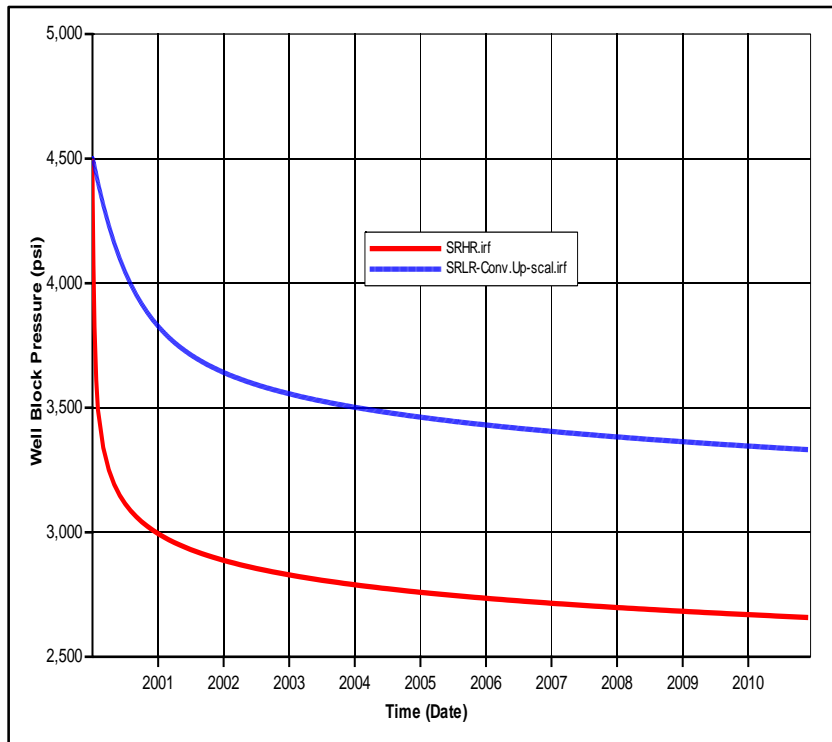

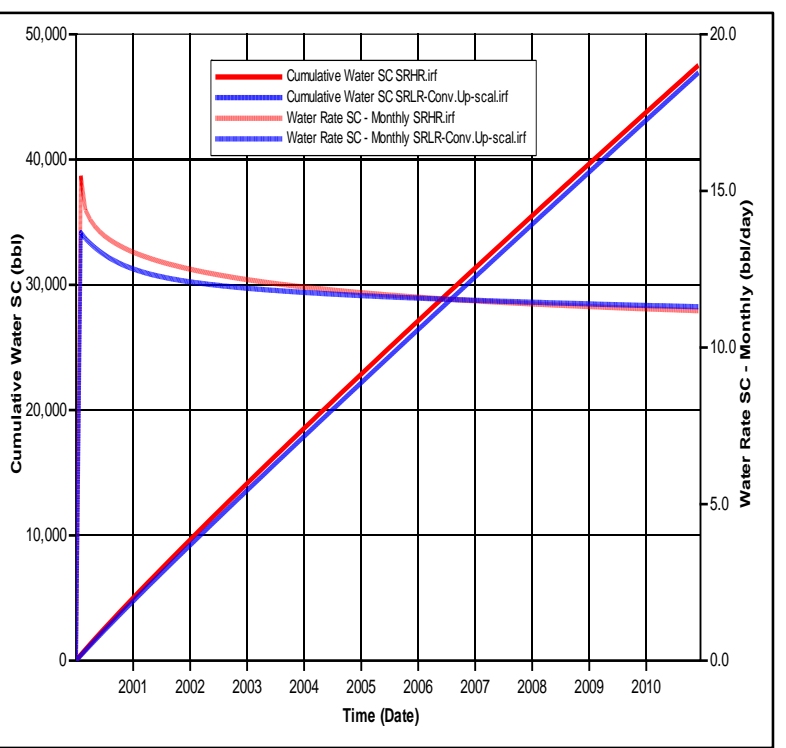

Figure E - 10.SRHR and SRLR - Water Production

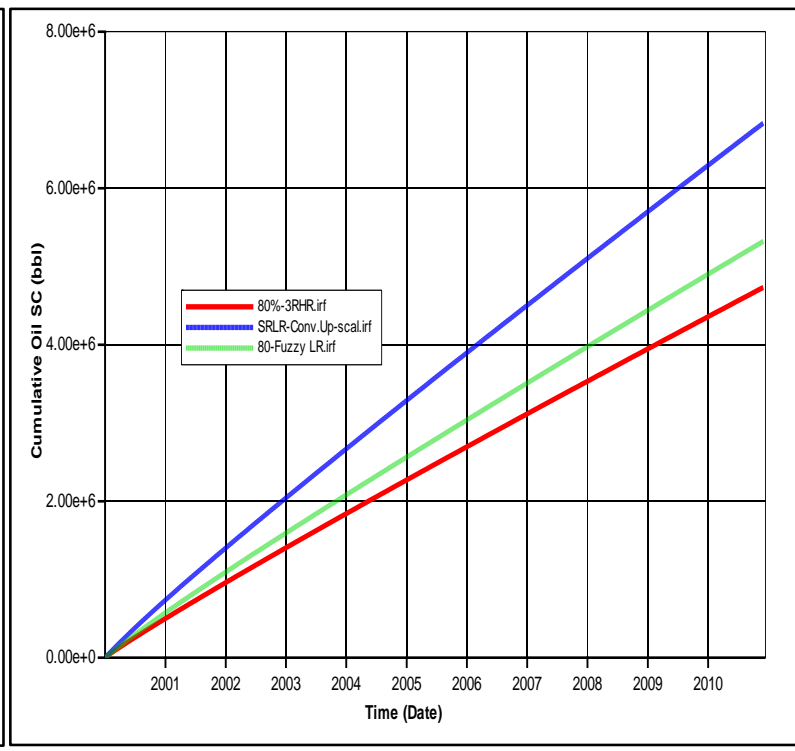

Figure E - 11.SRHR and SRLR Models - Well Block Pressure Figure E - 12.3RHR-80\% and SRLR80\% - Oil Production 


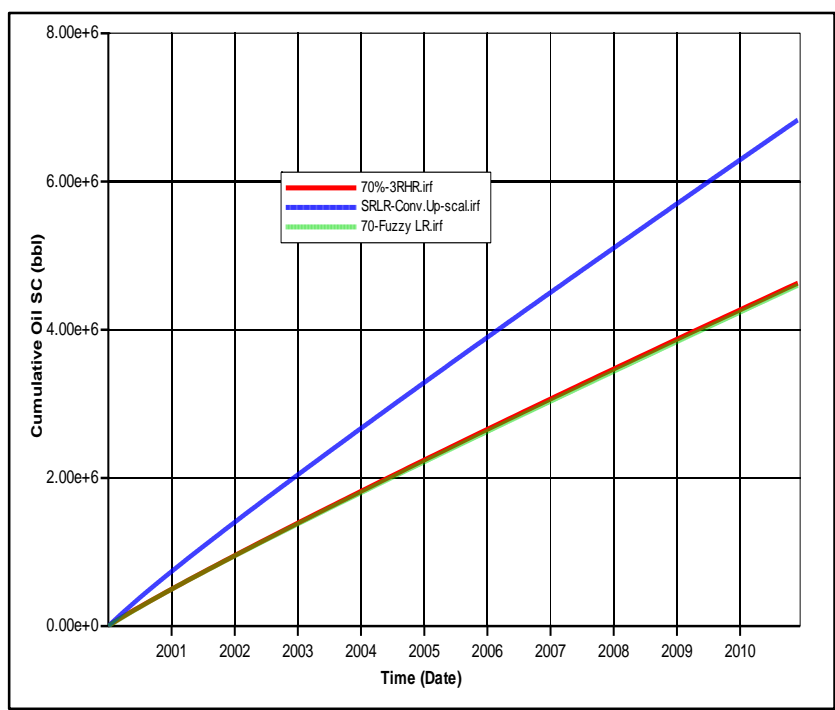

Figure E - 13.3RHR-70\% and SRLR-70\% - Oil Production

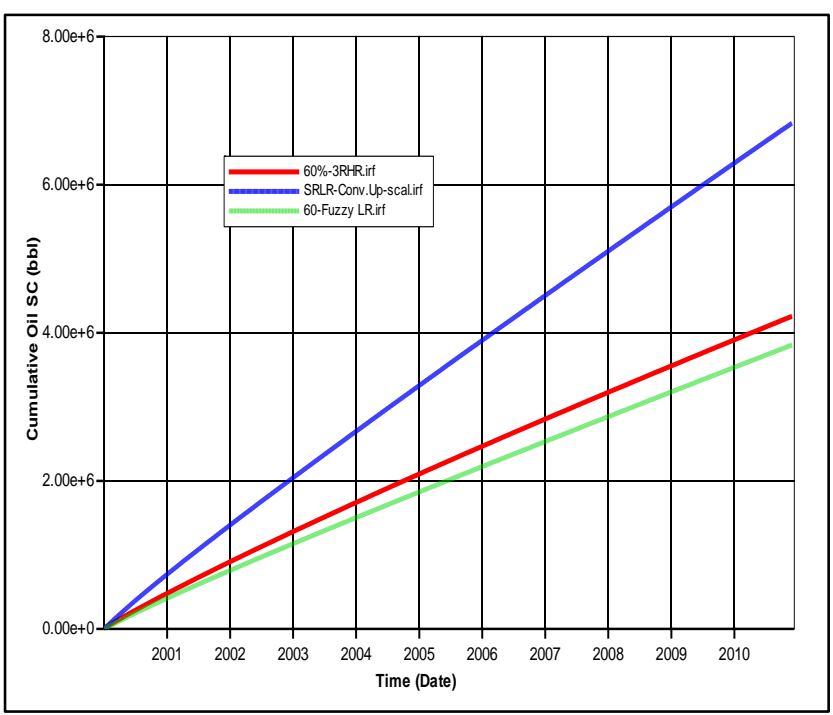

Figure E - 14.3RHR-60\% and SRLR-60\% - Oil Production

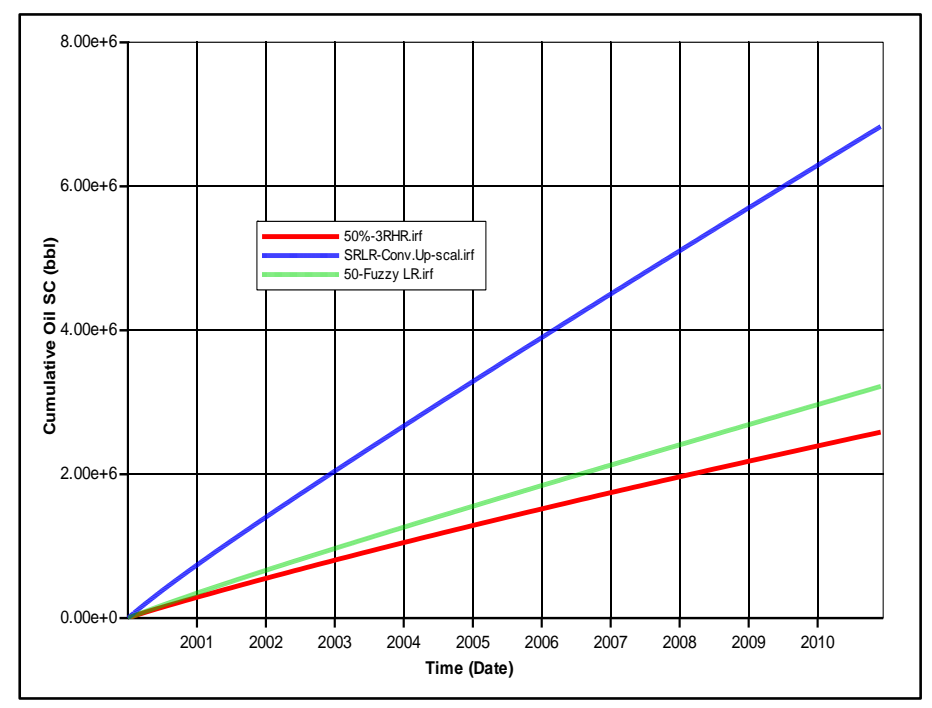

Figure E - 15.3RHR-50\% and SRLR-50\% Models comparison- Oil Production 


\section{Scenario 3-Results}

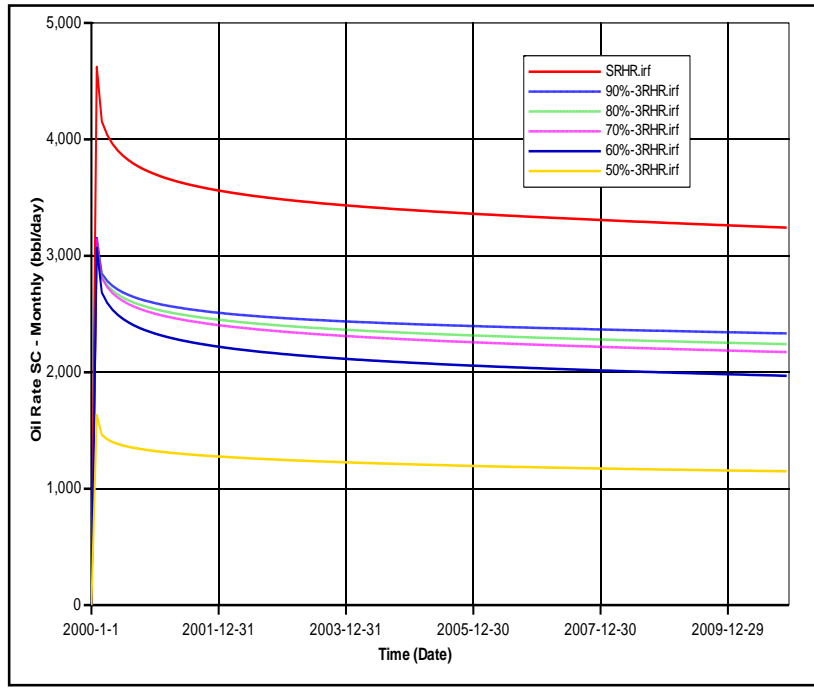

Figure E - 16. Monthly oil rate comparison

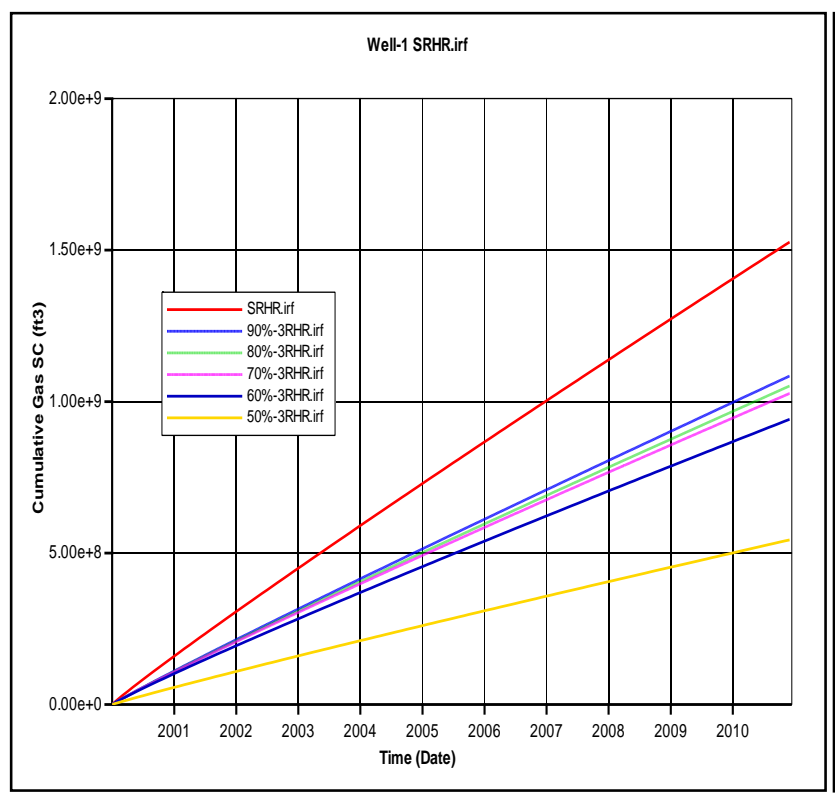

Figure E - 18.Cumulative gas production comparison Figure E - 19. Well block pressure during 10 years of production

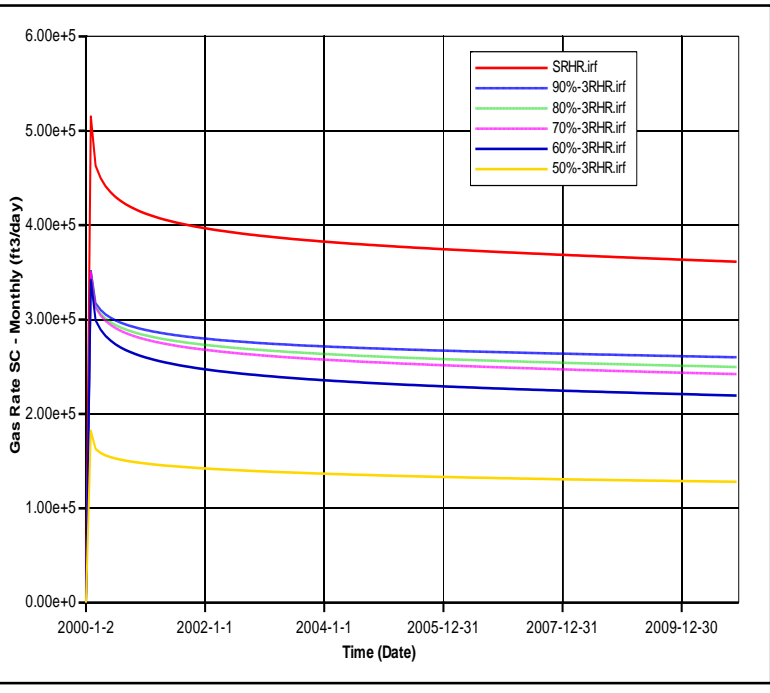

Figure E - 17.Monthly gas rate comparison

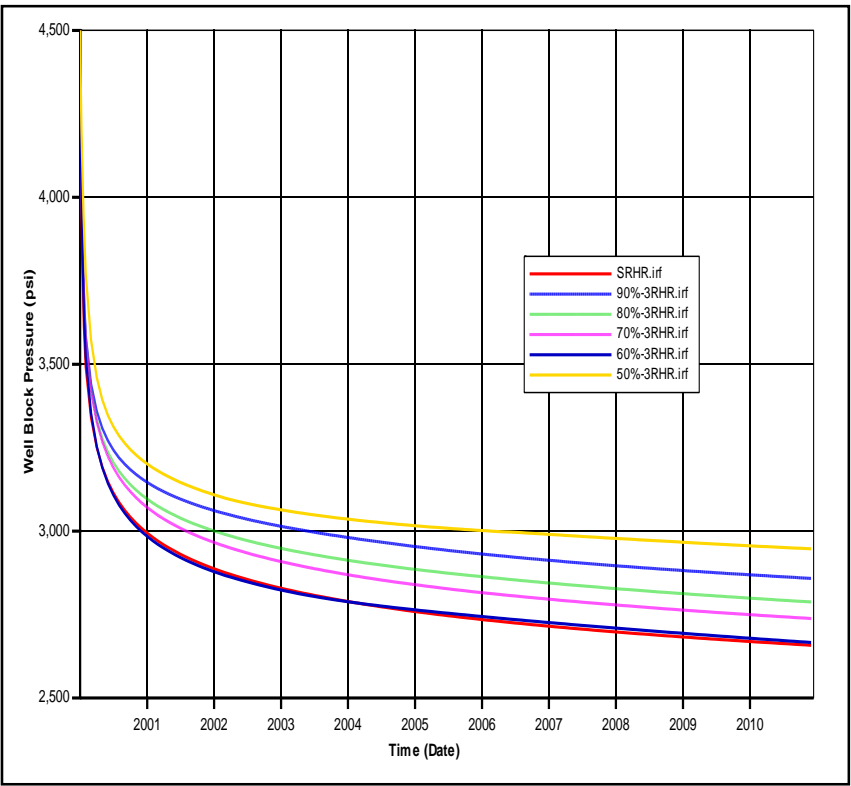




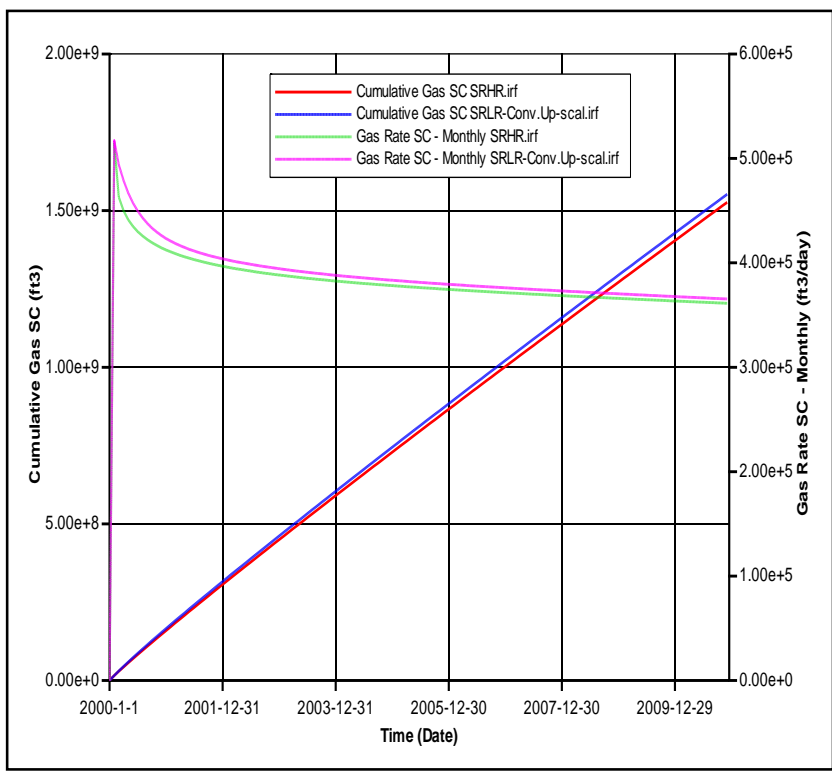

Figure E - 20.SRHR and SRLR Models - Water Production

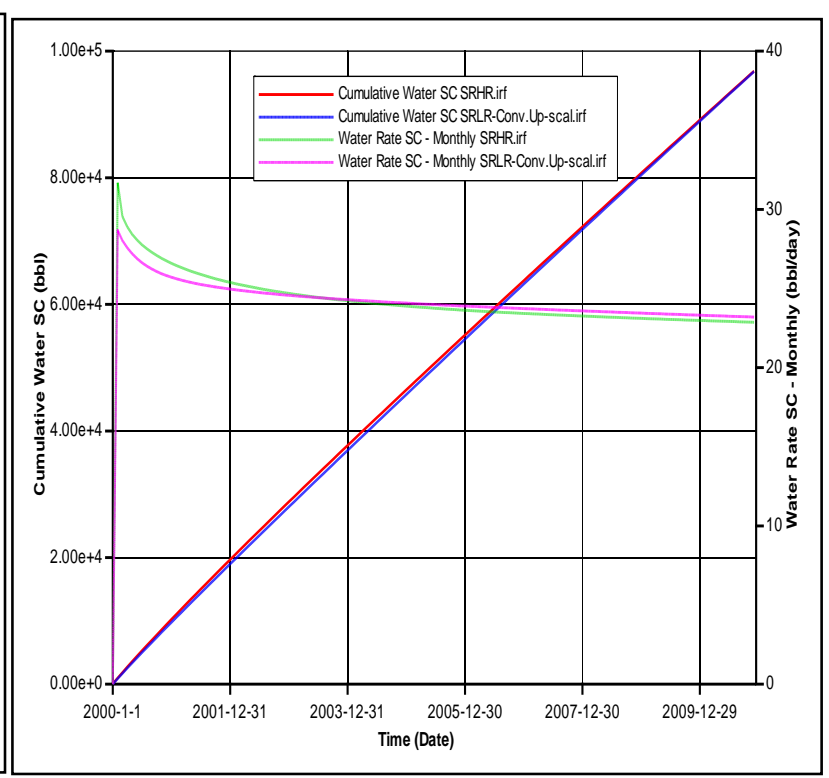

Figure E - 21.SRHR and SRLR Models - Gas Production

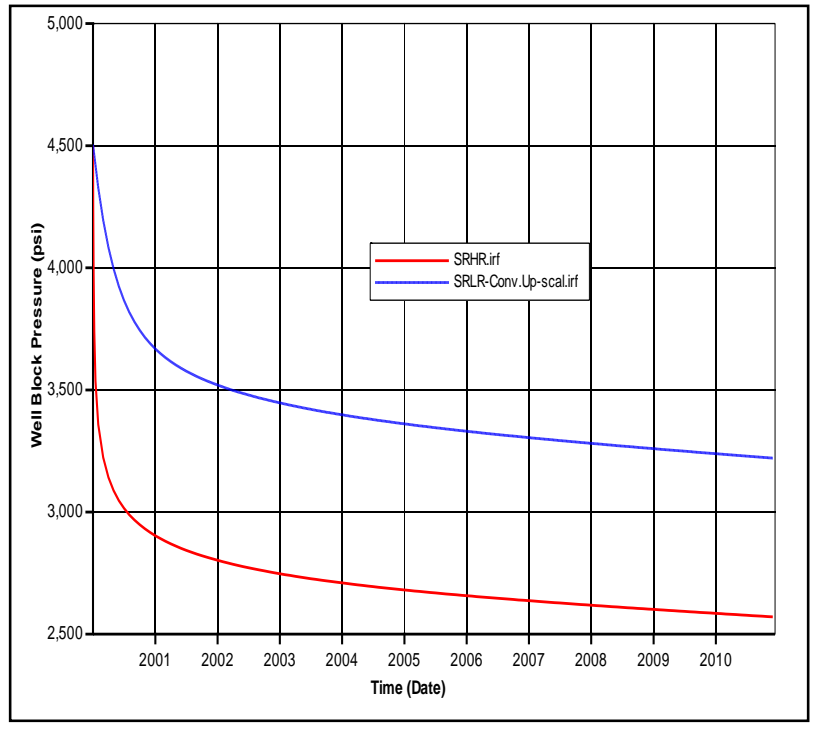

Figure E - 22.SRHR and SRLR - Well Block Pressure Figure Production

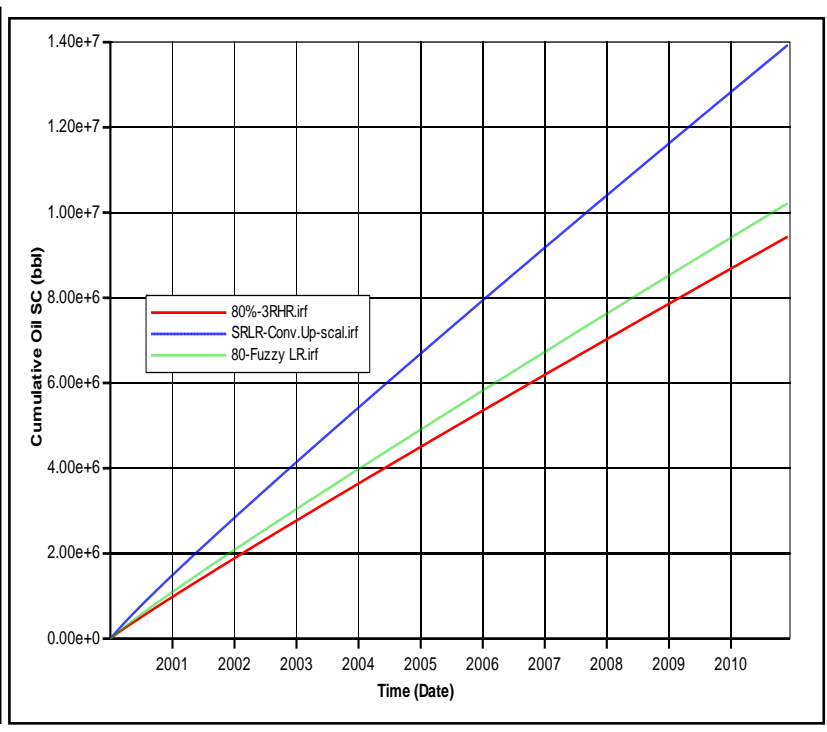

E - 23.3RHR-80\% and SRLR-80\% Models - Oil 


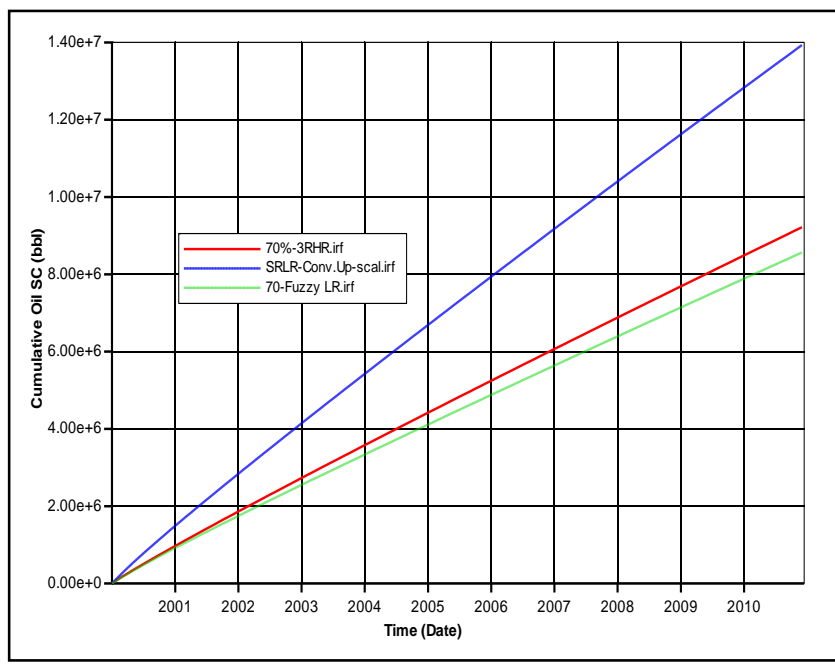

Figure E - 24.3RHR-70\% and SRLR-70\% - Oil Production Production

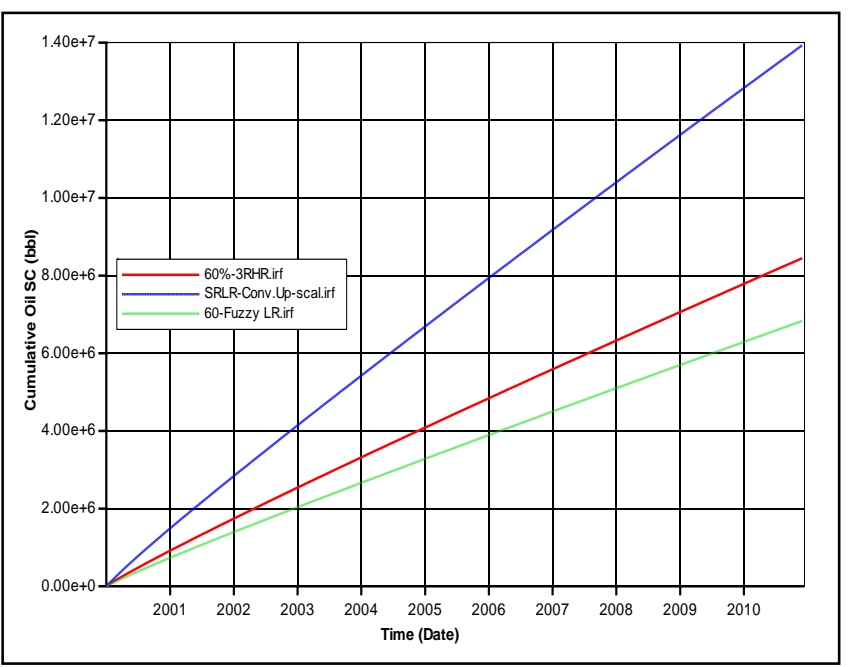

Figure E - 25.3RHR-60\% and SRLR-60\% - Oil

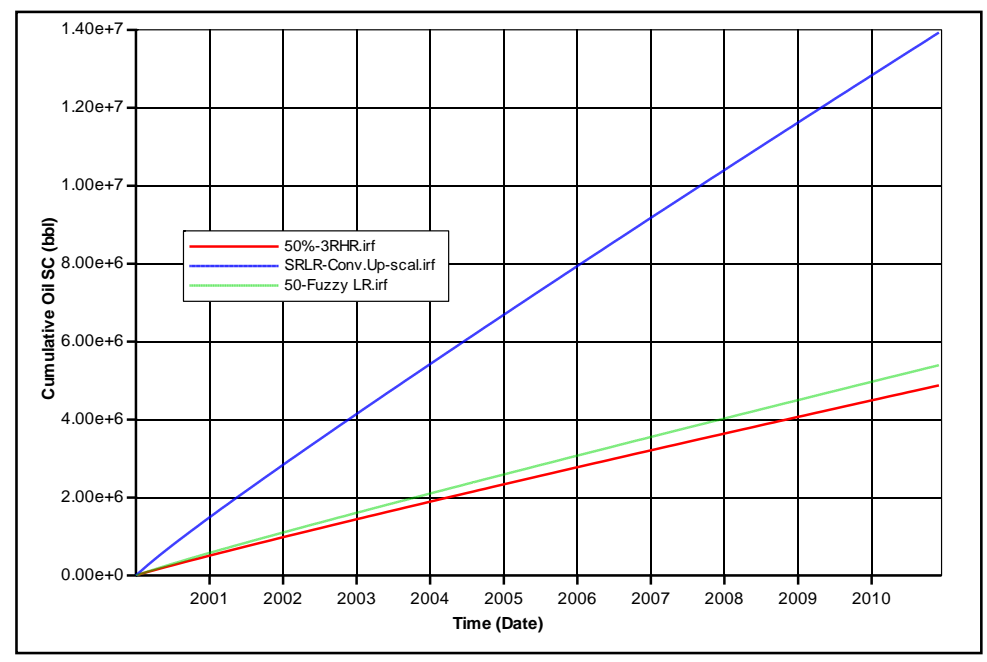

Figure E - 26. 3RHR-50\% and SRLR-50\% Models comparison- Oil Production 


\section{Scenario 4-Results}

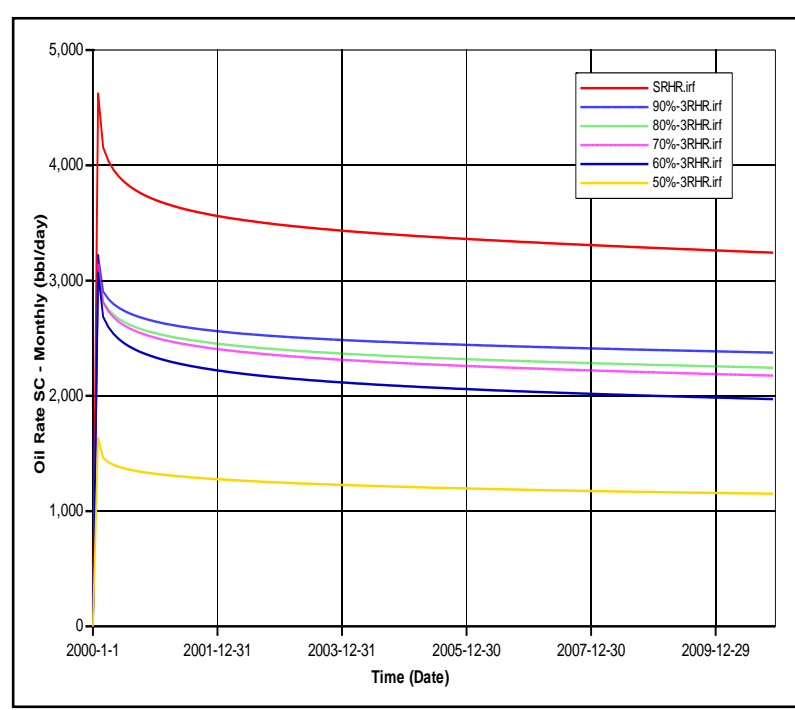

Figure E - 27.Monthly oil rate comparison

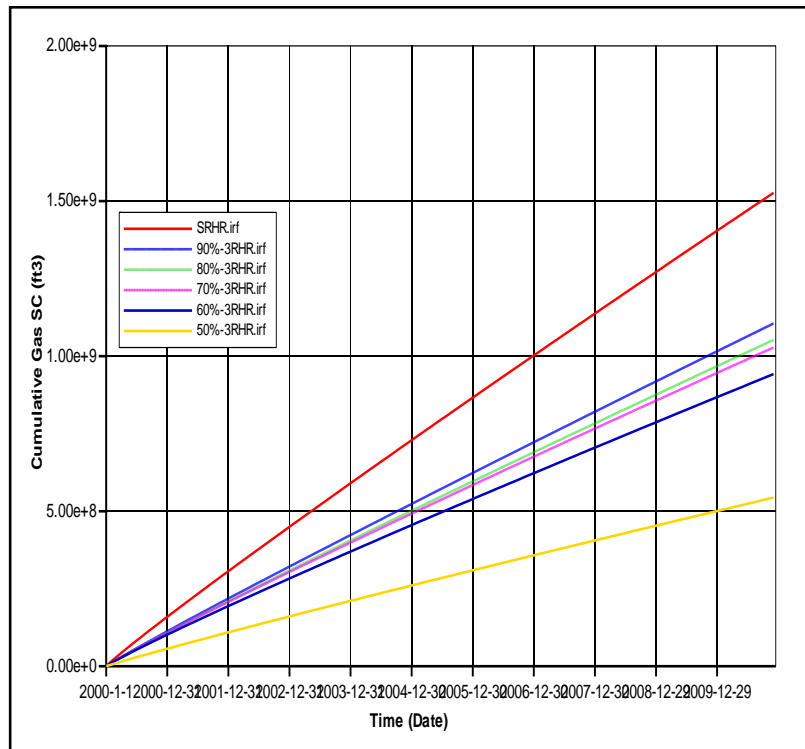

Figure E - 29.Cumulative gas production comparison of production

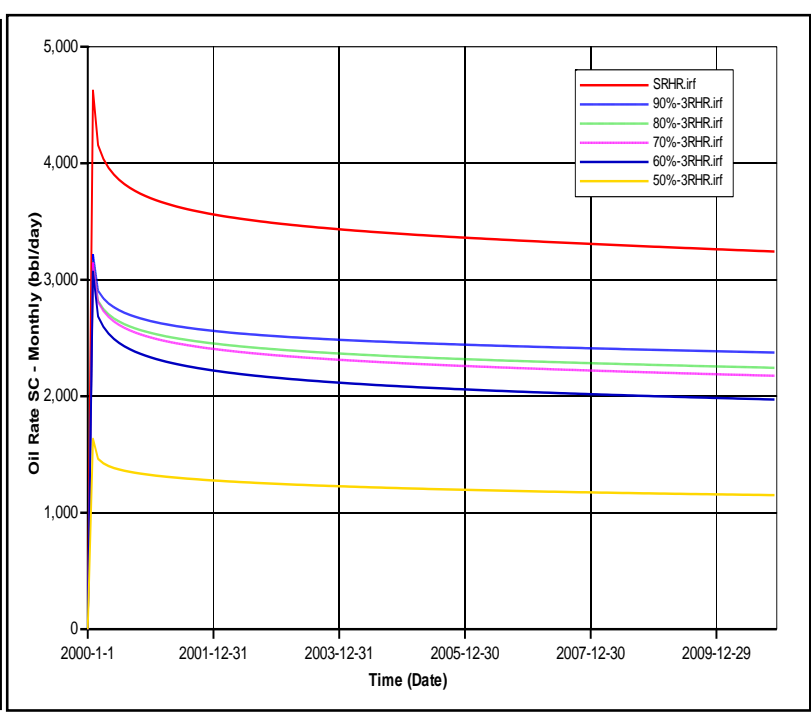

Figure E - 28.Monthly gas rate comparison

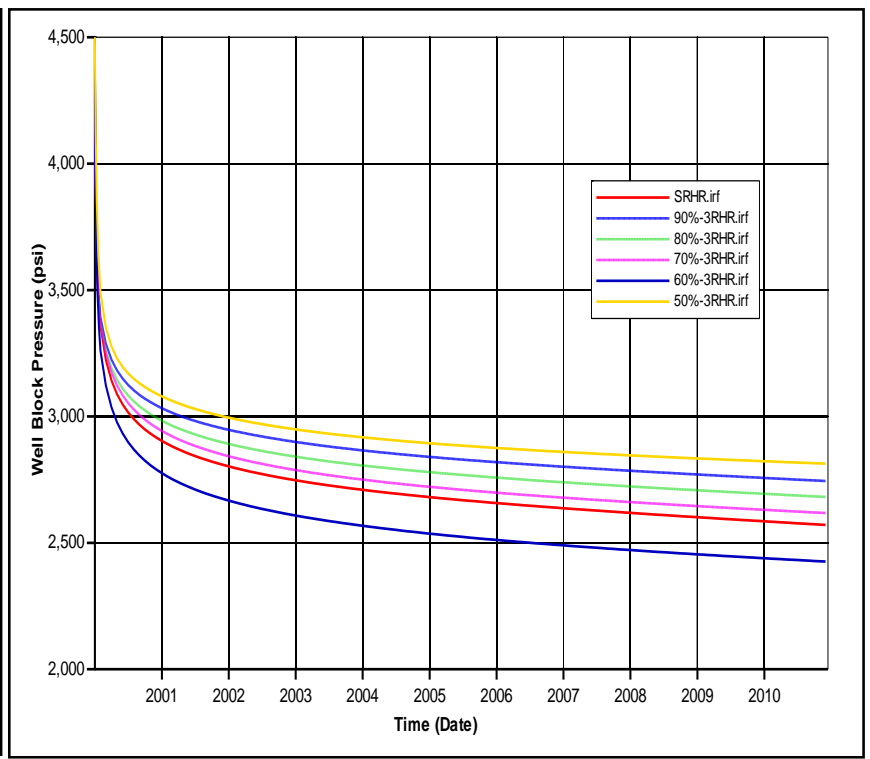

Figure E - 30.Well block pressure during 10 years 


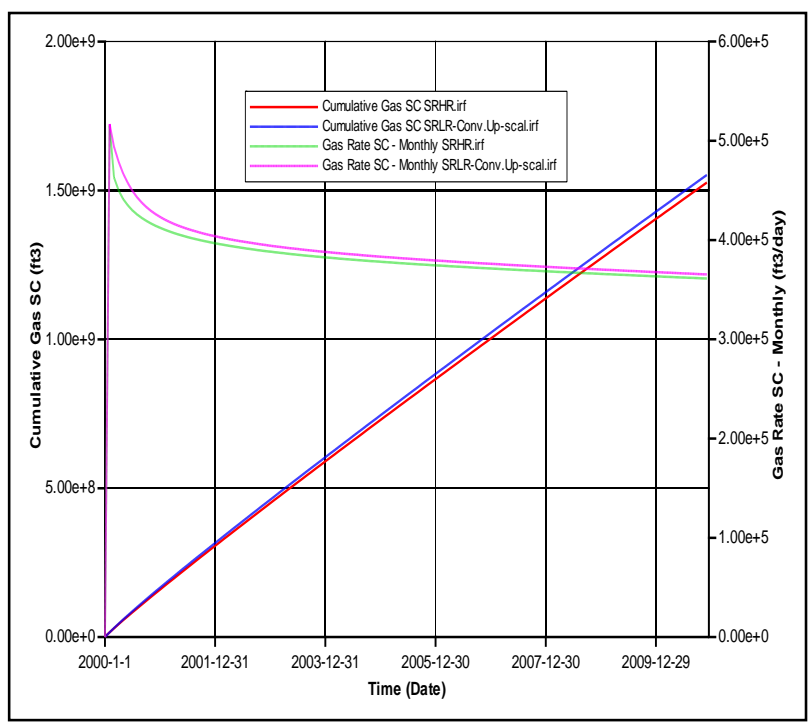

Figure E - 31. SRHR and SRLR Models - Gas Production

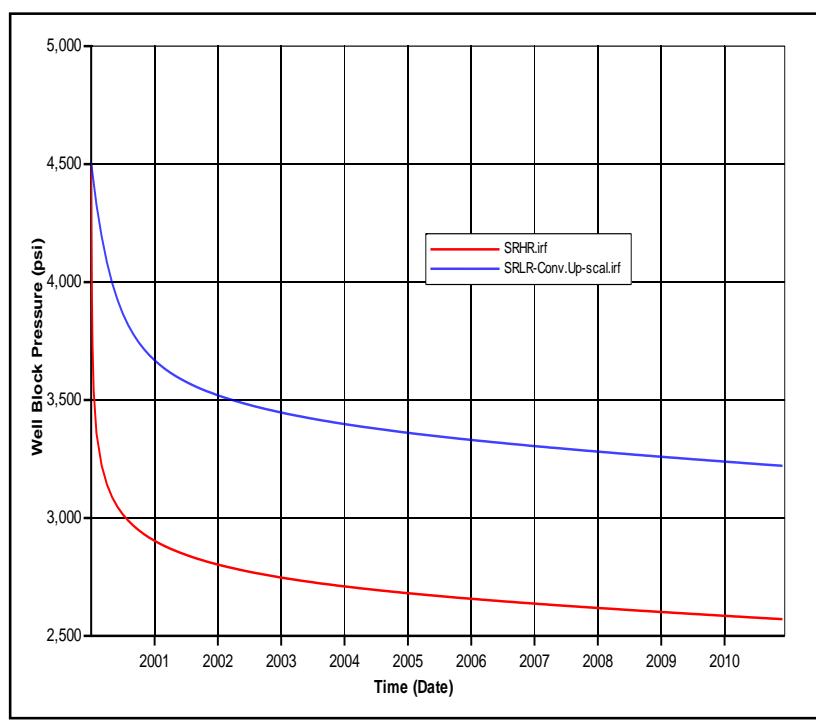

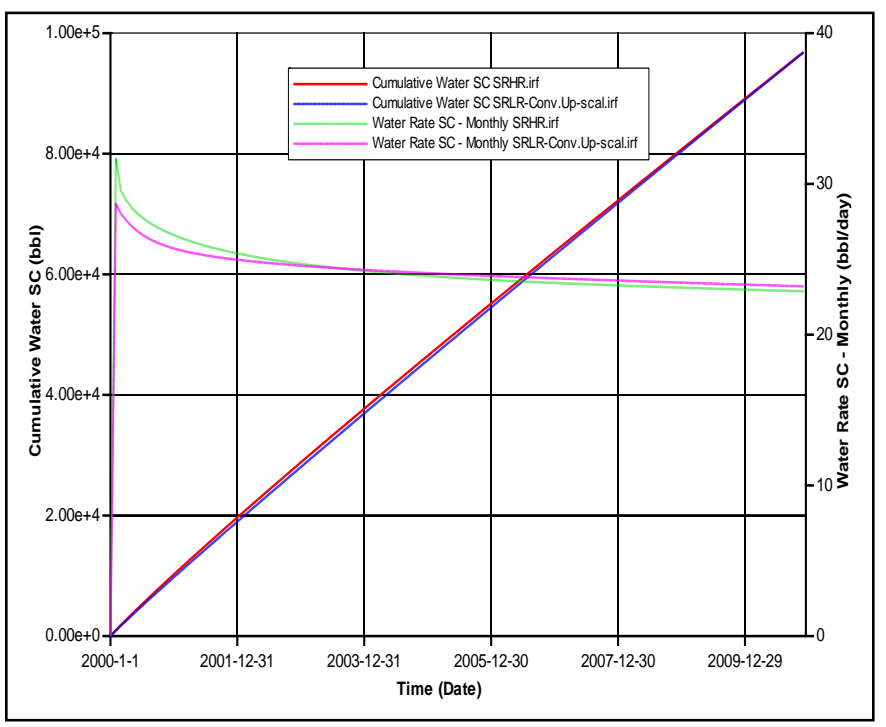

Figure E - 32. SRHR and SRLR Models - Water Production

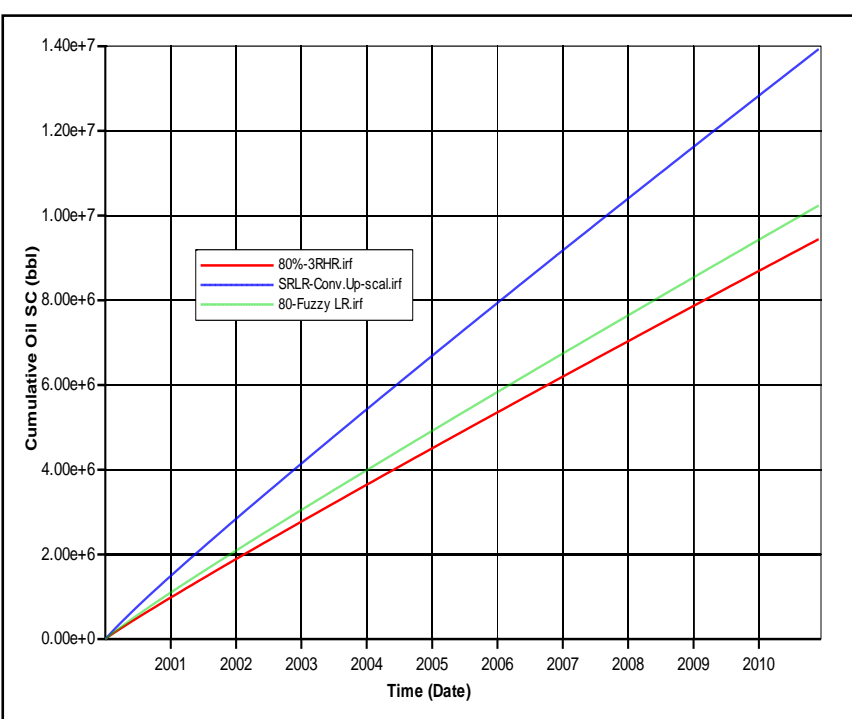

Figure E - 33. SRHR and SRLR Models - Well Block Pressure Figure E - 34. 3RHR-80\% and SRLR-80\% Oil Production 

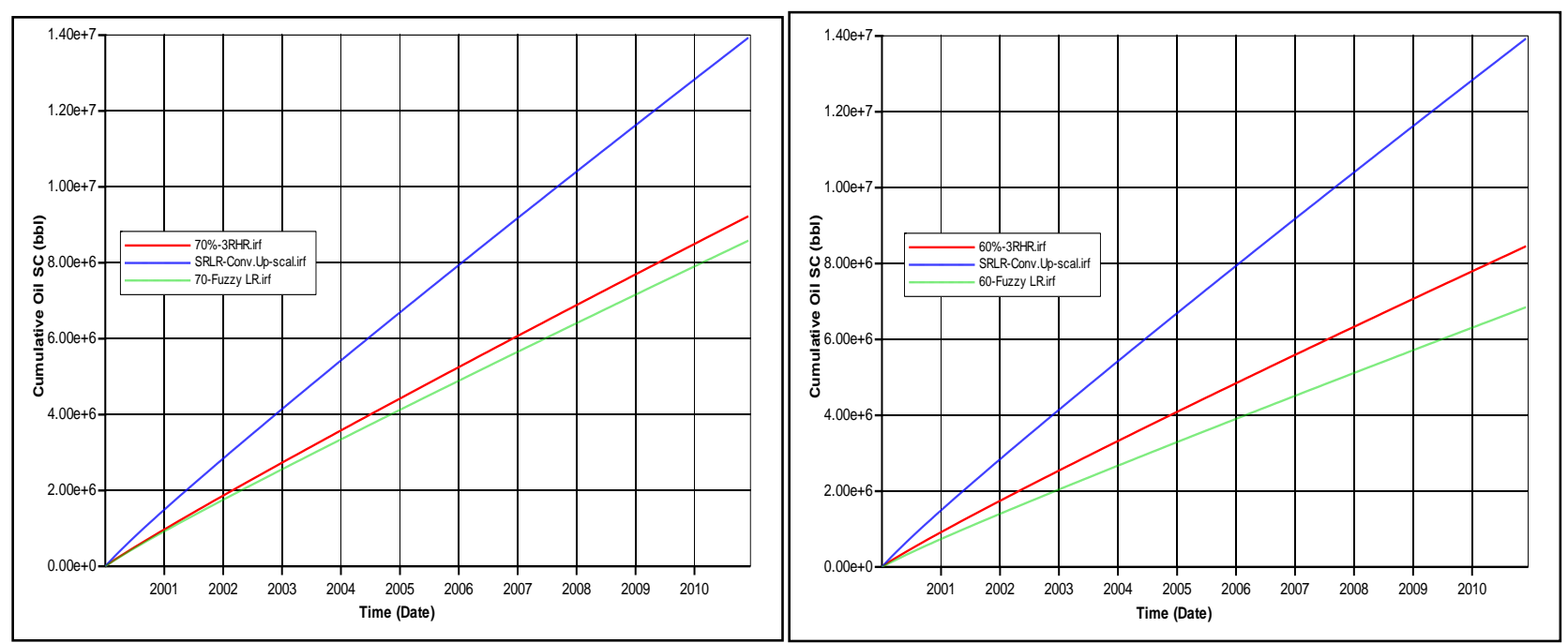

Figure E - 35. 3RHR-70\% and SRLR70\% Oil Production Figure E - 36.3RHR-60\% and SRLR60\% Oil Production

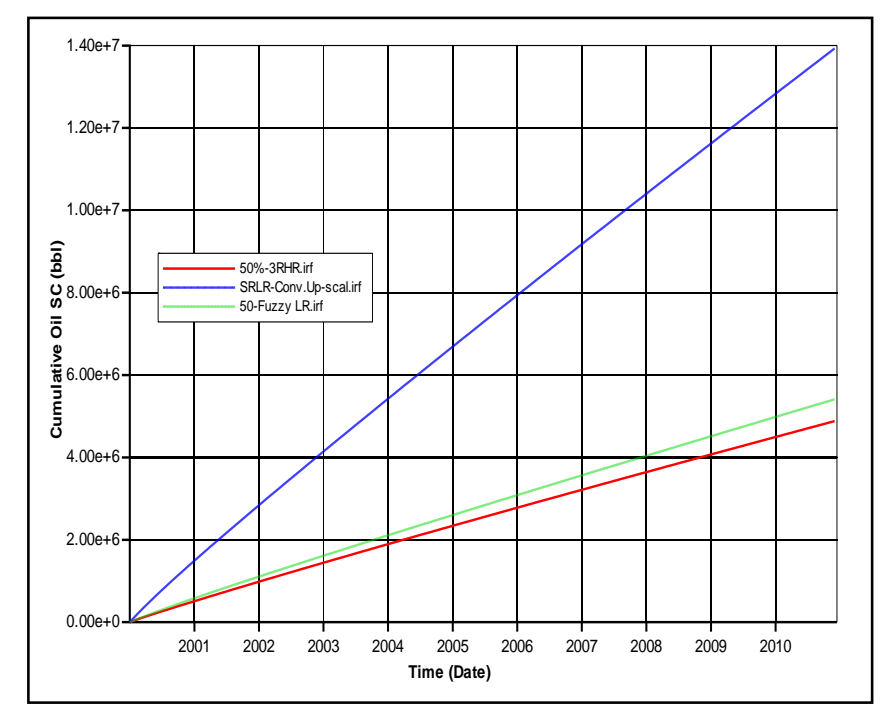

Figure E - 37. 3RHR-50\% and SRLR-50\% Models comparison- Oil Production 